Marcel Cobussen The Field of<smiles>[Mg][Mg]</smiles>

Musical

Improvisation 

The Field of

Musical

Improvisation 


\section{The Field of Musical Improvisation}

Marcel Cobussen

Cover design: Merel van Meurs

Publisher: Leiden University Press, www.lup.nl

$\begin{array}{lll}\text { ISBN } & \text { epub } & 9789400602632 \\ & \text { epdf } & 9789400603011 \\ & \text { print } & 9789087282899\end{array}$

NUR 664

C Marcel Cobussen / Leiden University Press, 2017

All rights reserved. Without limiting the rights under copyright reserved above, no part of this book may be reproduced, stored in or introduced into a retrieval system, or transmitted, in any form or by any means (electronic, mechanical, photocopying, recording or otherwise) without the written permission of the publisher.

Every effort has been made to comply with the laws regarding copyrights of the

images and video and audio materials used in this publication. Nonetheless,

whosoever believes to have rights to this material is advised to contact the publisher. 


\section{Introduction}

\section{Part 1 - Marking}

\section{Introduction}

Beginning

Baltic Suite

Context and Justification

Oligoptica and Prolegomena

The Omnipresence of Improvisation

The Fell Clutch

What is Improvisation (Not)?

\section{Part 2 - Digging}

\section{Introduction}

Bruno Latour and the Field of Musical Improvisation

Field

Gilles Deleuze and the Field of Musical Improvisation

Gregory Bateson and the Field of Musical Improvisation

Jakob von Uexküll and the Field of Musical Improvisation

Mitchell Waldrop and the Field of Musical Improvisation

Pierre Lévy and the Field of Musical Improvisation

\section{Part 2a - Capsulizing}

The FMI Theory

\section{Part 3 - Implementing}

Introduction

Michael Moore, Han Bennink, and Will Holshouser - Human Actants

Brian Ferneyhough - The Mistake as Actant

Jean Gilles and Skip Sempé - Authenticity as Actant

Alfred Brendel and W.A. Mozart - The Score as Actant

Paul Craenen - Technology as Actant

DJ Spooky - Records and Files as Actants

Fred Frith - The Instrument as Actant

Edwin van der Heide - The Audience as Actant

Heiner Goebbels - Theater as Actant

Keith Jarrett - The Spiritual and the Body as Actants

Miles Davis and Teo Macero - The Producer as Actant

Alain Renaud - The Internet as Actant

Vlatko Stefanovski - The Past as Actant

Steve Coleman - Rhythm and Musicians as Actants

The Taku Sugimoto Quartet and Johnny Chang - The Space as Actant 163

Yo La Tengo - The Audience as Actant

Nomen Nescio

\section{Part 4 - Exceeding}

Introduction

Revisiting Complexity Theories - Jimmy Giuffre, Paul Bley, Steve Swallow 179 Freedom - Medeski, Martin, and Wood

Management - Richard Barrett

Play - John Zorn

Politics - John Doe

Ending - Frank Zappa 


\section{Introduction}




\section{Introduction}

[1] People tell stories. Whether chatting at a tea party, exchanging itineraries, or analyzing soccer games. Through storytelling, people not only reconstruct, but also construct, realities. Not that these are disconnected from the realities that can be perceived through the senses (technologically augmented or not); however, in a narrative, fiction and fact are always already intertwined.

Loosely following historian Hayden White's erudite provocations, I think the same interweaving permeates, mutatis mutandis, the social sciences and humanities; both are, to a certain extent, artistic and creative practices. "Facts" need to be constructed, (re)presented, selected, and interconnected during the researching and writing process. Both are concerned with the making (inventio) rather than with finding (of facts). What they have in common with, for example, fiction, is that they creatively redescribe the world so that hidden patterns and hitherto unexplored meanings can unfold (Kearney 2002: 12).

[2] The Field of Musical Improvisation has approximately the same objective: to reposition improvisation within the world of music and sound, to make unusual connections between music and various scholarly disciplines, to rethink several concrete improvisation practices, and to extend and emphasize the significance of improvisation beyond the domain of music - all this in order to enrich the already existing discourse on musical improvisation.

The Field of Musical Improvisation thus tells stories about a specific field of human culture. It presents proposals to have another/an other look at this field by recombining "facts" and connecting them with "fictional" cement. As such, this book intertwines musical events and scholarly disciplines not generally regarded as related to music

[3] "We choose a performance or recording for study, we decide how to listen to a given passage, and ultimately we determine how to translate our analytical involvement with the music into a compelling narrative to be shared with fellow scholars and musicians," music theorist Paul Steinbeck writes in a short essay in which he exposes the fictional character of music theory and other discourses around music (Steinbeck 2013: n.p.). Regarded this way, The Field of Musical Improvisation is a "fiction" too, a carefully constructed story of my (theoretical as well as practical) involvement with improvisation in music, undeniably formed by aesthetic (a narrative strategy), epistemological (an explanatory model), and ethical (an ideological background) choices (White 1978: 69-70). Also, the "facts" that I use do not exist outside the presented discourse but are the results of my storytelling. What counts is, at least partly, an aesthetic pragmatism of the arguments: it is not the question "Is it true?" that should guide your reading of this text, but "Does it work?" or “Does it make sense?"

[4] The story I have woven around musical improvisation circles around two keywords: complexity and singularity. First, improvisation is, in my opinion, a complex event in which many actants, many actors, factors, and vectors, both human 
and non-human, converge and interact. It is this interaction which will take center stage in this study. Second, I think it is not a good idea to write about improvisation in general, as it encompasses too many and too diverse practices. As an alternative, I present here a radical empiricism, a focus on particular and individual cases. They are not case studies in the strict sense, not examples subsumable under a more general category; instead they (re)present the absolute distinctive character of each improvisation, understood here as the unique composition and interaction of various actants. As a consequence, I discuss improvisational qualities from a range of musical genres and movements, thereby also underpinning and supporting my basic assumption that improvisation takes place in all musicking.

In short, the contribution of The Field of Musical Improvisation to the already existing discourses can be summarized as a critical attitude towards forms of reductionism (focusing on not more than one or a few actants) and generalization ("improvisation is ..."). By focusing on concrete improvisational practices and by confronting them with several complexity theories, I hope to be able to open new ways of thinking about and listening to improvisations, although I am very well aware that so-called "new" stories always already and for a large part consist of other, previously told, narrations.

[5] Although it is my explicit wish that readers choose their own route throughout this book, I have subdivided it into four parts and also propose a kind of hierarchical order. Concerning the latter, each part starts with an introduction, which might serve as a kind of road map to the texts belonging to that section of the book. These texts, however, can be read in any order. In addition, hyperlinks can take you from one part of the book to another, thereby offering suggestions to connect texts that are "physically" separated.

Although it is not strictly necessary to read Part 1 before any of the other parts, the texts belonging to this section are designed as a kind of introduction to the rest of the book. It consists of some prolegomena concerning the (im)possibility of defining improvisation, the context and justification of this study, the basic assumption that improvisation is an inextricable aspect of all music making, and the short description of two musics which inspired me to write this book in the first place.

Part 2 contains discussions of the works of several philosophers and other scholars who, in one way or another, can be related to the concept of complexity. Where possible, I have already connected these texts with concrete musical works in order to make the relation between complexity and improvisation more concrete, more tangible. Part 2 thus contains the primarily theoretical backbone of this study. Part 3 consists exclusively of analyses (readings, interpretations) of various musics. Here, the two main concepts, complexity and singularity, directly unfold from the description of the improvisations themselves. Expressed differently, it has not been my intention to superimpose these concepts upon the music, but to show how the very specific interactions operative during a concrete musical improvisation necessarily prompt one to consider it as another example of a complex system. Part 4, finally, investigates and speculates upon the possible contribution of the outcomes of this study on musical improvisation when expanded into other cultural fields, scholarly disciplines, and everyday activities.

[6] The motivation to compose an e-pub is not induced by a desire to be trendy or to simply deviate from certain rigid academic standards and conventions. Rather, it opens the possibility of providing almost immediate access to the music I discuss. Furthermore, it should be noted that these musical fragments do not function as mere illustrations to make the book look (or sound) more attractive; instead, the music provides arguments and information which is difficult to convey through another medium, e.g. language. In other words, the music forms an inextricable part of the knowledge I want to present here. 
Part 1

Marking 


\section{Introduction to Part 1 - Marking}

[1] The first part of this study offers insights into some notable points of departure as well as a few initial steps which should, in the other sections, lead to a reformulation of certain ideas on improvisation, subsumed under the acronym FMI, The Field of Musical Improvisation.

[2] Two musical examples will be discussed, David Murray's Baltic Suite and a specific performance of The Fell Clutch, a trio formed by reed player Ned Rothenberg, here augmented by guitarist Marc Ribot. A concise summary will be given of the most important and inspiring literature that galvanized me to write this book. Of course, a reflection on the (im)possibilities and (un)desirabilities of defining improvisation will not be lacking. Also included is a kind of justification or legitimization: is it a good idea at all to pay attention to improvisation in

music? Furthermore, Part 1 contains two rather philosophical meditations, one on improvisation as a concept, the other on the problem of beginning - beginning a book as well as beginning a musical improvisation. And finally, to justify the great variety of musics drawn upon in this book, the claim that all music making contains elements of improvisation will be supported. This claim has important consequences for the way the term "improvisation" will be employed in the formulation of the FMI-theory. 


\section{Beginning}

[1] How might a book on improvisation begin? Where does it start? Where should it start? What are the options? Are these options in some sense akin to how an improvisation might begin? In theory, a typical free improvisation can have many different possible beginnings: tentative, e.g. through extended techniques, or with a firm tone; motorial, e.g. with a riff, or creating space through silences; communicative, questioning and waiting for an answer, or "in the middle", immediately presenting the music; etc.

Writing around improvisation seems to offer more or less the same possibilities: you could start with a firm statement or more hesitant, by posing questions; by throwing in some overwhelming theories or by commencing modestly, e.g. through some examples or case studies; by leaving space for the readers to form their own opinions or by throwing them in at the deep end, confronting them right away with new ideas.

[2] Be this as it may, each beginning intrinsically affects the sequel; in chaos theories, this principle is known as the butterfly effect, the sensitive dependence on initial conditions. The presence of a butterfly flapping its wings could lead to the creation, acceleration, or alteration of a hurricane. While the butterfly does not "cause" the hurricane in the strict sense of providing the energy for the hurricane, it does "cause" it in the sense that the flap of its wings is an essential part of the initial conditions resulting in that hurricane. In short, a small change at one place in a nonlinear system can result in drastic differences at a later state.

In improvisation, too, relatively small details can trigger huge transformations in the music, such that the eventual outcome is disproportionate to any initial causes. A small change in the first performance gesture "can lead to a sudden divergence from the evolution of a system started with nearly identical initial conditions" (Borgo 2005: 68 and 73).

Writing, at least for me, means entering a similar field of tension: the first sentences of a new, blank document often inadvertently determine the course of the argumentation, the style, the "grain" of a text, sometimes with unforeseeable consequences. Moderately small interventions - changing a title, shifting a sentence to another paragraph, deleting a phrase - can have far-reaching effects on the (rest of the) writing process. In short, musical improvisations and writing around those improvisations, activities ostensibly far removed from each other, seem to have some resemblances.

[3] Because of the potentially sweeping consequences, this book has had many beginnings too. Hesitations, doubts, and insecurities permeate all my writings, especially at the start of a new project, and this recurs each and every time. With each new text, as with each new improvisation, one must start again; each text must begin anew. 
However, each text, like each improvisation, has also always already begun. A true new beginning is impossible to realize. As David Toop observes with regard to (free) improvised music, "learning, social familiarity, established patterns within the brain, audience expectations, all conspire to defeat the possibility of beginning from the beginning each time, tabula rasa" (Toop 2004: 240).

Improvising regarded as starting from scratch is not possible (cf. What is

Improvisation?, section 3). Academic mores, stylistic conventions, traditions of certain discourses, and the simple impossibility of avoiding the reiteration of words, phrases, or grammatical rules, determine each text. So like all other texts, this one, too, rests on many previous texts. A beginning in the absolute sense, resulting in a truly original text, will always be an illusion; a beginning is not an origin.

[4] So, in fact, a beginning can only start in the middle. In the midst of other texts, in the midst of other improvisations, a new text or a new improvisation arises: intertextuality and, if you like, intermusicality. Based on, supported by, borrowing from, and inspired by a countless number of sources - material and immaterial, concrete and vague, direct and indirect, diachronically and synchronically, visible and audible - something "new" comes into existence: a text, an improvisation. Instead of regarding improvisation as a creation ex nihilo, as the presentation of the absolute new, I sympathize with Gary Peters who in The Philosophy of Improvisation "defines" improvisation as a process of "reappropriation," as the ability to find new ways of inhabiting old forms (Peters 2009: 18). In my opinion it is quite possible to replace the word "improvisation" in the last sentence by the word "writing."

\section{Baltic Suite}

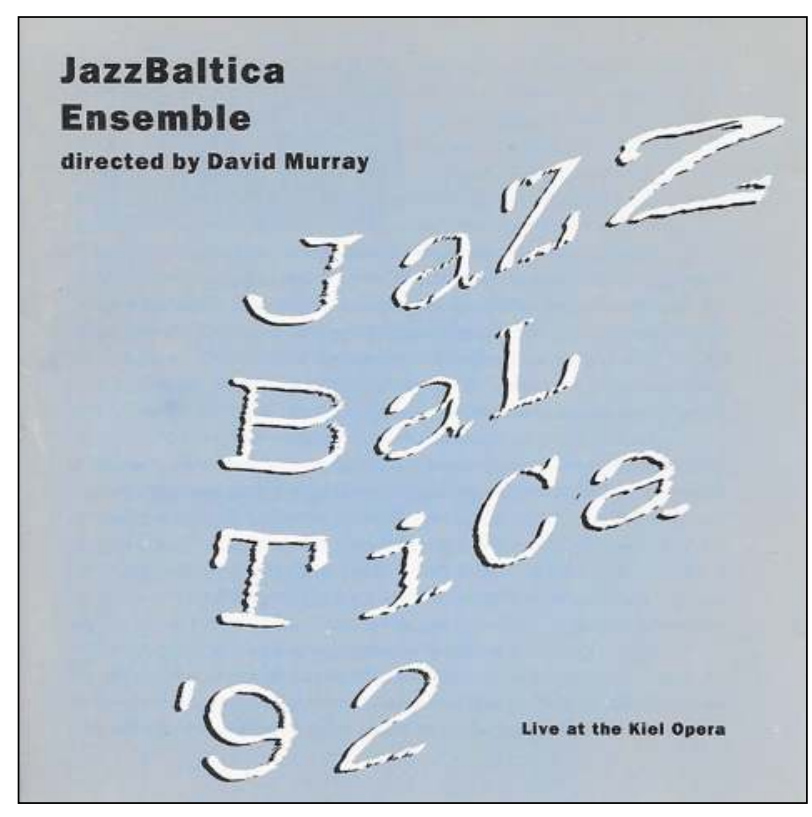

JazzBaltica cover

[1] Retrospectively, the occasion of listening to David Murray's Baltic Suite from 1992 can be considered as one of the instigations for writing this study. From the opening onward, three aspects of the suite, performed by a big band consisting mainly of jazz musicians from North-European countries around the Baltic Sea, fascinated me in particular.

First, the organic, almost logical ways in which musical materials are passed on from one to the next soloist.

\section{play}

Baltic Suite - tuba solo

To give a rough outline, tuba player Stein Erik Tafjord introduces two conspicuous themes in his solo: the opening notes of the main theme of "In the Hall of the Mountain King" from Edvard Grieg's Peer Gynt Suite, No. 1 and a very simple rhythmic motif on the tone $\mathrm{d}$.

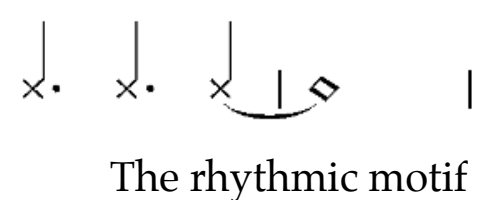


Toward the end of the solo, piano, drums, and bass take up the rhythmic motif before the next soloist, alto saxophonist Vladimir Chekasin, enters. His use of both themes leads to short dialogues with another alto sax and the electric guitar, bouncing back the same material, and smoothly develops into the development of new sonic motifs. Throughout the entire Baltic Suite, phrases or short themes from previous solos form the point of departure for the next solo or a collective interlude.

The second aspect that caught my immediate attention was the mobile but natural use of various jazz "languages." Freely following Latour (2007: 177), I would state that no structure acts (un)consciously within each specific musical event. At most, the structure or "language" is related, connected, or associated to all emanant concrete musical utterances. Simon Nabatov's piano solo, for example, easily flows from ragtime and stride through mainstream be-bop to "free" playing with clusters.

\section{Baltic Suite - piano solo}

The third easily-discerned sonic characteristic is the use of citations. Underscoring the Northern European roots of the musicians as well as the suite's name, references to Edvard Grieg's Peer Gynt Suite are sounded by more than just the tuba player. (Perhaps the word "citation" is slightly inappropriate here, as one of the favorites of Romanticism is filtered into some basic material for improvisational explorations.) However, other hors de jazz quotations enter Murray's composition. One example: A rather free trombone solo by Jörg Huke with non-harmonic interventions from the other winds suddenly morphs into a tribute to James Brown's monster hit "Sex Machine."

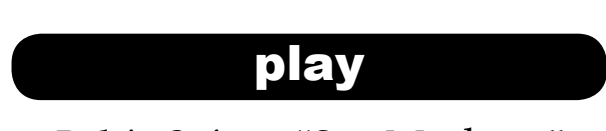

Baltic Suite - "Sex Machine"

[2] What is it that fascinates me in this music? Why do I regard this $C D$ as one of the biggest treasures in my collection? The main reason might be that I hear it as an almost paradigmatic example of one of the cornerstones of improvisation: interaction. Or, actually, interactions, plural, as they take place on many different levels. First of all, of course, the interaction between the musicians among themselves: the passing on of sonic material requires an attentive engagement on the part of both the giver and the receiver. As Ingrid Monson rightly remarks, especially improvising musicians need to listen in an active sense, that is, being able to engender and respond to musical opportunities. The response of one's fellow musicians is crucial as to whether a particular musical idea is picked up on, developed, or ignored (Monson 1996: 84 and 88). Second, alongside this sensitivity toward other musicians, a shared sense of musical styles and repertoire knowledge is indispensable. The entrance of the drum rhythm followed by the characteristic "Sex Machine" guitar motif is doomed if the other musicians simply don't recognize it. Especially in Baltic Suite, in this extraordinary example of musical syncretism and versatility, musicians are required to have at their disposal an extensive repertory of musical "languages" and reproducible pieces in order to be able to react to every potential quotation. In other words, a third type of interaction announces itself in the form of a relation with the musical past. Collectively or individually, the musicians are conversing with previous musics, incorporating them into their "own" stories. Their improvisations are thus built on a network of relations, both human and musical, both social and artistic, both synchronic and diachronic.

[3] Baltic Suite lets me experience the abundant and very specific interactions that can arise during improvisation. The piece lets me explore the complex connections between human(s) and environment, be it a musical instrument, historical

backgrounds, or socio-musical agreements and challenges. This comprovisation shows me that an analysis, interpretation, or mere encounter should not be reduced to one or more of the improvisation's individual constituents, but, on the contrary, should take the collective and interrelated behaviors of these constituents into account. 


\section{Context and Justification}

[1] Improvisation seems to be a hot topic. Although (perhaps) still found primarily in the margins of the discourses around music, the past decades have brought an increase of publications on improvisation. Although Bruno Nettl's (1998: 1) first sentence in his book In the Course of Performance from 1998 - "In the history of musicology, improvisation [...] has played a minor role" - might be true, quite a few monographs, edited volumes, journal articles, Internet essays, etc. have more or less recently been published on this subject. The list is already far too long and diverse to be used to provide a decent overview or a reliable enumeration of core publications. And one of the promising aspects of these publications is that many of them are written by improvising musicians themselves, thereby offering an insider's view on the topic, a phenomenon not always self-evident in the academic world.

[2] So, why do I wish to add another book on "the same" subject? Why this drive to create a new story, report, or narrative on the praxis of improvisation, even though I consider myself to be no more than a very modest improviser, making it almost inevitable that I will write from an outsider's perspective? What is my position with regard to some publications that once were (and, to be sure, still are) an enormous source of inspiration, a thrilling read, and which function now (also) as markers that, in my opinion, need to be supplemented, sometimes even ameliorated? These questions will only be answered for me during the writing process and for you during your reading of this text. Whether what I am hoping to bring forward is to some extent "new" and "useful" (in the sense of delivering some new insights or providing fresh perspectives) can, in the end, only be decided by you, the (future) readers of this book.

[3] Here, to open the narrative, to expose briefly and prematurely the context of this study, and to start revealing my position (whether I could be considered the best source of observations concerning my own position remains indeed a serious question), I will mention a few of the "stopping places" I have visited over the past few years while working on this project.

Derek Bailey's book Improvisation. Its Nature and Practice in Music from 1993, as well as Bruce Ellis Benson's The Improvisation of Musical Dialogue from 2003 provided me with the simple but far-reaching insight that improvisation actually is operative in (almost) all music making. The results of this "ear-opener" permeate this entire study as I deliberately chose many different musics to support my ideas on improvisation.

Saying Something by Ingrid Monson, published in 1996, first put me on the track of inquiring into the aspect of interaction in improvisation, an aspect which appears to be the most central in this study. However, her almost exclusive attention to jazz music and the human-human, real-time interaction taking place in this music, provided me with the opportunity to investigate different musics as well as different interactions: besides human-human interaction, many other interactions arise within 
and determine the improvisation process. And what's more, interaction appears to be a far too general term: specifications of various types of interaction are needed.

David Borgo's Sync or Swarm from 2005 has proven to be perhaps the most determinative book for this project. The book sowed the seeds for regarding musical improvisation as a space in which many actors, factors, and vectors are operative. Borgo's point of departure that "systems display collective behaviors that are not predictable in terms of the dynamics of their component parts" (Borgo 2005: xvii) also permeates the ideas on improvisation presented here. However, whereas Borgo mainly uses this insight, stemming from complexity and chaos theories, to cast new light on the ways certain (free) improvisations develop and are constructed musically, my focus here will be more directed towards tracing the main actors and their collective interactions, operative during a specific improvisation

One could call the approach proposed by people like Borgo and me ecological, thereby referring to the original definition of the term as proposed by German zoologist and philosopher Ernst Haeckel who conceived of ecology as "the science of the relations between the organisms and the environmental outer world" (Haeckel 1866: 286). Many musical examples used in this book deal with the interactions that arise between improvisers and their environment, the latter regarded as either material-physical or immaterial-metaphysical. This ecological imprology took me from the notion of Umwelt coined by the Baltic German biologist Jakob von Uexküll to the Actor-Network-Theory of the French sociologist Bruno Latour, and from the ecological anthropology of Gregory Bateson to the concept of assemblage as developed by Gilles Deleuze and Félix Guattari. Together with many others, their voices form the choir that is shifting from back- to foreground and vice versa during the rest of this book.

\section{Oligoptica and Prolegomena}

[1] "Every concept always has a history, even though the history zigzags, though it passes, if need be, through other problems or onto different planes" (Deleuze and Guattari 1994: 18). Improvisation, documented in audio, visual, and textual materials, but mostly locked up in the inaccessible archives of personal memories or relinquished to oblivion, has traversed many if not all musical, geographical, and historical planes, abused and adulated, disguised with many different names and displaying itself in many different forms (cf. "The Omnipresence of Improvisation").

[2] "A concept carries out a new cutting-out, takes on new contours, and must be reactivated or recut" (Deleuze and Guattari 1994: 18). In that sense, a concept also has "a becoming." To rethink the concept of improvisation, to re-address it, to de- and reterritorialize it; to demystify it, to discard from it too many romanticisms, too many prejudices; and also to include in its reconceptualizations enough radical empiricism those are the aims of this study.

However, improvisation might not be a concept. The set of works, the assemblage of events it refers to remain open. Halfway between the universal and the singular simultaneously model and guide, improvisation allows a general discourse, but cannot dispense with singularities. Rather than classifying certain musics in a closed way, it opens the musical field to new investigations, to new configurations, to new encounters and invitations.

[3] This book is not meant to unambiguously categorize, order, and analyze the rampant proliferation of musical improvisations, to escort them to a monotonous finality, or to reduce them to a putative origin or originality. This study is not a quest for a clearly delimitable essence of its subject, a search for its identity, an exploration of its immutable form. Rather, it is the aim of this book to report of events, directions, ramifications, and incidents - in short of the becoming of improvisation; spaces between instead of origins; no arrivals, but departures, perpetually on the way (Kleiner and Szepanski 2003: 7). Many terms here are used provisionally, as "conceptual placeholders," rather than definitely or categorically. The FMI-theory should not be evaluated as an end in itself, but for how it might change the way we think about improvisation, for how it allows us to reorganize the field, replacing previous insights with new, temporal, spatial, and morphological distinctions, in short, for how it is able to present a new physics of organization (Moretti in Berry 2008: 366).

[4] "Capitalism has no plausible enemy since it is 'everywhere', but a given trading room in Wall Street has many competitors in Shanghai, Frankfurt, and London - a computer breakdown, a sneaky movement by a competitor, an unexpected figure, a neglected variable in a pricing formula, a risky accounting procedure - that may shift the balance from an obscene profit to a dramatic loss" (Latour 2007: 178).

Following, interpreting, arrogating Latour here, the subject of this study will not be improvisation in a general sense, as a general principle operative in many, if not all 
music making. Instead, it will focus on particular sites, concrete manifestations, and specific articulations. Improvisation hinges on particularities, individual vectors, and singular connections.

\section{The Omnipresence of Improvisation}

[1] Improvisation is all over the musical place; it happens in all music making. In that sense, improvisation connects George Clinton to Franz Liszt, John Zorn to Ivo Papasov, Sachiko M to John Coltrane, and Beyoncé to Ustad Fateh Ali Khan.

In The Improvisation of Musical Dialogue, philosopher Bruce Ellis Benson gives an enumerative description of how improvisation is always already operative in the performing and composing of Western classical music. From the most "minimalistic" filling-in of details that are not notated in the score to the modification of a complete musical tradition by sometimes radical compositional transformations, Benson offers a whole list of possibilities, thereby claiming that the difference between various forms of improvisation is quantitative rather than qualitative: "Each instance involves a kind of reworking of something that already exists, so the differences concern the ways and the degrees to which this reworking takes place" (Benson 2003: 30; cf. "Alfred Brendel and W.A. Mozart" and "Vlatko Stefanovski"). Filling in notes required by a score that only supplies figured bass; playing Classical cadenzas; transcribing pieces for different instruments; adding or subtracting measures, passages, or even complete sections; making arrangements; altering the melody line and/or the chords (so typical for much jazz music); going beyond certain compositional templates - all these situations are subject to improvisation, Benson states (2004: 26-9). Benson's claim - far from exhaustive, if only because his sole focus is on pitch improvisations - is supported by pianist John Tilbury, who maintains that any musical performance always depends on the specifics of the situation and the moment. For example, acoustics, venue, and the available keyboard will always influence certain decisions regarding tempo, volume, intonation, and dynamics, which leads Tilbury to the opinion that improvisation is an inextricable and inevitable part of all music making (Tilbury in Hopkins 2009: n.p.). Each performance produces, therefore, a unique sound event, located somewhere on a continuum between iterability and alteration.

"Should we not then speak perhaps of rapid and slow composition rather than of composition juxtaposed to improvisation? And would we not do well to think of composition and improvisation as opposite ends of a continuum [...]?" Bruno Nettl (1974: 6) asks, rather more cautiously than Benson and Tilbury.

The term "rapid composition" resonates with the name of a Dutch improvisation ensemble, The Instant Composers Pool (ICP). "Instant composing" counters notions that improvising is either a lesser order of music-making than composing or an art without a memory, existing only in the moment, unmindful of form. The formulation posits improvisation as formal composition's equal, something that both the ICP and Nettl seem to pursue.

However, George Lewis warns against the tendency to regard composition as the starting point or standard. Improvisers do not automatically make use of the same raw materials that composers draw upon, the latter valorizing aspects one seeks out 
in composed music (style systems, formulas, referents, schemas, models, etc.). Why, then, subsume improvisation under the denominator of composition? Rather than sharing models, improvisation means to share capacities for interpretation, to share intentions, and to negotiate evaluations of meaningful utterances (Lewis 2013: 3).

In my opinion, Lewis' statement or formulation further blurs the distinction between composition and improvisation, as the types of sharing he identifies as improvising are certainly also intrinsic to composing. In fact, Lewis confirms Benson's claim that improvisation is always already an element in all music making; improvisation cannot be separated from any musical activity.

[2] Within Arabic and Turkish musical terminology exists a term that comes rather close to the Western concept of improvisation: taqsim. In Cantonese the term bao tou ("exploding one's belly") is used; in Iran one speaks of radif when referring to music including improvisation; in Northern India of upaj. (The Sanskrit term upaja means something like "variation" or "elaboration" but is also translated as "improvisation.") Of course, the use of different concepts to denote something which could (perhaps) also be called improvisation is not restricted to "non-Western" music only. Extemporization, intuitive music, phantasieren (fantasiren), ornamenting, and präludieren are but a few extant alternatives for naming more or less the same activities.

[3] Ethno-musicologist R. Anderson Sutton and jazz saxophonist Lee Konitz are but two of many people warning against the subsumption of many (apparently) different musical activities under one coordinating term, improvisation. In “Do Javanese Gamelan Musicians Really Improvise?" Sutton approvingly quotes Konitz who reserves the term improvisation for "the most radical transfigurations of the melody, as distinct from subtler alterations falling within the realm of variation, embellishment, and interpretation" (Sutton in Nettl 1998: 73; Konitz in Berliner 1994: 67). Sutton, too, likes to save the concept of improvisation for "more substantial choices being made at the moment of performance" (Sutton in Nettl 1998: 73).

How difficult might it turn out to be to decide when a variation changes into a transfiguration, an embellishment into an improvisation, an interpretation into an extemporization? How "substantial" is a transcription or a cadenza? And what do we do with terms such as "version", "modification", "deviation", or "reworking"; are they mere synonyms of variations, or do they already belong to the same category as improvisation? However, my main argument will not be against an inconvenien proliferation of terms to describe more or less "the same" musical events. Neither is it my intention to offhandedly simplify matters and to reduce differences by claiming that those various terms and musical activities should be lumped together and labeled as improvisation. Differences matter, and it is precisely my principle aim here in this text to emphasize those differences. Indeed, during each musical event, improvisation happens differently. Improvisation differs from itself. ("To exist is to differ," Gabriel Tarde remarks time and again.) And the same goes for any other term more or less pointing at more or less the same activity: a variation in piece $\mathrm{A}$ is not exactly the same as a variation in piece B. For Konitz this word will have a different meaning than for a composer in the nineteenth century, a contemporary pop musician, or a performer of traditional Indian music.

So, instead of erasing differences, the thinking on improvisation which I try to unfold here will never be one that deals with generalities or universalities. The Field of Musical Improvisation emphasizes singularity: each improvisation - here used in the broad sense, as proposed by Benson - will in a different way give shape to the amount and sort of freedom a musician has in the course of performance; each improvisation will offer different perspectives on concepts such as creativity, freedom, risk, etc.; each improvisation will yield a different network of (most prominent) agents and interactions; each improvisation will relate differently to previous improvisations; each improvisation creates a new story within given constraints.

An object that is heavy within a given space will be light or marginal in another. (Lévy 1997: 145)

Instead of claiming sameness, the concept of improvisation should be cracked and redefined in, for, and through each specific situation. As Bruno Latour writes (2007: 121) "it has to be able to register differences, to absorb multiplicity, to be remade for each new case at hand." Part 3 of this book, in particular, is composed to deconstruct over-generalization when discussing improvisation. 


\section{The Fell Clutch}
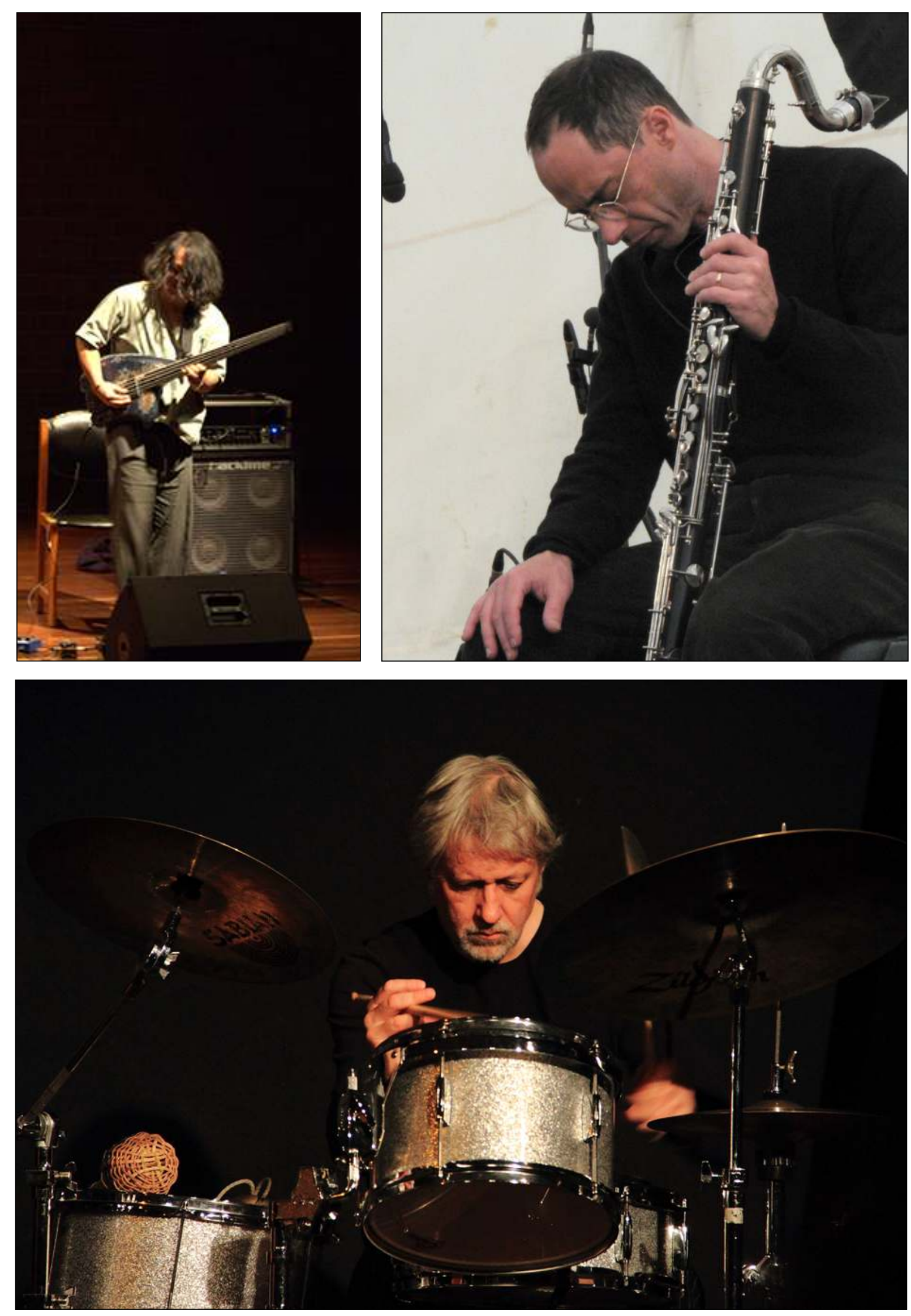

Clockwise from the left: Stomu Takeishi, Ned Rothenberg, Tony Buck
[1] One sonic landmark upon which this book is based was encountered on a Sunday afternoon during May of 2007 in Lantaren/Venster - a venue for contemporary performing arts in downtown Rotterdam (the Netherlands). On the program was, besides Sean Noonan's Brewed by Noon, The Fell Clutch.

play

The Fell Clutch - "No Memes, Mom"

The Fell Clutch trio consists of Ned Rothenberg (clarinets, alto sax, shakuhachi), Stomu Takeishi (bass guitar), and Tony Buck (drums), this time featuring electric guitarist Marc Ribot. When, following a few tunes by the trio, Ribot enters stage and plugs his guitar into an old Fender Twin Reverb, an enormous cracking fills the hall. The amplifier is obviously broken. Fortunately, there are three more Twins on stage, already installed for Brewed by Noon. However, to the surprise of both the audience and the other musicians, Ribot decides to hold onto his broken amp. Instead of switching to a working Twin, he starts switching the broken one on each time he plays his guitar; conversely, he turns the amp off when he abstains from playing. He thus operates the on/off switch some twenty times per minute before the collective improvisation has reached a level of intensity that does permit the permanent drone of the amp to be an integral part of it.

[2] The music, gradually evolving soundscapes frequently built up around repetitive, improvised patterns, was fascinating. And of course everyone knows that the instrument of an electric guitarist also includes the effects pedals and the amp. But a special situation is often needed to make one fully aware of the impact an amplifier has on the sonic results. The broken Fender Twin radically changed the development of the improvisation at hand. In other words, instead of remaining a seemingly neutral or inconspicuous transmitter of (prepared) guitar sounds, the amp turned into an important musical actant, without which the music would have taken a different direction. Suddenly, both the musicians and audience came to realize that a simple amplifier can determine to a great extent the course of an improvisation. Suddenly, the interaction between Ribot and the amplifier, or, more precisely, the interaction between Ribot, amplifier, and plug became the main event on stage. Suddenly, the three other musicians on stage were not interacting so much with Ribot as with a broken Fender Twin.

[3] With this concert, interaction, regarded as an important aspect of improvisation, at once received another meaning, an extra dimension. Unexpectedly I realized that the act of improvising takes place not only on a field where the musical and the social fuse, as Ingrid Monson writes (1996: 90). Besides humans, many more actors and 
factors play a role in the realization of an improvisation. In general, one could state that interaction in music takes place between a body - human or nonhuman - and its environment. This environment - physical or otherwise - can take on many forms and can encompass many different actors, thereby evoking manifold interactions. Realizing this brought me to the topic of complexity, which will be discussed in Part 2 .

\section{What is Improvisation (Not)?}

[1] What is improvisation in music? How can this term be defined? That is, how can it be distinguished from other concepts referring to music making, such as composing, performing, or interpreting? What is included and what is excluded when using this term? (Cf. "The Omnipresence of Improvisation", section 3.) According to August Sheeny and Paul Steinbeck it is much easier to say, "That is improvisation," than to provide positive content for "that", mainly because of the differences between the individual manifestations of musical events labeled with the word "improvisation" (Sheehy and Steinbeck 2013: 2). The main problem with coming up with a convincing, durable, and stable definition of this concept is that there are simply too many different models or modes of improvisation, and the more resolute an answer, the greater the inaccuracy and collateral damage will be; each definition of improvisation will simultaneously constitute it and thereby perchance restrict its working.

[2] Im-pro-vise. Literally: un-fore-seen. Undoubtedly, improvisation has something to do with providing space for originality, for newness, and for unexpectedness, and is thus connected to creativity, inventiveness, and openness (although one should be aware that these are all modern and Western concepts). Ethnomusicologists Bruno Nettl and Melinda Russell implement a current definition of improvisation as a book title: the creation of music in the course of performance. According to Nettl, the Western musicological world generally agrees on the basic description of improvisation, regarded as the creation of a musical utterance at the moment of its realization in performance or, in other words, the performance of music at the very moment of its conception (Nettl 1998: 11; Nettl 1974: 3). Put differently, the word improvisation connotes procedures that depend upon the selection of musical elements, the selection of which occurs in the moment by the players (Nettl 1998: 286).

Improvisation is a situation in which decisive aspects of composition occur during the performance. (Oxford Music Online)

[3] However, I think it is necessary to eliminate possible misunderstandings. Creating music "in the course of performance", "in real-time", or "on the spur of the moment" should not be equated with a "creatio ex nihilo", creation out of nothing. The Russian philosopher Mikhail Bakhtin argues that "something created is always created out of something" (Bakhtin 1986: 120). Following Bakhtin, improvising can therefore be understood as interacting with and transforming of certain historical predispositions or, in a less time-based formulation, engaging with existing structures and rules, accepting, rejecting, appropriating, or building on previous selections and decisions. Besides, a musician must be prepared in order to be able to improvise, to meet and take care of the unknown and emergent, and such preparation usually takes many years. As they say, the ability to improvise requires more transpiration than 
inspiration. Improvisation demands many hours of preparation and practicing of techne and practical knowledge, in order to master the instrument as well as certain musical traditions and conventions. Improvisation cannot operate without some sorts of constraints - temporal, material, technical, genre-specific, cultural, or societal - however loose, however subject to change, however unspoken (Benson 2003: 135; Landgraf 2014: 18). To quote Gerard Béhague, improvisation involves "a relative freedom to choose elements within stylistic norms and rules proper to a given culture" (Béhague 1980: 118). In much the same way, George Lewis writes that improvisation takes place between careful preparation and spontaneity: "The notion of improvisative spontaneity to the present moment insists on ephemerality" (Lewis in Fischlin and Heble 2004: 148). From a more philosophical plateau, French philosopher Jacques Derrida remarks that improvisation, regarded as a purely spontaneous creation of something absolutely new, is impossible. One is always more or less obliged to reproduce stereotypical discourses, schemas, and languages already existing, prescriptions that are inscribed in one's memory and culture (Derrida 1982: n.p.). Improvisation works as a simultaneous process of reiteration and alteration and is therefore not antithetical to stability and continuity; the latter two define the horizon that limits and at the same time enables the act of improvising. Said differently, the known and the familiar must be recognized as that from which an improvisation can distinguish itself (Landgraf 2014: 93).

All ways of musicking have some kind of syntax, some way of controlling the relationships between the sounds that are made: it is a necessary condition for the shared meanings between those taking part. (Small 1998: 122)

Although not referring to music, Bruno Latour's remark that "any given interaction seems to overflow with elements which are already in the situation coming from some other time, some other place, and generated by some other agency" (Latour 2007: 166) seems quite apt in refuting the romantic and mythical assertion that improvisation works with and through absolute beginnings. Granted, certain decisions are taken while playing, but these decisions are (always already) formed and informed by previous events.

However, that does not alter the fact that the space for creating music "in the course of performance" is far from unequivocal. Some music makes more space for contingencies to be improvised upon than others. Free jazz pianist Cecil Taylor must make considerably more musical choices during a performance than Evgeny Kissin, performer of mostly Romantic piano repertoire. However, the difference is quantitative rather than absolute: under the influence of many unforeseen factors, Kissin, too, needs to continually readjust his playing. In Music, Imagination, and Culture Nicolas Cook offers a similar assertion: playing a classical piece of music and a jazz improvisation involve the same creative synthesis of performance schemes in real time; the difference is merely in the nature of the constraints within which this creativity operates (Cook 1990: 113). (For a discussion on whether "readjusting" can already be subsumed under the denominator "improvisation", see "The Omnipresence of Improvisation".)

In all improvisations there are a number of contextual preconditions: participating musicians, employed instruments, playing space, etc., and the unfolding of events is a consequence of interaction and decisions made in real-time within these conditions. (Nilsson 2011: 101)

[4] In Duke - A Portrait of Duke Ellington, Derek Jewell quotes Ellington from an interview he gave at a radio station in Buenos Aires in 1968: "Improvisation? Anyone who plays anything worth hearing knows what he's going to play, no matter whether he prepares a day ahead or a beat ahead" (Ellington in Jewell 1977: 187).

However, although improvisation cannot exist without preparation, there is a kind of preparation not mentioned by Ellington here, and that is to be prepared for what saxophonist Steve Lacy calls "the leap," the "leap into the unknown." Although - or perhaps because of - being armed with hours and hours of preparation, all improvisation is, to a more or lesser extent, a play on the brink of the unknown and preparedness for the leap (Steve Lacy in Cox and Warner 2009: 249). However, rather than a sound definition, Lacy's remark describes how improvisation works or how musicians think and feel about it. This moving away from the ontological towards the empirical also permeates this book. Rather than presenting a treatise about the term improvisation, it is my aim to rethink musical practices and discourses through the use of that term. It is my conviction that improvisation is better approached through verbs than through nouns - "improvising" instead of "improvisation" implicating that a neat categorization or definition cannot keep up with the flow of musical events in which improvising plays a role in one way or another. 


\section{Part 2}

\section{Digging}




\section{Introduction to Part 2 - Digging}

[1] In Part 1 I discussed two musical instigations that brought me to this study on improvisation, complexity, and singularity: the CD Baltic Suite by David Murray (cf. "Baltic Suite") and a concert by The Fell Clutch (cf. "The Fell Clutch"). The more or less implicit conclusion I have drawn from these two musics is that, while both certainly offer prominent space for improvisation and both could be classified as jazz, their respective focal points are quite different: the most ear catching moments in Baltic Suite are those in which the musicians directly respond to each other's musical input, e.g. by repeating certain riffs, phrases, or rhythmical gestures. A second aspect is the frequent use of citations, appealing to a concrete musical history and background. These qualities are far less prominent in the Fell Clutch concert, in which the interaction between musicians and technical equipment predominates, primarily due to the use of a broken amplifier by guitarist Marc Ribot.

A similar "difference in sameness" could be concluded from Benson's extensive enumeration of various manifestations of improvisation (cf. "The Omnipresence of Improvisation", section 1): although the denominator "improvisation" seems to suggest a certain unity and homogeneity, its different forms and distinct sonic results cannot and should not be ignored. The practices of improvisation are far too diverse to justify a simple generalization. Of course, this may not sound very innovative or challenging; however, studies on improvisation do all too often suffer from ineffectual quibbling concerning the demarcation of the term as well as employing forms of reductionism that cannot answer questions regarding how things interact, how things come together, or how systems display collective behaviors that are not predictable in terms of the dynamics of their component parts (Borgo 2005: xvii). This book therefore suggests a shift from quantitative reductionism, decontextualization, and disjunctive ways of thinking toward a more qualitative and holistic appreciation of complex dynamics.

[2] It is the central aim of this study to add two things to the discussion on musical improvisation, two things that together form the core of the FMI theory: complexity and singularity. I understand complexity as the dynamic, nonlinear, and constantly changing interactions between several (independent) actors and factors that lead to various forms of self-organization. In my opinion, improvisations can be regarded as complex systems, as systems continuously trying to find a balance (or to create a tension) between fixity and fluidity. However, not all of the actors and factors are always present in each improvisation or determine every improvisation to the same extent; in certain situations (periods, styles, cultures as well as more singular circumstances), some are more prominent and active than others. Therefore, the FMI theory will not be a theory dealing with improvisation "in general." It emphasizes singularity: each improvisation will yield a different network of actors and interactions, a different configuration or a different assemblage. As Latour argues, the specificity of mediators needs to be taken into account every time (Latour 2007: 39). 
[3] Subsuming improvisation under the more general denominator of complex systems does not mean, however, that I equate musical improvisation with biological neurological, economic or other systems devised and revealed in and through hard and social sciences. In this book, improvisation encounters other systems but still has its own direction, working, meaning, and features - "an a-parallel evolution" (Deleuze and Parnet 1987: 7), and as such it might have its effects on either of them separately.

[4] Considering improvisation as a complex system, as an actor-network, implies a certain parting from a musical anthropocentrism in which the musician is the most important agent. The dynamics of systems and networks operate at levels "above" or "below" that of the human subject. When networks structure and organize the world, humans become nodes, subject positions for a host of active structural network formations that act and interact outside or beyond their direct control (Berry 2008: 365 and 368). As David Borgo notes, by way of example, "historical and economic factors often dictate which musicians and musical ideas gain notice and prestige" (Borgo 2005: 11).

More emphasis on systems that involve internal dynamics, interaction with their environment, as well as a pronounced ability to adapt to new circumstances and conditions may offer alternative insights into the working of improvisation in music without taking the human agent as an indispensable starting point.

[5] Part 3 consists of several concrete musical examples, specific musics in which improvisation plays a role and particular situations during which interactions take place between human subjects, non-human objects, and their environment. These examples are meant to concretize how each individual improvisation is determined by a very specific and unique configuration of actants, how these actants connect, and how they influence one another. In Part 2 several complexity and cognate theories are introduced: Bruno Latour's Actor Network Theory, Deleuze and Guattari's assemblage, Jakob von Uexküll's Umweltlehre, Mitchell Waldrop's discussions of complex systems, and Pierre Lévy's ideas on collective intelligence. In addition, a relation is suggested between the concept of complexity and the use of the word "field." As such, Part 2 forms the theoretical backbone of this study, frames the distinct musical examples discussed in Part 3, and provides a predominantly scholarly context to Part 3 and 4 . However, when possible, these theories are immediately connected to improvisation examples, sometimes presented as a practical illustration, sometimes as a critical comment.
Bruno Latour and the Field of Musical Improvisation

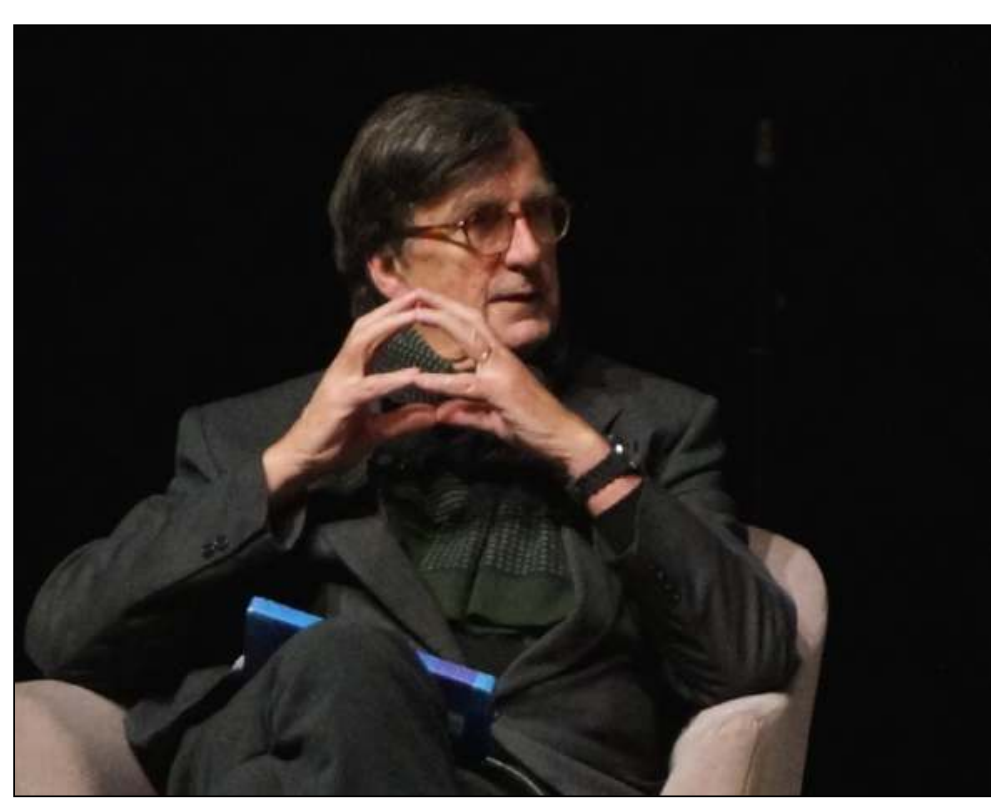

Bruno Latour

[1] Listen to some indiscriminate improvisations, e.g. Ornette Coleman's Free Jazz, Adama Yaloba's M'Bora or Karl-Heinz Stockhausen's Ylem. Who are the actors in these musical events? The answer seems to be trivial and self-evident: the musicians. But it is equally clear that these improvisations are not achieved by human input alone: instruments, technology, and space are but a few other actors that determine the musical outcomes.

[2] In Reassembling the Social, Bruno Latour states that especially phenomenologists place too much emphasis on human sources of action (Latour 2007: 61). Conversely, Latour argues in favor of including non-humans as actors: anything that does modify a state of affairs by making a difference is an actor, or an actant as Latour prefers to call it, thereby emphasizing his non-anthropocentric approach: "Any course of action will rarely consist of human-human connections [...] or of object-object connections, but will probably zigzag from one to the other" (Latour 2007: 75). Therefore, Latour writes, it is necessary to add the idea of interobjectivity, which should suggest worlds of action and significance shared by people and objects, to the understanding of intersubjective relations taking place between two or more humans (Latour 2007: 196). With this term, Latour does not return to a positivistic objectification; rather, his is a call to trace networks in which non-human actants are functioning.

[3] Despite their obvious differences, what connects and equals humans and objects is the simple fact that they both influence others; they have agency. Agency is the capacity of an actant to change the environment. Through agency, humans and objects are able to interact. For Latour, in order to describe a certain assemblage, it is necessary to pay attention to all heterogeneous (human and non-human) actants and the relations, associations, and interactions involved. Both the actants and their 
associations undergo a process of metamorphosis, a translation, in each mode of assemblage. With this, Latour obviously describes a field of encounters that cannot be reduced to a priori definitions about humans, actions, objects, or factual matters; their definitions and identities depend on the very results of concrete assemblages. Latour's ideas somehow reflect those of Spinoza, who stated that a body's power is both constituted in and augmented by its relations with other material beings. Besides Spinoza, philosophers such as Deleuze, Heidegger, and Sloterdijk resonate in Latour's theories: for example, Peter Sloterdijk, following Heidegger, concentrates, especially in his bulky trilogy Spheres, on the "in-between" by giving ontological priority not to "things" but to the relations between "things." Like Heidegger, Sloterdijk uses the term "inter-esse" in the literal sense of "being between things" or "dwelling on things."

The (temporary) result of this process of interaction and transformation is termed an actor-network by Latour. The main principle of the actor-network theory (ANT) is to follow the actants, that is, to trace their multiple associations and translations. In my view, the field of musical improvisation can be considered as an example of such an actor-network in which actants such as musicians, instruments, acoustics, repertoire, and audience are operative. If one of these actants undergoes more or less sweeping changes, the whole network will alter. A change of instruments, ways of playing, the amount and type of musicians, or acoustic reverberation will have an immediate impact on the development, the interactions, and the sounding result of the improvisation. Through translation, one actant thus influences all other actants, thereby inevitably affecting itself as well: changing a certain development in an improvisation, for instance by starting to play a radically different pattern, will simultaneously alter the field of possibilities for all players, including the one who started the transition.

In improvised performances in particular, small details in sound production or perception can, when attended to or acknowledged by participants and listeners at appropriate moments, trigger transformations in the music or its reception, such that the eventual outcome is disproportionate to any initial causes. (Borgo 2005: 68)

What is more, each actant is itself a network of mediations; each actant is at the same time also a network. The actant musician consists of fingers, limbs, ears, and brain, for example; the actant piano can be unfolded into strings, hammers, keys, pedals, body, etc.; the size of a space, the building materials, and damping devices, etc. are hidden behind the actant acoustics.

[4] What is wrong with the word actor, according to Latour, is not that it often is understood to denote only humans but, primarily, that it always seems to designate a source of initiative or a starting point. Conversely, the actor-network theory takes as its point of departure a large web of mediators flowing in and out of it. It is made to exist by its many ties: attachments are first, actors are second (Latour 2007: 216-7).

That (human) actors are second may sound a bit awkward when discussing improvisation in music; what counts here are precisely the actors, that is, the musicians, their ability to perform, to handle their instruments, to listen, to interact. Of course musical improvisation seems first of all a human affair; it is about human considerations and decisions, human initiatives and choices. But are these acts also the starting point? Let's take as an example Sachiko M's album Salon de Sachiko. Recorded in 2007, the one hour long track consists of soft ticks and sputters, chirps, slightly elongated high tones, and twittering, cut up sounds on the verge of the audible, produced by two oscillators. These sonic elements figure on a background of silence.

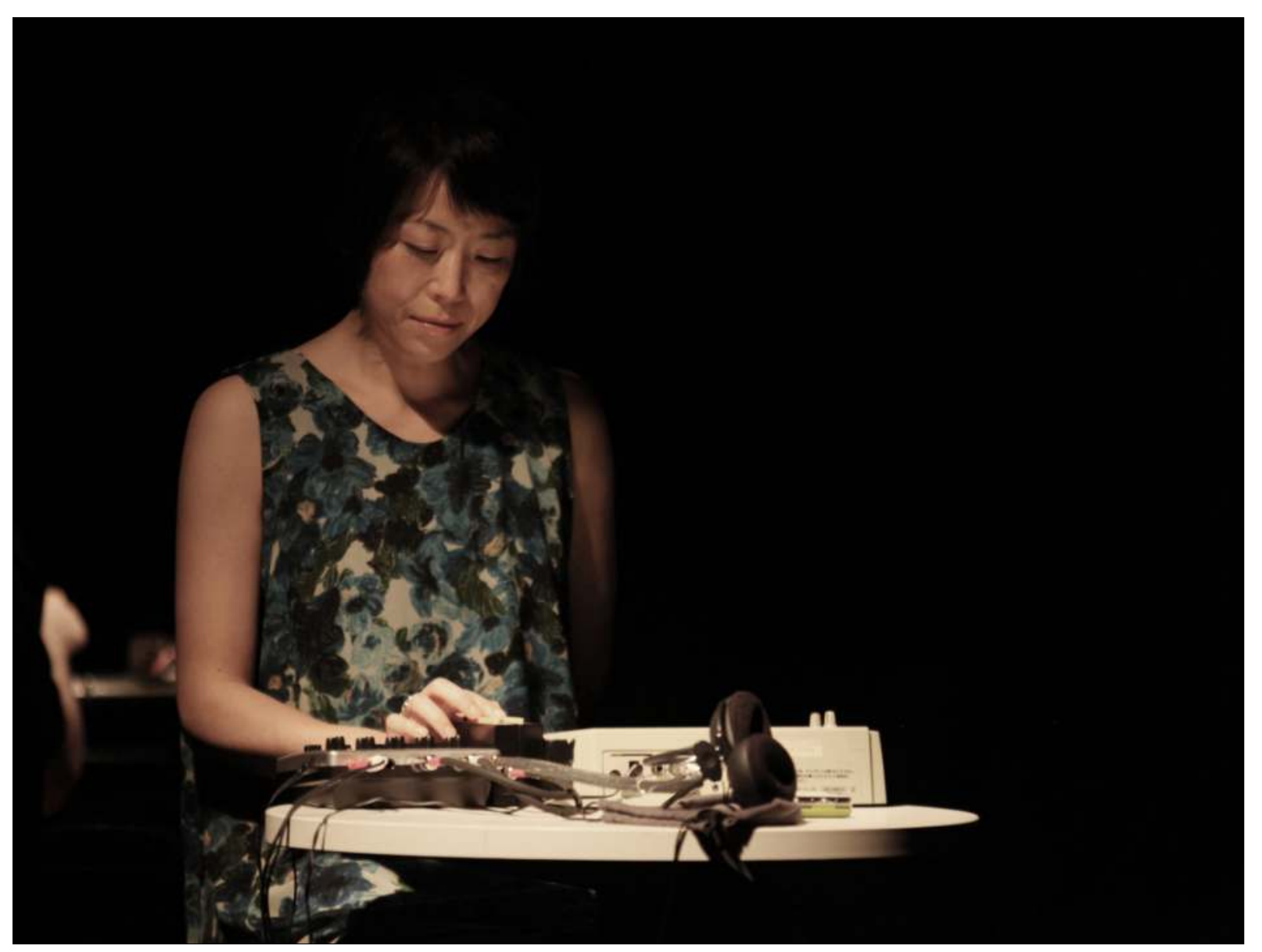

play

Sachiko M - Salon de Sachiko (Image: Sachiko M)

Of course, Sachiko M is operating the oscillators and designing the unfolding of the music's structure; she seems to be the main actor. However, as Brian Olewnick 
astutely remarks in a review of the album, the sounds also reveal themselves to Sachiko M, and her calm concentration allows the music to come into being on its own rather than forcing it down a given path (Olewnick 2007: n.p.). However, it is first of all the silences that leave their mark on Salon de Sachiko, silences that cannot be controlled by a musician, only facilitated. Listening to this $\mathrm{CD}$ without headphones that suppress any external sound results in a dialogue between the recorded sounds and those ambient sounds that are always already present in a space. Often it is hard to tell whether the sounds are coming from the $\mathrm{CD}$ or from other, external sources; what comes into being is a delicate and polyphonic play between intended and nonintended sounds, the latter sometimes described or perceived as silence.

Here the musician is not the prime mover anymore, not the incontrovertible starting point; Salon de Sachiko lets one encounter subtle, plural, and heterogeneous interactions between (the sounds produced by) two oscillators, one musician, and several types of silence, some internal, some external to the improvisation. None of these actors are the real source of the music making; rather, "an actor is what is made to act by many others" (Latour 2007: 46). All actors make others do things; unexpected events, e.g. caused by unpredictable "silences" or interferences between the two oscillators, might lead to unforeseen actions by Sachiko M. Conversely, through Sachiko M's actions, new unpredictable events occur. Instead of a chronological line with a clear starting point, Latour's ANT opens the possibility to regard musical improvisations as circles or spirals, where both human and nonhuman actors "might authorize, allow, afford, encourage, permit, suggest, influence, block, render possible, forbid, and so on" (Latour 2007: 72).

\section{Field}

[1] FMI: The Field of Musical Improvisation. Why a field? Why would I choose for a delimitation of improvisation, separating it from other musical fields? Why would I like to demarcate this concept, assigning it a specific territory, while claiming simultaneously that it takes place in all music making (cf. "The Omnipresence of Improvisation")?

Let me present three explanations that might support this deliberate choice for the word "field." First, a semantic reason. The meaning of the word as I use it here should bear some resemblance to Arjun Appadurai's use of the term "cultural form," that is, as possessing no Euclidean boundaries, structures, or regularities (Appadurai 1996: 46). "Field" signifies the fluid, irregular manifestations of musical improvisation in which many actants - human and non-human - are operative in various configurations. It is no attempt to classify, to divide, or to exclude; instead, "field" should emphasize the instability and the diversity of the practice of improvisation and refer to a "complex interplay of forces," a "configuration of possible events," and a "complete dynamism of structure" as used in physics (Eco in Cox and Warner 2009: 170). Perhaps it would be better to think about the formation rather than the form of the field, about structuring instead of structures, premising that a minimal order is required.

Furthermore, the field concept thus need not precede the events taking place within that field; these events are first needed to realize the field as a field. It can only manifest itself as a field on the basis of events that, invariably, lead to other events; all events exist as definable events by virtue of their relation to other events (Berger 2009: 70-1).

Rethink body, subjectivity, and social change in terms of movement, affect, force, and violence - before code, text, and signification. (Massumi 2002: 66)

[2] Second, a historical consideration. In his essay "The Poetics of the Open Work," Umberto Eco quotes the Belgium composer Henri Pousseur who says, regarding his electro-acoustic piece Scambi, that it is not so much a musical composition as a field of possibilities, an explicit invitation to exercise choice (Eco in Cox and Warner 2009: 168 , my emphasis). Instead of being more or less obliged to reproduce a pre-arranged assemblage of sound units along given structural coordinates, the performer of Scambi brings the work to a conclusion at the same time as she experiences it: the sixteen sections, which together build Scambi, can be played in a more or less random order; the performer is thus offered a kind of construction kit, meaning that she needs to make choices affecting the musical form during the course of the performance. 
Reflecting on Pousseur's work and explanation, Eco states that every performance of pieces such as Scambi "explains the composition, but does not exhaust it. Every performance makes the work an actuality, but is itself only complementary to all possible other performances of the work" (Eco in Cox and Warner 2009: 171). In his discussion of open works, it might seem remarkable that Eco does not mention any improvisations at all, e.g. those that are based on pre-determined harmonic schemes, so prevalent in most jazz music. Jazz standards constitute a field of possibilities that a singular performance actualizes but can never exhaust; the musicians are invited to explore and exploit the inherent possibilities of that field (Nilsson 2011: 5). Decisions made during a performance continually influence and actually change the potential of the field, turning the potential into (local) action.

[3] There is a third, more philosophical, motive. Although the FMI is in essence "a field of potential," i.e. the effect of a contingent intermixing of elements (Massum 2002: 76) rather than a principle of demarcation, the field-condition is necessary to avoid disorganization. "No field, no play, and the rules lose their power," Massumi (2002: 72) writes, analyzing soccer games. The same goes, mutatis mutandis, for improvisation: in the FMI, the rules, the (inter)actions, the necessary skills, and the aesthetics are determined to a certain degree in order to preserve the music from manifesting predominantly randomness and chaos. "All play moves and has its being within a playground marked off beforehand either materially or ideally, deliberately or as a matter of course," Johan Huizinga (1970: 28) writes in Homo Ludens (cf. "Play - John Zorn").

[4] In short, the FMI is a field of relations, a field of actions, actions of agents involved in the production of musical improvisations. The FMI forms and is formed by an uncertain interplay that concerns these relationships. These complex relations and interactions do not constitute a simple, stable system; it is all about dynamics. The field develops, expands and shrinks, crosses borders, incorporates aporias and paradoxes. There is no center of operations, no organizing core; there are no defining causes, no fundamental bases, no starting points or prime movers (Plant 1998: 45; cf. "Bruno Latour and the Field of Musical Improvisation"). In short, the field of musical improvisation has a dynamic structure.
Gilles Deleuze and the Field of Musical Improvisation

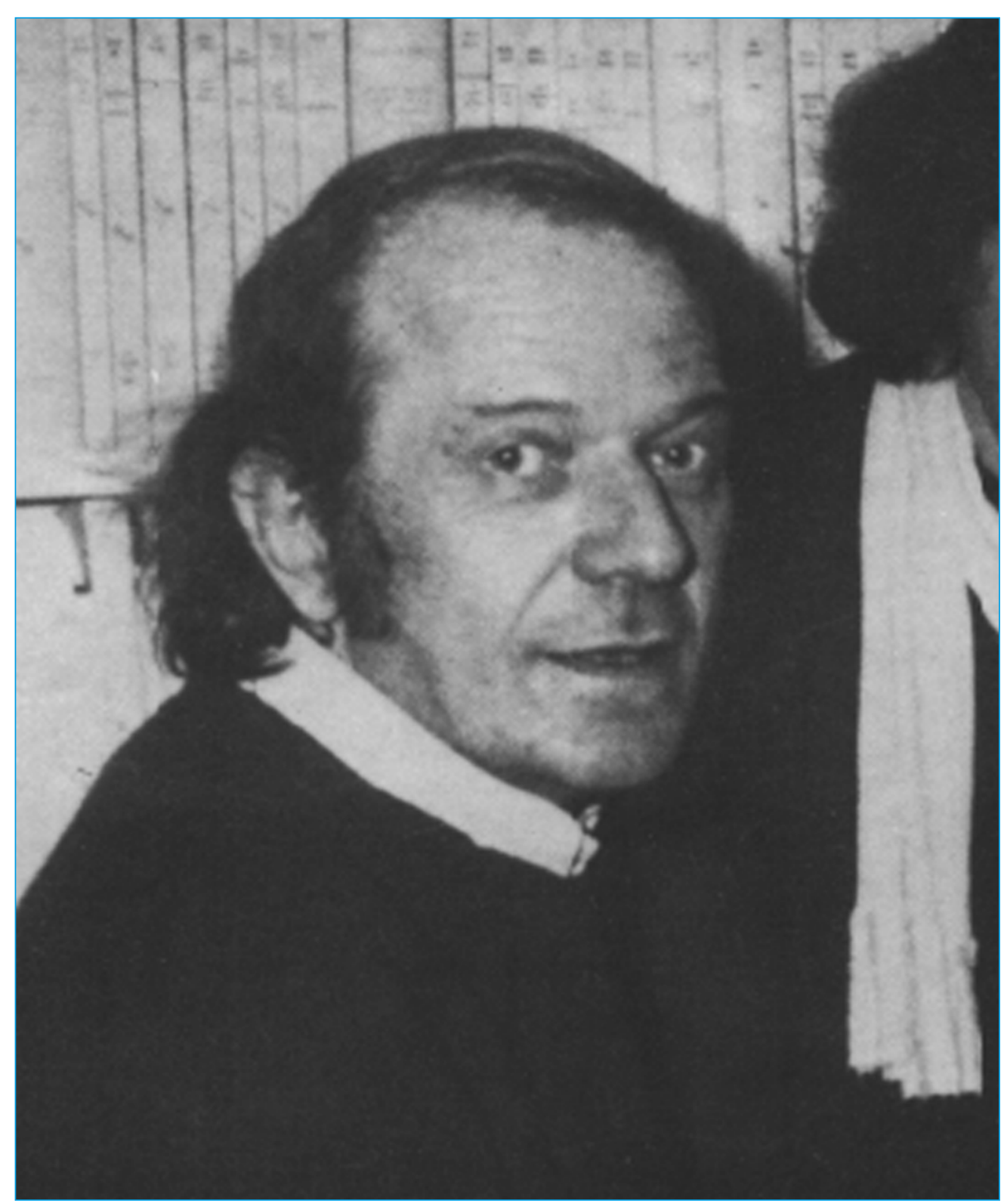

Gilles Deleuze

[1] How can a scholar approach improvisation? How should she understand all those different processes of music making, centralized in the concept of improvisation? Which outflanking maneuvers does she need to make in order to say something relevant and useful about improvisation? These are both practical and ethical questions. They touch the core of every discourse around music: how should a scholar write about music without falling into the trap of only letting the music say what the theoretical framework allows it to say (cf. Ferrara 1991)

[2] Throughout most of their books, Gilles Deleuze and Félix Guattari attempt to shed (new) light on social reality. They turn against a thinking in systems by means of which reality is constructed as a whole or a totality. In Mille plateaux their 
alternative is coined agencement, terminologically akin to the Latin "ago," meaning "to perform" but also "to put in motion." Deleuze and Guattari use this concept to describe the complexity and variability of the social. Hence, agencement is not static. It expresses the processes of arranging, organizing, assembling; it incites to action. Instead of an immutable essence or overall whole, Deleuze and Guattari use the term ensemble, translated in English as "assemblage." Unlike (organic) totalities, the parts of an assemblage do not form a seamless whole. Rather than logically necessary relations, relations in an assemblage may be only contingently obligatory (DeLanda 2006: 11).

Processes of arranging, organizing, and assembling, leading to relations that are only contingently obligatory - could this conceptual framework offer new insights into the praxis of musical improvisations? Or, suggesting a kind of reversal, do Deleuze and Guattari extrapolate common practice in the field of musical improvisation to the social in general? Not counting (many) exceptions, improvisers often work whether or not simultaneously - in several short-term and ad hoc projects. Within these projects, certain agreements apply, socially as well as musically, that need to be negotiated anew in subsequent situations. On a more inherently musical level, this might lead to collaborations in which the musical codes are created at the same time as the work, e.g. during a performance, emerging from a new, immediate, unstable, and local communication instead of an exchange of predetermined, generally coded messages. Is the field of musical improvisation thus the example par excellence of an assemblage in the Deleuzian sense?

\section{[3] In Dialogues Deleuze describes an assemblage as}

a multiplicity made up of many heterogeneous terms and which establishes liaisons, relations between them, across ages, sexes and reigns - different natures. Thus, the assemblage's only unity is that of co-functioning: it is a symbiosis, a 'sympathy'. It is never filiations which are important, but alliances, alloys; these are not successions, lines of descent, but contagions, epidemics, the wind. Magicians are well aware of this. An animal is defined less by its genus, its species, its organs, and its functions, than by the assemblages into which it enters. (Deleuze and Parnet 1987: 69)

In Voyager, the assemblage George Lewis - trombone - computer - saxophone Roscoe Mitchell forms a symbiosis. Musicians, instruments, and computers enter into new relationships. Voyager, in Lewis' words, employs "a computer-driven, interactive 'virtual improvising orchestra' that analyzes an improviser's performance in real time, generating both complex responses to the musician's playing and independent behavior arising from the program's own internal processes" (Lewis 2000: 33). In other words, the computer system does not function as a mere musical instrument to be controlled by a performer. Instead, the computer becomes a co-improviser; Voyager is designed to avoid the kind of uniformity in which the same kind of input routinely leads to a similar sonic result. It exhibits generative behavior independently of the improviser, which implies that decisions taken by the computer, either related or unrelated to the (human) improviser's input, have consequences for the music that must be taken into account by the musician. The traditional hierarchy of the (pro-)active human and the reactive computer is not so much subverted as it is deconstructed. Lewis thinks of Voyager in terms of "multidominance" or "bidirectional transfers," "multiple parallel streams of music generation, emanating from both the computers and the humans - a non-hierarchical, improvisational, subject-subject model of discourse, rather than a stimulus/response setup" (Lewis 2000: 34). The sympathy Deleuze is talking about is the mutual penetration of the bodies involved in this comprovisation, bodies that are physical, social, technical, political, and instrumental, bodies that become defined through sonic events. "What we may have in Voyager is a composing machine that allows outside intervention [...] an improvising machine that incorporates a dialogic imagination" (Lewis 2000: 38).

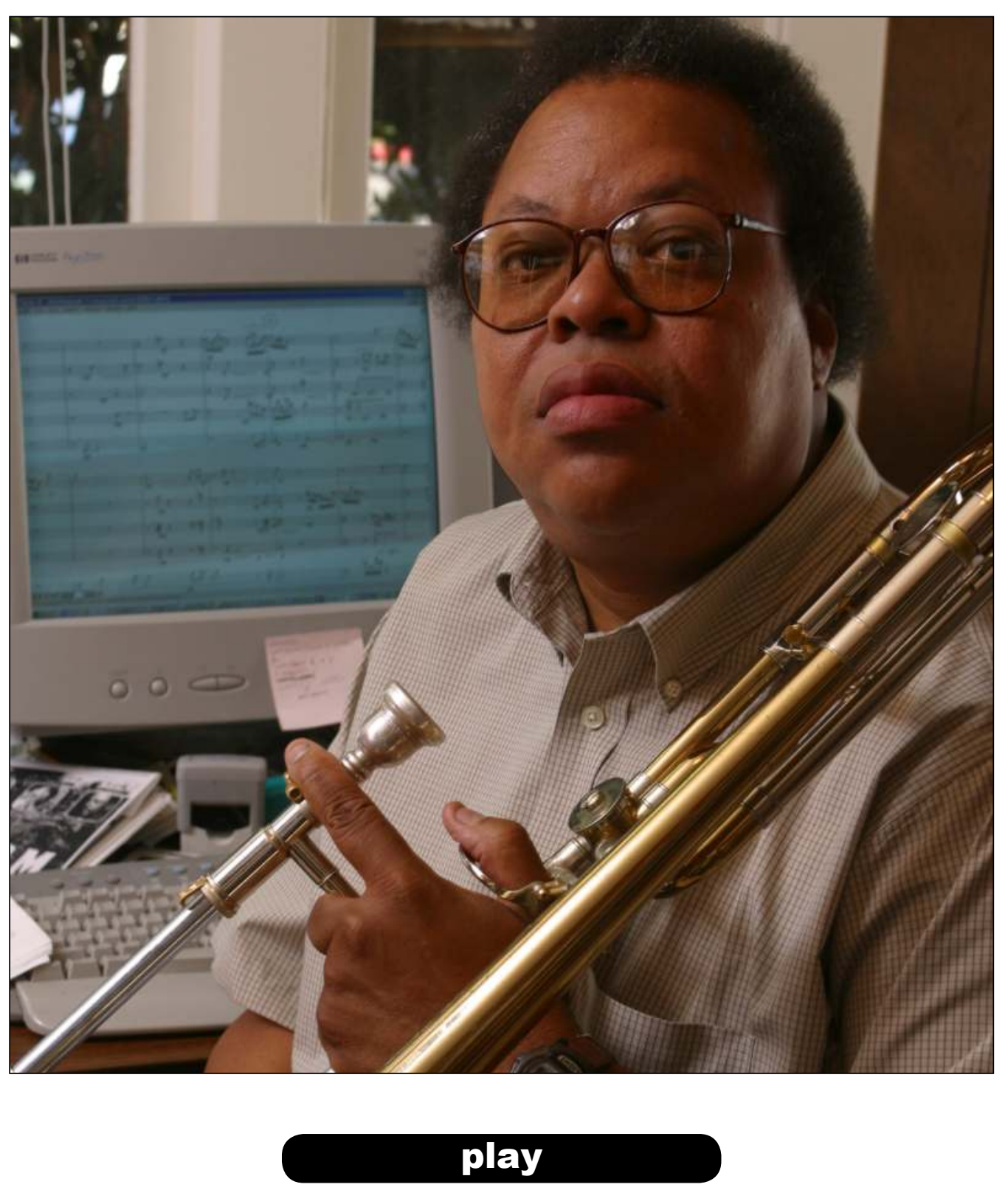

George Lewis - “Voyager Duo 4” (Image: George Lewis) 
[4] If we can describe the field of musical improvisation as an assemblage consisting of all the (relevant) actions, reactions, and interactions taking place between all

actants, it may be useful and even necessary to add some diversifications, submilieus, as Deleuze and Guattari call them.

Thus the living thing has an exterior milieu of materials, an interior milieu of composing elements and composed substances, an intermediary milieu of membranes and limits, and an annexed milieu of energy sources and actionsperceptions. (Deleuze and Guattari 1987: 313)

Attempting to adapt this subdivision of milieus to improvisation, one might perhaps say that the external milieu comprises the musicians' surroundings, the venue or studio, the acoustics of the room, the equipment, etc. Furthermore, it includes their socio-cultural and concrete musical backgrounds. The interior milieu refers to what actually characterizes these musicians: musical experiences, playing techniques, personal idioms, and, more generally, their ways of being. The intermediate milieu regulates the transformations and exchanges between the inside and the outside world. Through new information, aural and visual stimulation, and the sensations these induce, musicians relate, to a greater or lesser degree, to their external environment. With the annexed milieu, a segment of the external milieu, the interior one establishes connections and energy exchange. Much of the operating power in improvisations is based on a more or less direct connection with external milieus, on an energy exchange between musicians, but also between musician and instrument, musician and acoustics, musician and cultural background, etc. (Costa 2012: 6-7).

"The notion of the milieu is not unitary: not only does the living thing pass from one milieu into another, but the milieus pass into one another; they are essentially communicating" (Deleuze and Guattari 1987: 313). In other words, the milieus exist only through their exchanges, their interconnectedness, their permeability. In musical improvisation, this permanent recombining of milieus can be understood as the interaction processes that occur: musicians capture new sources of energy and inspiration from the perception and absorption of materials that can be more or less directly incorporated into their performance.

[5] Instead of wholes or totalities, Deleuze speaks of multiplicities, brought into play by an assemblage. In the preface to the English edition of Dialogues, he states:

Of course a multiplicity includes focuses of unification, centers of totalization, points of subjectivation, but as factors which can prevent its growth and stops its lines. These factors are in the multiplicity to which they belong, and not the reverse. In a multiplicity what counts are not the terms of the elements, but what there is 'between', the between, a set of relations which are not separable from each other. (Deleuze and Parnet 2002: vii-viii)
Two aspects of this quote seem to be especially relevant for the current discussion. First, Deleuze's emphasis on the relations between elements instead of the elements themselves resonates in the most common principles of complexity theories. According to Brian Arthur, one of the early economic researchers in the complexity field, complexity theories look at interacting elements and ask how they form patterns and how these patterns unfold, instead of being interested in classifying and dissecting individual elements (cf. "Mitchell Waldrop and the Field of Musical Improvisation").

Second, Deleuze stresses the idea that multiplicities not only contain "lines of flight" and "deterritorializing" elements, but also "focuses of unification" and "centers of totalization." This opposition bears resemblance to what David Toop describes as the simultaneous existence of fluid and fixed elements in improvisation (Toop 2004: 245; cf. "Mitchell Waldrop and the Field of Musical Improvisation", section 5). Deleuze seems to value these fixed elements as quite negative, as they "prevent growth," a valuation that falls in line with much discourse around free improvised music. In my opinion, many examples in musical improvisation may lead to the conclusion that the fixed and the fluid are not by definition (hierarchically organized) opposites; rather, the one is always already present in the other (cf. "Management - Richard Barrett", section 3)

[6] Is it useful to regard improvisation as an assemblage or a multiplicity? What do I gain if I present some arguments underpinning the idea that improvisation might be a good example of Deleuze's assemblage theory? It is certainly not my intention to prove that musical improvisations make nearly perfect illustrations of Deleuzian concepts. What I am investigating, with the help of this philosophy, is the complexity and singularity of improvisations. In my opinion, implicit in Deleuzian philosophy is a warning against reductionism, against generalizations, against theoretical models that try to simplify and disentangle reality. Furthermore, the idea that milieus pass into one another could mean that an assemblage or a multiplicity does not have a real beginning, a clear origin: living things or humans are not necessarily the prime movers, an idea reflecting that of Bruno Latour's (cf. "Bruno Latour and the Field of Musical Improvisation"). As I try to show in this study, both of these insights can have considerable effects on the way one investigates, analyzes, and thinks about improvisation. 
Gregory Bateson and the Field of Musical Improvisation

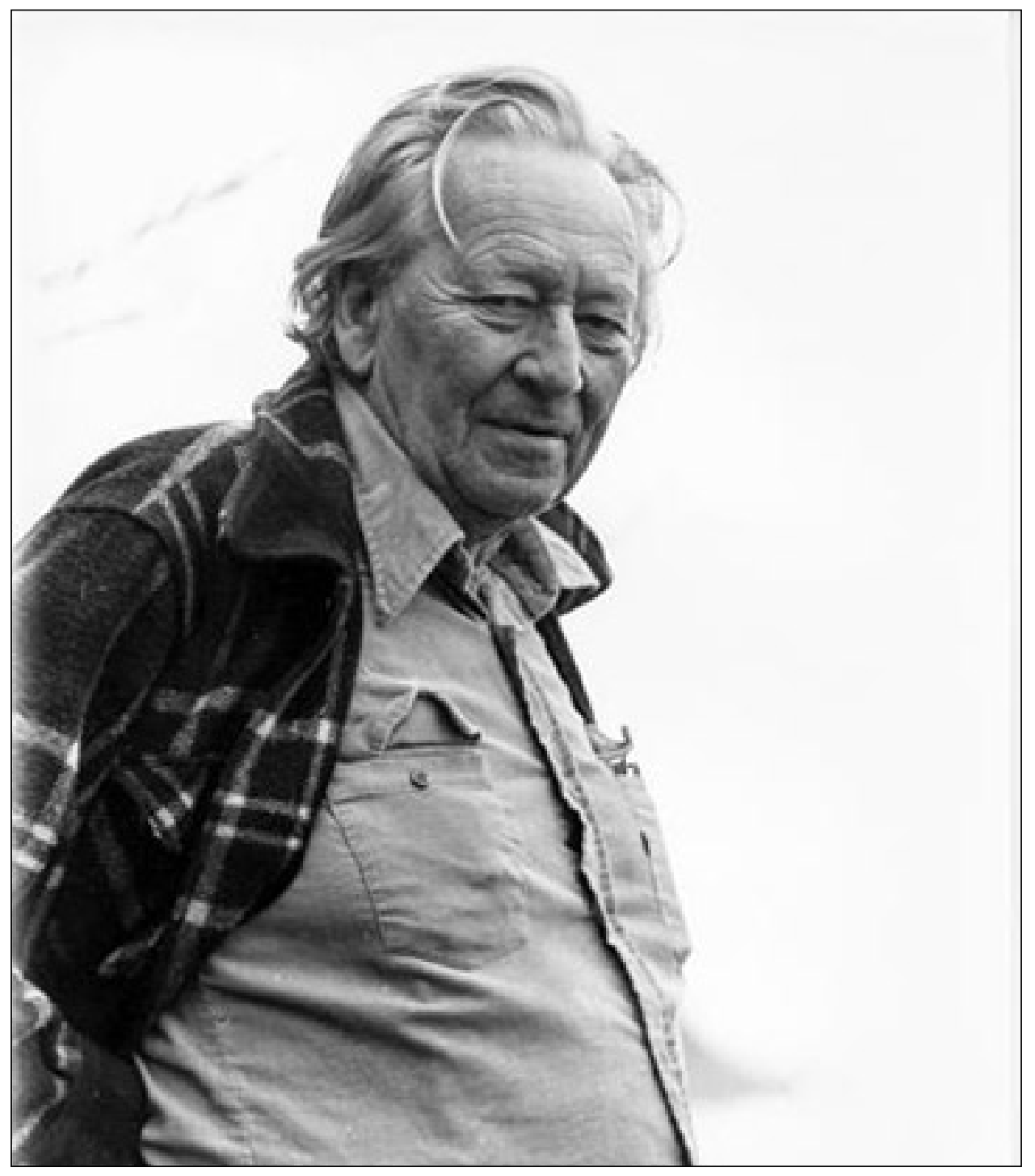

Gregory Bateson

[1] In Steps to an Ecology of Mind, Gregory Bateson writes:

Consider a man felling a tree with an axe. Each stroke of the axe is modified or corrected, according to the shape of the cut face of the tree left by the previous stroke. This self-corrective (i.e. mental) process is brought about by a total system, tree-eyes-brain-muscles-axe-stroke-tree; and it this total system that has the characteristics of immanent mind. More correctly, we should spell the matter as: (differences in tree) - (differences in retina) - (differences in brain) (differences in muscles) - (differences in movement of axe) - (differences in tree), etc. What is transmitted around the circuit is transforms of differences. And [...] a difference which makes a difference is an idea or unit of information. (Bateson 2000: 317-8) 
What immediately stands out in Bateson's ecological system theory is the nonanthropocentrism: man - dissolved into eyes, brain, and muscles - is but one actant in the entire network and is not considered the initiator or, in Bateson's words, the "governor." The behavior of this "governor" is not only determined by its own past but, more importantly here, by the behavior of the other actants within the system. In other words, man nor any other actant can have unilateral control over the whole; what is more, the unravelling of the system into its (hierarchically ordered) constituents is not productive, as it does not reveal how these constituents are dependent upon their interactions within the system.

To further stress this non-anthropocentrism, Bateson speaks of "mind" when a system shows mental characteristics, i.e., when it operates according to trial and error and demonstrates a creative character. Minds are aggregates of ideas. The mind is immanent, but not only in the human body; it is also immanent in pathways outside that body, e.g. in a network or system. This system is in perpetual motion or in a constant state of becoming because of the changes or differences that occur within and between the actants. Expressed differently, the system operates in such a way that it creates differences. However, not all differences are equally important or relevant; only those that make a difference in some later event matter; Bateson calls them "ideas" or "information." And just as with plants and animals in a tangible ecosystem, information is subject to evolution, extinction, or successful flourishing. Bateson's "ecology of mind" attempts to understand the processes by which ideas interact with one another and why some ideas thrive and others wither.

Music as I conceive it is ecological. You could go further and say that it is ecology. (Cage 1981: 229)

[2] In my opinion, Bateson's ecological thinking can cast light on and emphasize the importance of environmental influences on musical improvisation. Actants such as instruments, technology, participating musicians, and / or venues all play a vital role in the creation and development of an improvisation. The aspects of the musician that make playing possible - her senses, bodily parts, her brain - are determined by the environment, that is, by all other actors, factors, and vectors involved. A change in instruments will affect the playing behavior; a particular ensemble affords a certain kind of playing; different concert venues will lead to distinctive ways of performing, interaction, and thus to different outcomes; musical rules and concepts demonstrate comparable influences (Nilsson 2011: 17 and 128).

Of course, a musician can also alter the affordances of her environment, but she is simultaneously dependent upon the situation (Gibson 1986: 143). With Eric Clarke, I could call this mutual determination and interdependency "resonance," the active exploratory engagement and interaction between organism and environment (Clarke 2005: 19).

This interaction also plays a crucial role in the exchange and development of musical ideas. As Ingrid Monson (1996: 88) writes, “the response of musicians is clearly crucial to whether a particular musical idea is picked up on, developed, or ignored." According to Monson, the choice to seize a certain musical opportunity or not effectively fuses the social and the musical. However, unlike Monson who exclusively concentrates on human-human interaction here, Bateson's (as well as Latour's) thinking opens the possibility of including other actors and factors that regulate the survival or decline of the musical input during an improvisation. For example, the sonic environment might prevent or encourage specific attention for new musical ideas, while the instrument on which this idea is presented of course plays a crucial role too.

[3] Bateson's more general remarks about the working of complex, dynamic systems are counterbalanced by numerous examples from various disciplines, such as

biology, (neuro)psychology, and computer science. It is important to notice that these examples do not merely illustrate the general theories but somehow act as a warning against the generality of the conceptual and theoretical framework.

If what you are trying to explain is a given piece of behavior, such as the locomotion of the blind man, then, for this purpose, you will need the street, the stick, the man; the street, the stick, and so on, round and round. But when the blind man sits down to eat his lunch, his stick and its messages will no longer

be relevant - if it is his eating that you want to understand. (Bateson 2000: 465)

For me, Bateson's example supports my fundamental principle that thoughts on improvisation should not become caught in generalities but gain more expressiveness and persuasiveness when made concrete in musical situations (see Introduction to Part 2, section 2). In some (parts of) improvisations, certain actants are quite prominent if not defining, while the same actants can be less important or even totally absent in others. This is why my claim that improvisation is present in all musicking (see The Omnipresence of Improvisation) cannot lead to uniformity and equalization but, conversely, to differentiation and singularity. One of the specific challenges of this book is to find out if there are considerable differences between the interactions and the presence of certain actants in several different musics. Such is the main objective of Part 3.

Some participants are pressing very strongly, requesting to be heard and taken into account, while others are fully routine customs sunk rather mysteriously into bodily habits [...] At every point [...] something could break [...] If any of the intermediaries mutates into a mediator, then the whole set up [...] may become unpredictable. (Latour 2007: 202) 


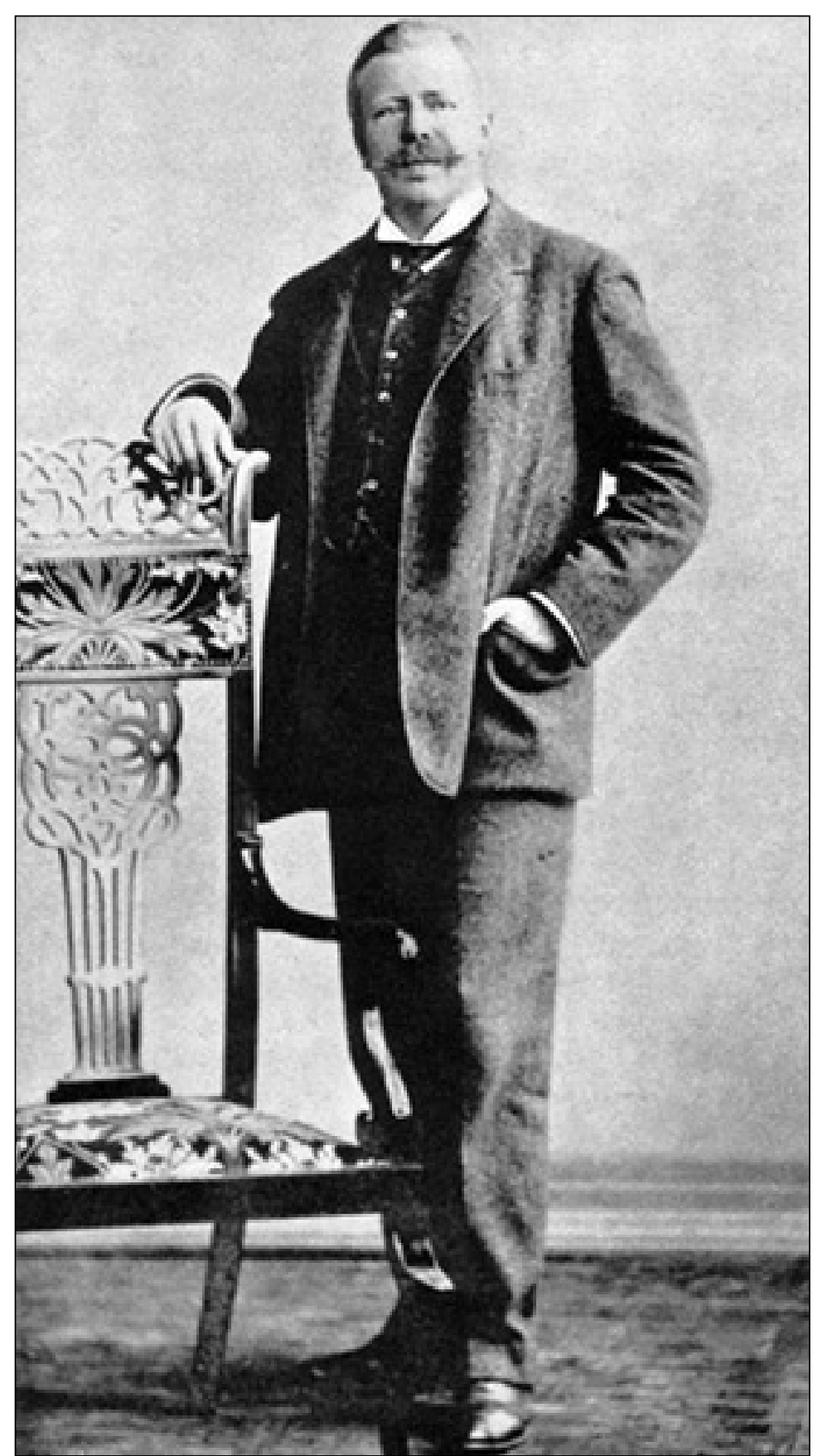

Jakob von Uexküll

[1] As Brandon LaBelle writes in Background Noise, the Japanese improvisation collective Group Ongaku, active between 1958 and 1962, was, in the words of its member Yasunao Tone, doing "action painting in music" (LaBelle 2006: 36). Their improvisations, sometimes taking place in the house of one of the musicians, were produced on found objects: chairs were turned into percussion instruments, lamps into amplified hum-machines, thereby "resituating domestic action onto acts of sonic improvisation" (LaBelle 2006: 39). 


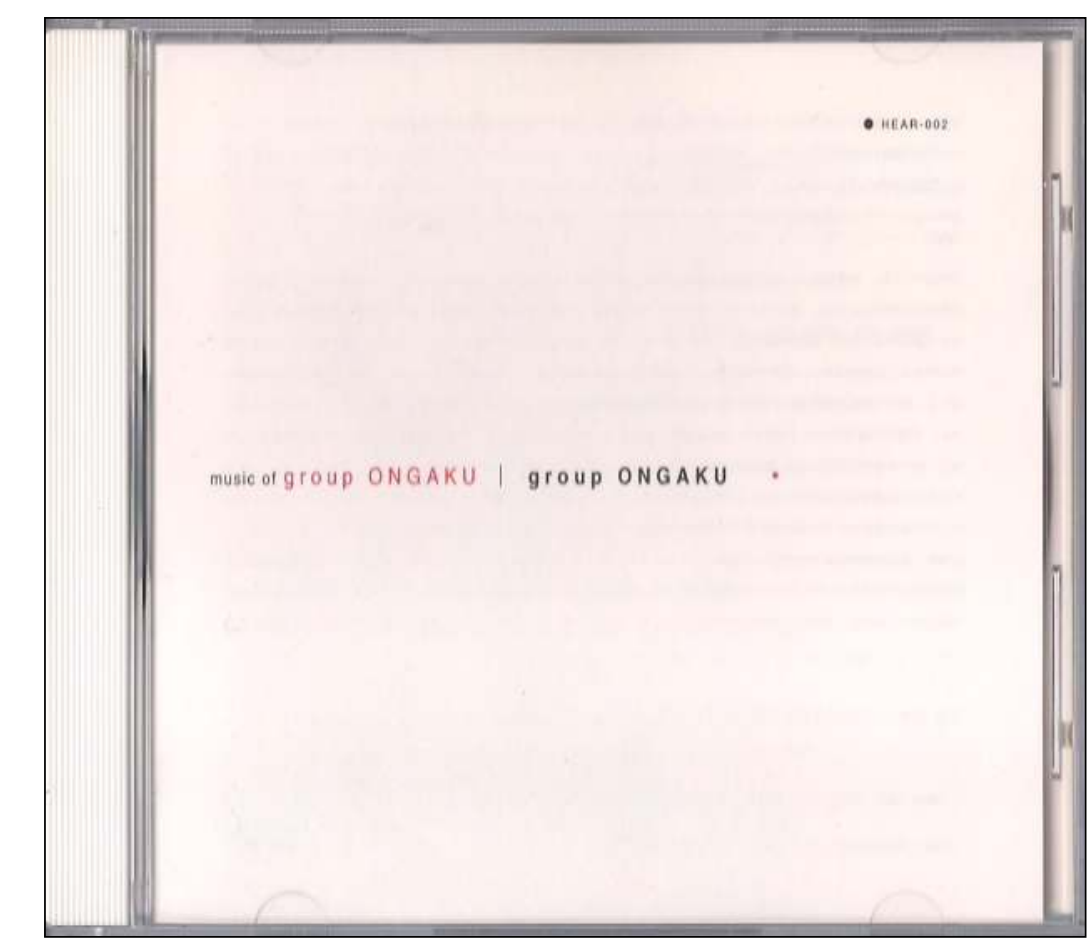

play

Group Ongaku - “Automatism” (Image: Music of Group Ongaku front cover)

LaBelle calls the improvisations of Group Ongaku "contact music." The music appears through a kind of forerunner to artistic research: the musicians move through a space in search for non-human bodies that might produce interesting sounds when confronted with and touched by humans. Human body and mind become the conscious vehicles to uncover a creative potential for making music through a direct contact with the environment; musical improvisation is unfolded as, first of all, a space of physical (inter)action (LaBelle 2006: 35-45).

[2] Starting from the idea that improvising happens in an interaction between a human being and the environment, one could assume a connection between improvisation and ecology. Mind and body of the musician and environment, which can consist of instruments, audience, space, acoustics, and the like, form a milieu in which each one forms, informs, and transforms the other.

[3] Umweltlehre. Biologist Jakob von Uexküll coined the term in the late 1930s, circumscribing the interaction of an organism with its environment. Von Uexküll's basic assumption is that this organism perceives the world through a network of "functional relations," constituting its own phenomenal world or Umwelt. This is the world surrounding an organism, as perceived by itself, a collection of subjective meanings that are imprinted upon all objects and that include all meaningful aspects of the world for a particular organism. Umwelts, according to this view, are not "out there," but are constructed and constrained. They are the effect of an organism's sensitivity to the practical characteristics of its environment, the "functional tone" as Von Uexküll calls it. The actual meaning of an object is dependent on a number of different qualities, or tones, that are, in turn, dependent on the intentions that an organism confers on them (Reybroeck 2005: n.p.). Hence, the stem of a wildflower is a different object for the tick that climbs it, the girl who plucks it, the locust larva that pierces the stem and extracts its sap, and the cow that eats it (Bogue 2003: 59). What matters, then, are not merely the objective qualities of the wildflower, but the functional qualities it affords to the user of the wildflower during a particular occasion. According to Von Uexküll, phenomena receive properties that they do not possess independently from the (re)acting subject. More specifically, the Umweltlehre concentrates on the role of sense-making and construction of knowledge as the outcome of interactions.

In general, our perception of situations already incorporates a judgment on the appropriateness of certain kinds of action. This explains why situations are not merely a neutral field of activity for intentions which were conceived outside of that situation. (Joas 1996: 160)

Particularly in lower animals, organism and environment are closely attuned to each other through stimulation and response. This relatively closed system opens up when humans are involved, as it gives way to choice responses, to modifiability of behavior, and to an increasing trend toward learning through individual experience. The human process of relating to one's milieu and of living in a continuous exchange with the environment, involves a formation of the world of objects in terms of one's equipment and biopsychological "goals." The human world, then, is a coherent, wo/man-specific Umwelt, a representation of "what there is" by means available to the human being (Werner and Kaplan 1963: 12-13). Because of this permanent interaction, stationary equilibrium is nonexistent, dissolving continually and unendingly into a state of flux.

[4] Aspects of Von Uexküll's theory resonate in today's situated cognition, locational externalism, or the extended mind thesis, movements in cognitive science with a focus on connections between the structure of mental processes and physical embodiment (cf. Iyer 2002). Situated cognition offers the view that cognition is an activity that is structured by the body positioned in its environment ("embodied action" as it is called by Varela, Thompson, and Rosch in The Embodied Mind) instead of the mere representation of a pre-given world and by a pre-given world. Rather, cognition is the enactment of a world and a mind on the basis of a history of a variety of actions that a being in the world performs. (Varela, Thompson, and Rosch 1991: 9); it is dynamically coupled to artifacts and phenomena once conceived as discontinuous with the human mind. These artifacts and phenomena have a direct impact on the organism and on its behavior. Because external objects play a significant role in 
aiding cognitive processes, mind and environment act as a "coupled system." This coupled system can be seen as a complete cognitive system of its own.

Philosophers Andy Clark and David Chalmers refer to this as "active externalism" (Clark and Chalmers 1998). In much the same way neuroscientist Hillel Chiel and cognitive scientist Randall Beer assert that mind, body, and environment interact with one another in a perpetual feedback system. Interestingly, they make a connection between this feedback system and improvisation:

The nervous system is often seen as the conductor of the body, choosing the program for the players and directing exactly how they play. The results reviewed above suggest a different metaphor: the nervous system is one of a group of players engaged in jazz improvisation, and the final result emerges from the continued give and take between them. (Chiel and Beer 1997: 555)

On the basis of their findings, Chiel and Beer suggest that, instead of focusing almost exclusively on the functioning of the mind or the nervous system of a living being, one should investigate "the contributions of all components of the coupled system" (Chiel and Beer 1997: 555).

Against this background of Umweltlehre, "active externalism," and "feedback," I reinterpret the beginning of a concert in January 2002 in Rotterdam (NL), performed by a trio consisting of Dutch musicians Ernst Reijseger (cello), Eric Vloeimans (trumpet), and German Dirk-Peter Kölsch (drums). The concert is about to begin, the audience is quieting and the tuning of trumpet and cello is checked once more, when a latecomer takes a seat, which emits a rasping and creaking sound. Playfully responding to the rasping, Reijseger starts moving his chair, deliberately imitating the creaking, turning it into a rhythmic musical phrase to which the cello adds, after a while, a second voice: a duet for stool and cello. Later again, the drums take over the rhythmic part, extending it, elaborating on it, before, ultimately, the trumpet inserts thin, empty sounds from which a theme originates.

Such as with the "contact music" of Group Ongaku, an ordinary stool is suddenly transformed into a musical instrument. The beginning of this improvisation not only shows that the boundary between music and non-music, between sounds already belonging to the musical domain and others not yet having that status, is arbitrary and porous; it also makes manifest how "the same" object can be changed into something else by "the same" person: the stool, pendulating between be(com) ing a seat and an instrument, turns Reijseger from a quietly sitting person into a sound discoverer aware of the fact that his seat is as much a potential sound maker as his cello. In the interaction, both are transformed, the one determining the other. Reminiscent of Von Uexküll, the alleged objective qualities of the stool are replaced by some unexpected functional qualities it affords to its user at a specific event.

Reijseger's reaction can be regarded as a kind of adaptation (cf. Mitchell Waldrop and the Field of Musical Improvisation, section 1), applied most commonly in the sense of an actant responding to its physical universe but extended here to the cultural environment. The whole trio adapts itself to cope musically with its sonically changed environment.

In my work I explore evolutionary and interactive strategies, non-linear behaviors and processes of movement to create communicative spaces. I use participation as a continuous mutation of the initial spatial conditions, to get away from the concept of the 'external-to-you' as something invariable. Individual being does not emerge in isolation. (Cillari 2010: 177) 


\section{Mitchell Waldrop and the Field of Musical Improvisation}

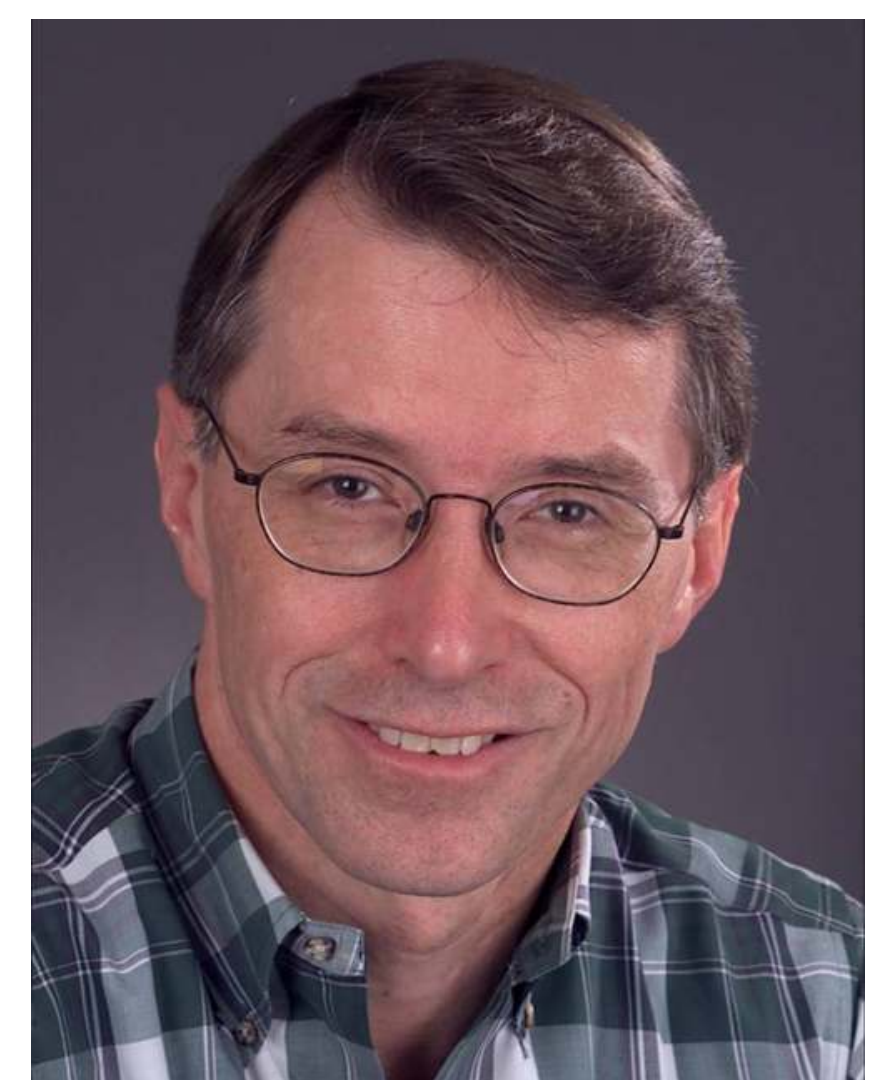

Mitchell Waldrop

[1] In his book Complexity, physician Mitchell Waldrop distills four distinctive aspect of complexity in defining the homonymic term. First, complexity can be described as the interaction of a great many independent agents or components with each other in a multitude of ways. Quoting informatician and physicist Stephen Wolfram on complicated systems in biology and physics, Waldrop states that, in general, the basic components and laws can be quite simple; complexity arises because these components interact simultaneously and in a myriad of possible ways. The complexity thus lies in the organization (Waldrop 1992: 86). The essence of a system is not to be found in any individual component, but in its overall dynamics, in its collective behavior; everything is interlocked, no piece of the system can be considered in isolation from the others (Waldrop 1992: 27). Physicist Doyne Farmer calls it connectionism, "the idea of representing a population of interacting agents as a network of 'nodes' linked by 'connections'"' (Waldrop 1992: 289).

You can start with very, very simple nodes - linear 'polymers,' 'messages' that are just binary numbers, 'neurons' that are essentially just on-off switches - and still generate surprising and sophisticated outcomes just from the way they interact. (Waldrop 1992: 291) 
Though the sound of an oboe and the sound of a string section may be independent when they enter your ear, the emotional impact of both sounds together may be very much greater than either one alone. (Waldrop 1992: 65)

Second, the power of these interactions allows a system as a whole to undergo spontaneous self-organization (cf. "Pierre Lévy and the Field of Musical Improvisation," section 4). Many agents - be they molecules, neurons, species, consumers, or corporations - constantly organize and reorganize themselves into larger and ever more complex structures, either through a clash of mutual accommodation or through mutual rivalry (Waldrop 1992: 88). A laser is a selforganizing system in which particles of light can spontaneously group themselves into a single powerful beam. A hurricane is a self-organizing system, and so is a living cell, surviving by taking energy in the form of food and excreting energy in the form of heat and waste (Waldrop 1992: 33-34). Waldrop calls this incessant urge of complex systems to organize themselves into patterns emergence (Waldrop 1992: 118). In short, Waldrop maintains, complexity is the science of emergence.

In addition, the control within complex systems tends to be highly dispersed. Instead of a top-down design, systems seem to emerge from bottom up. The way in which they function and develop arises from the interactions among the agents themselves in conjunction with a continual feedback from their environment. Hence, although their dynamics are hard to predict because they are open to energy influxes from outside, agents do not function at random, but are able to produce actions quite coherently, not so much aiming for optimization as for mutual accommodation (Waldrop 1992: 145).

Three, complex systems are adaptive: they organize and reorganize themselves in reaction to internal and external changes; they change themselves in order to survive in their environment. Systems ceaselessly revise and rearrange their building blocks as they gain experience; this revision and recombination is one of the fundamental mechanisms of adaptation (Waldrop 1992: 146). In complex systems, agents are continuously adapting to (the actions of) other agents. A good strategy for a frog to feed on a fly depends on the tactics of a fly, and vice versa: if the frog evolves a longer tongue, the fly has to learn how to make a faster getaway. If the fly evolves a chemical to make itself repulsive to a frog, the frog must learn how to tolerate that taste. Thus, each agent adapts and thereby changes the fitness landscape of all the other agents. The frog climbs up hills toward a peak in its strategy space, and a fly climbs up hills toward a peak in its space. But the landscapes are not independent; they are coupled. And both also deform as the animals develop (Waldrop 1992: 310). In complex systems, agents constantly adapt themselves to changing circumstances; they do not just evolve, they co-evolve, producing extensive webs of dependencies.
Four, as a consequence of the principle of adaptation, complex systems possess a kind of dynamism that makes them qualitatively different from static objects. Already in 1949 neurophysiologist Donald Webb came to the conclusion that a healthy brain is not static: it refines and adapts its behavior through experience by constantly making subtle changes in the "synapses," the points of connection where nerve impulses make the leap from one cell to the next (Waldrop 1992: 158). The human nervous system interacts with the environment by continually modulating its structure.

As every complex system thus constantly creates new opportunities, it can never be in equilibrium; it is always unfolding, always in transition, always dynamic (Waldrop 1992: 147).

[2] In complex systems, all agents are thus caught up in a vast, nonlinear web of incentives, constraints, and connections. The slightest change in one place causes a tremor everywhere else; it can spread interferences until the system's future becomes utterly unpredictable (Waldrop 1992: 65-6). At a molecular level, every living cell looks alike. The basic mechanisms are universal. But a tiny, almost undetectable, mutation in the genetic blueprint "might be enough to produce an enormous change in the organism as a whole" (Waldrop 1992: 30). Differen sets of accidents can cause radically different outcomes to emerge. In a seed, a genetic code regulates how growth proceeds, while the final shape and size of a particular organism is a consequence of its interaction with the environment rather than a materialization of a predestined form.

There seems to be a potential parallel between these thoughts on the functioning of cells and seeds, and improvisation. In improvisation, too, small details can, when attended to or acknowledged by participants, trigger transformations in the music, such that the eventual outcome is disproportionate to any initial causes. On a micro level, each gesture can conceivably produce rather sudden and dramatic shifts in an ensemble sound and approach (Borgo 2005: 72); on a higher level, a replacement of one member or position can change a group's identity significantly (Nilsson 2011: 5).

[3] Interactivity, self-organization, adaptiveness, and dynamism are necessary for a situation in which order and chaos are brought into a special kind of balance to arise: the components never quite lock into place and yet never dissolve into turbulence either. New ideas constantly undermine the status quo, thereby creating a zone between stagnation and anarchy, between stability and fluidity (Waldrop 1992: 12). However, this zone never leads to a stable equilibrium; it is always evolving, changing, entering new territory - the edge of chaos. By means of a dense web of feedbacks and regulations - which simultaneously leave plenty of room for creativity, change, and response to new conditions - living cells, just like healthy societies, need to keep order and chaos in balance (Waldrop 1992: 294). 
Instead of viewing the economy as some kind of Newtonian machine, [...] see it as something organic, adaptive, surprising, alive. Instead of talking about the world as if it were a static thing [...], learn to think about the world as a dynamic, ever-changing system poised at edge of chaos. (Waldrop 1992: 252)

[4] Whereas Waldrop is mainly writing about complexity in biology (living organisms) and neurology (the brain), the idea I would like to defend here is that we will better be able to understand the process of musical improvisation when we regard it as a complex system. Much literature focuses on only one or a few elements that constitute an improvisation: a solo or other formal elements, social interactions on stage, the socio-cultural backgrounds of musicians, gender, technology, etc. Of course, this reductionism has been enormously helpful in gaining insight into this musical phenomenon. However, this research method is less suitable for investigating how several, ever-changing factors and actors interact in complex ways during an improvisation; this can only be described at levels higher than those of the individual units. Waldrop's book makes clear that systems display collective behaviors that are not predictable in terms of the dynamics of their component parts. The discourse around improvisation might also benefit from a more holistic approach as suggested by, among others, Mitchell Waldrop in Complexity and David Borgo in Sync or Swarm (cf. “Introduction to Part 3").

[5] Examining the relation between fixity and fluidity, Waldrop derives inspiration from computer scientist and psychologist John Holland. According to Holland, complex systems share certain crucial properties: in a network of agents, each agent constantly acts and reacts to what the others are doing. As a result, essentially nothing in its environment is fixed.

Discussing improvisation with free jazz guitarist Derek Bailey, David Toop notes a remarkable consonance with Waldrop's explanation of complex systems. Improvisation, he writes, is a negotiation between fixity and fluidity, between learning and unlearning, between refinement and becoming (Toop 2004: 245). To put it very concisely, Toop describes here the dynamism, adaptiveness, and balance between order and chaos, typical for complex systems and improvisation alike. It echoes Jacques Derrida's idea on improvisation as taking place between the absolutely spontaneous and instantaneous, on the one hand, and within a network of structures that seems to preclude this, on the other. Inevitably, the improviser occupies particular fixed structures, but it is precisely an active engagement with these structures that creates a fluidity of the fixed. Rather than taking place within standardized patterns and codified histories, improvisation happens between different histories and across mimetic traditions (Peters 2009: 97-101). Fixity and fluidity are thus no excluding opposites: the one operates within the other; they coexist as opposites (Rintzler 2008: 3; cf. Management - Richard Barrett, section 4). In re- addressing the fixed or the predictable, a difference is installed into the order of the same, an uncanny interruption of an alleged established situation: neither stagnation nor anarchy.

A system can exhibit complex, lifelike behavior only if it has the right balance of stability and fluidity. (Waldrop 1992: 308)

Deconstructing the binary (and hierarchical) opposition between the fixed and the fluid, as suggested here, cannot perhaps be directly related to Waldrop's explanation of complex systems. In the theories and examples he describes, the two quantities remain separated; that is, they interact but are - at least theoretically distinguishable. The deconstruction at work in the field of musical improvisation thus adds its own specific contribution to complexity theories. The discourses around improvisation not only benefit, as simple parasites, from the complexityhost; they are able to feed it as well. In so doing, they coexist in a mutually beneficial relationship (cf. Revisiting Complexity Theories - Jimmy Giuffre, Paul Bley, and Steve Swallow. 
Pierre Lévy and the Field of Musical Improvisation

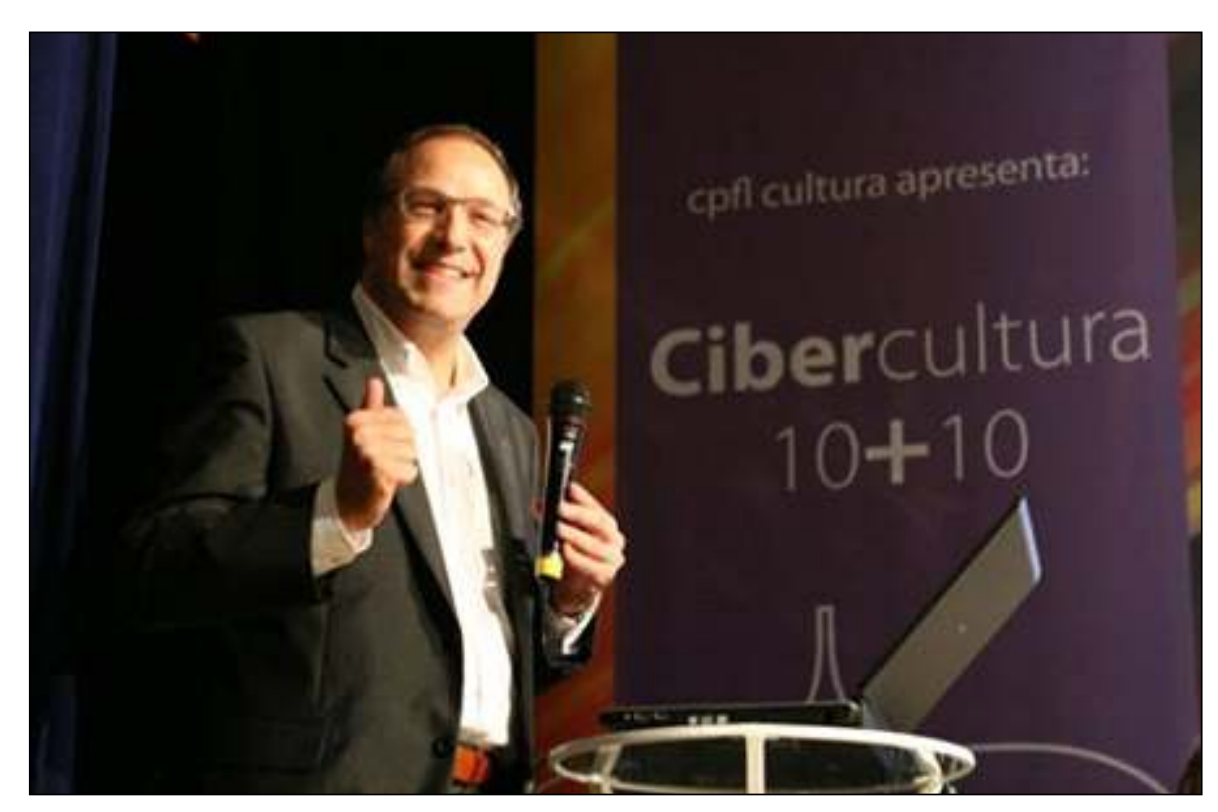

Pierre Lévy

[1] At first consideration it seems rather awkward and far-fetched to present Pierre Lévy's thoughts on collective intelligence in the context of complex systems. Lévy's work does not (explicitly) deal with how human and non-human elements within a certain system interconnect and depend on one another. On the other hand, early in his book Lévy already notes that "we are witnessing the development of complex forms of confrontational interdependence among skill zones that are fluid, delocalized, based on their singularities, and agitated by permanent molecular movements of association, exchange, and rivalry" (Lévy 1997: 5). This phrase should be read against the backdrop of his aim to reflect on systems of networked intelligence, a transition from focusing on individual knowledge toward forms of group knowledge and collective thinking. And it is exactly the concept of "collective intelligence" that interests me here, as in my opinion that concept can make a very fruitful contribution to the discourse on musical improvisations.

[2] According to Lévy, the Internet opens the space for a new kind of knowledge. Whereas older forms of knowledge are concentrated around rationality, on codes, rules, and traditions, Lévy sees the emergence of a collective knowledge that is "perpetually metamorphosing, bustling with the rhythm of quasi-animate inventions and discoveries," a large patchwork or continuum "in which each point can be folded over on any other" (Lévy 1997: 217). This collective intelligence is not a purely cognitive object; its ethical and aesthetical dimensions, its imagination, experimentation, and dreaming, its enduring invention and wandering are equally important and should prevent closure from taking place too quickly. Questions of truth are replaced with an uninterrupted dynamic of learning and exploration; the knowledge space is always in an emergent state, permanently recomposing 
itself (Lévy 1997: 103 and 183). Collective intelligence is far from being a contemporary avatar of Hegelian absolute knowledge. On the contrary, "an indefinite variety of collective intellects smooth out, extend, and constitute the knowledge space, each unfolding its own world, so that this space is always exposed to alterity" (Lévy 1997: 222).

[3] To underline the dynamic character of the knowledge space, Lévy uses phrasings that connect easily to Deleuze and Guattari's ideas about assemblages and multiplicities (cf. Gilles Deleuze and the Field of Musical Improvisation) as well as the basic principles of complexity theories (cf. Mitchell Waldrop and the Field of Musical Improvisation). Lévy repeatedly emphasizes the point that, within this knowledge space, collective intellects "reconstruct a plane of immanence of signification in which beings, signs, and things exist in a dynamic relationship of mutual participation" (Lévy 1997: 168), interconnecting, exchanging places, and creating a world of resonances and connections. Everything moves in relation to everything else; what counts are intensities, frequencies, and velocities.

[4] Thus, according to Lévy, the possibility of cyberspace allows us to envisage forms of organization based on collective intelligence. These forms are not organic, nor organized, but self-organized and in constant processes of mutation and deterritorialization. I think it is possible to trace comparable forms of self-organization based on collective intelligence in musical improvisation. In fact, I would assert that this manifestation of self-organization and collective intelligence in music precedes the Internet and cyberspace age. Let me make a case for this with a brief and rudimentary example.

In "Miles Davis and the Semiotics of Improvisation," Chris Smith makes clear in a few succinct but informative paragraphs that the second Miles Davis Quintet - featuring Miles, Wayne Shorter on sax, Herbie Hancock on piano, Ron Carter on bass, and Tony Williams on drums - developed a performance style based on extensive, sophisticated, complex, and almost instinctive interactions. Visual but mostly sonic cues turn each performance into a completely unique event; small bits of musical information indicate impending shifts, each time leading to different results (Smith in Nettl and Russell 1998: 264).

The CD Winter in Europe from 1967 provides a clear illustration of Smith's statement. In particular the many changes in tempo, the almost halting of musical time and its subsequent acceleration, are evidence of the extraordinary aural attention necessary to react accurately and creatively to initiatives by the individual musicians. Winter in Europe clearly indicates that these shifts are not composed beforehand: the $\mathrm{CD}$ provides a registration of two concerts, one in Stockholm (Sweden), the other, performed one week later, in Karlsruhe (Germany). Although the repertoire is almost the same, in each case the interactions lead to the exploration of new musical possibilities.
One of the most important innovations Smith notices is the inversion of the roles of the accompanying players and the soloist. Before, bass, piano, and drums maintained the harmonic and rhythmic framework, which the soloist could use as a stable basis for her solos. However, in this Quintet the accompanists often shift harmony, rhythm, and tempo only after the soloist does, essentially following his lead.

Typical examples of this appear in the Swedish version of "Footprints," e.g. when Shorter cues Carter and Williams by playing the last four bars of the theme to indicate the end of his solo (at 5'50") and the beginning of the piano solo, for which Hancock keeps repeating the beginning of the last phrase (at $\left.6^{\prime} 10^{\prime \prime}\right)$, thereby halting the harmonic development.

The question of whether it is appropriate at all to speak of accompanists and soloists is legitimate here. Perhaps with the exception of Carter, all musicians seem to be soloists rather than accompanists; this is especially noticeable in the performance of Williams, who is constantly provoking the others and prompting them to uncertain interactions with a playing style that sounds close to continuous soloing.

[5] In my opinion, one can hear in and through this Miles Davis Quintet a kind of group knowledge or collective thinking, a thinking-through-musicking. This collective intelligence is far from purely cognitive; rather, it should be understood in "its etymological sense of joining together (inter legere), as uniting not only ideas but people" (Lévy 1997: 10). The musical results do not rest on automatisms or mechanical (re)actions, but on the implicit objective of permanently negotiating situations and discovering new musical territories.

[6] Lévy's ideas about collective intelligence might be judged speculative, somewhere between an analysis of contemporary developments and idealistic prospects.

However, this is not the right place to subject his thoughts to a thorough analysis or a radical criticism; rather is it my aim to show how Lévy's text can be made productive for a discourse on improvisation. Lévy provides us with a vocabulary and conceptual framework to rethink and (re)formulate certain facets of concrete improvisations and to add new notions to the already existing discourses surrounding them. Or perhaps we need to reverse the order: Lévy's thoughts on collective intelligence, instead of the traditional focus on individual knowledge, and his follow-up insight that the intelligence of a group is not the mechanical result of automatized activities, but developing with the prime objective of remaining permanently open, might already be recognizable and operative in the functioning of an improvising ensemble. The conceptual framework with which Lévy analyzes and predicts developments in cyberspace might thus afford scholars the possibility to better (or in another way) articulate ideas about collective intelligence and group knowledge, elements which for a long time have been prerequisite for successful group improvisations. 

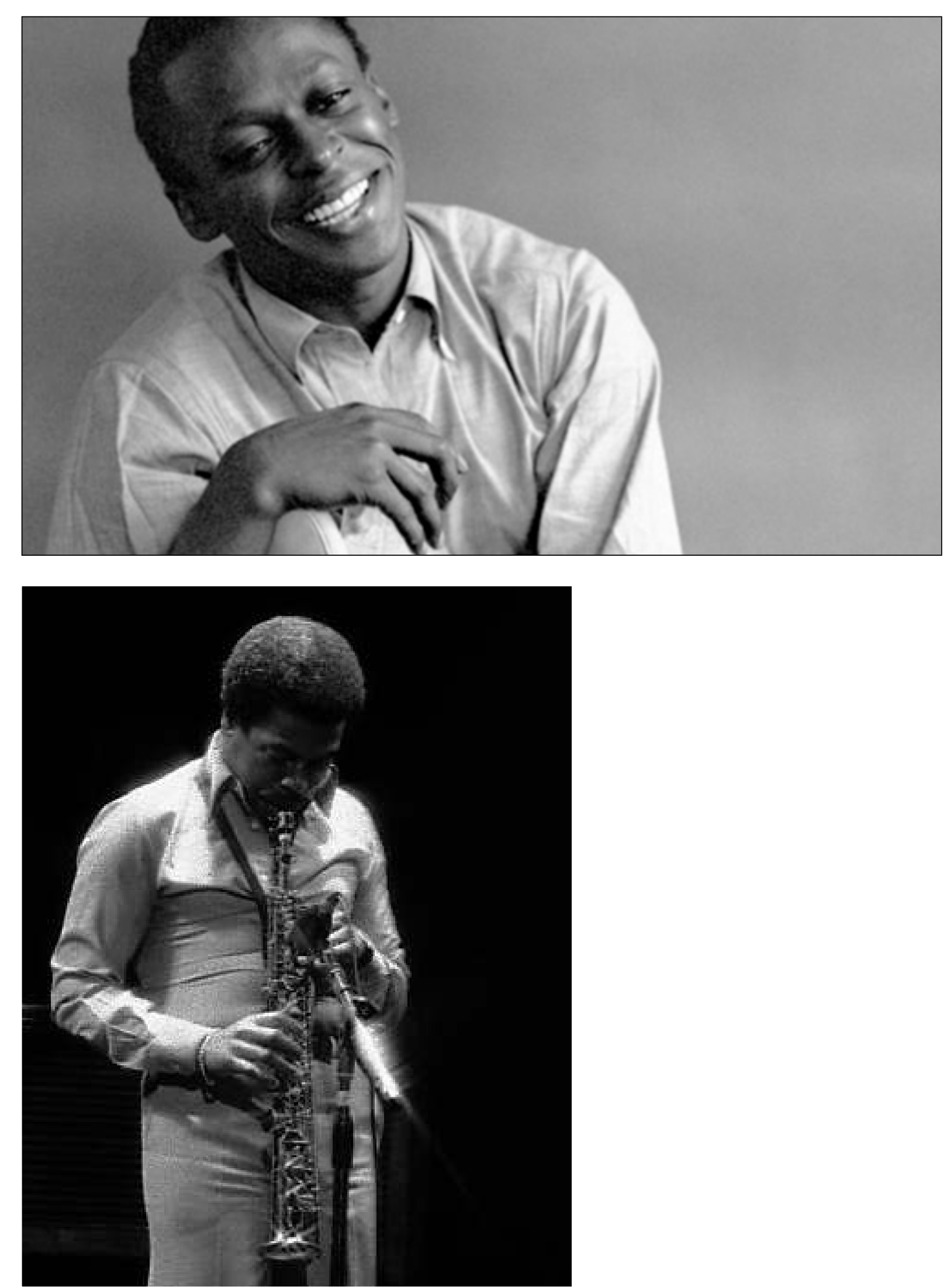

play

The Miles Davis Quintet - "Footprints"

(Images, clockwise from the left: Miles Davis, Tony Williams, Ron Carter, Herbie Hancock, Wayne Shorter)
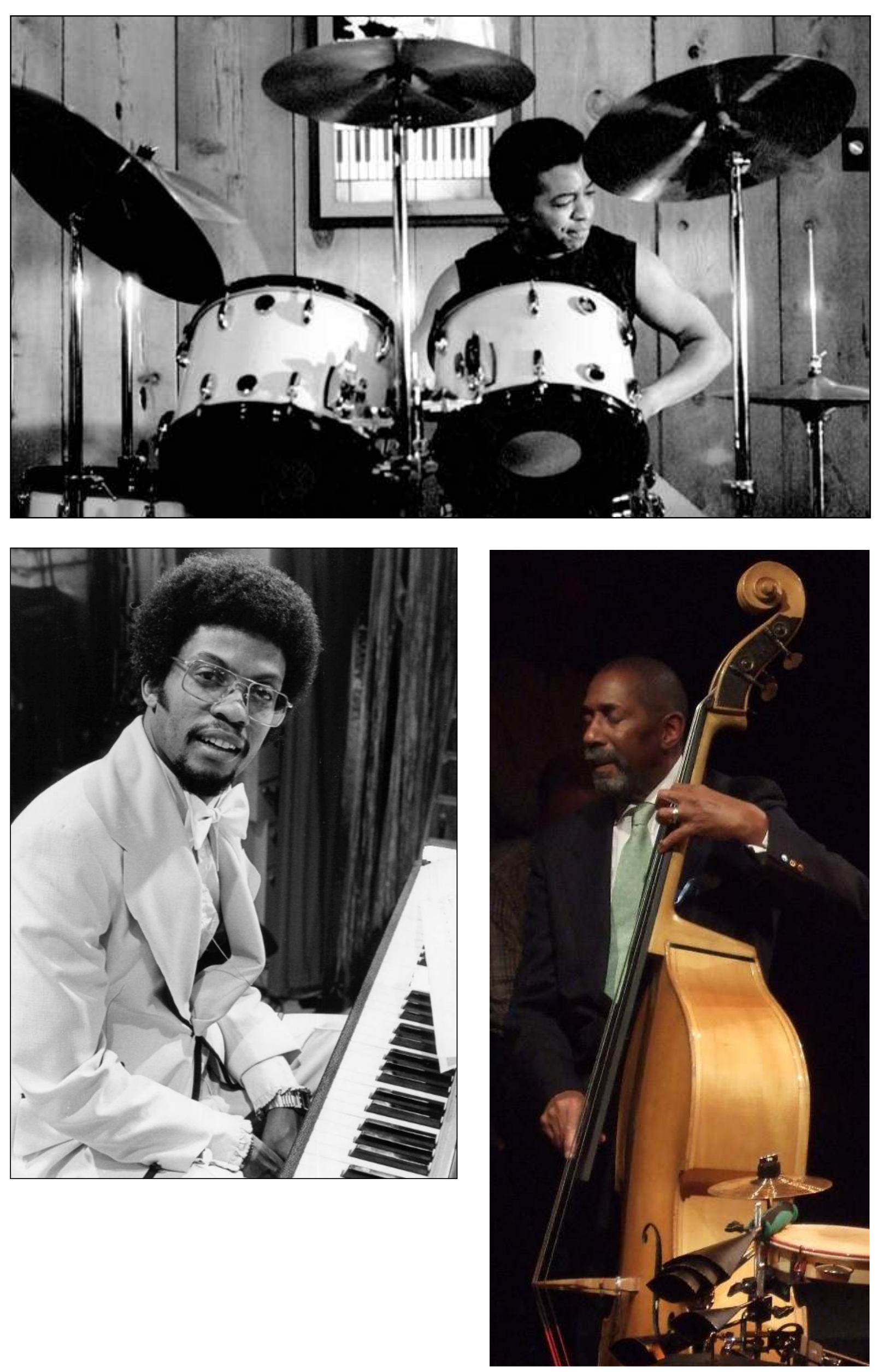


\section{Part 2a}

\section{Capsulizing}




\section{The FMI Theory}

[1] The FMI Theory is (not) a theory

A theory is not a tool to uncover reality or to reveal the truth. At its best it is a functional instrument to create a certain (and partial) order in a world that would otherwise remain chaotic or unknown. A theory offers a specific way of accessing and encountering reality. What is more, without theories - here understood in the broadest sense of the word - contact with something which we call "reality" would be impossible. In fact, there is no distinction between reality and its (re)presentation, even though we must acknowledge that each theory always falls short of grasping the inexhaustible multifacetedness of that reality; reality is only knowable through (re)presentations, being a product of our (re)presentational schemes, created in and through theories. Therefore, it would be difficult to maintain that the quality of a theory depends on its ability to better (re)present reality than other theories. Instead, my claim is that the value of a theory depends on its capacity to convince. Theorizing is in fact telling a story, and its auctor intellectualis may hope that it offers some new insights, some new ways of experiencing the world. As Milan Kundera remarks, the ambition of a story teller is not necessarily to do something better than his predecessors but to "say what they did not say" (Kundera 2006: 15).

The FMI Theory consists of stories about a specific musical phenomenon. It is a proposal, rather than a prescription to encounter improvisation in a (slightly) different way. Instead of, or next to, presenting knowledge and understanding, the FMI Theory is constructed to release new ways of perceiving music making, to propose new connections between various musics, to open up alternative modes of listening, to offer another means of accessing improvisations. Hopefully it says something that others have not said already.

[2] The FMI Theory encompasses all music making

The most basic principle of the FMI Theory is that improvisation in music should not be restricted to so-called improvised music; all music making, including composing and arranging, contains stages in its production process which could be called - or be interpreted as - improvisatory. No matter how detailed a score is, some elements that form an inextricable aspect of any performance might be notated - if notated at all - schematically, inaccurately, or open to many interpretations, which makes necessary some form and degree of improvisation on the part of the performer (Benson 2003: 26; Gould and Keaton 2000: 143).

In turn, composers "improvise" within as well as on the tradition to which they belong as they modify its rules and expectations by creating something "new." Here, improvisation can be regarded as the reworking of something that already exists (Benson 2003: 30), a connecting to what has come before by repetition and alteration. Although this type of improvisation seems far removed from the (often) more spontaneous performances in free jazz or improvised music, especially those in which no scores or other preconceived strategies are used, this idea of reworking the 
tradition can also be considered as that which connects them: neither composers nor free improvisers operate in a vacuum, but react to and transform previous musics. Improvisation happens in a space between an eternal beginning and an everlasting continuation, between iterability and alteration. This is what Gary Peters calls "the beginning of art and the tracing of that beginning in the expressive history of mimetic gestures, clichés, and formulae" (Peters 2009: 104).

\section{[3] The FMI Theory advocates singularity}

In my opinion, the connection between free jazz or improvised music and music that is not usually immediately associated with improvisation, as elaborated upon by Benson (2003) and Peters (2009), legitimates the use of the single term "improvising" at the expense of a wide range of partly overlapping terms such as "varying," "extemporizing," "embellishing," the German "fantasieren," and even "interpreting." However, and this is a crucial point, this does not make improvisation a coherent term; the word denotes numerous articulations in which practice and concept implicate one another, each time differently. So, using this one term does not imply that all improvising can be treated equally. On the contrary, each "improvisation-as-reworking" has its specific features, its contexts (social, technological, economic, historical, aesthetic, etc.), its actors, factors, and vectors. In the praxis of improvisation, relations and events are not fixed, but dependent on specific arrangements of human and non-human actants. As a consequence, the FMI Theory tries not to generalize but to singularize. As Gabriel Solis writes,

Are the jazz musician from 1927 who ornately elaborated and ornamented a melody, the free improviser of today who creates collective sound spaces, the Baroque keyboardist of the $17^{\text {th }}$ century or today who preludes, and the sitarist who plays an alap really all doing the same thing? All create new music using models known and in some way agreed upon beforehand, but the nature of the models, the degree of departure, the context for interpretation, the interactive frameworks, and the meaning those creations take on among the musicians and audiences are all distinct. (Solis in Nettl and Solis 2009: 3)

Even although many actants in various improvisations can and will stay the same, they always arrange themselves differently. The FMI is a matter of patterns that partly recur but also change in that recurrence; it occupies a space between repetition and difference. To call this "singularity" is in line with the way Jean-Luc Nancy describes the term in his book Being Singular Plural. Singularity, Nancy states, is "the punctuality of a "with"' that differs from "individuality" insomuch as the latter indicates a more or less fundamental separation and distance (Nancy 2000: 85). As a result, singularity is based on specific complexities of connections.

[4] The FMI is not anthropocentric

Musical improvisation involves all kinds of human and non-human actants; agency includes both people and matter (instruments, technology, space). Instead of taking instrumental actions of active people on passive objects as point of departure, the
FMI Theory assumes relations of interactivity between heterogeneous sources. Reflecting on these relations requires a more balancing approach of interactive contingency than a hierarchical one of instrumental causality (Rammert 2008: 2). The consequence of this line of thought is the realization that human beings are not the exclusive determinants. Contrary to Howard Becker's claim in Art Worlds that artists can be defined as persons who perform the core activity (i.e. in one way or another producing the artwork), thus operating in the center of a network of cooperating people (Becker 1982: 25), they are - sometimes at least - out of the center, removed to the periphery. Instead of maintaining this anthropocentrism, the field of musical improvisation functions as a multiplicity made up of many heterogeneous actants of many different natures, a network of interconnected, human and non-human, nodes, which, through multiple feedback loops, create a temporary system of resonances, amplifications, and interferences. In other words, the FMI shifts the perspective from the musicians to the system, locating artistic productivity beyond what can be planned, intended, or foreseen.

[5] The FMI is ecological

The FMI can be regarded as an ecosystem as it is composed of dynamically interacting parts, including humans (the bodies and minds of the musicians), the communities they make up (bands, ensembles, and other more or less ad hoc cooperatives), and the non-living components of their environment (instruments, space, acoustics, etc.).

Improvising, in fact, may be one of the most complex abilities humans can develop: it requires a tremendous coordination of ears, hands (body), and mind; some learned or instinctive understanding of music (techniques, theory, history, styles, etc.); sufficient motor control, as the improviser needs to be both fast and accurate; and the ability to interact with the environment (fellow musicians, audience, space, acoustics, etc.) while simultaneously playing and reflecting on one's own playing.

The FMI Theory thus investigates and maps the complexity and singularity of the connections between mind, body, and biotic or abiotic actants, operative during a musical process. However, this connectivity is not a pre-existent given, but is produced in the process (Pranger 2010: 4). In much the same way, neither human nor non-human actants precede the FMI, but receive their identities as actants primarily through their contribution to the FMI and in their interaction with other actants: an object really becomes a musical instrument when it is played upon in a musical context; one's identity as an improviser is first of all established and acknowledged in and during the act of improvising; an amplifier might get a specific identity and become an important actant when it starts influencing a specific performance in a particular and significant way (cf. The Fell Clutch).

The FMI Theory proposes regarding musical improvisation as an ecological system in which heterogeneous instances are distributed and connected with one another These instances or actants do not just evolve; they coevolve and thereby produce webs of interdependencies. The rationale is not to start a priori from single or 
collective human actants who stand in a hierarchical relation to other, non-human, actants; the FMI Theory is not designed to track down general origins nor a central authority; it presupposes many loci of agency, not one prime mover, no dualism between doers and done-to, because they are all part of this interlocking network. The FMI ecology is primarily concerned with the interactivities and interconnections between all these actants in a concrete process and how the connections are stabilized or deterritorialized and transformed through these interactions, thus unfolding into new connections. This is what sociologist Werner Rammert describes with the term "collective agency" (Rammert 2008: 12-18).

[6] The FMI is a complex system

Closely connected to the ecological principles of the FMI is the idea that the FMI is a complex system. This complexity is not (necessarily) situated in the music itself, the sonic results of the acts of improvisation (though this can and should not be excluded); first of all, it refers to the myriad possible ways that the actants, operative within a system - here: a concrete improvisation -, can interact. The complexity is thus in the organization, as many separate actants interact simultaneously (Waldrop 1992: 86). Contributing to this complexity is the fact that relatively small mutations, formed while the actants explore their way into an immense field of musical possibilities, might be enough to produce quite radical changes in the music making and results as a whole. As such, an improvisation is an emergent, self-organizing, and adaptive structure, growing through constant adjustments and readjustments by the input from musicians (both learned and spontaneous [re]actions) and the environment (both human and non-human), and resulting in a perpetual negotiating between order and disorder, structure and chaos, free and fixed elements, stability and fluidity, etc. Though every FMI, whether "free improvisation" or improvisation in a more composed context, contains rules, they are never absolute; they always lead to mobile music, never quite settling down.

Instead of assuming a simple boundary, separating order from chaos, the FMI is a special space in itself, a field where one can find systems with complex behaviors and organizing processes that rely on and stage particular constraints that encourage the emergence of something new (Landgraf 2014: 5).

[7] The FMI Theory is radical empirical

Charlie Parker and Giovanni Pierluigi da Palestrina. Elvis Presley and the Berliner Philharmoniker. James Brown and Ikue Mori. Ravi Shankar and Fela Kuti.

Einstürzende Neubauten and Sofia Gubaidulina. Christina Kubisch and ABBA. Planxty and Valentina Chuldum. Connect them. Compare them. Relate them to your own favorites. There is improvisation in their music making, albeit each time differently: a different quantity, different quality, different role, different position, different language, different conventions, different freedom, different relation to the (acoustic, musical) environment, etc.

My (random) choice here: Deep Purple and David Rothenberg

\section{play}

Deep Purple - "Strange Kind of Woman"

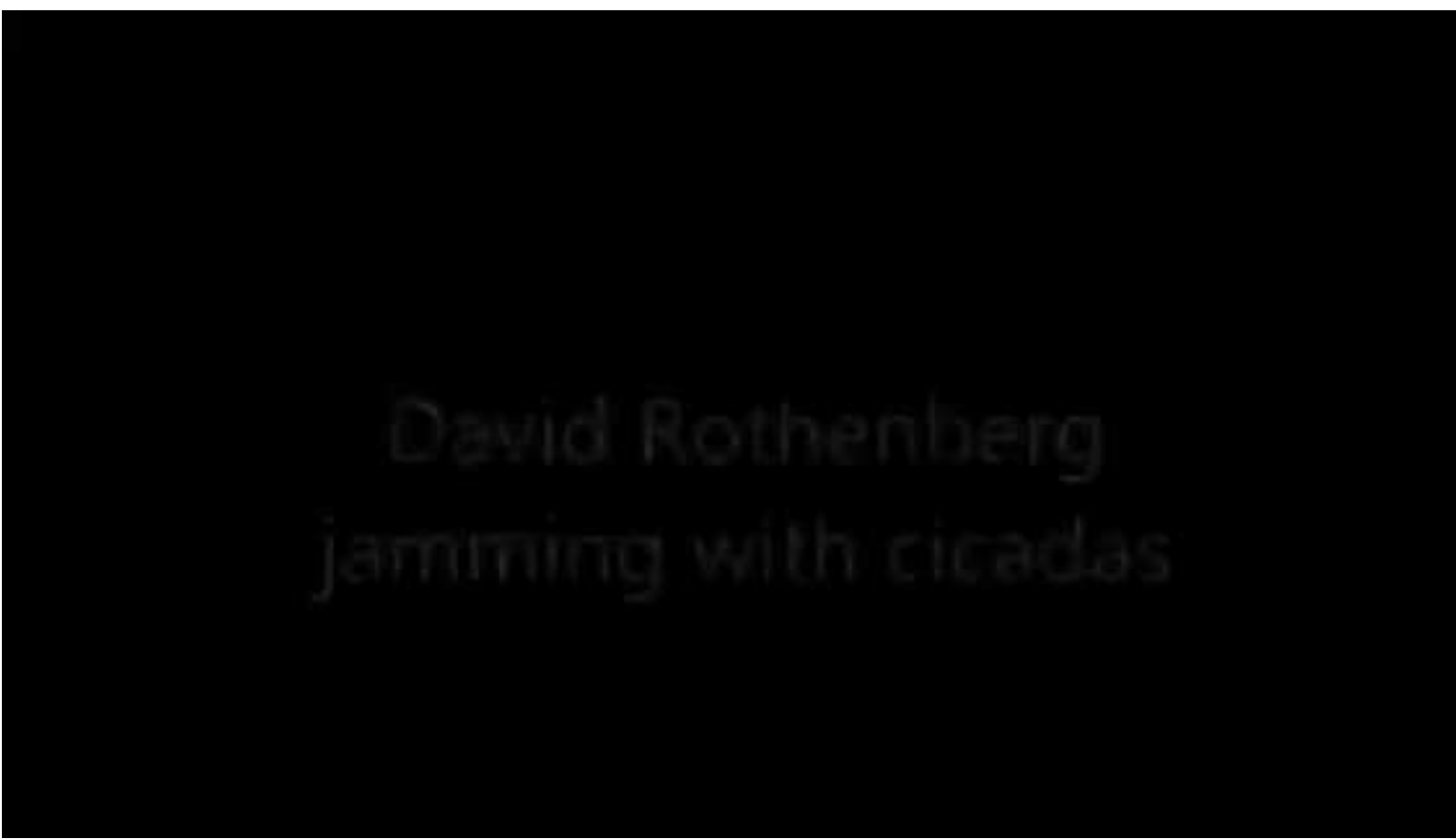

David Rothenberg jamming with cicadas

The attention of the listener who compares the studio version of Deep Purple's "Strange Kind of Woman" with the live version from their album Made in Japan, will, without doubt, be drawn towards the end of the song: the final guitar solo of the studio recording is not only extended in the live performance but also interposed by a call and response game by Ian Gillan (vocals) and Ritchie Blackmore (guitar), accompanied by drums and the hand clapping of the fanatic Japanese audience. Playing a well-known tune - at least for the insiders - with prolonged intro, outro, and/or solos is quite typical at a rock concert, thus creating a play of repetition and alteration, a mixture of known and unknown elements, simultaneous feelings of familiarity and surprise. The reworking of this song - it can of course not be excluded that the band rehearsed this intervention at length - can be understood as "a complex feedback process that builds forms out of contingent elements by relating present decisions to past ones" (Landgraf 2014: 146).

The assemblage created during this interactive play between Gillan and Blackmore consists of a set of relations, with guitar, vocals, audience, musical background (a previous version of the same song), social and cultural background (British Rock music from the 1970s performed for an Asian audience) as perhaps the main actants, but with more or less direct influences from interactions between location, time, technology, venue, routine, experience, challenge, etc. as well; the assemblage - 
which, in principle, could be expanded endlessly - consists of encounters between human and non-human actants in which each affects, infects, and inflects the other, drawing them toward lines of flight in a combined deterritorialization (Deleuze and Parnet 1987: 44). Said differently, the relationships articulated by this (as well as any other) improvisation do not pre-exist but are created by all participating actants.

Relating "Strange Kind of Woman" to David Rothenberg's clarinet improvisation, a musical venture strongly influenced and determined by a sonic environment dominated by the sounds of cicadas, seems almost absurd. However, the rationale behind this juxtaposition is to stress the point that improvisations can take so many different forms that any attempt to come to a general description might fail.

Of course, in both examples interaction is key: interaction with the instrument, with the other "musicians" involved, with the (natural, physical, acoustic) environment, with a cultural and musical context, etc. And location, time, routine, and challenge play a substantial role in the Rothenberg-cicadas assemblage as well (e.g. the invasion of cicadas in a particular part of the state of New York only occurs at a particular time of the year). Nevertheless, the relations may change without (all of) the actants changing; the component parts may be very much alike, their involvement and mutual influencing can vary a great deal. Or as Mitchell Waldrop (1992: 86) has put it, "the complexity is actually in the organization - the myriad possible ways that the components of the system can interact."

However, the differences between Deep Purple and Rothenberg are of course significant: Rothenberg's musical language seems to be rooted predominately in a jazz tradition with a slight classical undertone. The cicadas' ebb and flow of "white noise," the rhythmic pulses as well as the kind of fundamental they produce, create a natural soundscape within which the jazzy clarinet sometimes sounds as an alien intruder. And Rothenberg's rationale to let nature inspire (his) music and (thereby) expand the whole notion of music, will, very likely, not be found within the artistic motivation of Deep Purple, but forms a non-negligible actant in the realization of his improvisation.

In Deleuzian terms, the block of becoming that unites Rothenberg and the cicadas produces a shared deterritorialization: the becoming-cicada of Rothenberg, in that he becomes an active participant in the cicadas' sonic system, and the becoming-music of the cicadas, Rothenberg's principal musical partners in this improvisation.

Each case is a singular one, a complex system in which all actants present relate to one another in a very particular and unique way. That is why the FMI Theory advocates and applies a radical empiricism. Therefore, the next part, Part 3, will be dedicated in its entirety to specific musics in which improvisation is somehow present - each time differently, that is, each time with a different configuration of actants. 


\section{Part 3}

\section{Implementing}




\section{Introduction to Part 3 - Implementing}

[1] As already mentioned in Part 1 (cf. "Context and Justification", section 3), David Borgo's book Sync or Swarm sowed the seeds of this publication as it was the first (and the only?) study on improvisation that made direct links to complexity theories. According to Borgo, nonlinear dynamical systems theories may offer fresh insights into the complex forces that are involved in contemporary forms of - especially and specifically - group improvisation.

Like other complex dynamical systems, the exact development and structure of an ensemble improvisation is inherently unpredictable, and yet through certain shared understandings, nuanced interactions and interconnections, and a shared cognitive ability to attend to and parse musical sound, dynamical orderings can emerge that are both surprising and comprehensible. (Borgo 2005: 74)

Borgo sees a clear resemblance between chaos and complexity theories on the one hand and improvised music on the other: both regard diversity and adaptability as desirable traits, and consider irregularity and unpredictability as essential qualities. Complex dynamical systems allow for enduring patterns of organization as well as spontaneous responses to unexpected occurrences; the same goes for improvisation, which can be characterized by a tension between stabilization through communication and instability through fluctuations and surprise (Borgo 2005: 133).

Like complex systems, improvised music depends on an ensemble's ability to selforganize so that "critical levels of complexity, responsiveness, and surprise can be reached and maintained over the course of an extended performance." While each new gesture can potentially offer fundamental musical transformations, the ensemble members should avoid becoming "overwhelmed by the speed of interaction and availability of options in order to avoid potentially crippling states of oversaturation and indecision" (Borgo 2005: 81). In Complexity Mitchell Waldrop regards this search for a balance between order and chaos, between stability and fluidity, a balance that will never be achieved completely, as a main characteristic of dynamic, emergent systems. In other words, too much chaos will undermine and destroy any system, improvisation or otherwise, while too much order restrains a creative and necessary dynamism (cf. "Mitchell Waldrop and the Field of Musical Improvisation", section 3).

[2] Borgo illustrates and concretizes his theoretical exegesis with some examples from (free) improvised music: the Sam Rivers trio, Evan Parker, Derek Bailey, Peter Brötzmann, and The Art Ensemble of Chicago. Indeed, at times it seems as if improvisation becomes almost a synonym for free improvised music, as if complex dynamical systems can only find their sonic counterpart in this music. Perhaps Borgo's choice has something to do with the fact that, in the end, he locates complexity first of all in actual musical structures. Although he firmly states that "to examine a group or an individual in isolation of historical, cultural, and societal contingencies and opportunities ignores the richness of network dynamics" (Borgo 2005: 10), his concrete 
analyses mainly consist of sonograms showing some remarkable similarities between concrete solos and fractal developments.

[3] The Field of Musical Improvisation deviates in three quite fundamental aspects from Borgo's work. First, I fully agree with Borgo that mind and body, moment and place, emotion and intellect, preparation, experience, and spontaneity are all important actors in musical improvisations. And in a group setting the variety of interactions, influences, intentions, and potential (mis)interpretations warrant complexity of collective dynamics and decision-making (Borgo 2005: 62). Moreover, cultural and social conventions, material artifacts, economic, technological, and educational factors, the influences of audience and venues all shape the musicians' activities and lead to a "dynamic interplay of social, material, and sonic culture" (Borgo 2005: 136). So, while Borgo eventually concentrates on intrinsic musical developments, my focus is first of all on the specific actors, factors, and vectors that make the music possible. This study therefore concentrates on the many interactions that characterize and define each improvisation. Naturally, these interactions cannot be restricted to human-human ones only. As Bruno Latour states, "face-to-face interaction is not a plausible departure point to trace social connections for humans are being constantly interfered with by other agencies" (Latour 2007: 198). In other words, human-human relations do not suffice to map the dynamics, forces, and intensities operative in an improvisation; attention is needed for both human and non-human actors, for interactions between human bodies, objects (instruments), environment, locations, and acoustics, as well as less tangible agents such as past, culture, politics, ethics, etc.

No wonder interactions provided social scientists with the strong impression that they were overflowing in all directions. They are! That does not mean that some solid overarching context holds them solidly in place through the grip of some hidden structural force. It means that a bewildering array of participants is simultaneously at work in them and which are dislocating their neat boundaries in all sorts of ways, redistributing them away and making it impossible to start anywhere that can be said to be 'local.' (Latour 2007: 201)

A second important difference between Borgo's book and my work concerns the music. As asserted above, Borgo seems almost to equate improvisation in music with free improvised music. He, im- as well as explicitly, restricts himself to relating complexity theories to examples from the European and American free jazz tradition. Likewise, authors such as Derek Bailey, Gary Peters, George Lewis, and Georgina Born seem to regard free improvised music as the standard against which other improvisational activities need to be measured (and often dismissed as mediocre and perfunctory). As a counter-narrative, and in an attempt to broaden the horizon of scholars dealing with musical improvisation as well as to draw attention to nonWestern forms of improvisation, ethnomusicologist Bruno Nettl suggested back in 1974 to consider each musical style or model as consisting of a set of macro-units or points of reference. The denser these units or points, the less freedom a musician may exercise to deviate from a specific musical model; in other words, density is inversely proportional to improvisation. With regard to musical styles in which improvisation is emphatically present, Nettl concludes that figured bass and Baroque music are perhaps the densest models, jazz and Persian music of medium density, whereas Arabic taqsim and Indian alap are almost lacking density, thereby offering the greatest amount of freedom to a performing musician (Nettl 1974: 15).

Again, it is not my aim here to quibble about a ranking from the most to the least improvised music. What I want to stress is that already in the mid-seventies of the twentieth century, Nettl hands down a theoretical model in which (almost) all musics can become nodes in a network built around the concept of "improvisation." I take Nettl's observations as a license and a justification to not restrict myself here to musical examples from renowned improvisers but to expand the range of musics and musicians and to include some who are in general not considered immediately as "members" of an improvisatory community; nevertheless, I will argue that their musicking certainly contains improvisational aspects and moments too.

To explain the third divergence with Borgo's Sync or Swarm I stay with Nettl's work for a little while. In a short essay from 2013 he sighs that scholars might have made a mistake by using this single denominator "improvisation" for an enormous variety of musical practices: "Indeed I wonder whether all the things we include under the rubric of improvisation have enough in common to justify a collective term" (Nettl 2013: 2). For me, this is a problem that comes with all efforts to demarcate, to delimit, to in- and exclude, to define, etc., and perhaps this is not so much (or not only) an ontological as an ethical issue. However, my basic assumption that improvisation is an inextricable part of all music making (cf. "The Omnipresence of Improvisation") is not meant to add just another voice to the chorus of members who have tried to give a satisfying - that is, a universal and everlasting - definition. Rather, this idea opens (for me) the possibility to encounter many different musics in a new way. In other words and paraphrasing Gilles Deleuze, using the concept "improvisation" to describe certain features of musical practices should not (only) lead to the question "Is it true?" but, rather, to considerations such as "Does it work?" “What new thoughts does it make possible?" "What new sensations and perceptions does it open?" "Can it shift the attention, transform existing discourses, open up new listening experiences, and lead to other insights?" "Is it meaningful?"

However, and again I go back to Deleuze, using one term for such a comprehensive and versatile practice simultaneously demands a kind of radical empiricism (cf. The FMI Theory, section 7). "The aim is not to rediscover the eternal or the universal, but to find the conditions under which something new is produced (creativeness)," Deleuze writes in the English preface to Dialogues II (Deleuze and Parnet 1987: vii). Aiming to find the conditions under which something new, e.g. an improvisation, is produced, requires first of all attention to the specifics of a musical performance: which actors, factors, and vectors determine the improvisation? What are the most important actants? (In Love's Knowledge, her book on literature and philosophy from 1990, Martha Nussbaum writes about the importance of art, as it shows life's 
complexity and how everything revolves on "particulars", details, and exceptions.) Or, as Nettl writes in the introduction to In the Course of Performance, "we will increasingly have to look at improvisation as a group of perhaps very different phenomena" (Nettl 1998: 16).

[4] On the basis of this reasoning, Part 3 consists of a series of musical examples in which improvisation plays a role in one way or another. In other words, I do not want to equate musical improvisation with, nor restrict it, to improvised music (cf. Cobussen in Schroeder and Ó hAodha 2014: 17). By paying attention to a relative diversity of musics, I first of all want to make feasible and do justice to my belief that improvisation takes place in all music making. Second, the examples should sustain my claim that studying improvisation might benefit from a more singular approach instead of attempting to formulate some generalizations: each improvisation takes place in a unique constellation of various actants, each improvisation knows its own presence or absence, its own multitude or modesty, its own centrality or peripheral position of human as well as non-human actors. Third, it should become evident that improvisations in music can be regarded as complex systems, thereby emphasizing the interactions of a great many agents and components as well as the dynamic character of these interactions. However, as Oliver Human and Paul Cilliers argue, we can never know complex systems completely: "we cannot comprehensively determine the limits of the system and hence accurately define the field of possibilities" (Human and Cilliers 2013: 25). In that sense, it will always be necessary and inevitable to focus on a limited set of relationships between parts or the play between parts within a system, within an improvisation. I cannot escape from a process of prioritization granted to certain actants and thus to a certain kind of reductionism. "A 'general' approach to complexity is one which recognizes that we have to reduce and constrain, but that the heterogeneous will remain a force which disrupts our provisional reductions" (Human and Cilliers 2013: 32). With this is mind, I have composed the texts of Part 3: in each musical example I focus on a few particular actants, a few interactions that stand out in particular, but always keeping in mind that the actual improvisation is far more complex than I will ever be able to put into words

No individual case is ever just an individual or a case [...] Thus to study the particular is to study the general. (Denzin and Lincoln 2000: 370)

I assume that the readers will be able to generalize subjectively from the cases in question to their own personal experiences.
Michael Moore, Han Bennink, and Will Holshouser - Human

Actants

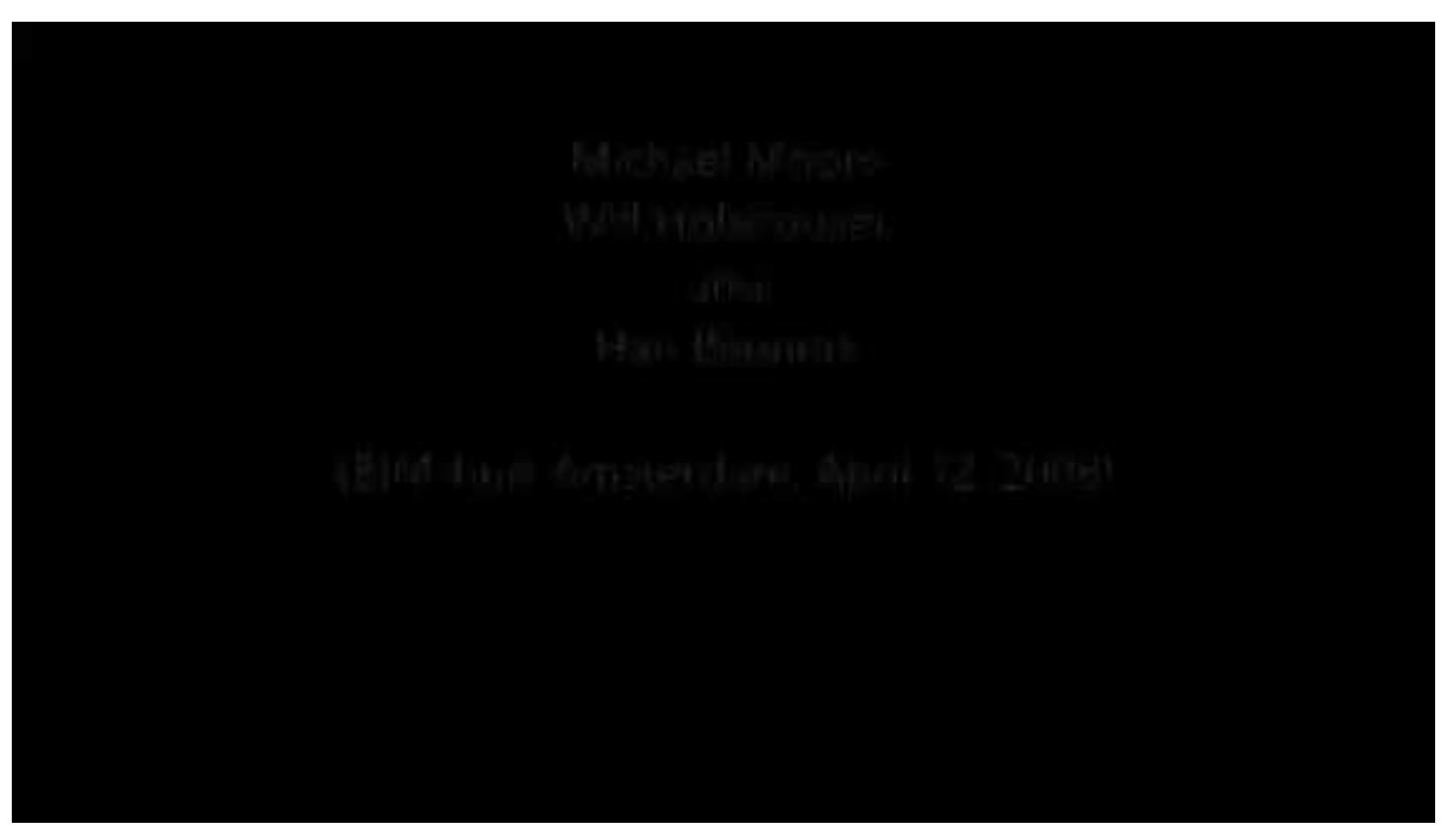

Moore, Holshouser, Bennink - “Skylark" (Bimhuis Amsterdam, April 12, 2008)

Will Holshouser (accordion), Michael Moore (clarinet and sax), and Han Bennink (snare drum) in the BIM-huis in Amsterdam. The complexity of this performance cannot be situated in the "music itself." The structure of most pieces is rather straightforward and predictable: after a free introduction of basic musical materials, a theme is exposed, followed by an improvised section. The outro is free again, creating a passage to the next tune.

Nevertheless, it is hard, if not impossible, to describe the multitude of interactions between the various actants that determine this performance. Bennink turns the whole stage into a drum kit: stamping with his feet, the wooden floor becomes a bass drum, while treating the same floor with brushes turns it into a tom; Moore and Holshouser reverse the division of tasks: sometimes the solo instrument accompanies the chordal instrument; Moore ends a solo because he has to clean his clarinet; Bennink incites reactions from the audience by lying on the ground while continuing to play a swing rhythm; and "Skylark", the tune played on the video, immediately connects these musicians not only to composer Hoagy Carmichael but also to illustrious predecessors such as Paul Desmond, Sonny Rollins, Art Blakey, and Keith Jarrett.

The list could easily be extended, and the concert therefore offers a good example of a musical ecology in which musicians, instruments, stage, audience, music history, entertainment, and several other actants are interactively connected. However, while keeping this network of actants and their interactions in mind, the focus of this short meditation will be on the ways the musicians on stage proact, act, and react. 
[2] Even if one does not like the music, a concert can be entertaining and interesting for different reasons. Besides a musical, it is a physical as well as a social encounter between human beings. In this particular example, the three musicians attentively listen to each other and respond to the musical choices of the others in order to make music together. They make eye contact, employ visual and visible cues, but, more often, their interactions happen through intense listening, through the sonic, through musical intuition, knowledge, and experience. The trio is formed through music, establishing itself and its artistic language through the experience and exchange of musical ideas, intuitions, and intensities; simultaneously, the improvisations are based on social involvement, on empathetic interactions, on responsibility (that is, on the ability to respond), and on intercorporeal collaborations.

The fundamental nature and meaning of music lie not in objects, not in musical works at all, but in action, in what people do. (Small 1998: 8)

In Relational Aesthetics, the French art critic Nicolas Bourriaud attempts to renew some thoughts on contemporary art by presenting an aesthetic of the inter-human, of encounters, of proximity. Relational art takes as its theoretical horizon the realm of human interactions and its social context; it is an art form where the substrate is formed by intersubjectivity, taking being-together as its central theme (Bourriaud 2002: 14-5). According to Bourriaud, contemporary art is a state of encounter, creating relational micro-territories in which intersubjectivity becomes the quintessence of present-day as well as future artistic practices: "In our post-industrial societies, the most pressing thing is no longer the emancipation of individuals, but the freeingup of inter-human communications, the dimensional emancipation of existence" (Bourriaud 2002: 60).

This may sound quite revolutionary and new in the domains of painting and sculpture, but these ideas are almost self-evident in music performances and musical improvisation in particular. In The Other Side of Nowhere, Daniel Fischlin and Ajay Heble rightly claim that the assumption that improvisation is, first and foremost, about unblocking the obstacles that impede access to forms of individual selfexpression, is a myth (Fischlin and Heble 2004: 23). And the concert by Holshouser, Moore, and Bennink clearly shows that especially improvised music hinges on the ability of all participating musicians to synchronize their ideas and actions and to maintain a keen awareness of, sensitivity to, and connection with the evolving group dynamics and experiences. For improvisation to be successful, being able to synchronize energies, intentions, and moments of inspiration is almost a prerequisite. One should remain aware of and sensitive to the many musical gestures and processes circulating within the playing of each individual as well as between the members of the group (Borgo 2005: 9 and 144).

However, this argumentation is not meant to advocate a simple inversion, favoring the collective over the individual. The process of improvisation is more complex and cannot be understood through the traditional opposition between the individual and the collective. Rather, it might be regarded as a perpetual interplay or dynamic reciprocity between individual and collective music-making. Improvisation flows from the individual to the collective and back again. Especially in small bands like the Holshouser/Moore/Bennink trio, the input of a specific individual determines the music to a large extent: replacing cellist Ernst Reijseger by accordionist

Holshouser (the trio with Moore, Bennink and Reijseger, called Clusone, preceded the one with Holshouser) not only changed the musical possibilities of the band but also its social constellation. On a primarily individual level, Holshouser brings in different musical ideas, different socio-musical behavior, different ways of making music. Regarding the collective aspect, it is precisely the interplay that leads players beyond the bounds of their individual vocabularies and spurs them to invent new musical forms that subsequently serve as vehicles for the group's improvisations (Berliner 1994: 386).

This exteriority of relations is not a principle, it is a vital protest against principles [...] If one takes this exteriority of relations as a conducting wire or as a line, one sees a very strange world unfold, fragment by fragment: a Harlequin's jacket or patchwork, made up of solid parts and voids, blocs and ruptures, attractions and divisions, nuances and bluntnesses, conjunctions and separations, alternations and interweavings, additions which never reach a total and subtractions whose remainder is never fixed. (Deleuze and Parnet 1987: 55)

[3] Without omitting the impact of the artistic knowledge of each individual Holshouser, Moore, and Bennink must think as a group, develop forms of collective thought and joint artistic intelligence, in order to arrive at a satisfying musical process and event. This intelligence - understood in its etymological sense of "joining together" (Lévy 1999: 10) - is not the mechanical result of automatic activities; rather, its specific objective is to permanently negotiate the group process and its artistic development and outcomes. "This intelligent collective neither submits to nor limits individual intelligences, but on the contrary exalts them, fructifies, and reinvigorates them [...] It gives rise to a qualitatively different form of intelligence, which is added to personal intelligences" (Lévy 1997: 105; cf. "Pierre Lévy and the Field of Musical Improvisation").

For example, the beginning of "Skylark" shows how the group dynamics and the concert's atmosphere may push the individual musician to relinquish control over the shape of the piece: while Moore is changing from clarinet to alto and Holshouser is searching for the right sheet music, Bennink decides not to wait and begins a drum solo. When Moore starts playing the theme, Bennink is pushed toward changing his playing from soloing to accompanying while Holshouser comes in 
after eight bars with some very sparse, soft, and high dyads so as not to destroy the sonic atmosphere that has arisen. These are but a few pieces to a puzzle in which no one "owns" a finalized version; instead, the coordinated behavior results from cooperative synchrony, not hierarchical but not purely democratic either.

This collective intelligence, this coordinated knowledge, this collaborative thinking cannot be reduced to rationality. As Pierre Lévy (1997: 139) states in his book Collective Intelligence there are body-thoughts, affect-thoughts, percept-thoughts, etc. (cf. "Pierre Lévy and the Field of Musical Improvisation"). Likewise, Holshouser, Moore, and Bennink not only think with their brains, but also with their bodies and through their instruments; their interactions, mainly (in)formed by attentive listening, are articulated through musical and bodily gestures. (cf. Keith Jarrett, section 3) There is, in other words, a close connection between the performers' intercorporeal activities, the physical connections to their instruments, and the sound relationships they create.

\section{Brian Ferneyhough - The Mistake as Actant}

[1] Improvisation takes place by necessity when musicians need to deal with aspects in the complex field of music making that cannot be determined in advance. Generally speaking, one could make a distinction here between negative and positive improvisation. Negative improvisation is reactive, indispensable to resolve uninvited problems, a reaction to external pressure; conversely, positive improvisation is proactive, more voluntary, not freedom from something negative but freedom to create and to be innovative (Dehlin 2008: 219-273). When Marc Ribot has to play with a broken amplifier (cf. "The Fell Clutch", section 1) or when Sonny Rollins must interrupt his solo because his reed is damaged (filmed in the Dutch documentary Morgen speel ik beter [Tomorrow I will play better], a tribute to Rollins), they are perhaps forced to improvise, that is, to improvise "negatively."

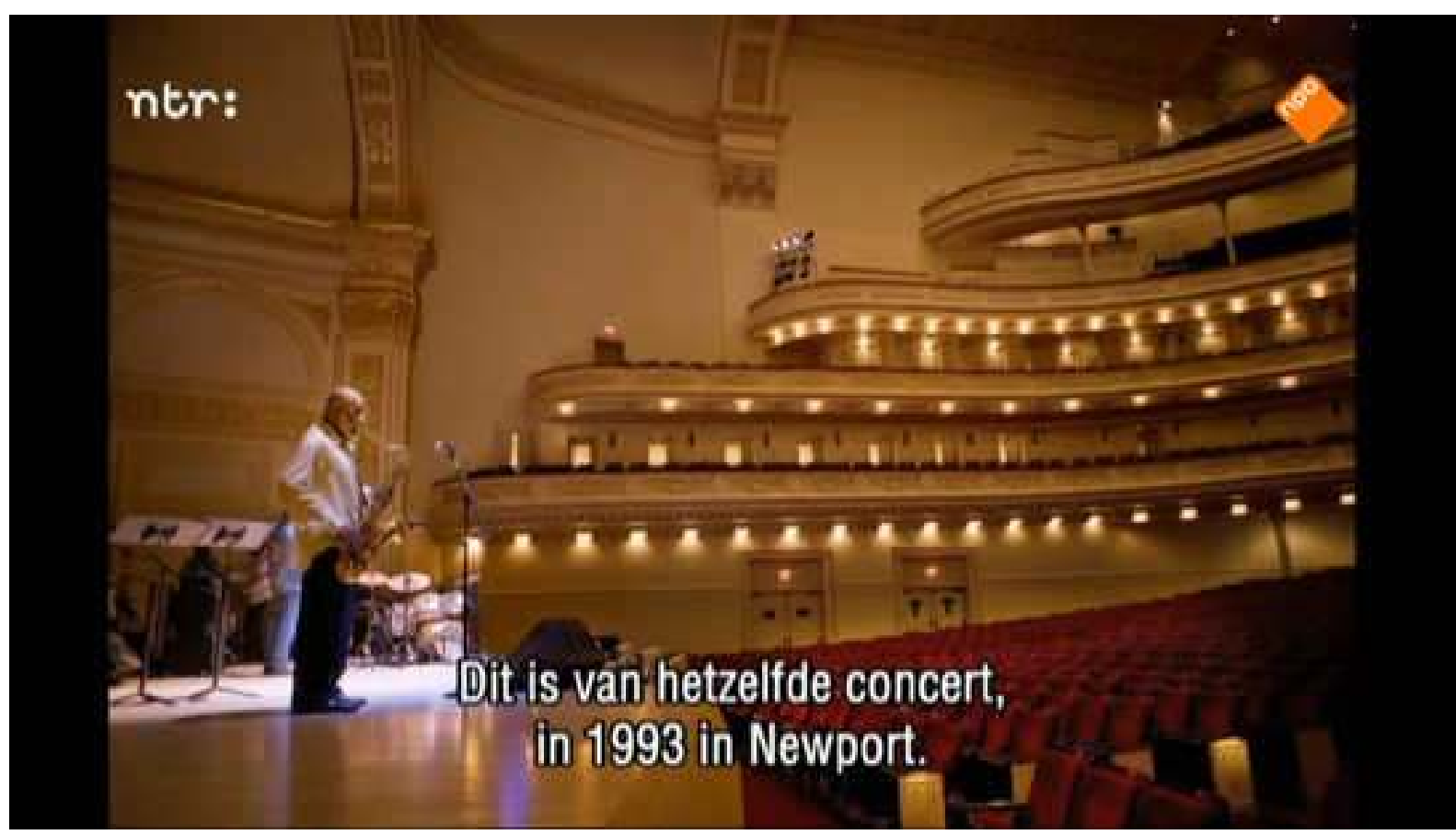

Morgen speel ik beter, a documentary by Hans Hylkema en Olaf van Paassen

On the other hand, when alto saxophonist Ornette Coleman picks up the violin - an instrument he isn't really a master of - or when pianist Misha Mengelberg deliberately attempts to disrupt interactions between fellow-musicians by playing notes and phrases that - ostensibly - have nothing to do with the employed musical vocabulary, they use improvisation in a pro-active and positive way, opening new unknown possibilities; they purposely interrupt the already known by seeking and generating resistances

Besides malfunctioning instruments and the injection of randomness or musical game playing, another occurrence that activates improvisation - negatively or positively, inadvertently or intentionally - is the playing of mistakes, for a mistake is the production of the accidental, not pre-determinable (Evens 2005: 154). 
In Steve Coleman - Rhythm and Musicians as Actants I describe the problems the pianist and the drummer encountered when asked by Coleman to play the rhythmic pattern he had in mind for them. They both make mistakes, compelling Coleman to suggest adaptations for the interlocking rhythmical patterns he has invented in advance.

Here, I also address the notion of mistakes, investigating how they may become important actants in the field of musical improvisation.

[2] In Thinking in Jazz, Paul Berliner devotes a few pages to mistakes in jazz music. Miscalculations by soloists or rhythm sections may "obscure formal landmarks for everyone," and deliberately stretching the limits of form or meter can lead to "unintentionally, turning the beat around" (Berliner 1994: 379-381). Apart from trying to avoid such mistakes by taking less risks, Berliner suggests, as possible solutions, to keep playing the way you believe is correct, so the others can catch up, or to listen carefully to what the others are doing in order to adjust your own playing (Berliner 1994: 382). One could say that both strategies are grounded in the principle of noticing the mistake and, successively, trying to rectify or hide it, with the assumption that it is only negatively impacting the ongoing event.

However, Berliner briefly discusses a third option. Musicians may also use a mistake as an inspiration for improvisation. Performance errors can also be treated as "compositional problems" that require instant, collective solutions: "Within group interaction, the responses of other artists to unintended events may, in fact, reveal their value to a player [...] Tactful responses not only mitigate musical errors, but can at times produce unexpected benefits for the entire group" (Berliner 1994: 382-3). Mistakes do not always need to be resolved, but may lead performers into musical areas otherwise undiscovered, and thus even strengthen the improvisation. This option concerns how performers use what was "right about the mistake," turning the mistake around through subsequent notes and thereby erasing it as a mere mistake (Klemp et al. 2008: 7-8; cf. Rintzler 2008: 192).

Miles Davis' reaction to a wrong chord by Herbie Hancock in "So What?" has more than once been used as a paradigmatic example (Shipp 1991; Berliner 1994; Eskow 2002). Hancock's mistake appears at the peak of Davis' solo. Davis retorts instantaneously by playing a phrase that makes the chord sound right. According to Hancock "Miles didn't hear it as wrong, but instead as something that happened" (Hancock in Eskow 2002: 171). For Davis, the mistake was not so much a mistake as another unexpected event for him to react to. Hancock's error was not so much rectified as used to push the solo into a new direction. In fact, one could say that Davis let his creative skills be put to the test by Hancock's "wrong" chord.

[3] Improvisation and risk - and, thus, potential failure - seem to go hand in hand. Starting from the premise that all music has an improvisational tendency, Aden Evens states that, therefore, "every music making risks something, tries something that may fail [...] The faculty of music has failure built in" (Evens 2005: 155). With this assertion, Evens not only supports my idea that improvisation is an inherent aspect of all music making (cf. "The FMI Theory", section 2), the quote also implies that risk, failure, and mistakes are not exclusive to improvised music but an inextricable part of all musicking. However, while dealing with mistakes might be accepted as an integral aspect of (free) jazz and free improvised music, the question regarding what the role of a mistake could be in so-called classical music, where the performer is usually asked to reproduce a score as best as he can, becomes relevant. Can an error be anything but devastating? I am not interested here in examples such as the famous aberration with Maria João Pires who, as the orchestra started playing, suddenly realized that they were playing a different concerto than the one she had prepared.

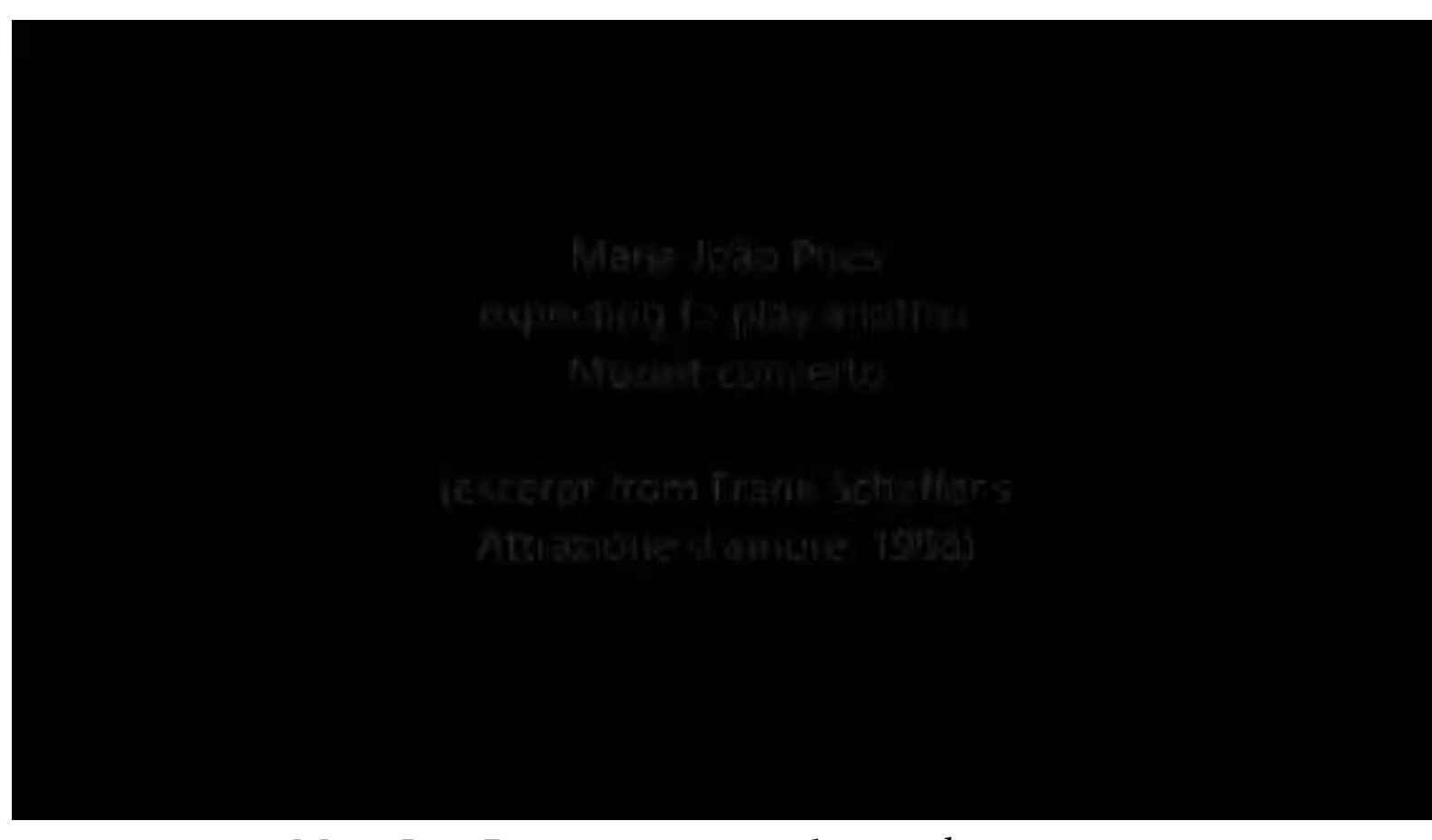

Maria João Pires expecting to play another concerto

Instead, I turn to a piece by Brian Ferneyhough entitled Time and Motion Study II (TMS2) for cello and electronics, in which the performer is challenged to almost constantly play on the verge of failure, in a space between right and wrong, where wrong can become right. ${ }^{1}$

1 For this third section I am highly indebted to Arne Deforce's trailblazing and thoughtful PhD-dissertation “Laborinth II: denken als experiment: 472 'meditaties' over de noodzaak van het creatief denken en experimenteren in het uitvoeren van complexe muziek van 1962 tot heden." [Laborinth II: Thinking as Experiment: 472 "Meditations" on the Urgency of Creative Thinking and Experimentation in Performing Complex Music from 1962 to the Present.] 


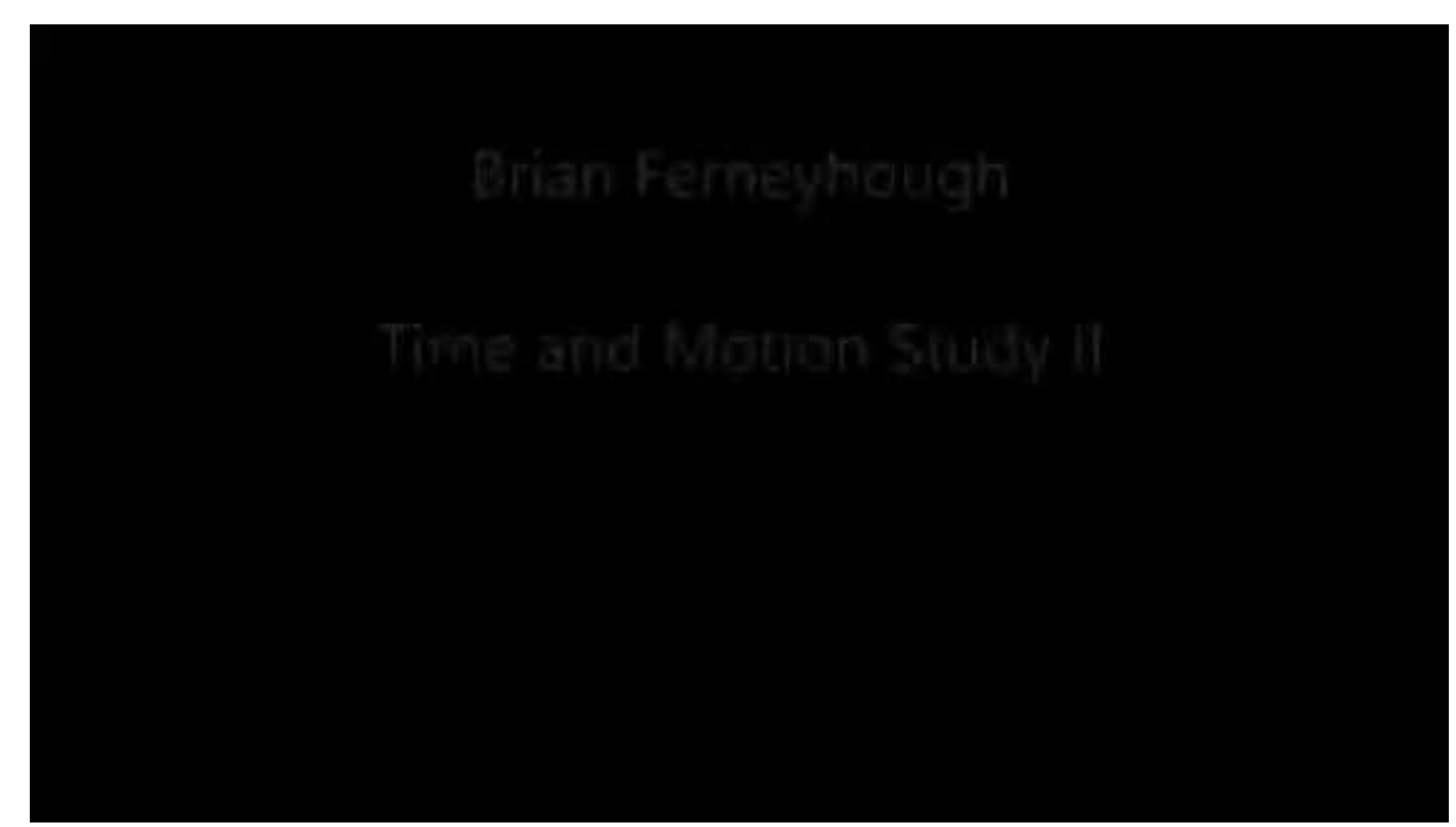

Arne Deforce performing Brian Ferneyhough's Time and Motion Study II

TMS2 fits into the category of "new complexity," mostly non-tonal music questioning the limits of playability and notation techniques by touching on the unplayable and unnotatable. That is, certain passages in TMS2's over-notated score are perfectly playable, while at other places only $60-80 \%$ can be achieved. Ferneyhough:

I try to compose music which [...] achieves two things: the first is, to consistently overstep the bounds of the human possible - not in an irresponsible way, but extremely finely gradated, and plotted over the total length of the piece; secondly, I attempt to produce a counterpoint between the perceived aural complexity and the actual performative difficulty at any given moment. (Ferneyhough 1998: 233)

The TMS2 score consists of over-notated actions of time and movement and discusses and evokes a plurality of possible interpretations; the score is not so much a visual representation for what should sound, as a condition and invitation to make music. Because of its extreme complexity and the equally extreme physical demands the score imposes on the cellist, a successful performance - successful in the sense of giving an adequate aural rendition of the score - becomes an impossibility. This observation has two further consequences. First, the impossibility to perform the score forces the performer to articulate a "most adequate proposal" in and through her playing. Moving between the playable and the unplayable, the cellist operates in a space-between. No longer able to play what the score demands, she has to make choices and to take responsibility; she can only perform the piece by not doing what the score prescribes and by doing what the score does not prescribe. Hence, in this space-between, the performer cannot not improvise. Of course, this type of improvising - negative, as the musician is confronted with an external problem, but also positive, as she deliberately sought this problem - does not have much to do with the alleged spontaneity so often accredited to, for example, free jazz; the score does not provide a carte blanche to fill in certain passages as the performer pleases. (In that sense it deviates from the concept of an open work as Umberto Eco has defined it.) This improvisation requires discipline, a creative act based on a controlled contingency and a musical spontaneity that can only be achieved through a profound analysis of the score. The performer has to improvise without being asked to improvise nor having a desire to improvise; she has to improvise without being an improviser.

Second, an inevitable fallibility is part of TMS2's musical mise en scène. The borders of the technical possibilities are specified in such a way that any certainty of success is undermined. The structure of TMS2 cannot be musically communicated without making mistakes. The score becomes a utopia, failure its unavoidable effect. Therefore, correct and erroneous playing are two consequences of TMS2's complex notation, two inevitable features of any performance of this piece. However, this erroneous playing must be practiced, refined, and transformed into a form of "correct erroneous playing" as it cannot transcend into correct playing per se. Performing TMS2 implies making failure audible. But this failing is no mere receding; it is a creative and affirmative force necessary to make the score sound successfully. Practicing is required in order to achieve a successful failing.

[4] Through TMS2, the concept of the mistake can not only be rethought of as the possibility of freedom instead of the unfreedom of the impossible; a mistake is an important actant in the field of music making, which is always already permeated by acts of improvisation, risk, and responsibility.

How different is the position of a performer of TMS2 compared to the context someone like Miles Davis was functioning in? Davis is often depicted negatively, as being notorious for his missed notes, fluffs, and flaws. However, Robert Walser proposes that Davis, although generally bothered by failures, accepted them as a consequence of the way he played (Walser 1993: 356). His consistent and deliberate use of risky and rare techniques - e.g. bending notes with his lips, using a loose, flexible embouchure, and half-valving (depressing a valve only part of the way down), which inevitably resulted in a fuzzy sound, not quite in tune - were attempts to produce a wider variety of timbres than those typically "allowed" by the instrument, the canon, and the critics (Walser 1993: 353-4). The so-called missed notes only became mistakes when related to a canon of Western (classical) music in which technical perfection was the primary yardstick against which to measure playing. In my opinion this is the very same canon, with all its commands and prohibitions, against which Ferneyhough objected and which he tried to destruct, reconstruct, or deconstruct by composing and notating his extremely complex music, thereby forcing performers to make mistakes, to take responsibility, and to explore their own creativity. Both Davis and a cellist performing TMS2 improvise around, with, and through "mistakes." 

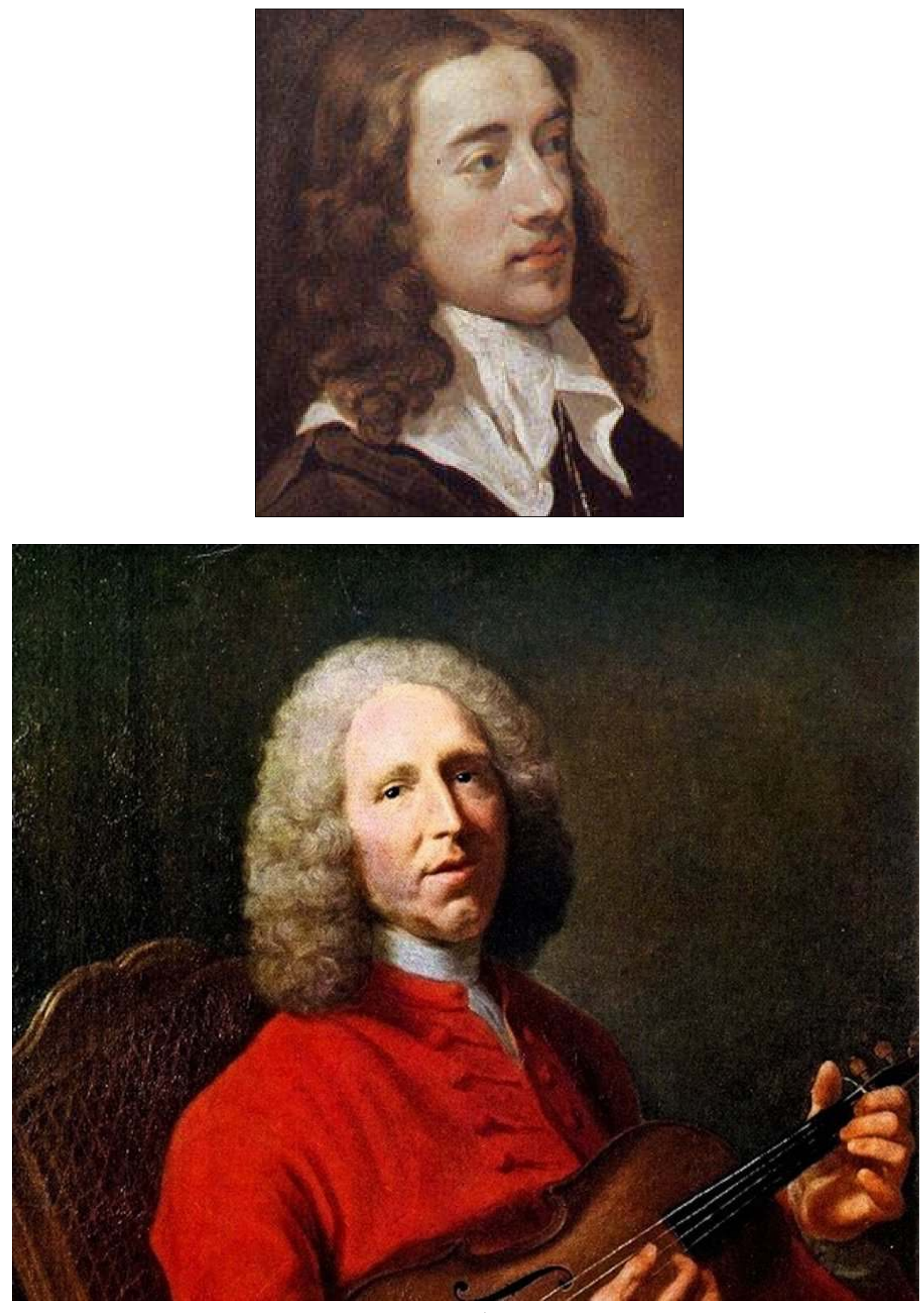

Jean Gilles (top) and Jean-Philippe Rameau (bottom)
[1] While listening to Rameau's Funeral, a CD containing Jean Gilles' Requiem from the beginning of the eighteenth century interspersed with works by Rameau, conducted by Skip Sempé and performed by Capriccio Stravagante Les 24 Violons and

Collegium Vocale Gent, I have to think of Bruce Ellis Benson's (2003: 77) remark that written scores lead to both preservation and improvisation.

Jean Gilles - Messe des Morts: I. Introit. Excerpt from Rameau's Funeral

[2] Piano lessons in a small town in The Netherlands during the 1970s always focused only on notated classical music. Music making meant playing pre-composed music; "composer", "score", and "work" were inviolable and incontestable. Czerny's Schule der Geläufigkeit, Mozart's piano sonatas, and Chopin's preludes were unquestionably played to the letter. Improvisation simply didn't come to mind, neither the teacher's nor the pupil's: "everything" was notated and "only" needed to be represented as accurately or as "authentically" as possible.

Looking outside my own experiences, into the "real" professional world, the relation between classical music and improvisation also remained awkward, unnatural, almost impossible, at least so it (still) seems from musicological, music historical, and music theoretical discourses (Montuori 2003: 248; Bailey 1993: 19; Moore 1992). But did "classical music" - I use the term here in a broad sense, i.e. roughly distinguishable from jazz and pop music - indeed exclude improvisation? Contemporary scholars come more and more to the conclusion that this prevalent idea needs to be re-adjusted.

[3] With regard to Renaissance music, Rob Wegman stated that the specialized role of the composer first emerged at the end of the fifteenth century; before that time all musicians were "makers" or improvisers (Wegman 1996). Peter Schubert pointed out that the term "counterpoint" in Renaissance treatises referred to improvised polyphony for singers instead of written compositions; composed polyphony comprised only a small fraction of the musical landscape (Schubert 2002: 503). And according to Philippe Canguilhem, every choirboy in the Renaissance could improvise and did so every day. He estimated that "the vast majority" of the polyphony heard in Philip II's chapel in sixteenth-century Spain was improvised (Canguilhem 2011: 99). Improvised polyphony was pervasive in the Renaissance, but it was highly constrained: in order to produce a "correct" improvised counterpoint, one complied with a limited set of choices for every new note. It was this very limitation of choice - Derek Bailey calls this idiomatic improvisation - that made it relatively easy to improvise in real time. 
[4] It is now common knowledge that Renaissance and also Baroque musicians needed to improvise a lot, especially in the realization of the figured bass (the basso continuo or thorough-bass) and through the insertion of embellishments, an awareness gradually seeping through contemporary professional music education.

A general assumption is that the art of improvising slowly vanished after 1800 . Indeed, after 1850 hardly any textbooks on this subject were published, and after Liszt, improvisation disappeared from concert programs. Perhaps this tendency can be related to the rise of the work concept, as Lydia Goehr (1992: 234) suggests.

However, in documents from the nineteenth century, the improvisational skills of several composers (e.g. Franck, Bruckner, and Brahms) are specifically emphasized. And the musical practice of composer-pianists such as Beethoven Schumann, Chopin, and Liszt was saturated with improvisation. Considered in the broader context, many pianists would improvise preludes during recitals. In short, there is a wealth of material showing an elaborate improvisational practice at that time, giving soloists the opportunity to exhibit their virtuosity. An important source text is Carl Czerny's Systematische Anleitung zum Fantasieren auf dem Pianoforte from 1829. According to Czerny, every pianist should be able to improvise unique preludes during public performances (Czerny 1829: 15-6). And in his Briefe über den Unterricht auf dem Pianoforte, which ends with a chapter on improvisation, he advises his fictitious pupil Miss Cecilia to practice improvisation as much as possible, as improvising is not exclusively the birthright of the talented: "Simple chords serve as the foundation on which to invent and play all sorts of melodies, passages, skips, embellishments, etc." (Czerny 1837-1841: 80-1). As examples, Czerny included several fully-notated "improvised" scores in the tenth chapter of his Briefe.

[5] Continuing this concise chronological overview, it is especially from the 1950s on that modernistic composers attempted to integrate improvisation and composition, mainly as a reaction against the powerful and privileged position of the score. Earle Brown and Morton Feldman, to name only two, experimented with indeterminate compositions or notational flexibility, thereby re-introducing a certain amount of freedom for the performers and creating more space for sensitive communication in an ensemble (Bailey 1993: 60). Although allowing improvisation within a composition is all about the relinquishing of control on the composer's part, handing it over to the performers, people like Stockhausen used improvisation for more precise compositional aims, applying the performers' inventions in order to achieve certain predetermined ends or manipulating their choices through rather specific given instructions (Bailey 1993: 70 and 80). Today, rethinking the role and function of notation has led many musicians to the idea that a score can also be considered as an aid for possible musicmaking instead of being the sacrosanct and apodictic sediments of a composer's intentions (see e.g. Paul Craenen - Technology as Actant; Brian Ferneyhough The Mistake as Actant; Management - Richard Barrett).
[6] Whereas it seems clear that scholars who claim that improvisation gradually disappeared from most western performance practices are, in a way, right, it remained a vivid part of (pipe) organ playing throughout the centuries. From manuscripts dating back to the ninth century, one reads that the conventional manner to learn organ playing was at the instrument, suggesting that this was achieved by means of improvisation (Kruger 2008: 45). Sweelinck in the sixteenth, Buxtehude in the seventeenth, Straube in the nineteenth, the Paris school (Tournemire, Dupré, Messiaen, and several others) in the early twentieth, and musicians such as Zuzana Ferjencikova and Ansgar Wallenhorst in the twenty-first century have continued this tradition. Two reasons stand out in the explanations as to why there has been this perpetual connection between organ playing and improvisation: first, inventing voluntaries, interludes, and postludes during a church service has been and still is common practice for an organist even though there exists an enormous notated repertoire (Bailey 1993: 30). The second reason is that every organ exhibits its own individual characteristics: no two organs are the same; they are all tailor-made, without a single standardized sound and with infinite tone variations made possible by stop combinations. As a result, an organist interpreting a score is obliged to translate many more aspects than, for example, a violinist, as many parameters might not be reproducible on the particular instrument being played (Fidom 2008: 63).

[7] However, if - as I try to explain in, especially, parts 1 and 2a - improvisation can be considered as a "mode of engaging existing structures and constraints" (Landgraf 2014: 11) or the "reworking of something that already exists" (Benson 2003: 30) instead of inventing something completely new, it becomes all the more evident that improvisation can never be excluded from performance and compositional practices. Thinking of improvisation as a process of reiteration and alteration, it is no longer antithetical to stability and generality, expressed by strategies of fixation. To be able to hear certain alterations, certain adaptations, a certain freedom, playfulness, and inventiveness in a musical performance, requires a kind of recognition that ties that performance to the structure of iterability, to the known and the predictable. Hence, not only does improvisation derive from repetition and structure, notated music is in constant flux, as with every iteration, with every performance, certain elements are subject to change (Landgraf 2014: 34-5). Regarded this way, notated "classical" music can be described as "dynamically stable," and every performance as distinct from what came before, constrained by certain rules, but at the same time modifying them. In that sense improvisation can never be absent from music making, albeit sometimes arising as a form of negative freedom - being forced to solve unwanted problems instead of positively welcoming and promoting variation and unpredictability.

[8] According to a Dutch daily, Skip Sempé "reconstructed" Gilles' Requiem out of necessity, because the score contains many indeterminacies. This immediately raises questions about the relation between authenticity or historical accuracy and improvisation. In "classical music," being authentic in performance - understood as being historically informed about and respecting the intentions of the composer, the original sound of the musical work, and/or the circumstances under which the first 
performers played the piece - is extremely important; historical incorrectness is an almost cardinal sin, even though virtually every performer knows that a complete reconstruction is in fact impossible and, from an aesthetical point of view, often inexpedient.

However, what to do with a musical tradition in which it was not uncommon for performers to add embellishments, to make substantial changes to repeated parts, to omit certain notated sections, or to alter not only dynamic markings but also certain notes? How can present-day performers relate to a musical past, a past in which improvisation - again regarded here as a creative engagement with certain fixed elements - has never been absent? Or, to redirect this, can we think of Sempé's "reconstruction" as an (historically informed) improvisation on and with early eighteenth century French funeral music in which the intervening centuries unavoidably (though perhaps inaudibly) resonate? Regarding the underpinning of this $\mathrm{CD}$, one might need to add to the three strands of historical authenticity a fourth one, a personal authenticity, as Peter Kivy (1995) names it, so that historical accuracy and the style and originality of the performing musicians form an interesting and creative playground. This playground is in fact a field of musical improvisation as both reconstruction (historical authenticity) and construction (personal authenticity) contain elements of repetition and modification. As Roger Moseley writes,

If our efforts were no longer to be dictated by the fruitless pursuit of

'authenticity' in one of its many guises, we might instead take solace in the fact that our attempts to enter historical milieux of improvisation are destined to be at once overdetermined and unforeseeable. In this sense, we could understand such attempts as playful simulations rather than sober approximations, based on a subjunctive modeling of a process rather than on the mimesis of an imagined outcome. (Moseley 2013: n.p.)

Performing relatively roughly notated music thus leads to a complex feedback process, the sonic results of which rest upon contingent elements through the interpenetration of present decisions with past ones (Landgraf 2014: 146). And if we can define a musical work as consisting of (among others) all of its performances, the music on Rameau's Funeral can be regarded as an emergent and self-directing system, forming, informing, and transforming itself, using previous results as a base for further interpretations/improvisations.

\section{Alfred Brendel and W.A. Mozart - The Score as Actant}

[1] Alfred Brendel playing one of Mozart's piano concertos: mind, body (fingers), and environment (piano) creatively interact and mutually influence one another. Brendel affects and is affected by the instrument; sensory and motor systems link. Piano and pianist become actors within an ecological, self-organizing system, which in this particular case also encompasses biological, abiotic, cultural, historical, and aesthetic aspects; they are not so much predetermined from an outside, beforehand, but are immanent to the constitution of the system, of the performance itself. Said differently, piano and pianist stand in relation to each other through a process of codetermination, of mutual interdependency, established at the conjunction of the event, the performance, and the discursive.

Alfred Brendel playing Mozart's Piano Concerto in D, K 537, Coronation

Of course the system in which Brendel's mind and body as well as the piano are actants is far more complex: many more actants play a determining role in the performance of this piano concerto composed by Mozart, the latter being one of them. However, the actant on which I will focus here is neither directly visible nor audible in Brendel's performance: the score. Taking into account my claim that improvisation is an inextricable part of all music making (cf. "The Omnipresence of Improvisation"), the question becomes pertinent as to how the score relates to improvisation. More concretely, is Brendel improvising while performing Mozart's concerto, and what role does the score play in this? Posing this question in this context also implies that I do not regard improvisation exclusively as a strategy of radical transformation, of pursuing the unfamiliar, of radical innovation; rather, improvising may be regarded as being active, pro-active, and re-active in a specific situation without being led exclusively by unbreakable rules, rigid routines, and preestablished structures.

[2] Conventionally, the score is considered a fixed entity meant to facilitate the communication from composer to performer. The score represents the composer's ideas, encoded in a set of symbols that the performer should reconstruct and transform into sounds. In a lecture given at Darmstadt in 1960, Pierre Boulez neatly summarizes this causal chain:

A the composer originates a structure which he ciphers

$\mathrm{B}$ he ciphers it into a coded grid

$\mathrm{C}$ the interpreter deciphers this coded grid

$\mathrm{D}$ according to his decoding, he reconstitutes the structure that has been transmitted to him (Boulez 1986: 87). 
It seems compelling that terms like "deciphering" and "reconstituting" almost by definition exclude the possibility of improvising. Indeed, Boulez argues that, historically, the search has been for ever finer grids in order to ensure a maximum precision in transmitting the composer's message. This development has led several writers to the conclusion that improvisation almost completely disappeared from Western classical or high-brow music, at least since the (late) eighteenth century (Moore 1992; Bailey 1993; Sawyer 2008).

However, this is what Brendel writes in his book Music Sounding Out:

One look at the solo parts of Mozart's piano concertos should be enough to show the Mozart player that his warrant leaves that of a museum curator far behind. Mozart's notation is not complete. Not only do the solo parts lack dynamic markings almost entirely: the very notes to be played - at any rate in the later works that were not made ready for the engraver - require piecing out at times: by filling (when Mozart's manuscript is limited to sketchy indications); by variants (when relatively simple themes return several times without Mozart varying them himself); by embellishments (when the player is entrusted with a melodic outline to decorate); by reentry fermata (which are on the dominant and must be connected to the subsequent tonic); and by cadenzas (which lead from the six-four chord in quasi-improvisational fashion to the concluding tutti). (Brendel 1990: 6)

In other words, a performer of Mozart's music is required to do much more than simply reproducing what is written down by him (or by editors and pupils). From relatively modest interventions, such as filling in dynamics or ornamentation, to the "quasi-improvisational" elaboration of cadenzas, Mozart's scores require a certain amount of flexibility, creativity, and complicity from the performer in order for justice to be done to the compositions. According to Brendel "to do justice" means that the filling in of these voids should be (historically) informed: "Luckily, there are a good number of Mozart's own variants, embellishments, re-entries and cadenzas, and they give the player a clear idea of his freedom of movement" (Brendel 1990: 6) (Perhaps one should add that the player, simultaneously, becomes informed about his constraints, about the frame within which she is supposed to operate.) In short, Brendel, like every other musician, is somehow invited, invited by the very act of music making, to negotiate all kinds of musical contingencies.

[3] Hence, the task of the performer cannot be understood through the term "interpretation" alone, as this concept is linked too firmly to a representation of something that already exists. Neither is it appropriate to speak of "composing" here: not only does the result lack the decided character and a certain permanence we usually associate with compositions (Benson 2003: 24-5), it is also obvious that the performer does not have the intention to usurp Mozart here. Rather, one could say that Brendel does not merely perform Mozart's piano concerto but "cocomposes" it; he improvises upon that which he performs, as much is left to his own discretion. Also, his reading of the score cannot in the end result in some universal, verifiable, and demonstrable truth but is permeated by - what Derrida would call - a fundamental undecidability; there is a negotiable relation between the score and the performance event (Gould and Keaton 2000: 145).

Despite or thanks to this undecidability, Brendel is forced to make choices; he cannot not choose. He may be able to give (good) reasons - reasons based on various factors such as historical information, performance traditions, (contemporary) aesthetics, etc. - for choosing one performance action over others, but he is still compelled to decide. Not being able not to choose is for Bruce Ellis Benson the reason to describe performing as "improvising [...] on the music that [performers, $\mathrm{MC}$ ] play" (Benson 2003: 123). Musical notation can only give the performer a hint; she must constantly solve all kinds of "problems," employing her creative forces, thus escaping fixed rules and saving the music from petrification.

Is this indeed something that could be called improvisation? If one accepts that this performance practice contains, at the least, improvisatory elements, the concept of improvisation cannot be regarded as something done "on the spur of the moment" nor as a creatio ex nihilo (cf. "What is Improvisation (Not)?", section 3); rather, improvisation should be considered here as a kind of reworking. In fact, the whole performance tradition can be comprehended as a perpetual reworking on musical works. What musicians like Brendel do while performing is in an informed way improvising upon the past (Benson 2003: 103). In other words, Brendel's reworking of Mozart's "Coronation" concerto respects the past and, simultaneously, provides access to something new.

[4] What is the role and position of the score here? Perhaps it is time to get away from regarding the score as an authoritative or a coded grid, mainly designed to facilitate unidirectional instructions from composer to performer. Instead, the score can be understood as one possible element in the larger dynamic process of music making. Not only a vehicle for transmitting specific musical information, the score could be treated as an arena that allows for communication and interpretation between people, facilitating and articulating potential relationships between performers and an absent composer. As such, performers enter into the music more in the role of collaborators. The score is interactively connected to other actants in a concrete performing process, one element constituting and constituted by a network of many different actants; its position and its relations are neither fixed nor predetermined but depend on a specific material and discursive assemblage of human and non-human elements.

It is the score that instigates improvising, improvising as reworking; the fundamental and inevitable shortcomings of the score compel a performer to make her own decisions, to develop a personal authenticity in the space between the "text" and its execution, as philosopher Peter Kivy would have it. A performance is therefore not simply an interpretation (though it requires or involves one) or a presentation (though it requires that, too): it is another work of art (Kivy 1995: 119).

More or less applying the same arguments, the philosopher Roman Ingarden regards the score as nothing but a schematic formation: it prescribes the basic contours of a 
piece and allows the performer to fill in the rest: "The work is riddled with places of indeterminacy than can be eliminated only in the individual performances"

(Ingarden 1989: 90). Consequently, not only do performers have room for improvisation; it is also required, for there can be no performance without filling in these places of indeterminacy. A score is an underdetermination of a musical work an idea that becomes all the more evident in the use of lead sheets by jazz musicians. More interesting, however, is the idea that jazz and classical music should no longer be seen as ontologically different practices; its performers are in fact both acting within the same continuum of reworking, of improvising, of making choices based on all kinds of factors, forces, intensities, and information; the score is one of those information channels.

\section{Paul Craenen - Technology as Actant}

[1] The instrument used for tubes, a staged work for two performers from the Belgium composer-researcher Paul Craenen, consists in fact of four different elements: the first element comprises two microphones and two loudspeakers, each microphone turned towards one loudspeaker. Thus the loudspeaker can use the electric current produced by the microphone (that is, if it is sufficiently amplified) while, simultaneously, the microphone can pick up the air pressure waves emitted by the loudspeaker. Placing microphone and loudspeaker close enough to one another or using high volumes will create a process known as "acoustic feedback." Besides microphones and loudspeakers, the instrument comprises grey PVC tubes (normally used as drainpipes) of different sizes and with a choice of attachments. The sonic changes in tubes are the result of positioning the PVC tubes in various ways between microphone and loudspeaker. The tubes resonate the sound waves produced by the loudspeaker and - analogously to the relationship between the length of a flute and its pitch - force the feedback towards a frequency which is inversely proportional to the length of the tube. The overall amplitude increases in relation to the increased resonance of the sound. Finally, tubes not only consists of the sounds that result from altering or manipulating the acoustic conditions of the setup by two performers. Craenen has placed sensors in between the microphone input and the loudspeaker output that relay values, in this case volume levels, to computer software that processes the incoming sound according to the amplitude of the microphone signal. Each time the volume of the sound increases, a border is crossed in the software and a new preset is activated. As soon as the volume decreases again the preset switches back to the one belonging to the lower volume level. There are five levels of software preset changes, the fifth level being reached when a tube is placed in such a way that microphone and loudspeaker are directly connected to one another, thereby producing the loudest possible feedback levels for this set-up. Each level is processed live in a different way, applying techniques such as pitch shifting and granular synthesis to produce short melodies, clear pitches, fuzzy noises or rapid glissandi, depending on which software preset is activated (Eck 2013: 272-274).

[2] What takes place in tubes is a play between the acoustical and the digital. On the one hand, the size of the tubes (the larger the tube the louder and lower the sound), their distance to the microphone, and the option of changing their acoustic characteristics by closing one end, give rise to a field of possibilities, to an improvisatory exploration of playing this feedback system. On the other hand, the digital sound processing creates an additional alteration of these sounds. This aspect of the sound production is no longer related to acoustical laws but generated by the computer software on the basis of the acoustic feedback audio input (Eck 2013: 274). In other words, although the two performers are interacting with the microphones and loudspeakers, and although they are thus producing music through their gestures, it is relevant to acknowledge that the acoustic feedback sound used as input for a variety of sound processings is not immediately related to the gestures of the performers, but instead generating its own musical gestures. 


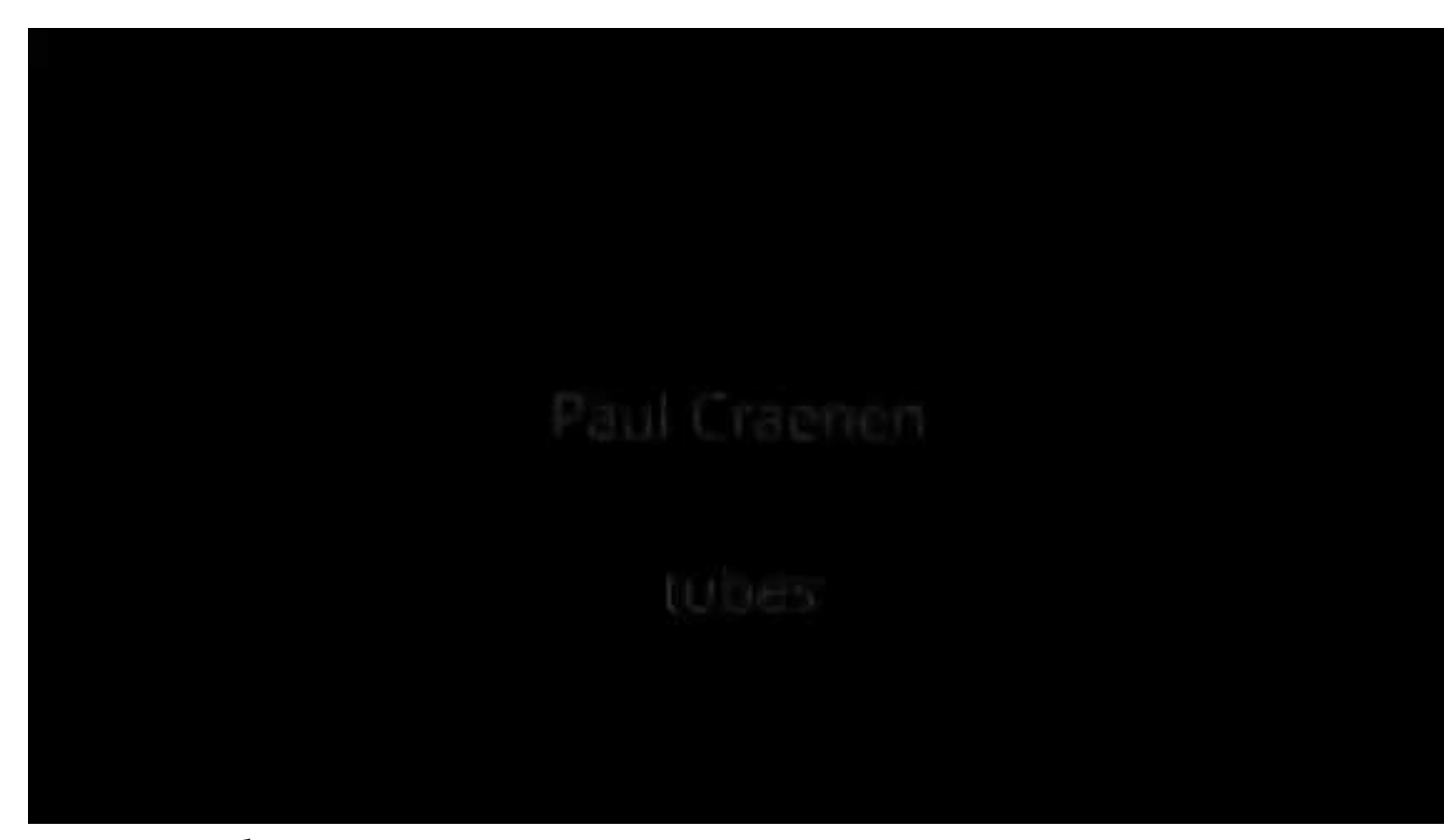

Cathy van Eck and Paul Craenen performing Paul Craenen's tubes

One could conclude that in tubes the performers are not necessarily the main actants, determining and controlling the musical outcomes. Instead, although the performers choreography is pre-composed and directed fairly strictly, the sonic result is mainly dependent upon the relative unpredictability of the feedback. A comparatively minor change in the position of a microphone, a loudspeaker, or a PVC tube might almost instantly lead to a significantly different sonic output (cf. "Mitchell Waldrop and the Field of Musical Improvisation", section 2). It is primarily the interaction between microphones, loudspeakers, tubes, and computer software, an interaction that changes with each performance, that creates a music which can be called improvisatory.

[3] In tubes, improvisation seems to dispose of its anthropocentric character. Indeed, one could even conclude from the above that the only actants who are not improvising are the two performers. However, this leads to the paradoxical situation that, although their actions are preordained and fixed, they are somehow forced to improvise during the course of the performance as their sound productions cannot be predicted in advance. The situational aspect not only determines the sonic results, it becomes part of the compositional process, as the instrument, instead of being a familiar device primarily applied to convey both Craenen's and the performers' intentions, is turned into an improvisational tool, a set-up coercing and encouraging the exploration of the unknown or the unexpected. Craenen designated salient aspects of the composition to be performer-supplied rather than composerspecified, thereby showing an interest in the generation of musical output in real time as a formal aspect of his work (Lewis in Fischlin and Heble 2004: 131). The improvisational character of tubes relies on the performer's pre-composed gestures and movements but also includes chance as a pathway to exploration and discovery.
Tubes is determined by the situational: the objective of the composition is not so much meant to accomplish a linear process from beginning to end, but, rather, to "unconceal" a multitude of sonic and performative gestures, potentially existing in the setting, the situation, the event.

[4] Although perhaps not the main actants in Craenen's work, one more aspect concerning the performers, which also contributes to the idea of complexity, needs to be mentioned. In Craenen's own words:

During the creation process of tubes, special attention was paid to the status of the performing bodies [...] The performer's identity oscillates between the identity of a dancer executing choreographic movements in a disciplined way, the identity of a musician playing the tubes in a close interaction with what he/ she hears, and the identity of a technician testing out sound possibilities and constructing a feedback instrument. (Craenen 2008: n.p.)

tubes thus plays with the identities of the performers: the pre-composed movements on stage turn them into dancers, building and rebuilding the PVC tubes makes them technicians, while their playing of the instrument gives them the identity of musicians. It is important to notice that these identities do not precede the musical event; they come into existence and are the effect of the interactions between the human and non-human actants operative during the performance of tubes. Said differently, these identity shifts are the results of the tubes assemblage (cf. "Bruno Latour and the Field of Musical Improvisation", section 3).

[5] In tubes, environment (acoustic feedback) and technology (computer programming) dictate the unfolding of the composition - which is at the same time an improvisation - and the musical outcomes. However, similar to the performers' identities, both environment and technology do not pre-exist the particular musical event. They too are produced and involved in the production of the event through constant interactions between all actants. Consequently, music/improvisation can never be considered as a static "object"; it takes place, it happens, in a dynamic open network in which musicians, objects, and environment are codependent and codetermine one another.

Unlike other improvisations in which musicians are deliberately seeking the unpredictable, tubes imposes this unpredictability on the performers, since the relation between their movements and the sounds is no longer the inevitable result of the mechanics of the instrument and thus, in principal, not anticipatable. In other words, the audible result is, to a certain extent at least, unrelated to the corporeal actions of the performers. Hence, they are challenged to react to sonic developments taking place outside of their direct control. Rather than considering this as a negative or impractical side effect, tubes thereby creates a situation of experimentation and creativity.

Performers and audience share a space of surprises, discoveries, and unexpected sonic results; they encounter the un-fore-seen (cf. "What is Improvisation (Not)?", section 2). 


\section{DJ Spooky - Records and Files as Actants}

[1] The practice of DJing doesn't take place behind closed doors; it is usually a live event in front of an audience. Therefore, it seems logical that interactions between musician and audience take center stage. However, more actants present themselves in this specific musical field.

Point of reference here is a short example/ sample of the scratch battle between DJ Spooky (Paul D. Miller) and Rob Swift, a former member of the turntablist group

The X-Ecutioners:

\section{play}

DJ Spooky vs. Rob Swift - "Scratch Battle" (Miller 2008)

[2] In the chapter called "Audience" in his book Improvisation, Derek Bailey gives the floor to Steve Howe, (former) guitarist of Yes, and Jerry Garcia, singer-guitarist of Grateful Dead. These two musicians express two almost radically opposed positions with regard to potential relations between improvising musicians and the audience. Howe prefers to stay on the safe side when playing in public as "there is a demand for it to be good" (Howe in Bailey 1993: 45); this "demand" seems to exclude too much experimentation for him. Garcia, on the other hand, is less inspired when playing privately: "the audience has gotten to be a homebase for us which allows the freedom to explore" (Garcia in Bailey 1993: 47). Garcia thus experienced the audience as impelling the musicians to take more risks, which is regarded as being exciting; it increases the desire to attend a live concert. Where on this continuum can DJing and DJ Spooky be positioned?

[3] "Improvisation. The knack of feeling a crowd and adjusting the music intuitively is one of the few things that elevates the DJ above an iTunes playlist" (Dan Leach 2011: n.p.). An improvising musician who is definitely, and perhaps necessarily so, open to the audience's reactions is the DJ; his success is at least partly dependent upon the positive feedback he gets from the people on the dance floor. One improvisational act of many DJs is therefore to work without a set playlist, thereby opening the possibility of letting the audience as well as the DJ's own intuition or informed listening - cognitive scientist Alva Nöe would call it "perceptually guided action" - influence the course of the concert. Sharing time and space turns the set into a co-performance between DJ and audience, a "participatory act of marking musical time with rhythmic bodily activity" (Iyer in Miller 2008: 276).

DJs like Paul Miller have returned the creation of music events into a constantly evolving act of performance. Working without a predetermined order of musical materials implies that the overall form, the large-scale structure, is not set in advance but "replaced with an alternative, modular approach, in which the meaning of the 
music is located in the free play of smaller constituent units [...] Thus, large-scale musical form emerges from an improvisational treatment of these short-range musical ingredients - that is, from the in-time manipulation of simple, modular components" (Iyer in Miller 2008: 278). While choosing a track or sound bite is certainly not completely unconstrained, but the result of a direct interaction with the environment - it needs to fit into the set, respond to the crowd, and match the way the event is unfolding - musical structure is executed "in time" as a result of using short sound samples that are de- and reterritorialized, that is, presented and transformed, combined and detached, re-edited and permeated with sounds and musical fragments from different contexts. Hence, the overall structure comes into existence through a process that can be called improvisational; this obstructs the possibility for both the DJ and the audience to perceive the entire event from a single, instant vantage point and can therefore at the same time be regarded as a musical correlate to experiential complexity. However, the concrete results of the DJ's work - like so many other musical works, especially when recorded - conceal or at least obscure the improvisatory nature of their genesis: the certainty that must be enacted in the moment on stage during the unfolding of the work fixes the unfixed; that is, it imposes an arbitrary structure upon the uncertain play of the DJ's aesthetical choices, actions, and reactions. The improvisatory dimension of DJing can be situated in a space framed by contingency of the moment of origination and the committing to particular structures (Peters 2012: 6).

[3] One of the most common techniques a DJ or turntablist uses is scratching, a technique also audible in Miller and Swifts track. By moving a vinyl record back and forth with one hand while optionally manipulating the crossfader on a mixer with the other hand, DJ Spooky produces distinctive sounds, generally dividable into two categories: one is a percussive sound derived from the rapid motion of the record, the other is a longer, recognizable fragment of recorded music or sound. In other words, Miller's DJing is often based on working sophisticatedly and precisely with found materials, with records and files that he can rip, mix, and edit. The sampling technique makes it possible to slice these objets trouvés into smaller temporal units and play them back in rearranged orders, sped up or slowed down, multiply triggered, or otherwise manipulated electronically. The DJ thus plays with the materials around him: every found record, fragment, or sound can be used and changed as she pleases; each performance combines basic sonic elements in new ways or puts them in a different order. However, in order to do so, the DJ must know her records and files extremely well to know exactly where and when to filter the mix, somehow similar to jazz musicians who must be familiar with a tune and its chord changes before being able to perform it. While scratching can be regarded as an improvisation within a work, sampling and reusing already existing materials move improvisation to a space between works: improvising within a DJ setting becomes a process of (re)combining.

[4] Implicitly, DJing questions several - often unspoken - assumptions that are operative within discourses around (free) improvisation. The specific interactions between musician, technology, materials, location, and audience, together creating a DJ event, put the concept of improvisation partly in a new light.

For example, the DJ deconstructs the binary between composition and improvisation. Taking found sounds and placing them, each time differently, alongside each other, is simultaneously an act done in the course of performance ("improvising") as well as building a new and large structure with these raw materials or constitutive elements ("composing", literally defined as "putting together" from Latin "com-ponere") (Miller and Iyer 2009: n.p.). The DJ improvises while composing and composes through improvising, thereby neglecting the two concepts as opposites but instead merging them seamlessly.

Improvisation in relation to a DJ set certainly also concerns the formal choices that are made: it includes the mechanism "by which one form is chosen rather than another within a contingent context, without absolute criteria, where all outcomes are thus intrinsically uncertain" (Peters 2012: 2). The final result could always be other than it is. However, the decisions that have to be made during the performance and which determine the unfolding of the work are not so much formed by a fundamental uncertainty, let alone by trial and error; they happen, rather, in a space of contingency. Formulated differently, the space of fundamental undecidability requires and contains instants of decision, even from moment to moment, in order to simply produce a work. The countless hours of finding and selecting raw materials, of sampling and editing, of practicing scratching and mastering hard- and software all of this work and disciplining is necessary to the extent that it allows the DJ, at the decisive moment, "to begin and sustain a work with a degree of certitude that belies the uncertainty of its origin and gestation" (Peters 2012: 6).

DJing replaces the ensemble - the group of musicians gathering and interacting on stage, the sort of community among which improvisation happens - with more global networks of information, thereby offering the possibility to rethink the idea of a live event. As Miller acknowledges "what ends up happening with music in the age of cybernetic replication is that ideas of authenticity are challenged. You need to think about how the root word of 'replication' is based on the term 'reply'. It's a response" (Miller and Iyer 2009: n.p.).

Although the scratch battle between Miller and Swift can easily remind us of the sax battles that sometimes occur at jazz festivals, Miller interacts with and responds perhaps first of all to his archive of records and files. Just as the DJ has become a musician, the turntables and sampler have become musical instruments, and the archive the musical building blocks: records and files have become non-negligible actants in this particular field of musical improvisation. 


\section{Fred Frith - The Instrument as Actant}

[1] The cliché tells us that a musician should be one with his instrument in a manner similar to Merleau-Ponty's analysis of the blind man using his cane: “The blind man's stick has ceased to be an object for him, and is no longer perceived for itself; its point has become an area of sensitivity, extending the scope and active radius of touch, and providing a parallel to sight" (Merleau-Ponty 2005: 165). A musical instrument, too, is often regarded as a direct prolongation of the human body (Pelinski 2005;

LaBelle 2005). Instrument and player must harmonize; the musician must grow into the instrument, while the instrument functions as a kind of interface, playing the role of mediator of musical ideas; it serves as a partner in the unfolding of musical expression. One could even state that the instrument should not be overtly present in a performance, in much the same way as loudspeakers are, to a certain extent, absent or inaudible while playing a recording. As Pierre Schaeffer (1966: 43) remarks, "instrumental activity, the visible and first cause of every musical phenomenon, has the distinctive quality that first and foremost it tends to cancel itself out as material cause." Focusing on the traits of the sound itself, independent of its cause and of its meaning, one hears a melody or a rhythm rather than the actual instrument that produces it, a mode of listening Schaeffer calls reduced listening.

If complexity can be regarded as sets of relationships between parts or the play between parts of a system, the most obvious relationship in a musical improvisation is the one between a musician and his instrument. The most salient interactions during an improvisation often take place between these two actants. In order to come to an interesting improvisation there has to be, first of all, a "resonance" between the body of the musician and the body of the instrument. The musician needs the instrument to sound the music and, conversely, the instrument cannot sound without the body of the musician. Due to this close connection, musicians often appear to be one with their instruments. Subject and object are integrated, musician and instrument become a single body "driven by a choreography of movement and energy, precision and improvisation, skill and its reciprocal gestures" (LaBelle 2005: n.p.).

[2] In Sound Ideas, philosopher Aden Evens proposes an additional and also critical view to this conventional idea of the interaction between musician and instrument forming a kind of symbiosis. According to Evens, the relationship is not one of unproblematic resonance but constantly permeated and challenged by a friction, or, as he calls it, a resistance.

The instrument does not mediate, does not stand between the musician and the music. Neither does the instrument disappear, for it remains integral to the music, offering itself to the musician. What sort of offer is this? It offers to the musician a resistance; it pushes back. (Evens 2005: 159) 
The instrument cooperates by resisting instead of endeavoring to make an immediate contact between musician and music possible. "Music does not result from the triumph of the musician over the resistance of the instrument, but from their struggle, accord and discord, push and pull" (Evens 2005: 160). This struggle, this resistance, this strife, is mainly of a physical nature, deriving from the instrument's materiality and its interaction with the musician's flesh.

In my opinion Evens' addition should not be regarded as creating a fundamental opposition between resonance and resistance. I'd rather think of the latter term as a further deepening of the relation between musician and instrument. Evens' ideas on resistance are not applicable to beginners but address professional players perhaps mainly improvisers - who attempt to explore unknown possibilities of their instruments. The relation between or transition from resonance to resistance has to do with ideas about control, about being (un)able and (un)willing to master the instrument. In Amplified Gesture, a documentary by Phil Hopkins about free improvisation, saxophonist Evan Parker explains his ambivalent and heterogeneous relation to the instrument, somewhere between resonance and resistance, through the concept of biofeedback:

You couple yourself to that instrument and it teaches you as much as you tell it what to do. So you're sensitive to [...] how it's responding to your efforts to control it. By hearing it, the way it's feeding back to you, you learn to control it better. So it's a very dynamic and very sensitive process [...] And the instrument at the same time seems to be giving you additional information. So there are things that you have under your control, but every so often something will go wrong. You'll lose control. In that moment you are given an opportunity to learn something else that the instrument can do [...] The saxophone has a destiny, has a will, and it has a set of intentions in its relationship with you, and you start to find it difficult to distinguish yourself and your intentions from the instrument's intentions, or let's say I've found it difficult to do that. (Parker in Hopkins 2009: n.p.)

Drummer Eddie Prévost agrees with Parker. According to him the aim should not be to "command" the instrument but to "explore" and to "engage" with its materiality. How it responds should dictate the further development of the musician's relation with that instrument (Prévost in Hopkins 2009: n.p.). No-input mixing board player Toshimara Nakamura adds that he is often just following the machine, to which he is only giving a helping hand, thereby creating a more reciprocal balance between himself and the instrument (Nakamura in Hopkins 2009: n.p.). The interaction between musician and instrument is always already permeated by a certain amount of contingency: the uncontrollable is part of any instrument's identity.

Nakamura's remark can thus be extended to a process of oscillation between "control" and "forsaking control," happening in and through the resonances and resistances between the musician's mind (intellect as well as intuition), her bodily activities (controlled by the mind but also operative on a so-called unconscious level, a thinking- through-the-body), and the instrument's idiosyncrasies, all three continually engineered by the processes in which they are engaged. (Both musician and instrument exist only in relation to the interminglings they make possible or that make them possible.)

[3] Two of the main actants in Fred Frith's solo performances are the musician and the instrument, and their interaction takes place on the brink of resonance and resistance. There is an almost constant strife or friction between the two. Frith affectionately torments the guitar, e.g. with all kinds of objects (a rope, a stick, a paint brush, a scarf - other actants in this particular musical assemblage), and the instrument answers with sounds that are not always immediately recognizable as proper guitar sounds. With every performance Frith re-explores his instrument, elicits unknown sounds and playing possibilities, in short, searches for its resistances. And, of course, in order to be able to do so, Frith has to know the instrument extremely well; in that sense, a resonance is always needed, too. His (extended) techniques encourage the most effective meeting with the instrument's resistances; they evoke experimentation and place the instrument's resistances in contact with his own body. The guitar, for its part, constantly poses problems to Frith, thereby holding within itself a permanently creative potential, as these problems are never solved once and for all (Evens 2005: 160-1). Hence, for Frith the guitar becomes a site of experimentation.

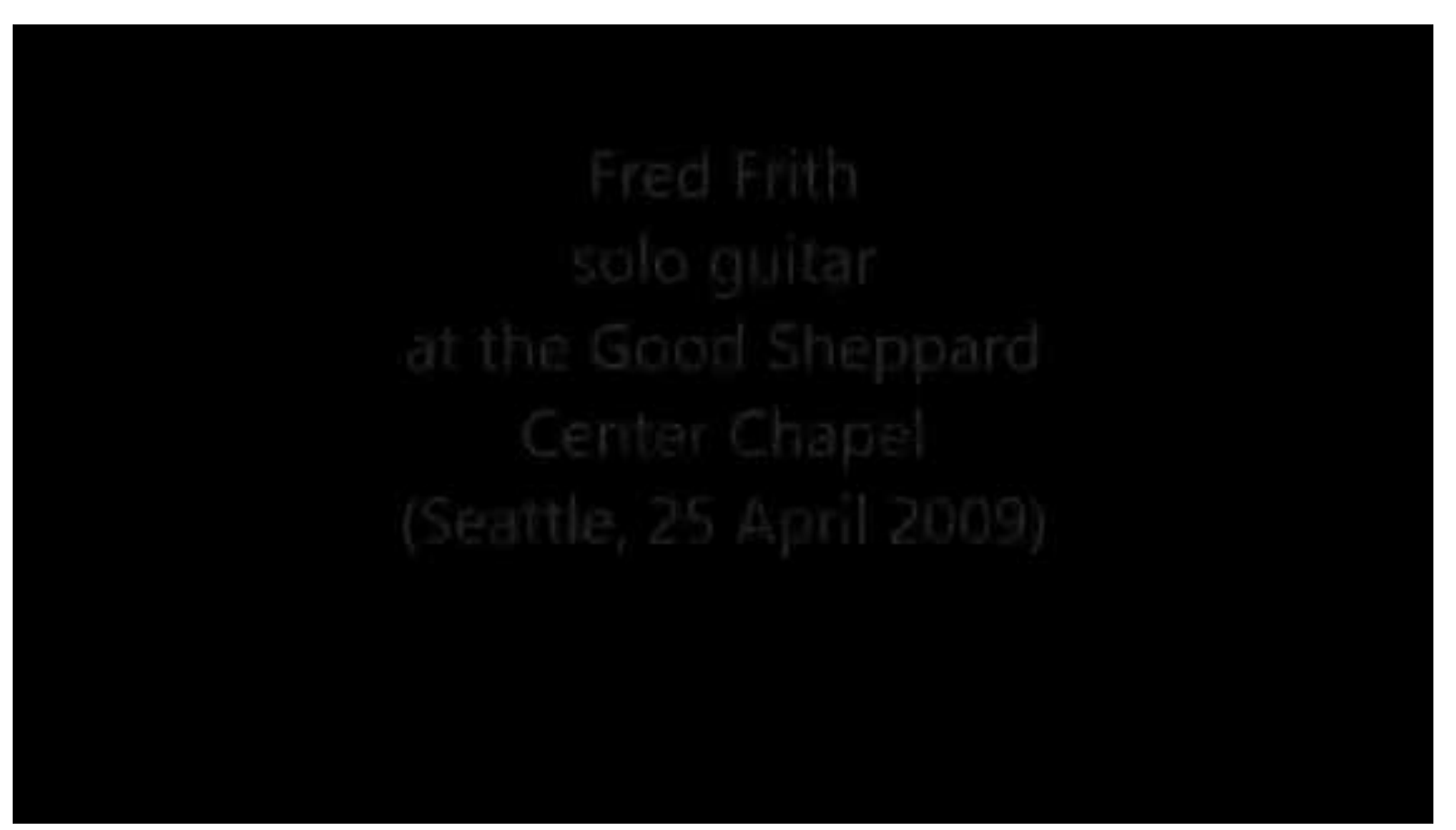

Fred Frith - solo (The Good Sheppard Center Chapel in Seattle, 25 April 2009)

According to Evens, a more interesting and creative improvisation might benefit from increasing an instrument's resistance; altering the instrument provokes the unforeseen (Evens 2005: 153). In other words, a musician basically has the possibility to apply two different strategies to enlarge the field of virtual interactions, both of 
which are used by Frith: "defamiliarizing" the instrument (e.g. by detuning it or by using effect equipment) or "defamiliarizing" the playing techniques (e.g. by using extended techniques). However, it is at the same time clear that Frith is used to the instrument and the instrument is used to its player. Frith's solo improvisations thus emerge between skill and curiosity, between technique and (de-)learning, between contemplation and operation, between control and uncontrollability.

[4] However, how precise do I need to be when describing the interaction between musician and instrument? How far do I need to go in specifying the actants that seem most prominent here, in the Frith-guitar assemblage? Not to arrive at a form of reductionism (dissecting a complex event or object into its smallest units) but to do justice to the complexity of the performative forces determined by their interactions. For example, it is Frith's performance that turns the concept of "the instrument" into a category that is far too generic. Besides the guitar, amplifier and effect equipment must also be included, as they co-determine the interactions to a large extent. And Frith is not simply playing the guitar: he plays the strings, the body, the bridge, the neck, the control knobs, the pick-ups; he plays them, using plectrum, capo, tremolo stick, etc. In other words, Frith makes me aware that the guitar consists of many elements which themselves are constantly interacting when touched by the musician's body. The guitar is a complex system already in itself.

And what about the human body? Frith uses his arms, hands, fingers, legs, feet. Sweeping arms, slapping hands, plucking fingers, stretching legs, tapping feet, humming voice, nodding head - all parts work together in fluid motion (cf. Gregory Bateson and the Field of Musical Improvisation, section 1). As Varela, Thompson, and Rosch write in The Embodied Mind, "a hand is an agency of which the fingers, palm, etc. are agents; it is also an agent of the body. These are different levels of description; neither agent nor agency would exist without the other" (Varela, Thompson, and Rosch 1991: 119). Much more differentiation is needed to describe Frith's bodily relation to the instrument. Besides, the body is not just the physical object needed to make an interaction between mind and music possible, any more than the instrument is: Frith thinks with and through the body, and many of the bodily interactions take place outside of his brain's direct control.

And the mind? The mind's agents are the nerve cells and

each nerve cell sends out thousands of random filaments that connect willynilly to thousands of other nerve cells. And yet this densely interconnected network is obviously not random. A healthy brain produces perception, thought, and action quite coherently. Moreover, the brain is obviously not static. It refines and adapts its behavior through experience. It learns. (Waldrop 1992: 157-8)

This general complexity of the brain can be complemented by neurological research on brain activity during improvisations. According to neuroscientist Charles
Limb, different things happen in the brain while playing memorized and overlearned music and while improvising. In the latter case, the lateral prefrontal cortex (associated with self-monitoring, introspection and working memory) is "turning off," while the medial prefrontal cortex (associated with self-expression) is "turning on." Limb hypothesizes that in order to be creative, the brain has to shut off the part of the brain that is self-inhibiting. In other words, creating novel ideas requires that the musician not censor himself or be afraid to make mistakes (Limb 2010: n.p.). What Waldrop and Limb make clear here is that talking about the brain as a homogeneous entity does injustice to the enormous complexity of interactions taking place there, especially while improvising.

An instrument has a presence, doesn't it? I've got about five guitars and they're totally different. Their presence is completely different. The character's different. Nobody might notice it but I would play differently on each of them. (Derek Bailey in Toop 2004: 212)

[5] "The body moves differently when incorporating the musical instrument, while the instrument implies the body, presupposing the individual by its very design, where arms and legs are given new fittings, and the imagination is driven by the material potential of strings and their harmonics, objects and their textures" (LaBelle 2005: n.p.).

There is a complex feedback system, a perpetual circular causality between Frith's mind and body and the guitar; musician and instrument determine each other through reciprocal structuring and selection. The guitar is more than a body with neck, strings, knobs, and pick-ups; it takes on a specific musical identity in interaction with Frith. Conversely, it is not simply dependent on his playing, nor an extension of his body; it also shapes his playing and has a voice of its own (Borgo 2005: 57). The resonances and resistances that come into existence as a result of the interactions between Frith and his guitar justify the idea that Frith plays the guitar but also that the guitar plays Frith. 
Edwin van der Heide - The Audience as Actant

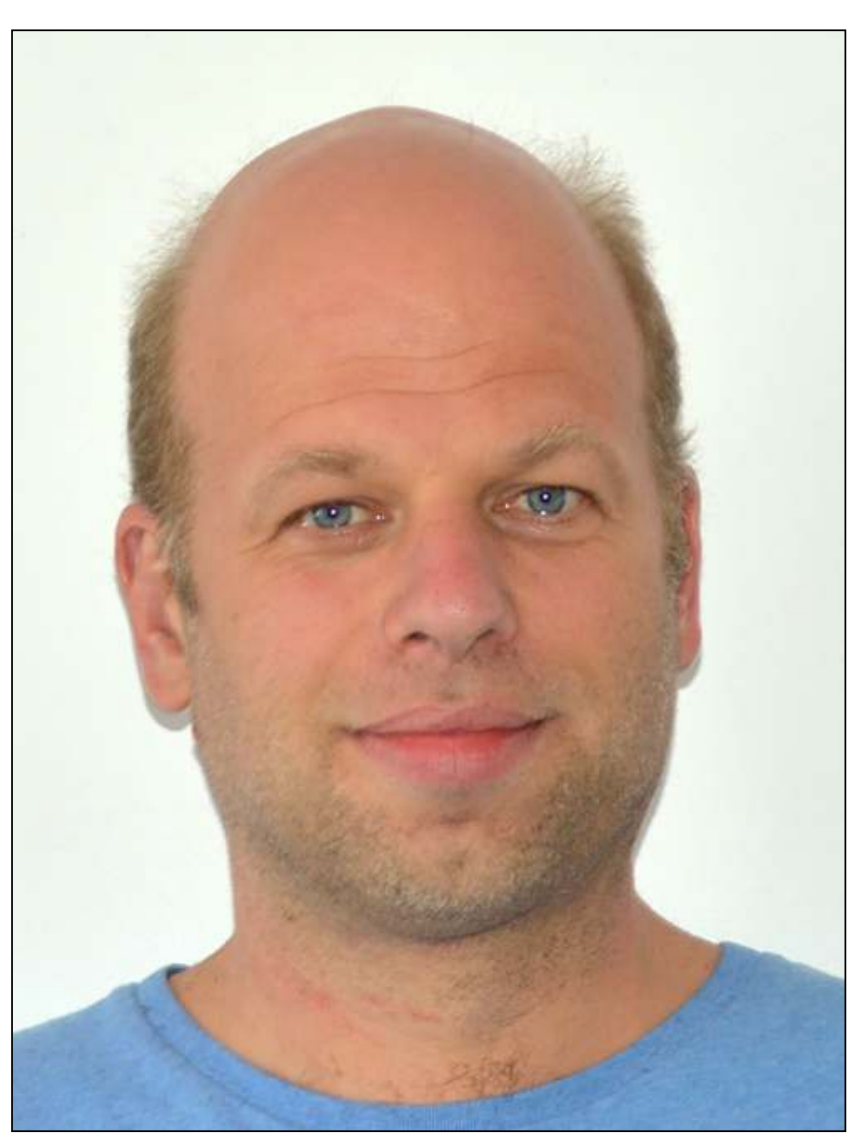

Edwin van der Heide

[1] In my reflections on the concerts by Yo La Tengo and the Taku Sugimoto Quartet it became clear that often the audience is an important actor, manipulating and even co-executing a musical improvisation. However, in both cases there remains a split between audience and musicians. The audience's influence on the music can only occur through the musicians and their instruments. Ultimately the performers decide when and how the audience can affect the music; it is with the help of the audience that the musicians improvise.

But what happens when there are no musicians or, better, when the audience is no longer just visiting a situated artwork but, simultaneously, the performer of that work? What happens when the audience becomes part of the artistic process, the work of art, and even the instrument through which the art work comes into existence? In my opinion, this is exactly what takes place during a soundwalk, defined by Andra McCartney as "the exploration of a location through walking, in which listening becomes the primary mode of attention" (McCartney 2012: n.p.).

Of course, soundwalks are frequently planned in advance, pre-composed and conceptualized, as if they are musical compositions. Although the soundwalker can often traverse the space on his own will, time, and speed, she is not completely free: 
the soundwalk composer leads her in certain (sonic) directions. Nevertheless it is my suggestion to consider the act of walking while listening to a sonic environment as an improvisational activity. The mobile context of soundwalks and the motions of the soundwalkers generate possibilities for creative (improvisational) listening and interacting (McCartney 2010: n.p.).

[2] Edwin van der Heide's Radioscape (Radioscape I, 2000; Radioscape II - IV, 2004-2007) consists of fifteen custom-developed radio transmitters that are distributed over a part of a city. Each transmitter conveys one layer of a "metacomposition" made by Van der Heide; these pre-composed layers slowly change over time and eventually repeat after 4-10 minutes.

The audible reach of a transmitter ranges from 50 to 200 meters. The transmitters are placed in such a way that one can receive about two to five different signals at the same time.

In order to receive a signal, the "audience" uses a receiver, a device with two different antennas mounted on top of it, a loop antenna and a vertical antenna. Each antenna has its own directional sensitivity pattern, which creates an effect similar to the working of a stereo microphone. The output of the receiver is connected to a stereo headphone in such a way that transmitters to the left of the antenna will be heard more on the left side of the headphone and transmitters to the right side of the antenna will be heard more on the right side. The receiver should be held with two hands and moved and rotated continuously, thus making it possible to receive more than one signal simultaneously, to mix the signals coming from the individual transmitters, and to directly change the stereo image.

\section{RADIOSCAPE I V}

Edwin van der Heide - Radioscape
Participants are invited to explore and interact with Radioscape by navigating through the urban environment, thereby being able to experience different mixes of the transmitted signals. Not walking and not moving the receiver will give a participant the opportunity to focus primarily on the slow changes of the composed layers that can be received on a particular spot. Standing still but moving the receiver will lead to a reorientation in the field of received signals, resulting in new experiences of the sonic (in combination with the visual, tactile, and olfactory) environment. Walking will bring the participant closer to other transmitters while distancing her from the ones she just had contact with; certain signals will decrease or disappear while other signals will fade in or become louder.

[3] Although Radioscape also comprises Van der Heide's meta-composition, it is not a composed piece with a predetermined structure. Rather, it could be considered as a partly pre-organized system that needs a participant in order to activate it, to realize and to perform it. The sonic events that can be experienced depend directly on the actions of the participant; they rest on an interaction between place, time, and the soundwalker's movements. By navigating a region of a city, the participants generate their own sonic order, combinations, and timing of the art work. While or through listening, they alternate their focus and the way of interacting, and acquire the possibility to assign new meanings to a place. This is further enhanced by the fact that the antennas of the receiver are also picking up other electromagnetic signals besides those coming from the transmitters: neon lights, computer controlled street lights, security systems, etc. all radiate sounds that can unexpectedly occur on certain places and blend with Radioscape's "own," pre-composed sounds. Furthermore, buildings might behave as additional conductors for the radio waves; approaching or moving away from a building thus also affects the perceivable soundscape.

[4] Through technological inventions, developments, and applications the soundwalker, passive listener and active performer at the same time, becomes an important and even dominant actant in the realization of this art work. Said differently, what is important in Radioscape is the interaction between technology and audience, while actants such as architecture, artist, and pre-composed sounds contribute to the complexity of this sonic event. Radioscape creates a situation where the listener, by walking and handling the receiver, can intervene directly in the sonic potentialities and actualities of the environment.

In Saying Something, Ingrid Monson notes that the ongoing process of decisionmaking that takes place in an improvisation relies to a large extent on the ability of the musicians to listen closely. Responding to musical opportunities or correcting mistakes requires an active and careful listening attitude. Radioscape's participants should actually display the very same qualities: choosing, mixing, walking, and reflecting are all based on and informed by a listening engagement with the sounds of the transmitters as well as those unexpected sounds coming from interactions with already-present electromagnetic signals and buildings. As Andra McCartney remarks, "listening in soundwalks needs to be active, imaginative, dynamic, and 
attendant to the requirements of the moment, similar to the listening of improvising musicians" (McCartney 2010: n.p.). Perhaps it is even justified to state that

soundwalkers are improvising musicians, potentially changing the whole further sonic process by a relatively small intervention, such as moving the receiver. And this characteristic, in which future developments are fundamentally unpredictable and emerging out of the interaction of many forces, each leaving its indelible trace on the course of events, also connects soundwalking to complex systems. A minor variation in the action of a Radioscape participant may cause a chain of events leading to large alterations in the way the art work will finally unfold and present itself to the listener. Soundwalking is a way of improvising, as each movement can imaginably produce significant modifications in the experience of the sonic environment. Radioscape can be regarded as a complex system in which many actants - among them technology, architecture, electromagnetism, and soundwalkers - interact and influence one another.

\section{Heiner Goebbels - Theater as Actant}

[1] Somewhere halfway through the recording of an interview with Heiner Goebbels - inventor, composer, and director of the music theater production Schwarz auf Weiss [Black on White] - he makes himself very clear: "Everything is predetermined. There are a few improvisational parts but they are very clearly defined in their characteristics." And, stressing this point once more: "Everything is planned in detail" (Goebbels 2008: n.p.). Schwarz auf Weiss is not an improvised work; that much should be evident, even though it contains noticeably marked passages where the musicians are allowed to improvise, albeit within patently set limits. One obvious example would be the saxophone solo played against a background vamp by wind instruments:

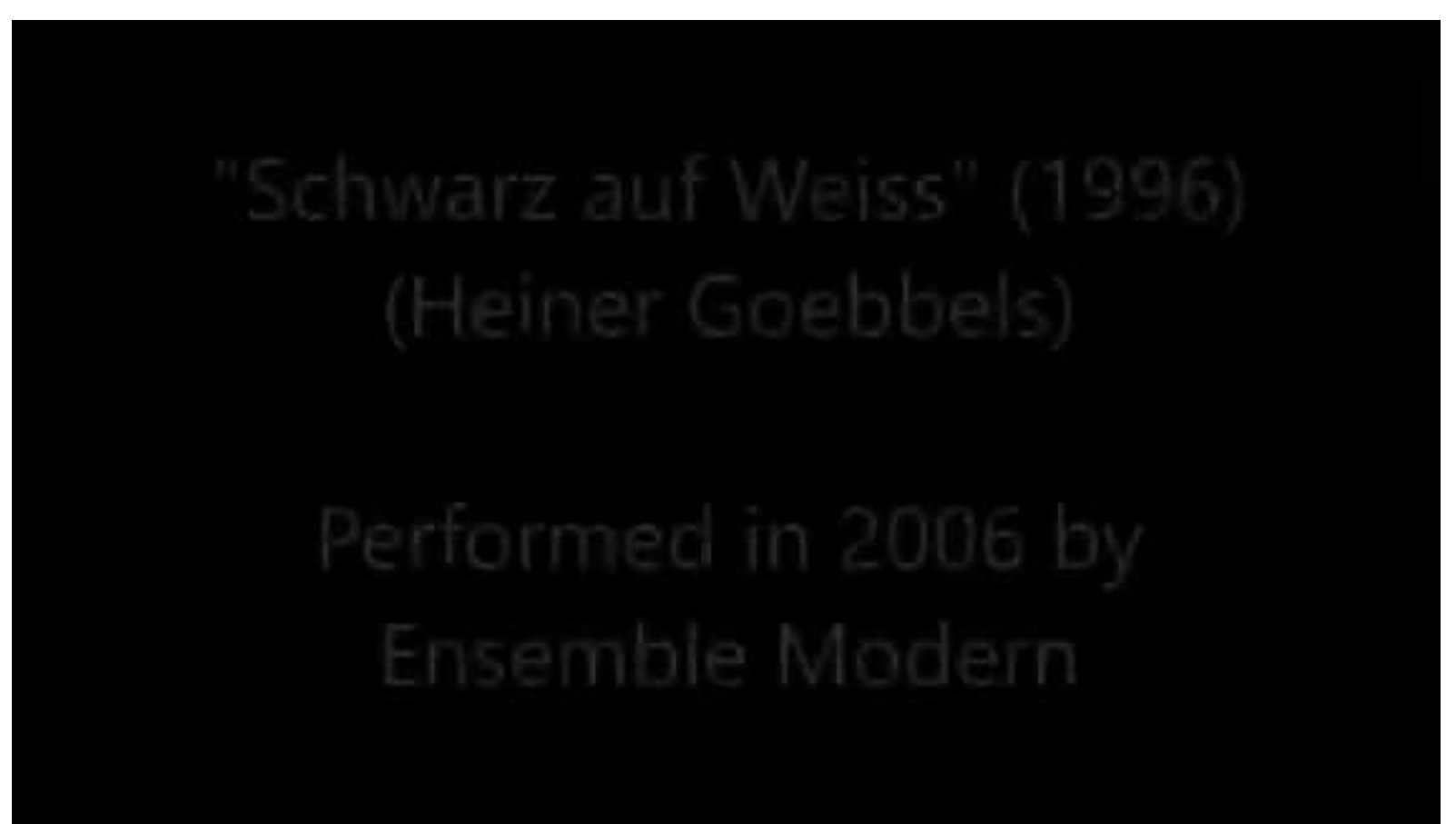

Heiner Goebbels - Schwarz auf Weiss (sax solo)

According to Goebbels, many other passages in Schwarz auf Weiss may perhaps sound like they are improvised, but they are in fact meticulously notated. (This aspect reminds me of Frank Zappa's earlier works, especially, in which ostensibly improvised parts appeared also to be completely written out.)

As is so often the case, notation and improvisation are constructed as opposites here, seemingly excluding one another, each making the other impossible. In this theater piece, improvisation is only allowed within the strict constraints of the composed superstructure.

[2] In my opinion, however, Schwarz auf Weiss permits the spectator-listener to reflect on another idea concerning the relation between notation and improvisation. First of all, as I make clear in, for example, the text on Alfred Brendel's playing of Mozart's 
piano concertos (cf. Alfred Brendel and W.A. Mozart, section 2), notation always already derails in and through a performance: playing a score inevitably implies also adding elements to a performance that cannot be (sufficiently) notated. The "same" of the score starts to merge into the "other" of the performance practice. As Belgian cellist Arne Deforce writes,

it is about letting enter into a performance what is derailed within the text, about thinking improvisation within the notation itself. The musician will unravel and decipher the notation and its ambivalent components; he will let them be integrated as improvisation in the act of performing. Creating here means taking calculated risks, destruction and release, giving shape musically to the ingenious chaos of writing. Playing the score is to let this ingenious chaos of writing return within the performance, as unlimited as improvisation. Only as such does improvisation become the terrible force in which the true potential of writing can assert itself. Here, notation and improvisation are each other's limit. They are the double-faced head of musical reality: the Same of the score, which is differing in the performance, and the difference, which makes itself

heard while it "becomes difference." (Deforce 2012: 44-45, my translation)

[3] More specifically relevant within the context of Schwarz auf Weiss is that notating the various movements and actions of the musician-actors does not automatically imply that the composer - used in the broad sense of word as someone who puts things together - can control the sonic output.

Schwarz auf Weiss is music theater, which means that the musicians - here the members of Ensemble Modern - are required to do things that do not usually belong to their core activities. Goebbels asked them, for example, if they were prepared to

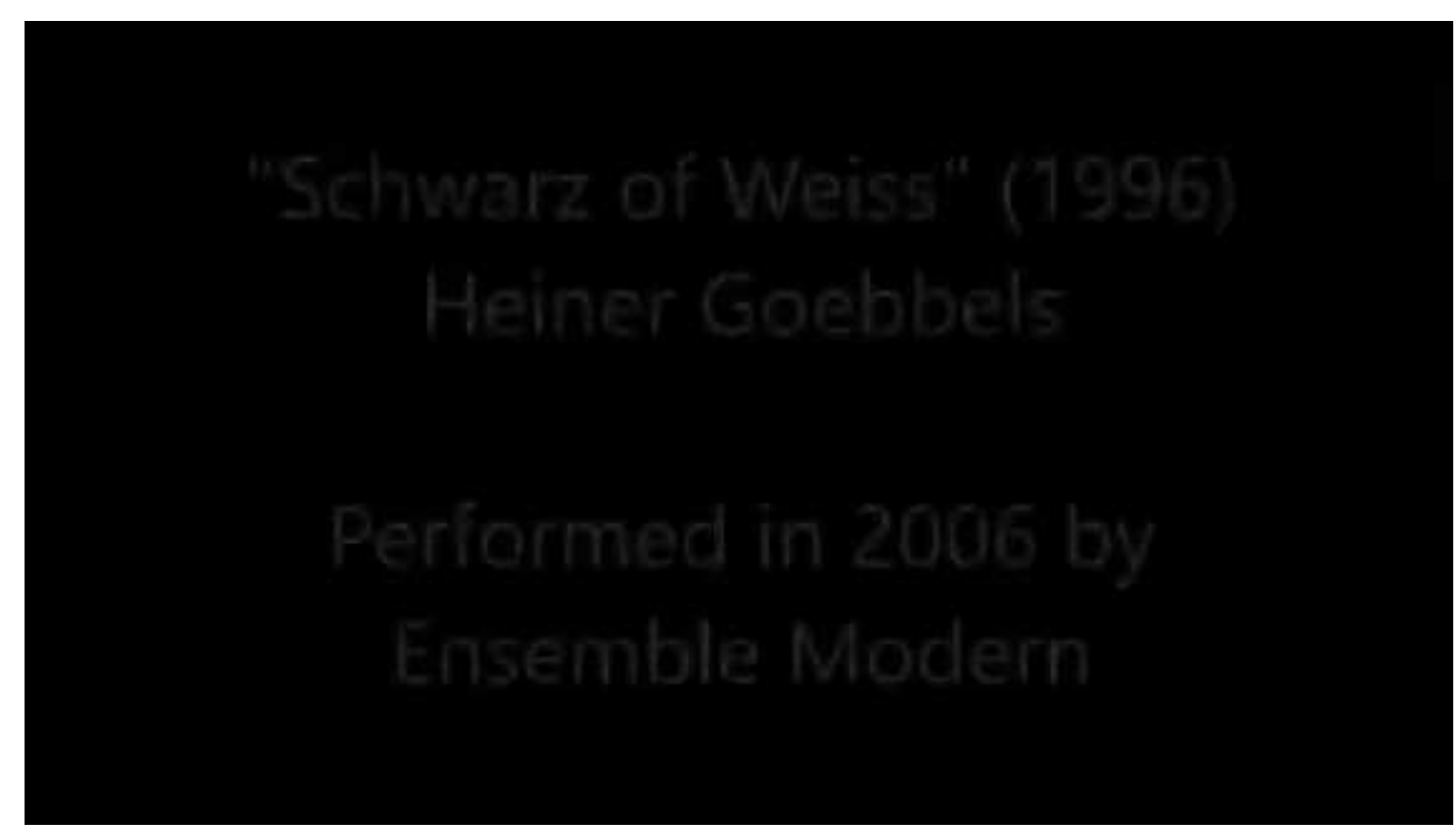

Heiner Goebbels - Schwarz auf Weiss (benches) perform on instruments that they did not learn to play in order to overcome sheer virtuosity. This breaking, perhaps only in order to achieve certain theatrical effects, of one of the most normal and accepted conventions in (especially classical) music making - musicians play only instruments which they, more or less, master - will, in one way or another, affect the sonic results during the performance, meticulously notated or not; unexpected noises can be anticipated, as musicians playing instruments which are unfamiliar to them are almost by definition not in full control. Besides, while playing those rather unknown instruments, the performers were sometimes requested to walk and to climb over benches or other obstacles, which of course also hampers controlled musical gestures.

[4] Besides the (musical) activities mentioned above, other theatrical aspects of Schwarz auf Weiss include rolling a big drum, throwing dice, moving checkers, playing tennis, setting up things while other musicians are already playing, and throwing balls towards a drum or steel plate. The balls may miss the steel plate, hit it right in the middle or more toward the edge - these possibilities all have their influence on the sonic results. Perhaps one could identify this as non-intended improvising within intended acting: in any case it redirects our understanding of sound generation by highlighting the accidental, the chance event, and it changes our perception of material objects whose bodies hold within themselves a universe of potential sounds.

The staging, the composing, the directing, and the production may be completely planned and structured; the very concrete sonic results will remain indeterminable to a certain extent. These indeterminable sounds, often stemming from the theatrical elements of Schwarz auf Weiss, but actually part and parcel of performing per se, blend with the composed parts of the piece; they are the non-notatable, improvisatory dimensions of the performance, inevitable effects of music making. In other words, what afterwards is excluded in and through Goebbels' verbal discourse, is irrevocably and consciously brought in during the music-theatrical acting; what his words try to deny is in fact an inextricable part of performing, and especially so with regard to the performative acts that Goebbels requires from the performers. Although the macro-structure of Schwarz auf Weiss can certainly be repeated, differences on micro level will turn each of its performances into a singular event. The musicians are improvising without (intended) improvisation; their (theatrical) actions may not alter the superstructure of the piece, yet they certainly affect the sonic outcome and thus give access to the un-fore-seen. 
[1] Keith Jarrett's solo piano concerts are often referred to as "spontaneous compositions": improvised, but sounding almost as if they are pre-composed (Carr 1991; Ake 2002; Petsche 2009). In a sense they can even be regarded as free improvisations as Jarrett asserts that he begins with a tabula rasa, creating textures, rhythms, themes, harmonic sequences, and structures from scratch. Prior to his concerts he often lectures the audience on the risky nature of his performances, emphasizing the notion that they are prone to failure, as he has no idea where the music will go (Strickland 1983: 90). However, contrary to the prevalent idea that improvisations are shaped largely according to the intentions and abilities of the musician, Jarrett designates another origin, another source. Before starting to play, he tries to empty himself of self-consciousness and preconceptions, allowing the music to flow through and out of him, thereby aspiring to a "rapt state of total inspiration in which the self is forgotten" (Carr 1991: 67). Often he sits still at the piano for a number of minutes in order to reach this state of "emptiness," as can be observed at the beginning of his 1984 Tokyo solo concert.

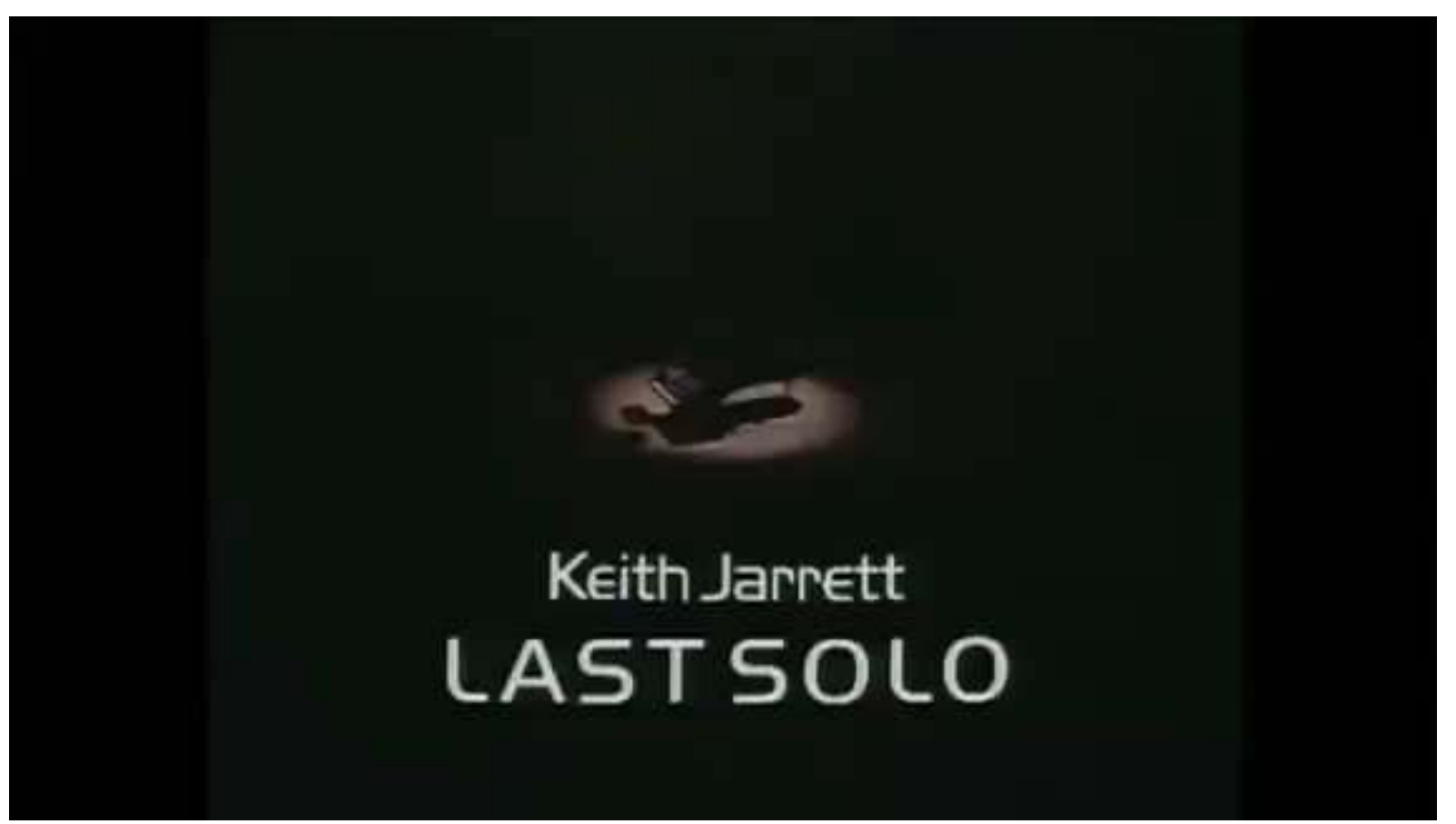

Keith Jarrett - Last Solo (Tokyo '84 \#1 - the beginning of the concert)

In interviews and album liner notes, Jarrett describes this preparatory process, void of observable physical activity, in terms of an ability to "turn off the thought process," to "channel" or "surrender to" a source of inspiration, which he ambiguously terms the "ongoing harmony," the "Creative," or the "Divine Will" (see for example, the liner notes of Bridge of Light, Solo Concerts, and Concerts). As Johanna Petsche writes, "by stating that he 'surrenders' to an eternal harmony, he implies that his improvisations are not personal expressions but are, instead, objective forms of 
art that convey cosmic truth" (Petsche 2009: 154). Jarrett regards himself as a kind of medium, transposing transcendental and extra-personal energies to the piano. As he writes in the liner notes of his recording of J.S. Bach's Das Wohltemperierte Klavier Buch 1 , "the music does not need my assistance." Improvisation is for Jarrett a spiritual process; he reaches into a realm beyond himself for inspiration and aims to connect with a cosmic principle rather than presenting a personal aesthetic. He tries to convey this to his listeners in a pure and unadulterated way (Petsche 2009: 156).

The music that results from this circumventing of the direct control of Jarrett's mind contains a frequent use of prolonged ostinatos - "mantra grooves" as he calls them structured around highly rhythmic patterns generated by left-hand vamp figures, in combination with constantly mutating and developing melodic material and chords in a single key, reiterated over long periods of time; both the repetitive patterns and the "endlessly floating" melodies give an impression of a music that exists outside or above time (Ake 2002: 103). These musical features, for their part, contribute to a potential state of immersion in which Jarrett might lose a conscious and rational grip on his concrete actions and the musical development. The intrinsic qualities of the music thus seem to reinforce a reduced activity in the frontal lobe in favor of a heightened bodily awareness.

[2] Is Jarrett here, by pulling down the mind-body-environment triangle undermining the fundaments of complexity and ecological thinking? After all, point of departure for these theories is the idea that human beings - their bodies and their minds - organize themselves by interacting with their environment (cf. \acob von Uexküll and the Field of Musical Improvisation, section 4). Jarrett seems to set aside the mind as an actant, replacing it by an extra-human, spiritual, or metaphysical force. I must admit that I have some reservations about such a pseudosacral discourse (see also my book Thresholds. Rethinking Spirituality Through Music), although I do believe in Jarrett's veracity as well as the human desire and ability - so often expressed by various improvisers - to empty one's mind in order to increase a certain directness, to avoid too many clichés, or to renounce too much rational control. In any event, Jarrett's accounts about his solo improvisations not being directed by his mind, not only makes the attention shift toward the spiritual as a virtual actant but also opens the possibility of reinforcing the role of the body in the act of improvisation as well as rethinking the relation between body and instrument; the very act of musical creation through corporeal accomplishments can be brought to center stage as Jarrett's mental state is simultaneously reflected in and shaped by the way he physically treats the piano (Ake 2002: 110).

[3] Of course, musicians do not just listen and think during a performance; first of all they participate with their whole bodies, constructing and enacting the music (Bowman 2004: 47). This idea might prompt us to consider the role of the body with its sensory and motor interfaces: musicians think with or through their bodies, thereby negating not only the Cartesian split between body and mind but also challenging the (still dominant) view that the senses provide information to the brain, which then starts to process and plan before activating the (physical) motor systems. According to this latter view, the body's role still remains subservient to that of the mind.

As Wayne Bowman maintains, however, the body is not something to be transcended during a musical experience, as it is not only indispensable in, but constitutive of all musical knowledge. Actually, actions of the mind are themselves "emergent from, structured by, and never wholly separable from the material facts of bodily experience" (Bowman 2004: 36). This leads Bowman to the conclusion that musical knowledge should not be sought on a conceptual or rational plateau; musical intelligence is corporeal; it is about acting and agency (Bowman 2004: 37).

[4] Watching Jarrett play, one cannot deny or ignore the body as a determining actant during his solo improvisations if only because it is almost impossible not to notice a performance style so radically different from orthodox instrumental technique (Ake 2002: 104). His playing style sharply contrasts the absence of physical movement during the preparatory process. Not only are his improvisations accompanied by wrenching vocalizations - cries, howls, grunts, and sighs well beyond Glenn Gould's "singing-along" - his physical behavior towards the piano closely resembles, in Jack DeJohnette's words, a "love affair."

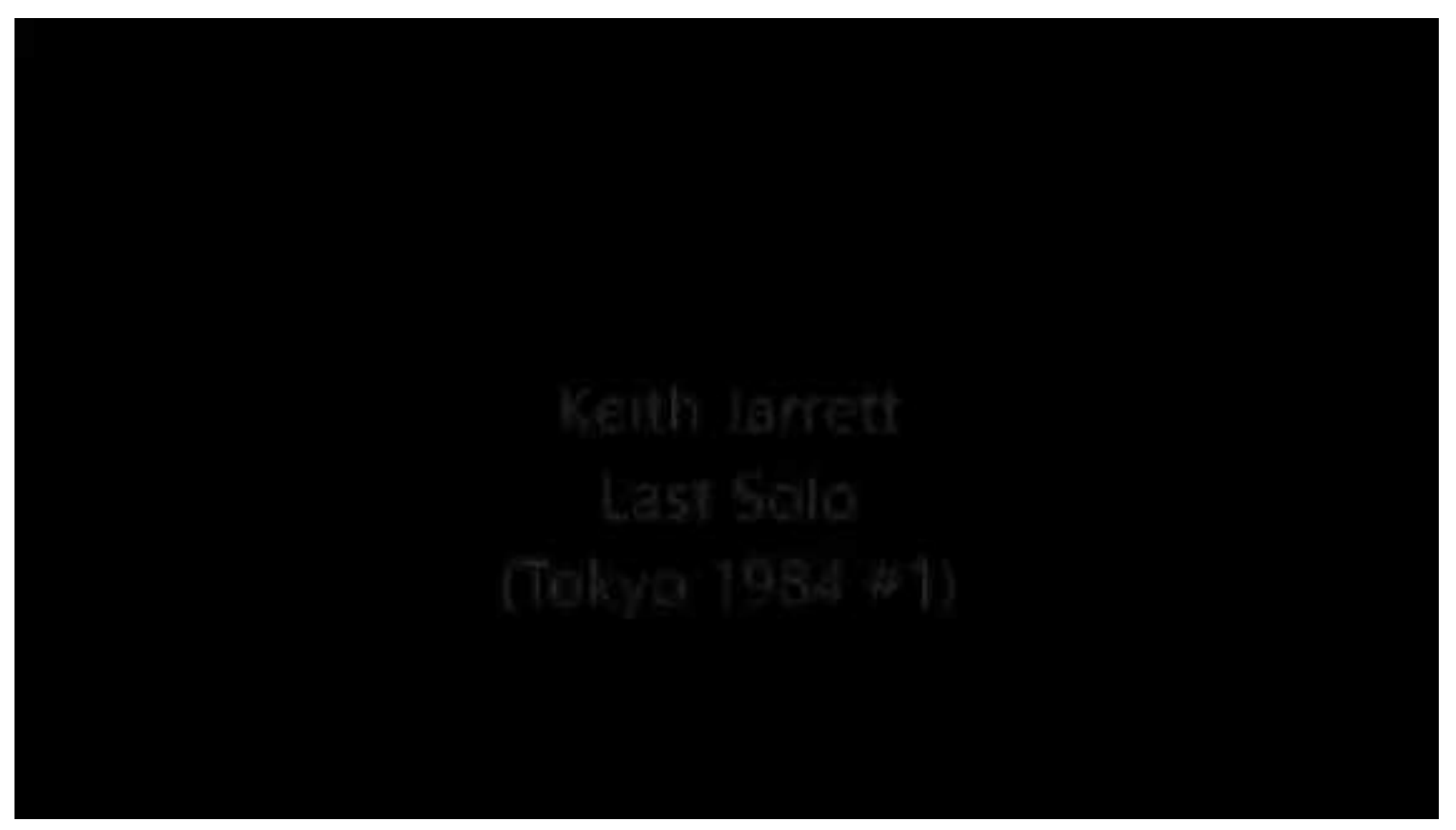

Keith Jarrett - Last Solo (Tokyo '84 \#1 - a “love affair")

Jarrett's solo piano performances foreground the body through physical and verbal gestures that are often regarded as extrinsic to the music, "traces of physicality which bleed through into an idealized space marked out for purely aesthetic contemplation" (Elsdon 2006: 192-3). Through his improvisations, the body can be 
seen as a primary site of musicking, a pervasive actant, acting on, reacting to, and interacting with the musical instrument. Jarrett's concerts reveal that improvisation is (also) stored in the performer's body. Nevertheless, he seems to deny or efface the body in his verbal or discursive accounts as he reinforces the idea that his improvisations are beyond the realm of rationality and physicality. Paradoxically, however, he also states (Jarrett 2009: n.p.) that he is "asking his left hand to tell him what it wants to do," thereby trying to sidestep inveterate patterns of thinking and preparation so that new creative possibilities can announce themselves. Here, Jarrett seems to be aware of the idea that his musical knowledge is embodied, structured by his body situated in its environment. His non- or pre-rational knowledge is rooted in aptitudes acquired through practice, which not only sediments experiences or develops motor schemes, but also provides him with the opportunity to surpass these habits in and through musical action.

[5] It seems justified to state, on the basis of his playing, that Jarrett is actually striving for a total fusion of musician and instrument. The orgiastic movements of the lower parts of his body suggest his desire to penetrate the piano, thereby trying to realize a communion or complete unification. In an immediate connection, Jarret wants his body to merge with the piano. The music should reverberate in the piano with the performer as (only) an intermediary. In order to make this happen, there needs to be an almost perfect match between the performer and his instrument. The instrument must become an extension of the performer's body, which requires that the latter has a deep understanding as to how the instrument will react to his actions. However, fusion or mergence logically presupposes distance or separation. Fusion is only possible between two bodies that are normally apart. In other words, Jarrett's playing is also, and by definition, an encounter with the instrument's resistance (cf. Fred Frith - The Instrument as Actant). Although he tries to resist the resistance, to minimize it, in order to achieve a kind of immediacy, resistance proves to be inherent to playing an instrument. As Aden Evens rightfully claims, "the dream of immediacy forgets the effort by which the desire is forged into expression" (Evens 2005: 162).

[5] It is, however, not my intention to simply substitute Jarrett's insistence on the spiritual aspects of his concerts with an exclusive emphasis on the embodiment of his musicking: both are interwoven in his musical experience to such an extent that it seems meaningless - and perhaps even unnecessary - to maintain a clear distinction between the two. Although most of Jarrett's statements seem to imply that his sources of inspiration disallow a purely physical account of his performances, Jarrett's contortions and spirituality perhaps meet in what could be called a state of ecstasy or sensual sacrality. Against the prevailing, humanistic idea of the autonomous subject with its own predisposition, philosophers such as Nietzsche and Sloterdijk propose the heteronomous subject whose will and actions are determined by something external, e.g. bodily inclinations. Something similar seems to be the case with Jarrett: consciously halting a defining mental activity creates space for a pre-conceptuality and pre-rationality in the shape of motor habits, bodily action schemata, and auditory images. The body senses and perceives in a pre-rational, ante-predicative, pre-logic state: the body knows without thinking (Merleau-Ponty 2005: 149).

During music making one is almost living in the music, "without conceptual or rational mediation that separates the subject from its object, the perceiver from the perceived" (Pelinski 2005: n.p.). It might well be that Jarrett's knowing goes beyond his consciousness, rationality, and mental control; his knowledge is action and his action is knowledge, a setting into action, a mise en action, "enaction" or "embodied cognition." His musical behavior is not originally an "I think" but an "I can." As such, Jarrett's "Divine Will" is not necessarily an external force but closely connected to the knowing body as another important actant in the field of musical improvisation. Jarrett challenges the idea of a singular controlling intellect in improvisation, and this hunch is shared by many improvising musicians. By stressing the non-conscious and non-analytical processes in his performances, he simultaneously establishes the importance of the body. 


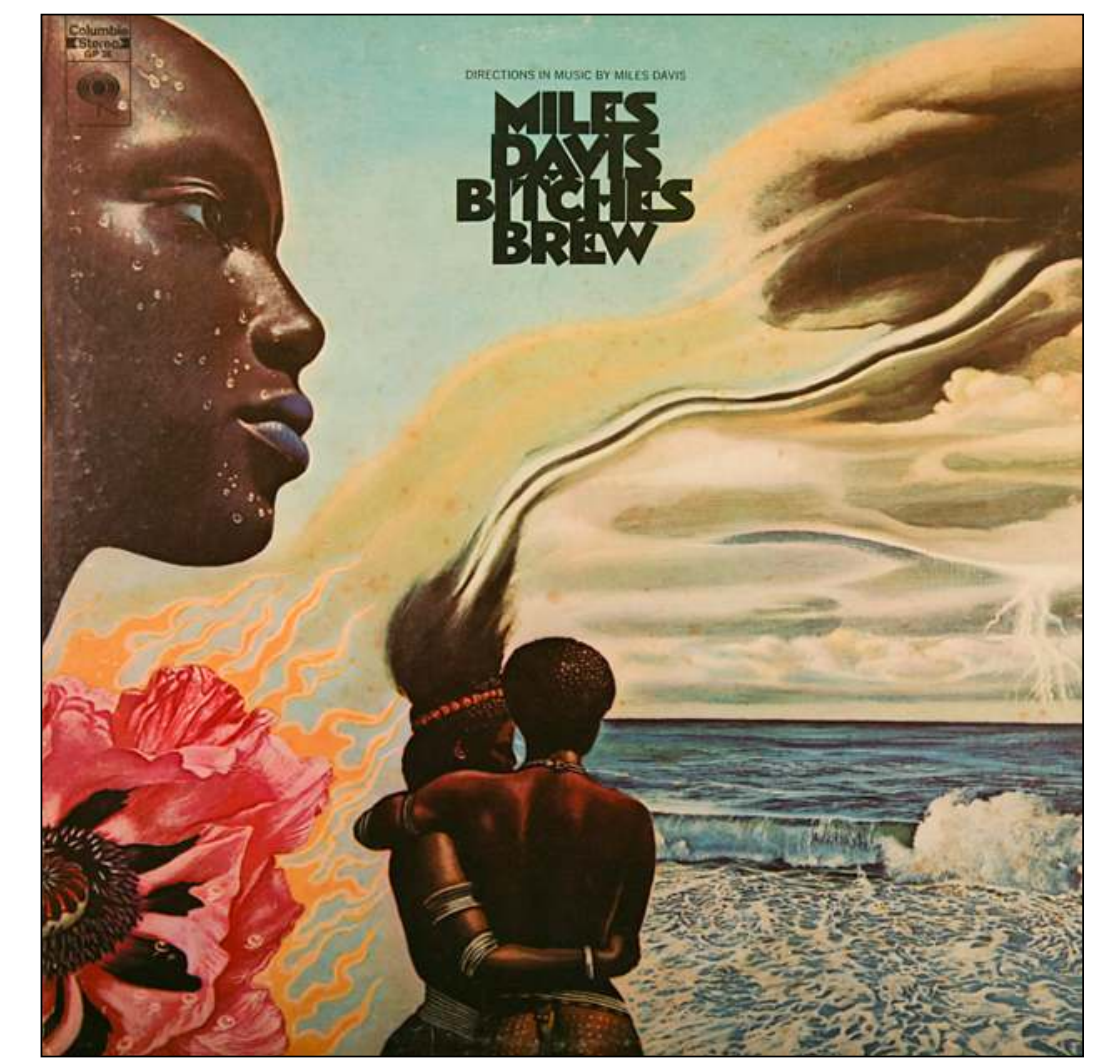

Bitches Brew front cover
[1] Bitches Brew. A musical concoction by some of the most outstanding jazz players of the late twentieth century; a soundmark in music's history; a hybrid mix of jazz, rock, funk, James Brown-style rhythm \& blues, classical music, African and Brazilian polyrhythms, notated and collectively improvised music, played live as well as emerging through postproduction editing, and, simultaneously, breaking away from all of these. Without a few easily identifiable melodies, motifs, or vamps, Bitches Brew reveals a stunning soundscape, exploring new, uncanny, and intangible musical universes. Most of its improvisations are not based on conventional preset chord changes but emerge from one chord. The rhythm section's function oscillates somewhere between the traditional supporting manner of post-bop jazz ensembles and the more liberal manner of free jazz. Insistent ostinatos suggesting static or repetitive harmonies and an uncompromising metric framework are interspersed with a thick web of collective soloing during which the underlying beat dissolves. Often the traditional function of soloists and rhythm section is reversed: trumpet, sax, and/or clarinet might play a melodic fragment over and over with minimal variation as a kind of cantus firmus "bottom" for collective improvisations by keyboards, guitar, bass, and percussion (Tomlinson in Kirchner 1997: 242-3).

As Gary Tomlinson states, the word "brew" is not a noun but a verb and "the title does not describe the music on the album so much as the musicians and their activity in making it" (Tomlinson in Kirchner 1997: 247).

[2] Bitches Brew came into existence through the complex interactions of musicians, instruments, and technology during three studio sessions in August 1969. No AABA form, no head-solo-head, but also no free jazz. The essence of the album lies not in its solos, themes, or developments as one often encounters in more mainstream jazz; rather, the listener is invited to enter and roam in the music's ambient atmosphere: immersion instead of control, surrender instead of understanding, experience instead of analysis. Several aspects of Bitches Brew and its realization contribute to this: for example, the "melody" of "Miles Runs the Voodoo Down" consists of nothing more than a two bar bass line; the use of the different scales, modes, and key centers in "Spanish Key" (E altered, D altered, D Phrygian, E Phrygian, and G Mixolydian) are cued at the improviser's will; the music, mostly based on sketches brought in by Miles, contains hypnotic grooves, rooted in rock and African music; once they started to play in the studio, Miles directed the musicians, either by writing down some music or by telling someone to play differently, although he, at the same time, allowed his fellow musicians to try and find something that worked. "Miles was recording like the way we would write songs. You know, you just jam until you find something and that becomes part of the song" (Harvey Brooks in Bitches Brew liner notes: 22). At certain moments, the rhythm section consists of as many as eleven players three keyboardists, electric guitar, two basses, four drummers / percussionists, and a bass clarinet - producing a rich variety of tone colors and textures. Ring 
modulators, Echoplexes, fuzz boxes, and Wah-Wah pedals adorn the keyboards and guitar. Miles himself often uses the Echoplex and the octave-divider. Sounds of the instruments are also modified by an extensive use of reverb.

[3] Although instruments, effect equipment, and studio technologies definitely had a great impact on the innovative aspects of this music, the musicians involved in the production of Bitches Brew mainly recollect the interactions with Miles. Bass player Dave Holland emphasizes the (controlled) freedom whereby Miles allowed the musicians to be creative. According to Holland, Miles definitely had a vision, but this vision was not fixed and finished; it was highly influenced by the musicians' approach and style of playing (Tingen 2001: 76). At the same time, however, it was Miles who created the context for the music; he was listening and selecting what he liked. This "double bind" is also noticed by drummer and percussion player Lenny White who regards Bitches Brew as "a big pot and Miles was the sorcerer" (Tingen 2001: 65). Drummer Jack DeJohnette adds that "you always had to be prepared for the unexpected. You had to be on your toes and alert. He kept you thinking all the time, and that was fun. You never knew what was going to happen, and that made it exciting, but also very challenging" (Tingen 2001: 78).

Obviously, the way Miles worked with the musicians made a deep impression on them. However, of course they cooperated not only with or via Miles. The ensemble's collective improvisations were also based on the working methods developed by Miles' so-called second great quintet: with subtle visual and sonic cues, the musicians indicated impending shifts, leading to a complex network of actions, reactions, and interactions.

[4] However, perhaps the most important actant was neither one of the performing musicians, nor an instrument, nor the effects equipment. Perhaps the decisive factor in the realization of Bitches Brew was not even the interaction between Miles and his fellow musicians. The actant that determined the end result to a large extent is hardly ever mentioned. However, the 1998 release of the four-CD boxed set The Complete Bitches Brew Sessions as well as research performed by several music scholars and journalists have cast important new light on the album's postproduction process.

I didn't really like the sessions at the time. I didn't think they were exciting enough But a short while later I was at the CBS offices, and a secretary was playing this incredible music. It was really smoking. So I asked her, 'Who the hell is this?' And she replied, 'It's that Bitches Brew thing.' I thought, damn, that's great. (Zawinul in Ouellette 1999: 37)

As percussion player Don Alias remembers, the recording of Bitches Brew was very fragmented. Things would mainly be recorded in segments. The goal of performing and recording "Pharaoh's Dance," for example, was not to try for a continuous take, but to be able to assemble parts of parts into a whole. Likewise, "Spanish Key" was recorded in various fragments before making the master take in one continuous performance. And with regard to "Orange Lady," Alias remarks that there were a few measures played at the rehearsal that did not end up on the master version recorded three months later, in which the form is altered by heavy editing (Alias in Bitches Brew liner notes: 19-21).

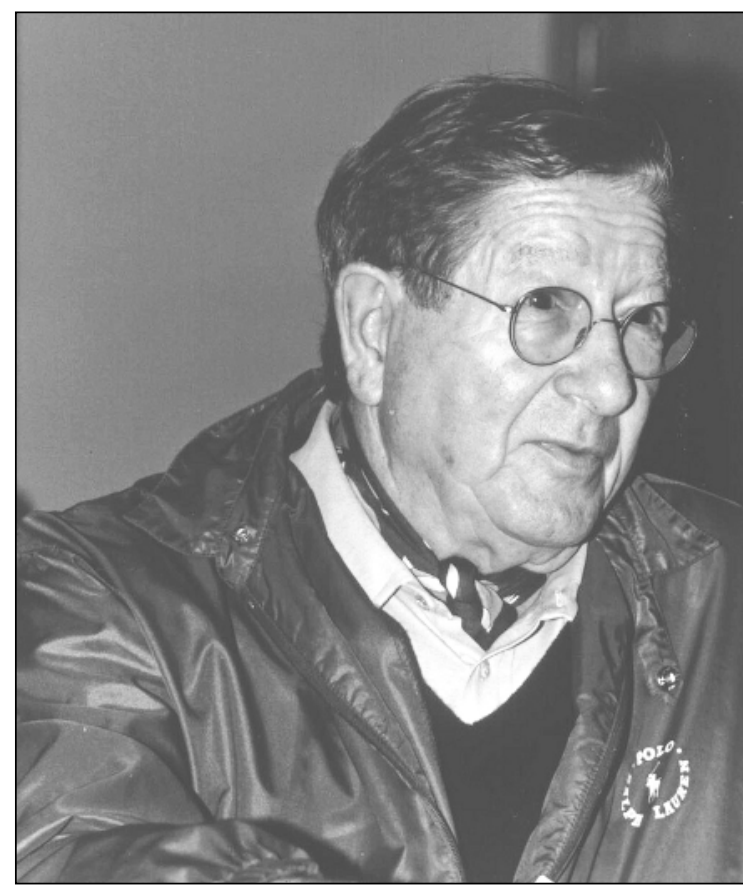

Teo Macero

Lenny White agrees with Alias' observations; he also remarks that the end result is rather different from the recording sessions, as "they' $\mathrm{d}$ taken the front end of one tune and put that in the middle and so on" (Tingen 2001: 67). "They" here refers to Miles, and, particularly, producer Teo Macero. His tape editing and use of studio effects like echo, reverb, slap (tape) delay, and overlays had a far-reaching effect on the music.

As Paul Tingen (2001: 67) argues, "Macero did not only use tape editing to glue together large musical sections [...] but extended his scope to editing tiny musical segments to create brand-new musical themes" not unlike the cut-and-paste ideas coming from Pierre Schaeffer's musique concrète and his thinking about music as abstract blocks of sound. For example, the opening theme of "Pharaoh's Dance" was constructed entirely during postproduction; micro-edits occur, for example, between 8:53 and 9:00, where a fragment of only one second appearing at 8:39 is repeated five times; and the use of tape delay can be heard on the trumpet at 8:41 (Tingen 2001: 67). 
Miles Davis - "Pharaoh's Dance"

According to Macero, Miles gave him carte blanche to work with the raw musical materials. He thus selected all the good parts, sometimes as short as one second, combined them and then added in all the effects. "[I would] be working it out in the studio and take it back and re-edit it - front to back, back to front and the middle somewhere else and make it into a piece. I was a madman in the engineering room" (Macero in Lewis 1994: 24). One of the results was that keyboard player Joe Zawinul didn't even recognize the resulting music when he heard it later in another context. It was Macero who created the final musical structures to which Miles gave his approval.

It is interesting to notice how Macero regards his share in the fulfilment of the album:

I learned from the standpoint of editing, shifting the compositions around. It's a creative process being a producer with Miles. In fact, it's more of a creative process than it is with any other artist. You have to know something about the music. You really need to be a composer, because for a lot of it he relies on you and your judgment. I'm going through them as a composer, Miles as a composer-musician-performer. You must be very creative along with the artist, because if you're not as creative as he is - forget it. (Macero in Hall 1974: 14)

Macero presents himself not only as a producer, but also as an artist, a musician, a composer, and a careful listener: "I spend as much time listening to it as he [Miles, MC] spent creating it" (Macero in Hall 1974: 14). In much the same way as Miles and the other musicians were reacting to what they heard during the recording sessions, Macero listened to the tapes and grounded his editing decisions on what he heard. In his own specific way he improvised with the material on hand.

[5] Many scholars preceded me in focusing on the human-human interactions taking place in an improvisation (Berliner 1994; Monson 1996; Nettl 1998; Fischlin and Heble 2004). However, examining the role of the postproduction process is still quite rare; it seems as if the discourse on improvisation seeks to neglect the influence of the producer on the sonic results of the improvisation. Of course one could state that there is no direct impact from producers on the interaction taking place among the performing musicians. However, in the case of Bitches Brew, this idea cannot hold. The fact that Miles and Macero already anticipated on the importance of the postproduction also had a direct effect on the way the musicians were "allowed" to interact. In other words, Macero's role was not restricted to the postproduction process alone, but already predetermined the music made during the recording sessions. Not only can Macero be considered an improvising musician, just like the other contributors to Bitches Brew, the events that took place after the studio sessions already had a defining impact on the performers' improvisational activities during the sessions.

From the concrete example of the realization of Bitches Brew, it becomes clear that the producer, studio equipment, and the whole postproduction process as well can play a significant role in the complex field of musical improvisation. This role might change with every project, it might differ from producer to producer, but it remains irrefutable. 
Alain Renaud - The Internet as Actant

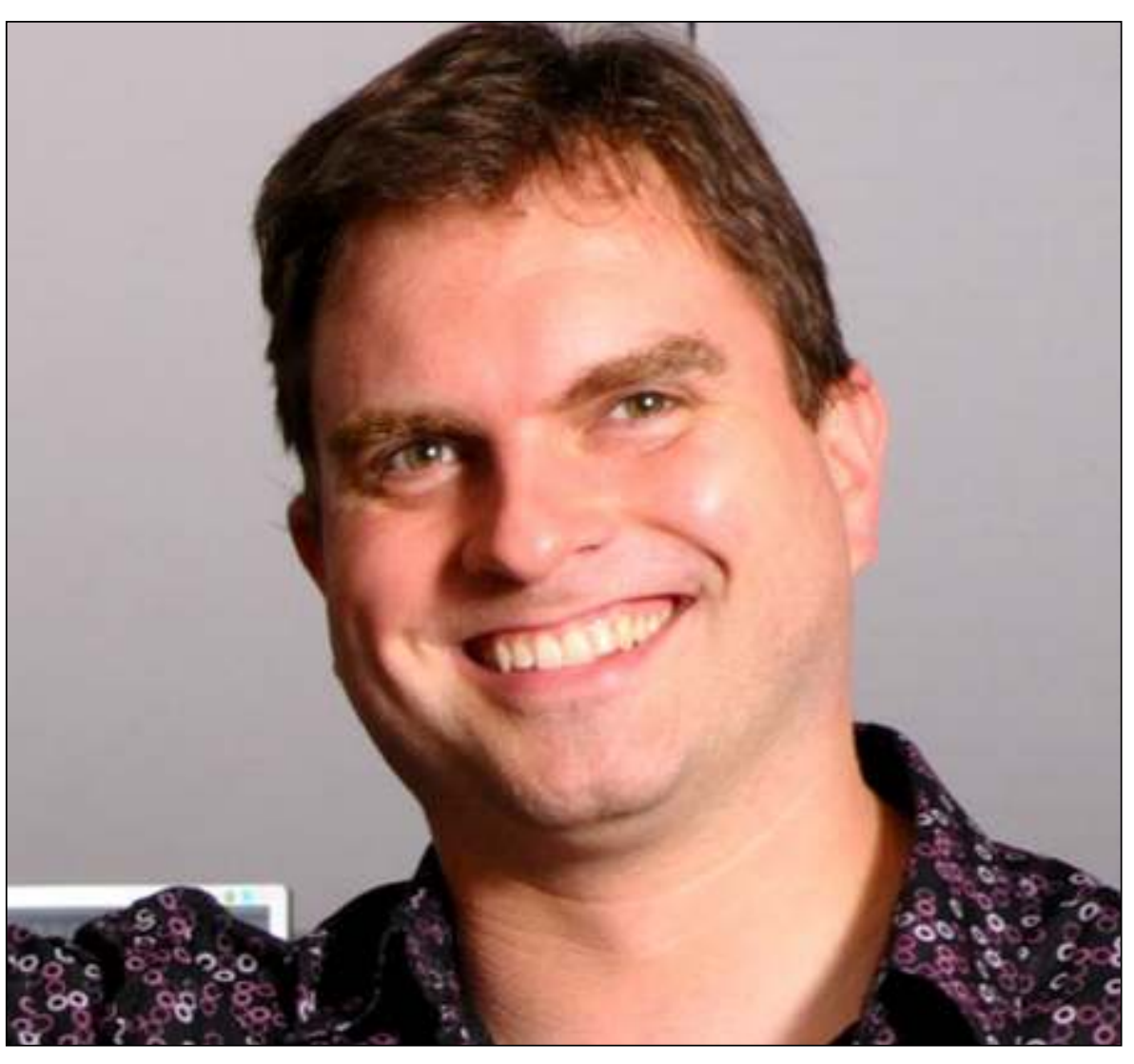

Alain Renaud

[1] One of the things a string quartet, a jazz band, a symphony orchestra, and a guitar duo have in common when performing is that parts of their interactions take place through visual or gestural cues apart from aural ones. The members of a string quartet nod in order to, for example, synchronize the beginning of a piece; jazz musicians use many different corporeal gestures to somehow change the directions of a performance. (John Zorn's Cobra can count as an almost paradigmatic example here. Cf. Play - John Zorn, section 2); orchestral musicians (almost) cannot do their job without carefully paying attention to the gesticulations of the conductor; and the two guitarists will almost inevitably exchange subtle face expressions to coordinate and fine-tune their interactions. Perhaps not all of these events would simply and immediately fall under the category of improvisation; however, when most of these visual and gestural signals somehow lead to adaptations in the course of performance, we do enter a field of music making in which improvisation at least plays a role too.

Although music is usually considered to be an aural art form, I think we often forget and fail to acknowledge that it is a visual and embodied, tactile art as well: especially in live improvised music, a lot is lost when one is not able to register the eye contact and the physical interactions that take place among fellow musicians and with instruments. (Once again, Zorn's Cobra could be a perfect illustration here.) However, 
more recent developments in technology sometimes deprive musical improvisation of its visual and gestural transfers of (crucial) information: what I am aiming at are so-called networked improvisations in which musicians use the Internet as a means to come into contact with each other. Music making, traditionally tied to the physical space, explores a virtual space for collaborative work in sound through the Internet.

[2] Maturation of network technologies and the fast-paced improvements of broadband internet infrastructure, such as Internet2, have led to developments that enable synchronous as well as time-shifted networked improvisation across global distances and geographically displaced musicians (Mills and Beilharz 2012; Renaud, Carôt, and Rebelo 2007). The Internet can be used as a medium for real time improvisations between disparate locations as well as for music production processes that happen asynchronously.

Alain Renaud's "Renditions" from 2010 is a composition consisting of instructions for improvisation that

uses the network as a way to capture live audio bites from three performers in three different locations. On top of the live stream, the audio bites are heavily processed and re-injected into the network creating a multi-channel granular feedback loop which is spatialized as a quadraphonic stream across arrays of speakers in the three locations. This ever-changing loop acts as an audio basis for the performers to cue-in. Each sound stream, live and processed, is represented by a live graphic object with which the performers interact in real time. The dynamic graphics also have attached scenarios ranging from call \& response, drony and erratic modes, giving a sense of progression and promoting collaboration over the network. (Renaud 2013: n.p.)

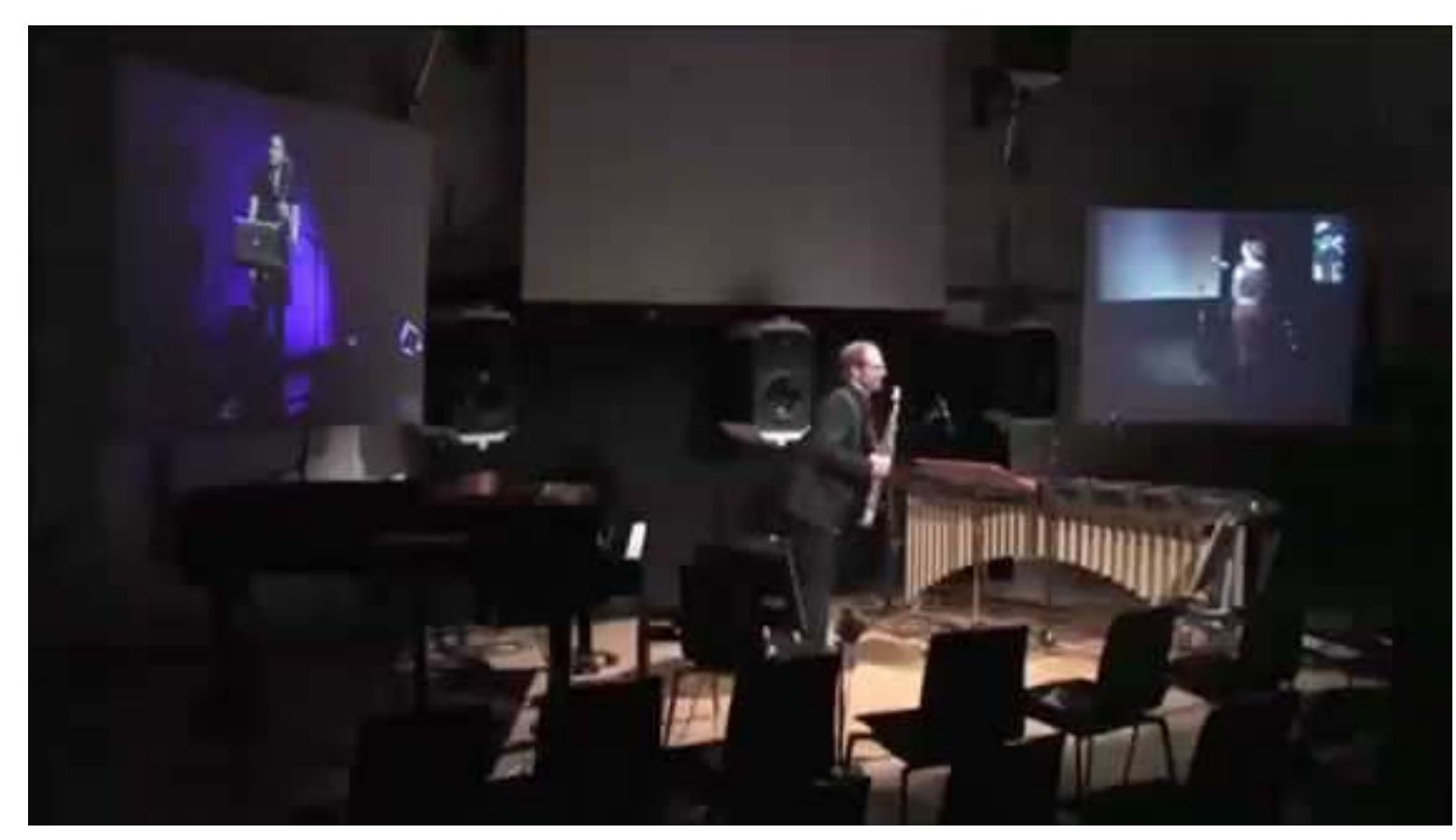

Alain Renaud - "Renditions"
Through "Renditions", here for two soprano saxophones and one clarinet, a complex network of interactions between musicians (including the one working the computer), instruments, processed and non-processed sounds, computers, loudspeakers, spaces, and graphics unfolds. Not one of these actants can be regarded as the beginning of this network, nor is one of them in control of the others. An always-evolving and changing balance between chaos and order cannot be pre-established but has to emanate from the actual interactions: relatively small interventions, e.g. by one of the musicians or by the computer processing, might lead to radical changes in the course of the improvisation. Another (f)actor is the environment. In this video the performance spaces of the three musicians are roughly indicated by the city names: Belfast, Graz, and Hamburg. However, researchers Roger Mills and Kirsty Beilharz note that the effect of the concrete environment of the musicians should not be neglected, as it shapes their creative cognition during the event and thus the complete performance (Mills and Beilharz 2012: 23). Technical issues, of course, but also whether or not an audience is present, the climate, and the influence of different time zones become factors that co-determine the improvisational directions.

Our theoretical language will need to shift as well, from notions of instrumental action and causality, and ideas of musical "mastery" and technical "manipulation," to interagency and interactive contingency between heterogeneous sources of activities. (Borgo n.d.: 12)

Besides the actants mentioned above, another one strongly affects the music making and thus the final musical outcomes. One of the major problems of performing over the Internet is latency, the time interval or delay between the activity of a musician in one space and the moment the others are able to hear and interact with it. Performers attempting to play as if they were spatially together while actually being geographically at different places require a delay in the system of less than 25 milliseconds. However, Internet packets are often delivered with a delay of more than $25 \mathrm{~ms}$; besides, this delay is often not constant. Software programs such as Soundjack and eJamming tried to solve these problems (the realistic jam approach). On the other hand, software such as Ninjam and Quintet.net accept the current situation that network latency prevents true real time synchronizations (the latency accepting approach).

"Renditions" works with the creative possibilities that Internet deficiencies, in this case latency, offer the musicians. Not the perfection of technology, but its imperfections - like, for example, in Clicks \& Cuts or Glitch music - its resistances (cf. Fred Frith - The Instrument as Actant, section 2) become an important factor during the improvisations. Depending upon the distance between nodes and resulting latency, the network can generate acoustical features ranging from reverberation to echo-like effects. In "Renditions" the acoustic properties afforded by the network are 
thus exploited and become an integral aspect of the piece. More concretely, Renaud implements the delay of the network as a catalyst for musical exchange (Davis,

Renaud, Geistweidt, and Dixon 2012).

[3] Although "Renditions" contains graphics - a kind of score developing simultaneously with the music - which implies that the eye is also involved in the process of improvisation, communication through gestures, facial expressions, and body language is hardly available to the three musicians. They must rely primarily on listening to mediate their interactions. Interpreting and reacting to timbre, pitch, and amplitude must guide them in their interactions with the other actants; negotiating the course of the improvisation must occur through the immediacy and specificity of sound rather than through visual or tactile cues.

Besides listening, imagination or mental imaging might guide the improvisers. In "Listening Through the Firewall" Mills and Beilharz write that

[a]s with the mental image of finger gesture on the staccato attack on violin or the trembling hand resonating vibrato on a guitar fret board, images of gesture help to codify qualities of sound in the minds of the musician and audience alike. This is significant in the non-visual networked environment as improvisers draw upon images of embodiment to support their interpretation of sound in a non-visual environment. (Mills and Beilharz 2012: 22)

What I want to put forward here, however, is the idea that the introduction of a new actant does not automatically lead to an increase in the amount of actants and interactions operative in a specific musical situation. On the contrary, in Renaud's composition the use of the Internet obstructs many communication strategies so commonly employed in a more traditional setting with all musicians present in the same space; several actants are therefore sidelined, moved to the periphery, or simply absent. As Renaud himself acknowledges,

some very basic interaction components such as the potential for common pulse, the synchronization of events that require negotiation and agreement from two or more performers, the identification of performative roles and the up-beats or the ability to anticipate various performative actions are very difficult to recreate in a networked environment. (Renaud, Carôt, and Rebelo 2007: 5)

Some actants might eliminate others while, simultaneously, making new interactions and ways of improvising possible.

[4] It is clear that technology plays a role in all music making and therefore in all musical improvisation. It might be hard to even imagine present-day music without amplifiers, synthesizers, microphones, loudspeakers, computers, and (electrical) instruments - technology has (always already) pervaded every aspect of music: its production, its distribution, and its reception. However, in a certain situation, technology is more defining, more prominently present than in others; sometimes it simply makes improvisation and interactions possible, while at other times it is concretely influencing and controlling them. Although in "Renditions" the network is merely employed as a communication infrastructure, it affects and determines the improvisations of the three musicians significantly. Rather than regarding the role of Internet here as an instrumental causality, "Renditions" is made possible through an interactive contingency between several heterogeneous sources, human as well as non-human (Rammert 2008: 2).

However, by presenting technology, in this case the Internet, as one actant among others, that is, in a non-hierarchical relationship to, for example, the three reed players, I do not wish to enter the discussion as to how similar or different humancomputer interaction is to human-human interaction; besides, both categories harbor many different concrete manifestations, making a general observation almost impossible and useless. In "Renditions" many of the interactions take place through the Internet, which makes it an important and determining actant in this particular and heterogeneous context. Like the other actants, it has its (sometimes unforeseeable) own specific possibilities as well as its particular confines. And like the other actants, its working, its functioning, its behavior is the result of the interaction processes with the other "players"; musicians, technologies, and environments configure one another as relatively autonomous actants in and through mutually constitutive processes.

The user of this type of advanced technologies is neither the master of the machine nor the slave of the technological system, neither the sovereign of his action nor the victim of media's manipulation. (Rammert 2008: 9) 


\section{Vlatko Stefanovski - The Past as Actant}

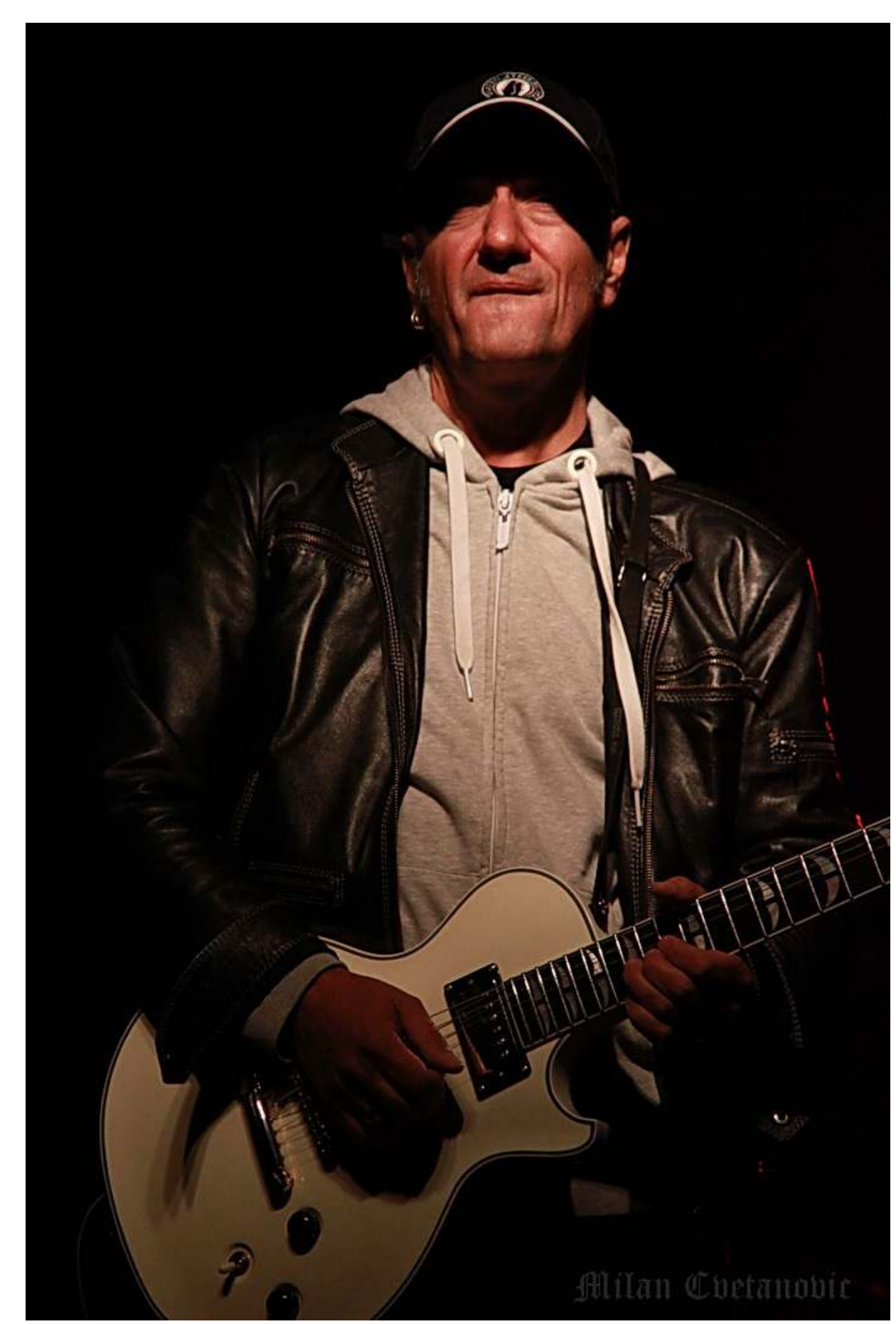

Vlatko Stefanovski
[1] Vlatko Stefanovski. Born in 1957 in Prilep, Macedonia. Electric and acoustic guitar player. Founder of the group Leb i Sol, one of the more well-known bands from the former Yugoslavia music scene. Since the mid-nineties, Stefanovski has developed a solo career. Since 1998, he also performs with fellow guitarist Miroslav Tadić.

[2] In "Alfred Brendel and W.A. Mozart - The Score as Actant," I approvingly "reworked" some thoughts by Bruce Ellis Benson on improvisation. Instead of regarding improvisation as music making "on the spot" or a "creatio ex nihilo," it might be considered as a "reworking of the past" (Benson 2003: 119) or the creation of something new "within the decaying site of the old" (Peters 2009: 16). Improvising requires a powerful memory, e.g. of the parameters of an idiom, a genre and its history, its possibilities and (thereby) its impossibilities (Peters 2009: 82). This proposition by Gary Peters echoes that of Robin Moore (1992: 66), who stated that any improvisational style has its own conventions and traditions, a combination of certain specific, and often longstanding, cultural models and individual interpretations of these models. They are usually so familiar to the performers that they have been internalized and are understood on both conscious and intuitive levels.

Getting familiar with a particular style of improvisation often also implies performing the same piece, or limited group of pieces, over and over. In this way a musician becomes intimately accustomed with the stylistic specificities of an improvisatory tradition and is able to experiment with different possibilities within the parameters of its aesthetic. Ultimately, the musician might be able to deviate from and transgress certain conventions and limitations and leave his own mark on some components of that style of improvisation (Moore 1992). In other words, something novel is created out of the negotiation of past experiences in relation to the present situation (Warren 2014: 117).

Although both Benson and Moore mainly refer to the improvisational practice within Western classical music, I think the ideas described above also apply to the ways Stefanovski reworked and (thus) improvised on parts of the Macedonian musical folk tradition in his music.

[3] Stefanovski recorded the well-known Macedonian folk tune "Jovano Jovanke" for the first time in 1977 with his band Leb i Sol.$$
\text { play }
$$

Leb i Sol - "Jovano Jovanke"

This instrumental performance offers a fusion of the traditional melody, in a $7 / 8$ meter, and seventies prog-rock in the style of Mahavishnu Orchestra, Dixie Dregs, 
or Soft Machine, still unchartered territory at that time. After a rubato intro, a bass riff forms the basis for the guitar playing the melody. A subsequent synthesizer solo leads back to the melody, thus giving the performance a rather simple structure: intro-themesolo-theme. By reworking folk tunes such as "Jovano Jovanke," Leb i Sol laid the foundations for what in the Balkans became known as "ethno-rock" or "world music." After the splitting of Leb i Sol in 1995, Stefanovski kept performing "Jovano Jovanke" in various settings. With his VS Trio he often plays the tune during live concerts, usually beginning by vocally presenting the meter and its subdivision: 3-2-2. The folk melody appears here - a concert in Zagreb (Croatia) in 2010 - in a power rock context.

\section{play}

VS Trio - "Jovano Jovanke"

A more jazz-rock oriented version can be heard during a concert Stefanovski gave in December 2010 in Belgrade (Serbia) with violinist Stefan Milenkovic (also including a short reference to Miles Davis' "Jean-Pierre" in the bass solo).

\section{play}

Vlatko Stefanovski and Stefan Milenkovic - "Jovano Jovanke"

Folk, (jazz)rock, and classical music merge when the tune is played in 2012 by Stefanovski, sax player Vasko Atanasovski, and members of the string section of the Slovenian Philharmonic Orchestra.

\section{play}

Vlatko Stefanovski, Vasko Atanasovski, and the SPSCO - "Jovane Jovanke”

By far the most restrained performance of "Jovano Jovanke" is Stefanovski's duet with fellow guitarist Miroslav Tadić; here Macedonian and Spanish folklore seem to merge.

\section{play}

Vlatko Stefanovski and Miroslav Tadić - "Jovano Jovanke"
The various versions reveal the way the material has advanced and matured through its many reincarnations over the years and in different settings. New potentialities of the tune are exposed, unknown musical terrains explored, unprecedented style combinations tried out. Furthermore the examples show Stefanovski's openminded approach of folklore and tradition. Although he is very well aware of the enormous responsibility when it comes to dealing with the rich, colorful, and delicate Macedonian folklore, he also stresses the point that a musician should not become the victim of a "musical correctness," for example by pursuing some kind of authenticity at the expense of new aesthetic explorations. For Stefanovski the tradition is there to be used, respectfully but also creatively. Former limitations should not interfere with current musical developments (Stefanovski 2005: n.p.). Like so many others, Stefanovski is improvising upon the past, not only by inserting space for solos, but primarily by reworking the music that is so familiar to him.

[4] Stefanovski's continuous returning to and reworking of one particular tune bears resemblance to the working methods of, among others, John Zorn and Frank Zappa, one main difference being that these two musicians take their own compositions as the point of departure. Over the years, Zorn's "Abidan," originally recorded by his acoustic quartet Masada on the CD Masada: Gimel in 1995, has been subjected to many transformations, from a chamber music-like version for violin, cello, and bass and a kind of loungy jazz-rock recording on At the Mountains Madness to a barely recognizable solo guitar interpretation performed by Bill Frisell.

Zappa calls the series of non-identical repetitions that permeate his complete oeuvre the "conceptual continuity of the output macrostructure" or, more concisely, "project/object": "A novelist invents a character. If the character is a good one, he takes on a life of his own. Why should he get to go to one party only? He could pop up anytime in a future novel [...] for no other reason than to unify the collection" (Zappa and Occhiogrosso 1989: 139-140). On the basis of this conceptual framework, the instrumental prog-rock tune "Dog Breath Variations" from his 1968 album Uncle Meat transforms in 1993 into a contemporary classical piece on The Yellow Shark, performed by the Ensemble Modern. However, already in 1972, the composition metamorphosed on Just Another Band from L.A., mainly through the addition of vocals from the ex-Turtle members Flo and Eddie.

According to Keith Johnstone, an audience will admire an improviser who not only generates new material but remembers and reincorporates earlier musical events (Johnstone 1979: 116). However, this remembering and reincorporating is no mere repetition of the same. Zorn, Zappa, and Stefanovski enable certain musical works to return to themselves as difference, a difference that always already permeates them, a difference that dwells within those works. The reappropriations of these musicians do not so much stress the resemblances with previous performances of "the same" works; they rather emphasize the production of difference. Or as Gary Peters puts it, "the improvisatory exigency is no longer to outstrip the dead weight of what is there but to give it again and again as if for the first time" (Peters 2009: 5). 
[5] In his challenging essay “Improvised Music After 1950," scholar and musician George Lewis distinguishes between a Eurological and an Afrological approach to improvisation. One of the differences is that a Eurological approach stresses innovation regarded as future-oriented while negating previous traditions, whereas an Afrological improviser cannot deny the influence and presence of history and (thus) memory (Lewis in Fischlin and Heble 2004: 148-9). Also, with regard to freedom, Lewis notices fundamental divergences: in the Eurological discourse, rules for improvisation are hardly mentioned (although Lewis also notices the opposite: composers distrust improvisation which can only become musically coherent when it is controlled and structured in some way); conversely, Afrologicality starts from the idea that freedom is only possible through discipline, defined as technical knowledge of music theory and of one's instrument (Lewis in Fischlin and Heble 2004: 153). A third difference, according to Lewis, is the Eurological objective of striving for autonomous significant structures versus the importance of personal narrative in Afrological improvisation (Lewis in Fischlin and Heble 2004: 156-7).

The question is if this binary opposition can last, especially with regard to the first aspect, the Eurological turning away from tradition versus the Afrological recognition of the past. Thinking further along the lines of repetition as difference, improvisation should be situated within rather than outside of reproduction and representation; but instead of stressing predictability and recognizability, Stefanovski's reworking of "Jovano Jovanke" could also give occasion for recognizing an infinite differentiation, for recognizing the unfamiliar within the familiar, the new within the old. By using the Macedonian folk tradition, culture, and history, he not only continues but also transforms it, stabilizes and destabilizes it, fixes and unfixes it. "The new and the old, the unpredictable and the predictable, innovation and re-novation are all part of a concept of originality thought historically as the preservation of the origin within the endless destruction of tradition" (Peters 2009: 104). The only relevant question is how a musician makes use of the available musical materials: are they persuasive and powerful at a particular moment (rather than original and authentic)?

We could never accomplish this encounter with the unknown without engaging the known. (Susan Leigh Foster 2003: 4)

What Stefanovski's versions of "Jovano Jovanke" make clear is that improvisation is not (always) a question of going beyond the known, of aiming for the new, of aspiring to originality; instead, his music is built on the idea of entering into the past, the familiar, the tradition, over and over again. As I already stated in Part 1, improvisation, like writing, is never so much a beginning as it is a continuation (cf. Beginning, sections 3 and 4). However, simultaneously, improvising means beginning time and again, albeit a beginning, not an origin, that is always already in the middle.
Steve Coleman - Rhythm and Musicians as Actants

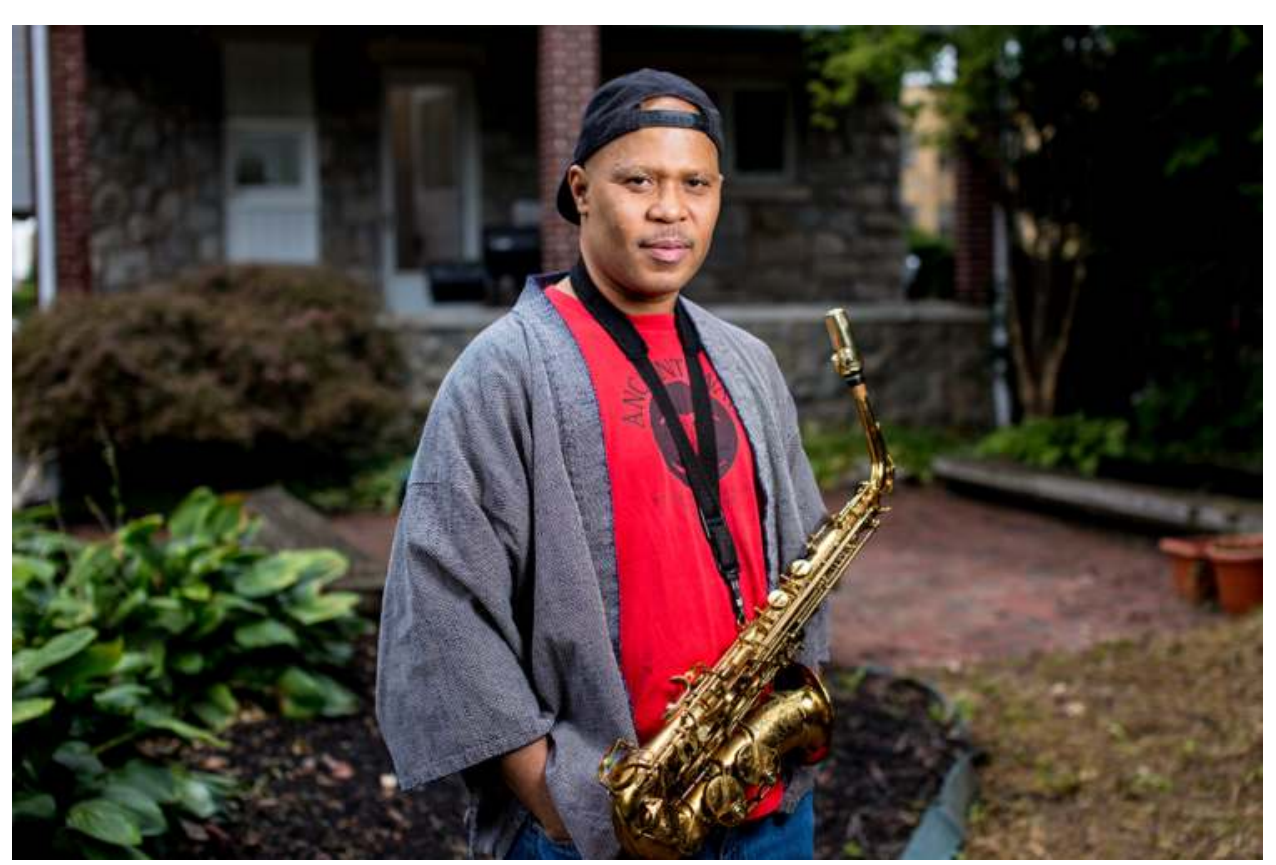

Steve Coleman

[1] The field of musical improvisation is a plane of composition, recomposition, communication, and singularization, where playing triggers playing in a continual process. As such, it is always in an emergent state instead of being structured a priori. Within this field, perhaps the most salient interactions take place between humans, especially where collective music making occurs. Or, as Ingrid Monson (1996: 90 and 74) puts it, whenever improvisation takes place in a group setting, the social and the musical fuse; therefore, this collaborative context of musical invention must be taken as a point of departure. Inter-human, joint interactions might lead to what Pierre Lévy terms "collective intelligence," which is always more than the sum of everyone's individual knowledge.

The collective intellect is a kind of corporation in which each shareholder supplies as capital his knowledge, experience, and his ability to learn and teach. The intelligent collective neither submits to nor limits individual intelligences, but on the contrary exalts them, fructifies and reinvigorates them. This transpersonal subject is not merely the sum of individual intelligence. Rather it gives rise to a qualitatively different form of intelligence, which is added to personal intelligences, forming a kind of collective brain. (Lévy 1997: 105)

What Lévy outlines here in more general terms can perhaps be recognized quite well in the development of rhythmical structures and groove in a musical ensemble on stage. As Vincent Meelberg (2011: n.p.) maintains, groove exceeds the individual contributions of the performers as well as the individual sounds that together constitute a groove; it does not "belong" to the musicians' individual input, but 
is a sonic event resulting from interactions between musicians and sounds, while simultaneously affecting the human bodies it originates from.

To make an ensemble groove often does not require substantial fractional shifts of rhythmic subdivisions; rather, it asks for small but constant micro-rhythmical adjustments (Iyer 2002). The small adjustments can only take place while playing together and cannot be determined in advance; each time they will be different, different in time, in place, and in content.

Groove and (pre-)structured rhythmical patterns not only meet in jazz but also in for example, Funk and the medieval practice of hocket: interlocking rhythms are divided among different instruments or musicians. Together they should create a rhythmically complex groove: "Each fragment is already a complete figure but one that, at each instant, only assumes its full meaning and value within the general configuration" (Lévy 1997: 191). Musicians need to adapt their personal timings in such a way that the end product results in rhythmical interconnections that create a groove. In order to achieve this, a type of musical as well as personal chemistry is required: "The use of the term feeling as a synonym for groove underscores the emotional and interpersonal character of groove - something negotiated between musicians that is larger than themselves" (Monson 1996: 68). Sociologist Alfred Schutz calls this the "'mutual tuning-in relationship' by which the 'I' and the 'Thou' are experienced by all participants as a 'We' in vivid presence" (Schutz 1977: 108). There is a shared "inner time," a shared experience of time within the flux of the music performed.

[2] Of course, in (almost) all improvisations in a group setting, interactions take place between humans in one way or another: interactions between the members of a rhythm section, between rhythm section and soloist, and between soloists are mutually composed, recomposed, communicated, as well as challenged in the course of performance in order to come to a satisfying musical event. And again, as these relationships can take many different forms, generalizations should be replaced by in-depth descriptions of particular examples. (See my plea for singularity in the

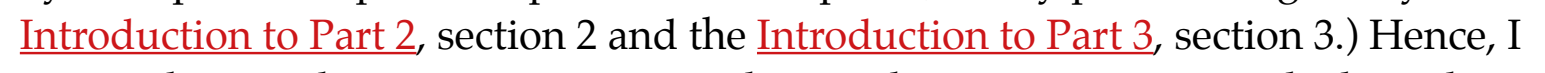
present here such a specific example of human-human interaction, which, in this particular case, takes place in and is expressed through rhythm.

\section{play}

Steve Coleman and Five Elements - "Laid-Back-Schematics"

The sound file presents the genesis of "Laid-Back-Schematics" as recorded on the CD The Tao of Mad Phat - Fringe Zones by Steve Coleman and Five Elements. The tune starts with Coleman playing a four-beat melodic pattern that has to be taken over by the bass player Reggie Washington. Next, Coleman plays a five-beat pattern, to be repeated and continued by David Gilmore, the guitarist. In a similar way, pianist Andy Milne and drummer Oliver Gene Lake are given their parts.

One could say that the first half of "Laid-Back-Schematics" resembles the form of a workshop, which might raise the question as to where the actual beginning of the piece can be situated: it could be argued that, although diverting and instructive,

Coleman's directives are part of the rehearsal process and (therefore) do not belong to the tune "itself." On the other hand, these directives are so prominently present that they seem to be an inextricable part of the piece. However, rather than solving this musical undecidability, the tension, and even the uncomfortable feeling it evokes, they emphasize the focus on the interactions taking place, primarily the human-human interactions made audible in and through the rhythmically complex, interlocking patterns as presented and demonstrated by Coleman. Coleman himself seems above all interested in the play of action and reaction with his co-musicians; hence, the piece that results is not so much a final work as a by-product of a specific strategy for music making. As such, the beginning of "Laid-Back-Schematics" could be regarded as a good example of testing one of the most important qualities an improvising musician should have: the ease with which she is able to pick up and react to certain new impulses from fellow musicians. Therefore, my main interest here lies not so much in the solos (which seem almost secondary to the basic rhythmical structure), but mainly in the repetition of the short musical patterns leading up to a complex architecture of interweaving rhythms.

[3] The gradual stacking of melodic and rhythmical patterns, interlocking like tracing wheels, makes "Laid-Back-Schematics" sound like a machine. However, this should not be understood in the sense of mechanical music: mechanics is a system of closer and closer connections between dependent (f)actors. The machine, by contrast, is a "proximity" grouping between independent and heterogeneous actors or events (Deleuze and Parnet 1987: 104). Rather than focusing on subjects or objects as the initiators and defining actants, in Deleuze's machine, relationships are primary, e.g.

git

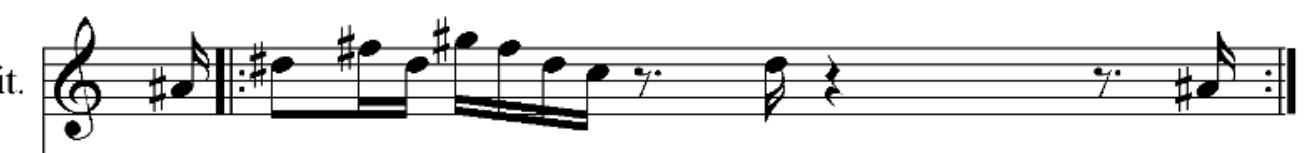

pno.

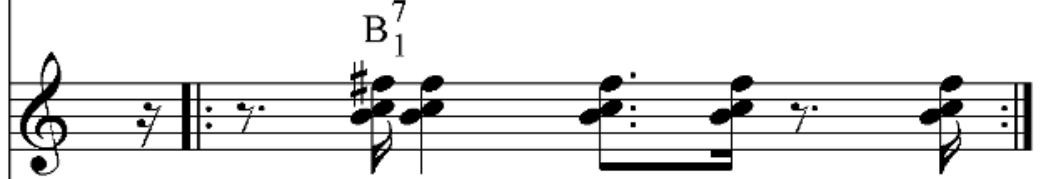

bas

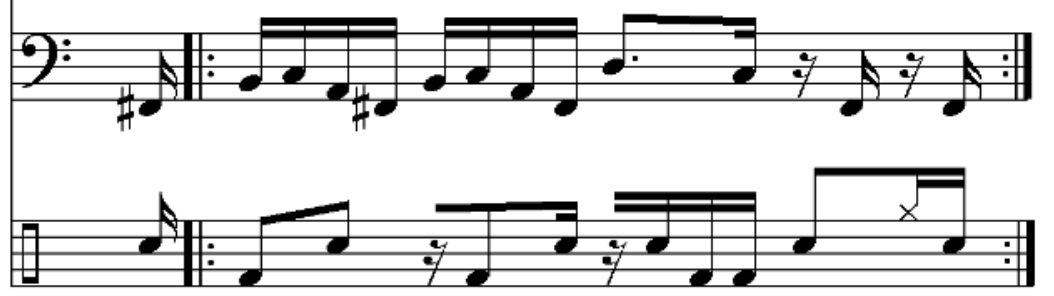

Figure 1 (Castelein 1995: 70) 
the relationships between the musicians performing "Laid-Back-Schematics" made audible through rhythm. And it is exactly relationships that deserve more attention here.

Each instrument gets its own, quite independent, rhythm. Proportionally, the guitar pattern has a longer duration than the other patterns (the relation is $5: 4$ ) which means that it presents a shifting layer in the rhythmical framework, a form of polymetrics. With the pattern Coleman has in mind for the pianist, the ambiguity would have been enhanced, as it starts one beat after the bass riff. However, it turns out that Milne is not able to maintain this pattern without Coleman's support; as soon as Coleman stops humming the rhythm, Milne changes it. After a short break

Coleman comes up with a new rhythmical proposal, an easier one as it coincides with the beginning of the bass riff.

git.

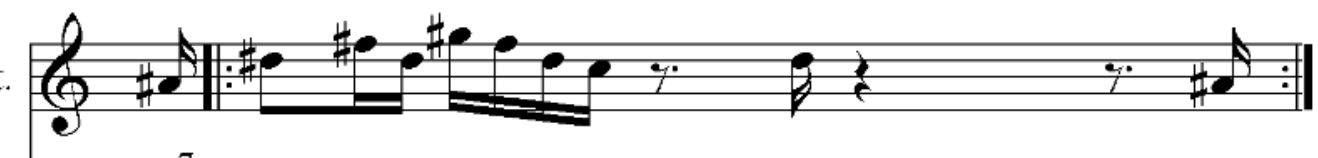

pno.

\section{$\mathrm{B}$}

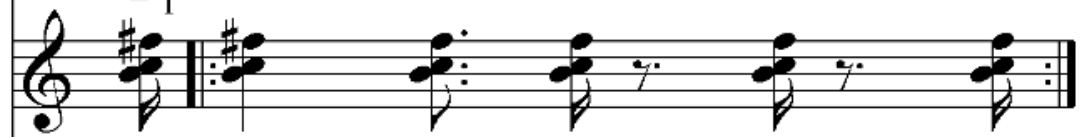

bass

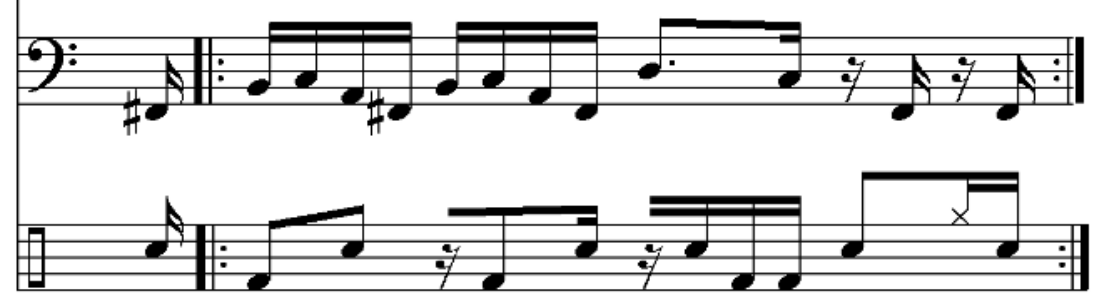

Figure 2 (Castelein 1995: 70)

It might be noticed that, at first, the drummer is also not able to repeat Coleman's sung idea exactly: he misplaces the proposed accentuated hit on the cymbal.

Coleman emphatically repeats the correct accentuation and waits till Lake is able to adopt it - "There you go."

Arguably, both Milne and Lake would have been able to repeat Coleman's rhythmical suggestions in another context, e.g. when he would have started with their patterns, instead of presenting them in relation to the already polymetrical context established by bass and guitar. In other words, it is exactly in the interactions and relations that these patterns gain their complexity; they are not complex in themselves. Milne's inability to play the proposed rhythm requires an adaptation to a new situation by both Coleman and Milne; within seconds they must explore new possibilities without letting the machine malfunction. Nevertheless, this adaptation has significant consequences for the eventual performance of "Laid-Back-
Schematics." Apparently, the overall capacities and capabilities extend beyond the scope of any of its participating members, yet are dependent on them.

[4] With Lévy, one could call The Five Elements a self-organizing or organic group:

Within a collectivity of this type, individuals obey rules, follow traditions, and respect codes. And yet, the organizing principles are not static, reified, or external to the group since they are maintained by the community as a whole. When a member of an organic group carries out an action, the others are immediately able to gauge how that action affects their own situation. (Lévy 1997: 52)

Improvisation is, almost by nature, permeated by dialogue, interaction, a sensitivity to others (adjusting what to do according to what is going on), and continual negotiation. These communication strategies between human actants are made manifest in and through the flow of sound and affect the musical process to a large extent.

As has become clear from the example above, the potential of interaction among improvisers - here, the rhythmical ideas advanced by Coleman - may not always lead to the projected musical results. However, according to Dana Reason, it is exactly this community dynamic without guaranteed success that reflects a social discourse put into practice through musical interaction (Reason in Fischlin and Heble 2004: 81). As intersubjectivity is so important in the practice of improvisation, Daniel Fischlin and Ajay Heble can rightly claim that improvisation is less about original acts of individual self-creation than about an ongoing process of community building (Fischlin and Heble 2004: 17). In my opinion, the micropolitics of the performance of "Laid-Back-Schematics" clearly supports this statement, as it is not modeled according to a pre-established plan; the social bond is immanent, integrating and creating synergy between the musicians' diversity of skills and individual qualities, without circumscribing or limiting them through the use of a priori molar structures (Lévy 1997: 54). 

doesn't mean you can conclude that they do nothing ... [Do not, MC] doubt the transporting power of all those humble mediators in making this a local place. (Latour 2007: 195)

[1] The Amplify 2002 Festival at Star's Pine Café in Kichijoji, Tokyo. First scheduled is the quartet of Taku Sugimoto, Tetuzi Akiyama, Otomo Yoshihide, and Toshimaru Nakamura, all on (semi-)electric guitar. Given the title of the festival, one could expect a Glenn Branca-like complex and noisy layering of guitar sounds playing with harmonic series and overtones. Instead, the twenty minute performance stages four men, bent over their guitars, listening strenuously, but hardly playing anything creating refuges of stillness in the midst of the fullness of acoustic stimulation. As Bill Ashline writes in the booklet that accompanies the registration of the festival in seven CDs and one DVD

the silence of the room, with only the occasional sound of movement in the chairs and activity in the bar, is briefly interrupted by the pluck of a string - with the silence intervening thereafter. The audience is nonetheless transfixed. The minimalism draws attention to the silence, making the audience dangerously aware of how fragile the circumstances of the performance are. Only one small mistake, a cell phone perhaps, the clumsy handling of a cocktail glass, the shuffling of feet and of chairs, potentially threaten the concentration, imperil the success of the program. (Ashline 2003: n.p.)

In Experimental Music, Michael Nyman writes that it was first of all Anton Webern who "composed" a unique dialectic between sounds and silences. Webern made listeners aware that sounds can be heard in silences, and that silence is an integrated part of the musical fabric (Nyman 1999: 38). With the performance of the Taku Sugimoto Quartet, "silence," understood, in Cagean terms, as all sounds already present in the venue, not only becomes an integral part of the improvisation but determines that improvisation to a large extent: the players musically react, comment and reflect on the environmental sounds that occur during their performance. In ultimate concentration they listen to how the sonic atmosphere unfolds, layer after layer, in order to cautiously add some sparse, single, soft notes. (One could call it an exercise in de-skilling, an effort to eliminate artisanal competence and other forms of instrumental virtuosity from the horizon of both artistic competence and aesthetic valuation. Quality, musicality, and technical abilities are not readily identifiable.) The musicians interact with each other, with the audience, with their instruments, but, primarily, with the silence. Silence becomes an important, if not the main actant, 
in this field of improvisation. The four musicians improvise on the different silences, with the different silences, as a result of the different silences, and these silences thereby become improvised as well. Thus, a complex interplay between musicians, space, audience, instruments, and silence comes into existence, resulting in an improvisation that neither fully dissolves into the already existing soundscape nor fully resuscitates itself as an autonomous event (LaBelle 2006: 168).

[2] In the experimental music scene of Berlin they call it "The New Silence." Johnny Chang (viola), Koen Nutters (upright bass), Morten J. Olsen (bass drum), the core members of this movement, aim to interact with a location by adjusting to the background sounds during a performance, thereby revealing and redefining the position of silence in improvised music. Incidental background sounds, sounds from everyday life, sounds from the performance space as well as from the urban surroundings, sounds usually referred to as silence, become an integral and substantial part of their improvisations. To this silence they add delicate, fragile sounds on the verge of the audible, reluctantly, not to interrupt, not to drown out, but to interrelate with the silence of the venue.

\section{play}

Johnny Chang, Koen Nutters, and Morten J. Olsen - “Adjustments Episode 2 - Chico Mello"

[3] Not only has silence become a crucial actant in these musical practices; so has the physical environment, the space, the acoustical qualities of the venue, the specifics of the room, which make the sounds behave in a particular manner. Both Sugimoto and Chang develop an extended sonic exploration of the performance space. The significant sonic architectural features of the venue are highlighted, consciously experienced, and incorporated into the soundscape of their improvisations. The musicians' creative inhabitations of the venues and their attentive listening lead to temporary, cautious, and sensible acoustic interventions and infiltrations, strongly influenced by the rooms' acoustics. The space is no longer a static object, not simply a given (if it ever was; especially contemporary concert halls are tunable and adjustable to enhance particular acoustical qualities), but has turned into a live instrument (LaBelle 2006: 192): Sugimoto and Chang are playing the space; they can be considered as organisms adapting themselves in order to cope with the environment (cf. Jacob von Uexküll and the Field of Musical Improvisation, sections 2 and 3).

The acoustics of the Rooms are so distinctive that I was pushed away from the kind of playing I'd had in mind; it seemed as though the room itself had something in mind too. (Parker 1993: n.p.)
[4] Interacting with the accidental sounds of a certain space at a particular moment, interacting with the unique audible silences, can only take place in and through improvisation. Any pre-composed, agreed, or notated music would at least diminish the conversational, reciprocally conducive, and actively integrating aspect of sounds and place. The silences or environmental sounds direct the ideas, interventions, and playing of the musicians. Listen and see how Sugimoto, Akiyama, Yoshihide, and Nakamura meticulously choose their scanty contributions. Listen to how they play the tones, sometimes raw with many interferences, at other times bright and clean, or with the pitch slightly altered through bending the string: universes of potentiality, each single tone a complex universe in itself. The sonic materiality of the venue shapes the contours of their sounds, molding it according to reflection and absorption, reverberation and diffraction (LaBelle 2006: x).

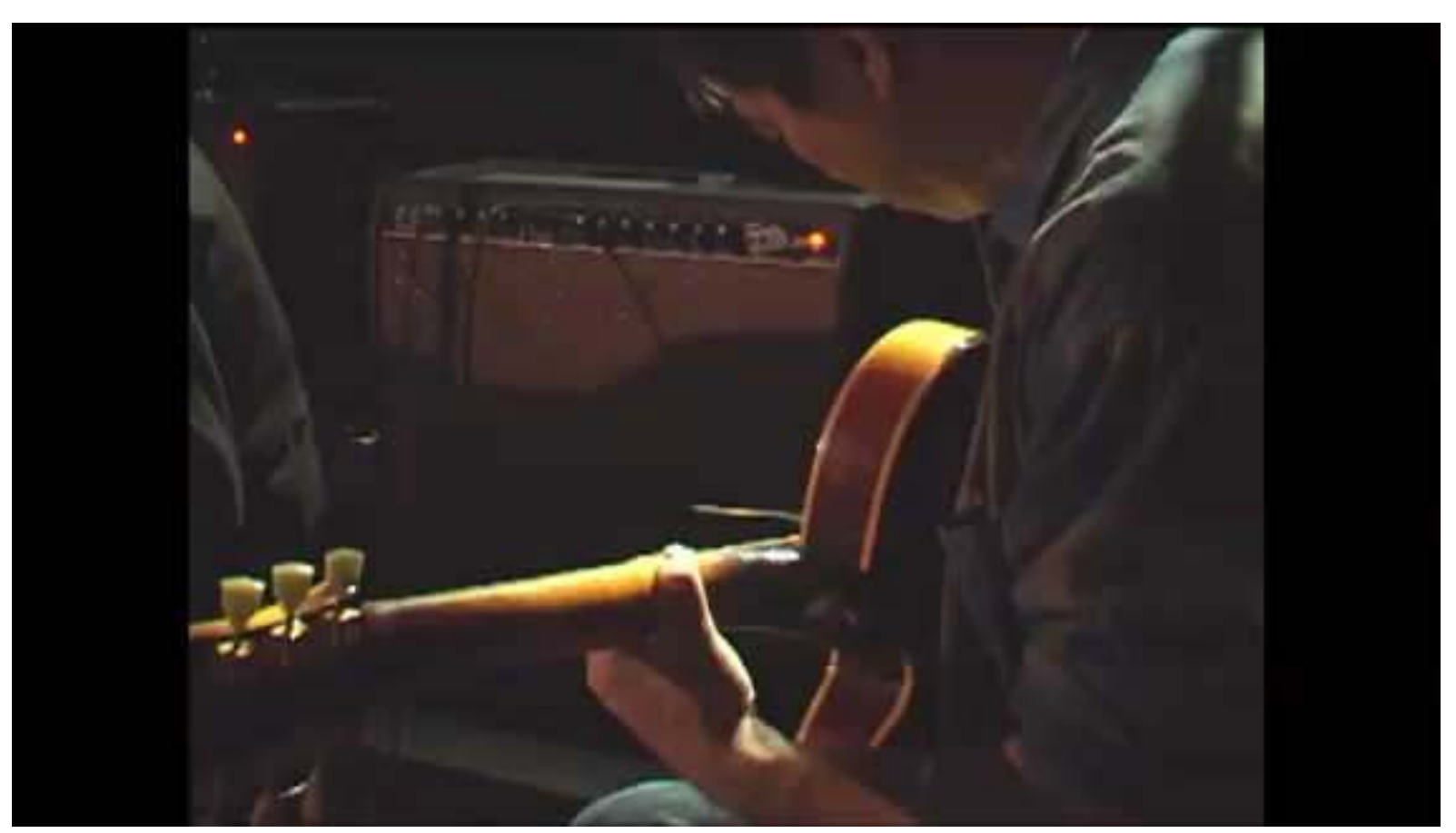

Taku Sugimoto Quartet - Live at Amplify 2002

Conversely, the musicians' playing makes the silences manifest, forces the groundfigure opposition to its limits by moving the environmental sounds from back- to foreground, and allows the space to become a box filled with exciting and refreshing sonic materials. The background contains the very substance through which the foreground gains significance. By accepting the inadvertent sounds/silences of the performance space as a decisive actant, improvisation becomes site-specific. It is articulating and articulated by space, silence, and accidental sounds, structuring and deconstructing the already existing silences or the acoustical events of place by giving them the chance to become important actants in the field of musical improvisation 


\section{Yo La Tengo - The Audience as Actant}

[1] Improvisation's responsiveness to its environment puts the performance in a position to be directly influenced by the audience [...] the effect of the audience's approval or disapproval is immediate, and, because its effect is on the creator at the time of making the music, its influence is not only on the performance but also on the forming and choice of the stuff used. (Bailey 1993: 44)

Bailey's statement might be summarized as such: the more a live music performance is improvised, the greater the influence of an audience on said performance. However, how an audience affects musicians and music might sufficiently differ with each show. Most obvious perhaps is the audience's impact during pop and jazz concerts when a musician plays a solo; positive feedback might encourage her to continue and impel her to unusual levels. Risk taking, originality, and spontaneity are often highly appreciated in these musics. In Javanese Gamelan music, however, the audience reaction towards musical innovation and the exploration of unknown terrain is more reserved, as it might display the relative inexperience and immatureness of a musician (Sutton in Nettl 1998: 77). During the concert of the Taku Sugimoto Quartet at the Amplify 2002 Festival, the role of the audience is quite different: they become cocreators of the improvisation as their accidental sounds - shifting glasses, shuffling shoes, coughing, cell phone ringing, etc. - are directly incorporated into and (thereby) transform the improvisation (cf. "The Taku Sugimoto Quartet and Johnny Chang - the Space as Actant", sections 3 and 4). I do not mean to suggest that in this particular example the audience's influence is more prominent or more direct; rather, the nature of the influence is different. Sugimoto prompts the listeners to become aware of the setting they find themselves in.

Contemporary art is definitely developing a political project when it endeavors to move into the relational realm by turning it into an issue. (Bourriaud 2002: 17)

[2] An alternative contribution of an audience to a concert featuring improvisation took place in the Amsterdam Bimhuis on 11 June 2009. After the first tune that evening, the three members of Yo La Tengo, rather awkwardly and unexpectedly, invited the audience not to ask for requests but to ask questions. The result was an uncommon unfolding of a pop concert. Question: "What will happen when you change instruments?" Answer: "Well, there's only one way to find out." Whereupon drummer Georgia Hubley takes the (acoustic) guitar, guitarist Ira Kaplan the bass and bassist James McNew switches over to the drums. A cover version of The Dead C's "Bad Politics" is the result. "Nuclear War", another cover originally from The Sun Ra Arkestra, is the culmination point of an answer to the question how it felt to collaborate with some members of The Arkestra. And following the question "Do you 
ever sing in another language?" McNew rushes to the dressing room to return with a small French booklet containing the Jacques Dutronc chanson "Et moi, et moi, et moi." He counts and the band starts playing.

As a result of this "Q \& A concert," Kaplan sometimes needs some preparation time, trying to remember the tunes and rehearsing the harmonic progressions, before the band can continue. The direct influence of the audience destabilizes and weakens the customary control (pop)musicians have over the macro-structure of a concert, the songs and their order. The video shows a short fragment of interaction between musicians and audience concerning the connection between Yo La Tengo and Sonic Youth, "subtly" redirected by Kaplan towards Neil Young.

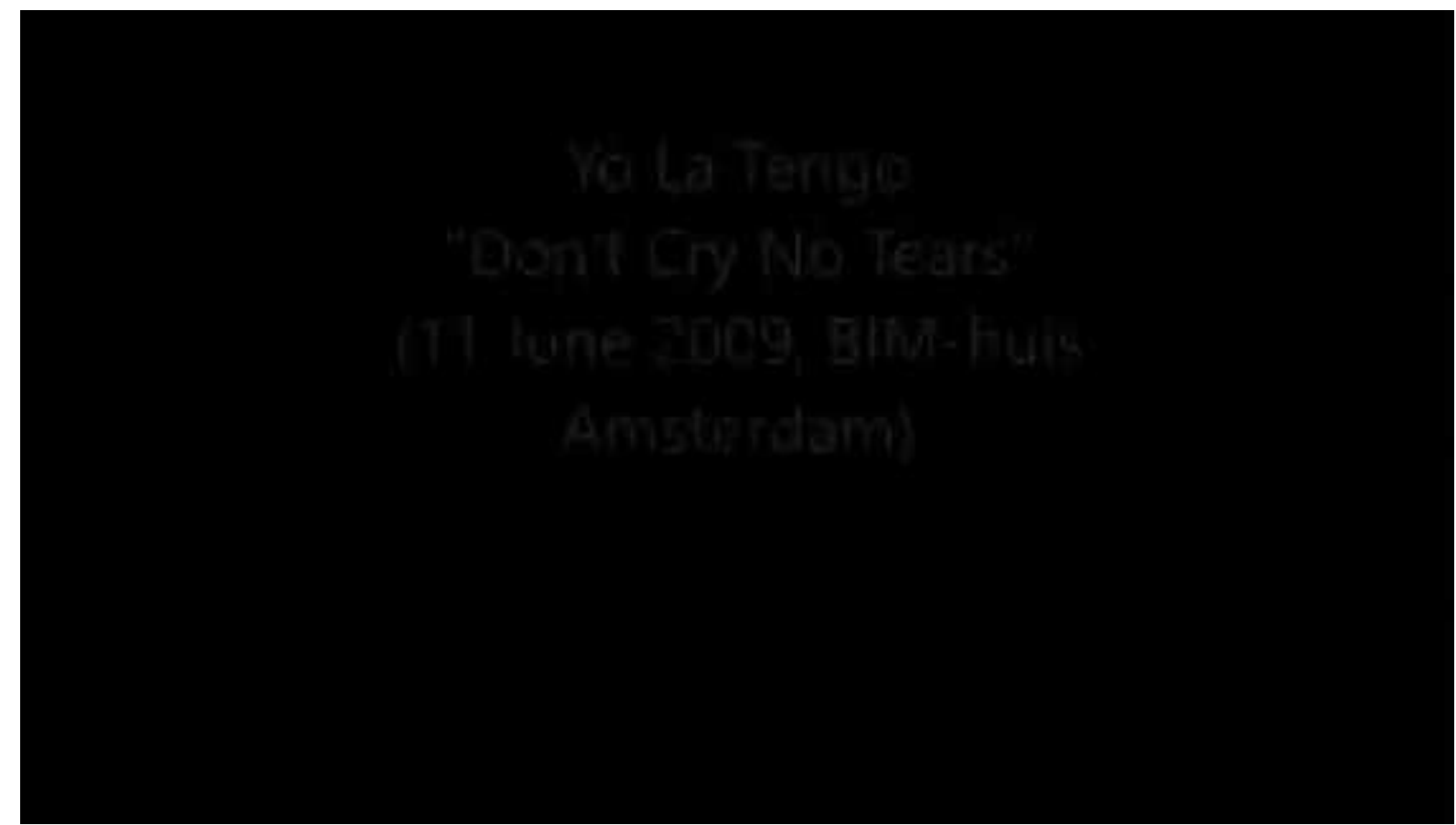

Yo La Tengo - “Don't Cry No Tears”

It is not so much the musical quality of Yo La Tengo's Bimhuis performance that I would like to highlight here; I would rather focus on the improvisation-audience axis, which is given a new dimension here. Yo La Tengo is somehow forced to improvise through their responses to the questions coming from the audience: the unexpected instructions not only put to the test the musicians' individual abilities and flexibilities but also determine the development of the concert as a whole, an event usually carefully planned in advance. The concert turns into a play of dialogues, negotiations, frictions, and expectations, enabling the emergence of something new, singular, and original that exists independent of its constitutive parts, musicians and audience (Landgraf 2014: 80); it is less about staged, "idealistic" improvisation as it is about the "real" practice of improvising.

[3] The auditorium's design not only discourages communication among members of the audience but also tells them that they are there to listen and not talk back. The performance is a spectacle for them to contemplate, and they have nothing to contribute to its course [...] Who we are, then, is spectators rather than participants, and our silence during the performance is a sign of this condition, that we have nothing to contribute but our attention to the spectacle that has been arranged for us. (Small 1998: 27 and 44)

With these words, Christopher Small characterizes the still common concert practice of classical music. The audience is condemned to a more or less passive consumerism; at least, the dividing line between music producer and consumer is almost absolute.

During the Yo La Tengo concert, the audience shifts between the status of consumer and the role of associate, guest, co-producer, and protagonist; it is, to a certain extent, actively involved in the production of the performance. The result comes close to Nicolas Bourriaud's definition of present-day art as "an activity consisting in producing relationships with the world with the help of signs, forms, actions, and objects" (Bourriaud 2002: 107). According to Bourriaud,

this generation of artists considers inter-subjectivity and interaction neither as fashionable theoretical gadgets, not as additives (alibis) of a traditional artistic practice. It takes them as point of departure and as an outcome, in brief, as the main informers of their activity. The space where their works are displayed is altogether the space of interaction, the space of openness that ushers in all dialogue. (Bourriaud 2002: 44)

Although Bourriaud's remarks are mainly based upon and directed toward highbrow plastic arts, what is important within the current context is, specifically, that the new no longer forms a significant criterion; central theme is the being-together, the encounter between musicians and audience. The Yo La Tengo concert can be described as an ecological system in which the environment, the social, and subjectivity form, inform, and transform one another permanently. What Bourriaud sees as a contemporary phenomenon starting somewhere in the early 1990s - the emphasis on the creation of relationships through art and the blurring of the border between the art producer and the art consumer emerging as a result of this desire has in fact always already been an inextricable part of most performing arts, perhaps especially within (highly) improvisatory musical performances. However, just as with all general remarks about interaction and relationships, Bourriaud's remarks, useful as they are, need to be connected to concrete artistic practices in order to see the many different possibilities of interaction and relating. With this reflection on a Yo La Tengo concert I have tried to describe one such inter-subjective project, taking the role of the audience as the main point of departure. 


\section{Nomen Nescio}

[1] Of course the list of possible artists, musical styles, albums, and performances dealing with improvisation is sheer endless. On the basis of, among others, the "examples" in this third part, you, the reader, undoubtedly can add your own

favorites in which improvisation, complexity, and singularity are combined. That is why this page will be reserved for you, for your own thoughts concerning this topic, for your own "case studies." Don't hesitate to share them with me: M.A.Cobussen@ umail.leidenuniv.nl. 


\section{Part 4}

\section{Exceeding}




\section{Introduction to Part 4 - Exceeding}

[1] One conclusion that could be drawn from the various lines of thought presented in Parts 1 to 3 might be that there is a need to add another analytical framework within which improvisation can be studied in order to be better able to take into account the various actants - a term I borrow from Bruno Latour - as well as the particular dynamics and interactions that are operative during a specific improvisation. Improvisation demonstrates complex and emergent properties that are greater than the sum of its parts; this requires an analytical model that transcends the investigation of actants in isolation of the network of surrounding actants and influences. Improvising, regardless of its cultural and historical particulars, is about complexity, not only in the sonic domain, as vibes coalesce and combine, but, more importantly, in the realms of intersubjectivity and interobjectivity. Emphasizing the specificities of every improvisation proved necessary; in each improvisation, different actants in different structures and different relations are active. Relying only on generalizations fails to do justice to the diversity of music making in which improvisation, in one way or another, always already takes place.

[2] Is improvising important? Is it necessary and useful to pay extensive attention to musical improvisation? Has the topic some urgency? When starting a new project, these questions always cross my mind. Why would I devote so many hours to dealing with a particular subject? Is it simply because I like it? Or is there something more? Is it, for example, because I am convinced - having been a music teacher specialized in improvisation for more than fifteen years - that (musical) improvisation can have a positive effect on someone...

Below, I will touch very briefly on three possible ways in which improvisation can affect one's being-in-the-world. This might sound pompous and pretentious, and it is often presented so. However, that is not my intention. Perhaps you can imagine this ex-student of mine, a prim middle-aged man, who once told me that, thanks to intensive lessons in piano improvisation, he dared to question and alter the agenda and seating arrangement at the conference table of a Monday morning meeting at his office. For me, such examples of behavioral adjustments already suffice as legitimization for the attention given to improvisation in and through music: improvisation as a (simplified) model of the real world. Perhaps improvisation is especially suited to test aspects of social interaction (because of its multiple potential significances). Perhaps it can create the conditions for different experiences of social space and social behavior. Perhaps it can break up entrenched orientations and simultaneously teach us to better deal with change, complexity, and chaos.

[3] In Improv Wisdom: Don't Prepare, Just Show Up, self-help advisor Patricia Ryan Madson expounds in thirteen maxims how someone can (and should) improvise her life. Her starting point is that the business mind is mostly looking for a formula to latch onto that will provide tried-and-true ways of solving problems. In general, we have become more cautious, less inclined to take risks in a world characterized 
by wars and crises. Safety has become the greatest good. However, Madson argues, the systems we put in place to keep us secure are often keeping us from our more creative selves. We find it hard to deal with setbacks and to react adequately to the course of life when it offers us something that we had not foreseen nor wanted. That is why the first maxim she discusses is called "Say Yes": say yes to the unknown and unforeseen, as it will open up new worlds that will enrich your life. When improvising, Madson says, one will make more mistakes, but one will also laugh more often and have more adventures (Madson 2005).

For Madson, to improvise means to affirm fear instead of rejecting all insecurities in advance: allow yourself to be afraid instead of trying to preclude it. In my opinion, music is perhaps the most appropriate field in which to experiment with such a maxim: it can be a relatively safe realm for exploring what might happen when a number of certainties are at least deferred for some moments. According to Eddie Prévost, improviser and cofounder of the AMM ensemble, risk and doubt are actually two crucial tools for the improvising musician (Prévost in Fischlin and Heble 2004: 355). In that sense, improvising in music might contribute to a life less built on an attachment to securities and safety.

Improvising music together may offer a consequence-free space in which to explore the complex dynamics created by a continual tension between stabilization through communication and instability through fluctuations and surprise. (Borgo 2005: 133)

[4] At the end of the text entitled "Labor, Work, Action," the first of five sections in The Vita Activa, Hannah Arendt writes that

without action, without the capacity to start something new and thus articulate the new beginning that comes into the world [...], the life of man [...] would be doomed beyond salvation. [...] Action, with all its uncertainties, is like an every-present reminder that men, though they must die, are not born in order to die but in order to begin something new. [...] With the creation of man, the principle of beginning came into the world - which, of course, is only another way of saying that with the creation of man, the principle of freedom appeared on earth. (Arendt 2000: 181)

It is Arendt's opinion that creativity, freedom, new beginnings, and insecurity - the latter being inextricably bound up with the other concepts - belong to the essence of the human condition, to man's being-in-the-world. And although her reflections are not about musical improvisations, many improvisers (at least in the Western world) will recognize them as distinctive features of an improvising process. In other words, improvisation in music might address, develop, activate, or intensify something essentially human; living is fundamentally improvisation, philosopher
Don Ihde maintains (Ihde 2007: 202). It might help us in accepting and dealing with an increasingly unpredictable, complex, and at times chaotic existence.

[5] In Music and Ethics (Cobussen and Nielsen 2012) I already elaborated on the role (free) improvised music might play in the - mostly philosophical - discourses on ethics as well as on concrete moral behavior. Various unexpected interactions, between musicians on stage or between musicians and electronics, for example, necessarily shift the emphasis of an aesthetical ethics based on individual responsibility to (moral or amoral) attitudes that stem from a responsibility that cannot be traced back to the input of each musician separately. However, this does not lead to an ethical behavior based on pre-determined rules and agreements; such would run counter to the principles of improvisation. Musical improvisation gives access to a third option, somewhere in the space between individual and collective ethical considerations (Cobussen and Nielsen 2012: 59-90). However, as Gary

Peters writes, "the much-heralded hyperawareness of the improviser should not be limited to an intersubjective, empathic awareness of the dialogical other, but should, rather, extend to the more fundamental issue of the beginning and continuation of the work" (Peters 2009: 98). Responsibility toward the work might ultimately be unconcerned with respecting the sanctity of the other's aesthetic space, without becoming unethical or amoral in the process. Improvisation in music - not simply as a spontaneous action, but as an interactive event between humans with multiple perspectives - thus contributes to provide us not only with alternative ideas on ethics and morality but also with concrete suggestions for ethical and moral behavior.

Congestion or confusion in improvised music [...] does not carry with it the immediate dangers of biological survival ... [W]e may be better prepared to survive and flourish in our increasingly interconnected, and therefore interdependent, world. (Borgo 2005: 133)

[6] However modest and small-scaled it may be, practicing improvisation confronts musicians with issues concerning (in)security, (a)morality, (un)freedom, creativity, etc. And through improvising, ideas about these concepts and concrete attitudes might change. Herein lies the justification for dealing with improvisation in music, a justification that exceeds the mere musical domain.

In addition, we need to immediately acknowledge that improvisation is not an exclusively musical affair. Both musical and extra-musical discourses can benefit from the idea that everyday practical life is packed with more or less unexpected and complex events that require an improvisational attitude. Better yet, improvisation is not a tool that can be turned on and off at will; especially in complex situations, people cannot not improvise at the same time they are striving for sense and 
meaning. Improvisation should not be understood in this context as exceptional or radical in terms of creativity, genuine novelty, and/or spontaneity; instead, it might be fruitful to recognize the quality of improvising as an everyday organizing process. Everyday life does not occur in a vacuum; it always occurs in a network of interactions, in a constant play of order and disorder, re- and de-organizing, stability and instability. Thinking about everyday life in terms of improvisation might help us to adapt in our own way to complex environments (Montuori 2003: 241-4). Thoughts of philosopher Philip Alperson lead in much the same direction:

If we think of improvisational activity along these lines, there would [exist, MC] an indefinitely large number of human activities that involve improvisation.

Indeed, improvisation would seem to be a feature of most, if not all, directed human thought and action. Improvisation is essential for our ability to learn to walk, to acquire language, to express oneself in bodily gesture, to develop skills of attention and appreciation, to build social skills, and to elaborate our understanding of our own selves. Perhaps, as Richard Barney has put it, our modern sense of individuality is an 'improvisational subjectivity.' Or, perhaps, following Judith Butler, social identity, and gender in particular, is a kind of performance, 'a practice of improvisation within a scene of constraint.' (Alperson 2010: 273)

[7] With this in mind, the three unexpended examples presented above can be regarded as the overture to the final part of this book in which I will touch lightly on the roles a discourse on musical improvisation can play in extra-musical contexts. As George Lewis says

many scholars are now asserting that the realization that the practice of improvisation is by no means limited to the artistic domain, but is a ubiquitous aspect of everyday life, can lead humanists, scientists, and artists alike toward the development of new models of intelligibility, agency, creativity, ethics, technology, and social and political transformation. (Lewis 2011: n.p.)

And on a different occasion he adds: "Thus, in addition to addressing the question of what the study of improvisation as such has to offer music scholarship, I want to ask what we music scholars can offer a wider field of critical improvisation studies, and what improvisation theorists can contribute to wider intellectual discourses" (Lewis 2013: 1). It would be far too arrogant and simply unrealistic to suggest that Part 4 will provide satisfying and conclusive answers to Lewis' question; however, I will present some cautious first initiatives - often taken by others and only supplemented with a few comments and thoughts of my own - to explore potential effects of thoughts on musical improvisation in extra-musical cultural fields. I hope at least to make clear that improvisation offers a particularly resonant topic for contemporary cultural debates.

\section{Revisiting Complexity Theories - Jimmy Giuffre, Paul Bley,} and Steve Swallow

[1] In Part 2 of this study, I have attempted to make plausible the idea that musical improvisation can be regarded as a complex system. Improvisation in music resembles biological, neurological, economic, and other systems in that it shows constantly changing, dynamic, and non-linear interactions between its various (human as well as non-human) actants; these actants are constantly organizing and reorganizing themselves into newly emergent structures. Studying improvisation from this perspective means shifting the focus from one particular component to the ways several components connect, relate, and determine one another. In Part 2 I recognized a similar way of thinking in Gregory Bateson's ecological system theory, Pierre Lévy's thoughts on collective intelligence, Gilles Deleuze's notion of assemblage, Mitchell Waldrop's explanation of complexity theories, Jakob von Uexküll's Umweltlehre, and Bruno Latour's actor-network theory. Although none of these thinkers pay attention to improvisation in music, my claim was that this field can easily be subsumed under the larger category of complex systems.

[2] However, it becomes necessary here to reassess the relationship between improvisation and complexity, to put forward a new connection, to rethink the unilateral subsumption described above. I will do so by bringing in one concept that is closely connected to complexity: emergence. Emergence, as it is generally used in literature about complexity, is the ability of low-level components to self-organize into higher-level systems of sophistication and intelligence. Local, parallel, cumulatively complex interactions result in some kind of discernable macro-behavior, and that behavior has the distinctive quality of growing smarter over time. Stated differently, higher-order complexity arises out of chaos, in which novel, coherent structures coalesce through interactions among the diverse actants of a system. So, instead of a hierarchical, top-down system that uses a centralized decision-making process based on abstract rules to guide behavior, complex, self-organizing systems are established through a bottom-up processing of a small number of rules by several interacting actants.

[3] In order to understand how improvisation, emergence, and complexity can be reconnected, de- and reterritorialized, I will briefly describe a piece by reed player Jimmy Giuffre, pianist Paul Bley, and bass player Steve Swallow from their 1989 live album The Life of a Trio: Saturday, their first recording after three studio albums dating back to 1961 and 1962. The album consists of free contrapuntal improvisations between the three musicians: “That's how it was done - no rehearsals, no false starts [...] There just weren't any alternate takes" (Carles 1989: n.p.). Often it is difficult to say who is the soloist, who the accompanist, and who the binding agent. The traditional division of roles is omitted, and the musicians base their contribution on their estimation of what the pieces need. Another distinctive feature is the space left for each of the musicians: playing simultaneously is the exception rather than the rule, resulting in a number of "silences" as an important additional musical parameter. 
Part One of "Clusters" begins with a piano solo, consisting of fast, antiphonal passages in the left and right hand, alternated by playing in unison or in contrary motion. In Part Two, soprano sax and bass join the piano, initiating a melodic interplay that lacks a clear harmonic structure, as hardly any chords are played. Each of the players contributes short and simple melodic fragments - sometimes alternating, sometimes blending - that interweave to form a musical tapestry with increasing and decreasing density and complexity. The structure is not pre-fixed, but gradually unfolds in and through the interactions of all actants and musical gestures.

[4] Loosely following the philosopher Donald Schön, I call the improvising quest of this trio a process of thinking-in-and-as-action, or an action/ perception feedback loop, borrowing this latter terminology from the composer Horacio Vaggione. While playing, Giuffre, Bley, and Swallow listen to their own playing as well as to the (re)actions of the others, which permanently leads to all kinds of adaptations and adjustments, finally resulting in this specific and unique performance of "Clusters." Put differently, their playing is not so much a result of a thinking process that precedes the music or that develops in isolation from this playing; this thinking, these adaptations and adjustments which arise from a critical reflection that occurs simultaneously with the playing, happens in and through their musical (inter)actions. Thought, perception, and action blend; mind, body, and environment are coupled.

Studying simple biological systems, such as seaweed, computer scientist and psychologist John Holland asked himself how these systems explore their way through an immense space of possibilities, with no realistic hope of ever finding the single "best" place to be. How can evolution explore this vast space and find a good way for a system to adapt itself to an environment without having to search over every square inch of territory (Waldrop 1992: 167-8)? The aim of improvising is probably not to find the "single best solution," nor is it possible for musicians to explore all potential "solutions" in a given situation. Nevertheless, confronted with complex circumstances, that is exactly what improvisers do: exploring the musical terrain in which they are thrown, investigating possibilities, trying out specific strategies in the knowledge that the "single best solution" will not only be a $u$ topia but also an atopia. Improvising means exploring this vast space and adapting oneself to the environment.

Giuffre, Bley, and Swallow create a specific, singular, and provisional order out of an amorphous and, in principle, infinite amount of musical possibilities. They react to the emergent, partly unpredictable, and complex flow of sonic, social, and physical events. Seeking and transgressing the borders of several formal structures (e.g. those of "free jazz," interaction, and the composition-improvisation dichotomy), they are thrown into erratic scenarios which need to be made musically significant. It is this complexity - this condition in which openness, versatility, and the unforeseeable overshadow predetermination, repetition, and familiarity - that triggers their improvisation. More broadly, one could say that improvising is an ongoing process of dealing with complexity through gestures and responses, a practice that exists only
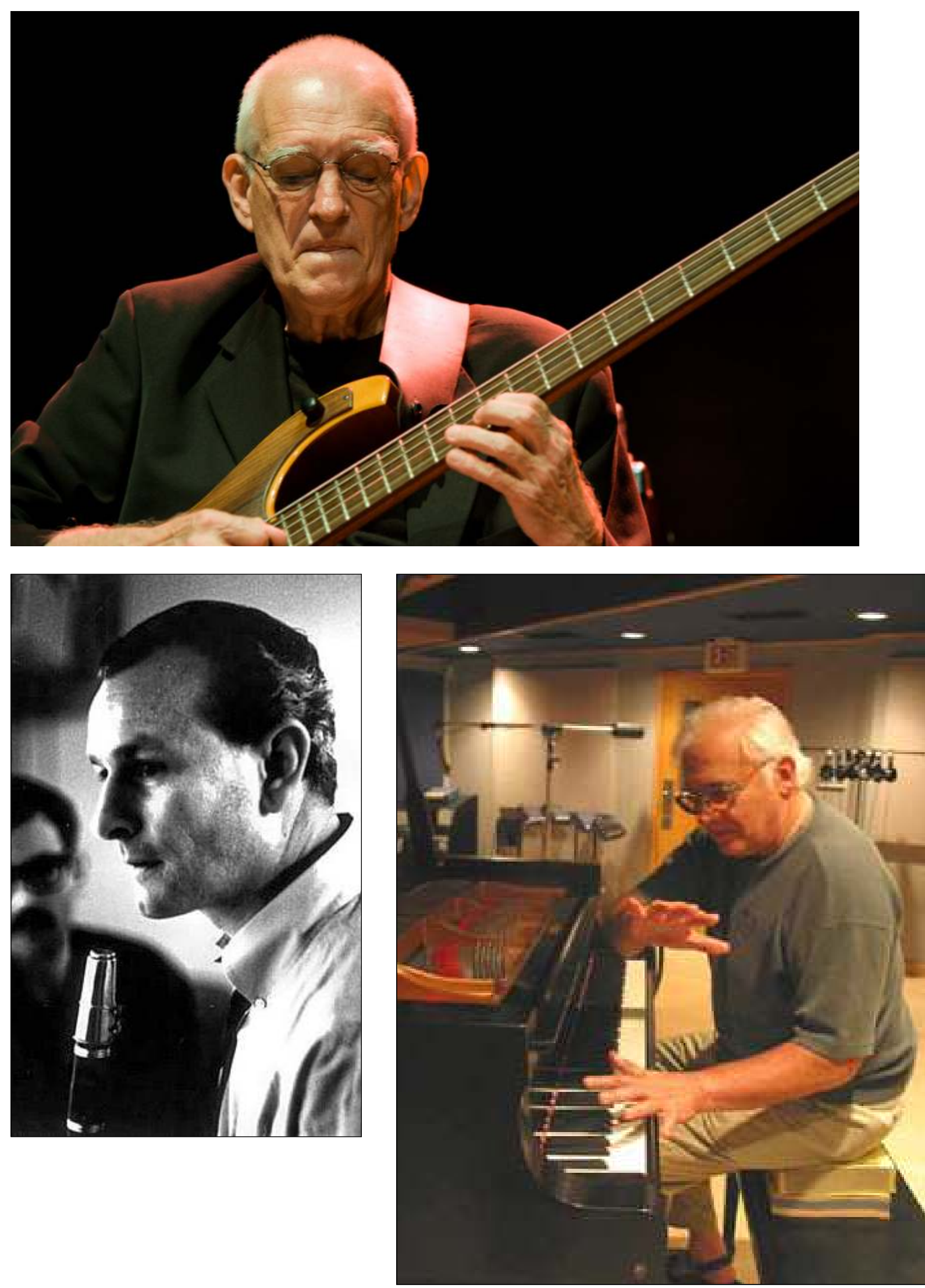

play

Steve Swallow, Paul Bley, Jimmy Giuffre - "Clusters" (Images, clockwise: Steve Swallow, Paul Bley, Jimmy Giuffre) 
in the evolving present; complex situations demand improvisation. And emergence, this actively searching for a momentary balance between chaos and order, can be regarded as an improvisatory process of making musical sense, of temporarily creating order out of a dynamic unfolding of a particular, complex situation.

[5] Through this brief analysis and interpretation of "Clusters," I arrive at the insight that simply regarding improvisation as another example of a complex system, although possible and also relevant, is not the end of the story; what needs to be added is that dealing with complexity demands an attitude which can be described as improvisatory. Musicians act in situations that are always already fluid and emergent, at least to a certain extent (that is, some more than others); these situations therefore call for improvisation, for entering the unknown while simultaneously being prepared as extensively as possible. Improvisation is thus not only one complex system among many others, but also a way of approaching and coping with complexity, a practice necessary to engage with complex situations, a response to instabilities.

\section{Freedom - Medeski, Martin, and Wood}

[1] It is very likely that the word or concept most often associated with improvisation is "(human) freedom" (e.g. Fischlin and Heble 2004; Nettl and Solis 2009; Peters 2009). Not only do laymen habitually equate improvising with doing whatever one wants to do, this understanding also holds a prominent position in $20^{\text {th }}$ and

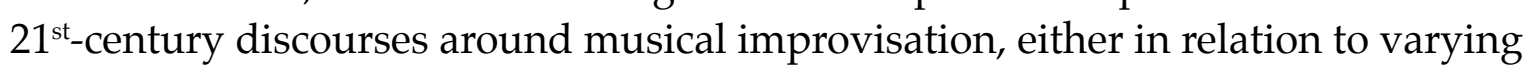
degrees of liberation from conventional musical parameters (e.g. Dean 1989; Prevost 1995; Nilsson 2011), by criticizing capitalism and the market economy (e.g. Attali 1985; Prevost 1995), or by offering responses and alternatives to all kinds of social, cultural, and ethical issues (e.g. Fischlin and Heble 2004; Peters 2009; Lewis 2013).

Therefore, the question seems legitimate as to what improvisation in music can offer to the concept of and more general ideas on freedom.

Of course it will not be feasible to try to come up with a satisfying working definition of "freedom" here, nor will I be able to shed light on the many different ways freedom and improvisation were, are, and could be connected. Nevertheless it might be useful and instructive to briefly touch on a contribution musical improvisation can offer to rethinking certain interpretations of "freedom" outside of the musical domain.

[2] A good starting point for discussing freedom in relation to improvisation might be Adorno's harsh criticism as formulated in his essay "On Jazz" from 1936. Although only referring to jazz music (which he - almost at least - equates with the popular [dance] music of the 1930s), Adorno rejects most improvisations on the grounds that they only offer pseudo-freedom, remaining subordinated to an objective order, e.g. a predetermined rhythm, meter, form, and/or harmonic scheme.

Even the much-invoked improvisations, the hot passages and breaks, are merely ornamental in their significance, and never part of the overall construction or determinant of the form. Not only is their placement, right down to the number of beats, assigned stereotypically; not only is their duration and harmonic structure as a dominant effect completely predetermined; even its melodic form and its potential for simultaneous combinations rely on a minimum of basic forms. (Adorno 2002: 477)

The improvising soloist seems willing to escape from these prearranged structures, but her individual efforts are just as much determined by clichés, formulas, and conventions. She is the sacrifice of the collective, relating to the collective in the same way syncopation relates to the underlying meter, or the verse relates to the refrain: different but obeying the law. "The ego begins to follow too weakly the standard of the collective which has been unproblematically set" (Adorno 2002: 490). The soloist is permitted to tug at the chains, but she cannot break them; she remains subordinated to the restrictions imposed on her by the collective. 
Adorno's main and general political-philosophical objective - a plea for a subject who is able to develop herself freely - doesn't resonate in the musical improvisations as he describes them, as they are, from the very beginning, too much limited by all kinds of objective and fixed laws; and because of these laws "very few possibilities for actual improvisation remain" (Adorno 2002: 445). Actual improvisation, and therefore perhaps also actual freedom, can only occur when a subject is able to free herself of any objective order.

[3] In a way, one could recognize Adorno's analysis not only in the popular music of the 1930s but also in (almost all) mainstream jazz played today. Certainly, jazz musicians, to this day, have (musically) questioned, criticized, and altered many conventions, but the very principle that a soloist improvises over a (more or less) pre-determined meter and harmonic structure still prevails. And the same goes for improvisations in "non-Western" music, in folk music, in pop, and in classical music. And free improvised music? Could that be the realm wherein "actual improvisation" is secured? Admittedly, musicians working in that musical domain have liberated themselves from all kinds of "restrictions" which still determine(d) most jazz music. But they too cannot escape from certain rules, conventions, formulas, and clichés. Repetition of particular patterns, forms, melodic and harmonic vocabularies, and interactions also permeate so-called "free jazz" and "free improvised music."

Let me be clear: this is no criticism, no disappointing observation following so many attempts to innovate music and invent new improvisational styles: improvisation always happens in a space between the fixed and the fluid, in a space determined by repetition and alteration. What I want to maintain here is that Adorno's ideas about "actual improvisation" and individual freedom, as not restricted by objective orders of any kind, may not be the most productive way to think about freedom in general and the relation of improvisation to freedom in particular. Said differently, musical improvisation might be able to nuance and refine a thinking that starts from the premise that personal freedom or individual autonomy means being free from any form of (external) regulation; at least, improvisation in music confirms that this idea of freedom is rather utopian, unrealistic, and (so far) non-existent.

[4] So what is it that the field of musical improvisation has to offer to the political, social, and / or ethical discourses on freedom, aside from the relativization stated above? In Improvisation as Art, germanist Edgar Landgraf maintains that "improvisation cannot be decoupled from structure and repetition; rather than being the expression of unbridled freedom, improvisation must be seen as a mode of engaging existing structures and constraints" (Landgraf 2014: 11). Another interesting observation comes from musician Ann Faber talking about collective improvisation: "Our aim is to play together with the greatest possible freedom - which, far from meaning without constraint, actually means to play together with sufficient skill and communication to be able to select proper constraints in the course of the piece, rather than being dependent on precisely chosen ones" (Faber in Belgrad 1998: 2, my italics). In this quote, freedom in and through improvisation lies not in striving for a formless music; it is not an "anything goes" but involves collective discovery in a communal environment, resulting in form-making music. Medeski, Martin, and Wood's "Invocation" from the CD Tonic gives a musical expression to Faber's words: out of relatively loose interactions between piano, bass, and drums, rhythmic or melodic patterns emerge frequently, which can be left behind at any moment in favor of a search for a next pattern, which will be or won't be accepted as a temporary anchorage by all three musicians.

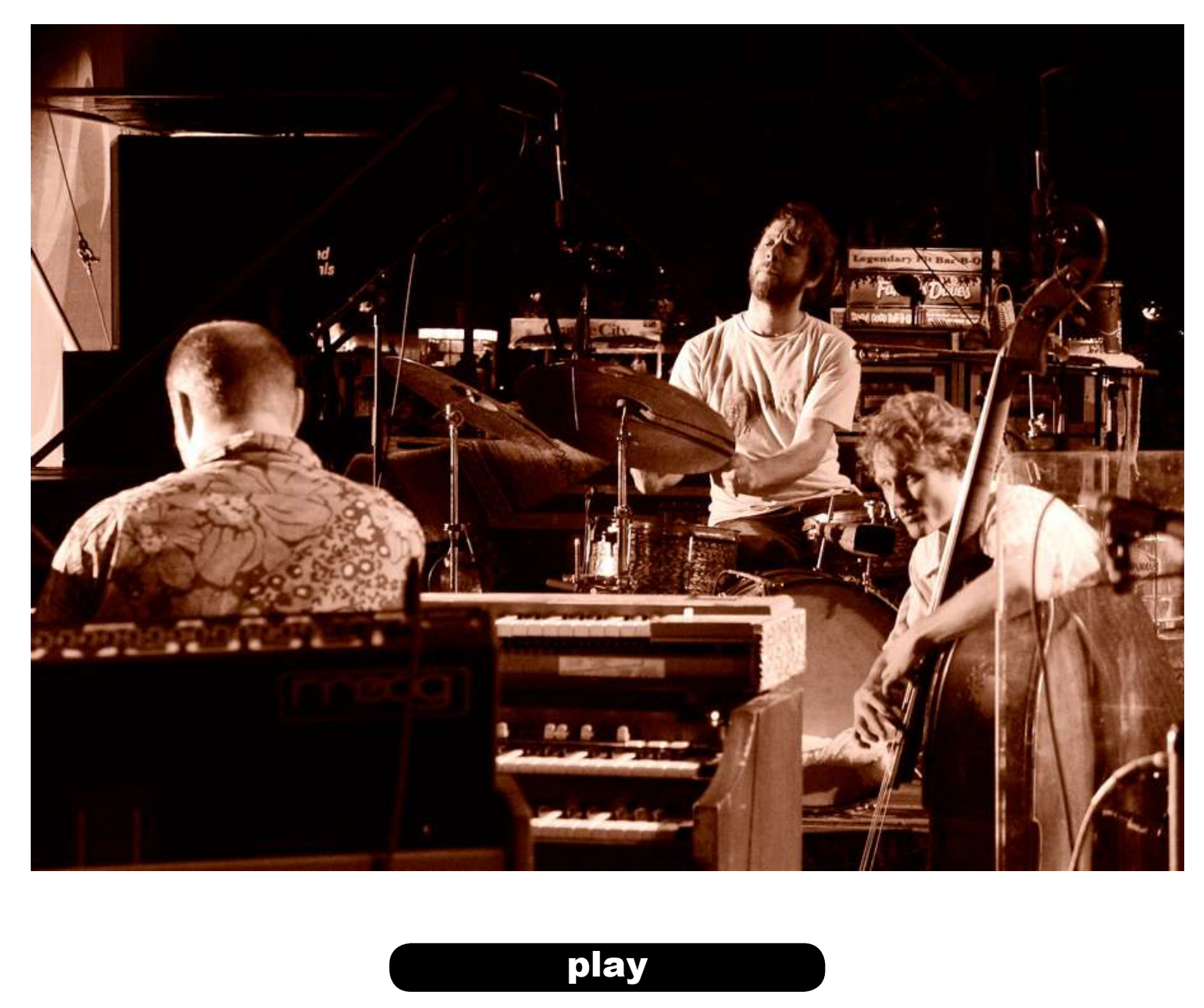

Medeski, Martin, and Wood - "Invocation" (Image: Medeski, Martin, and Wood)

What "Invocation" makes audible is that improvisation is not one pole in the freedom-fixity opposition, not criticizing and exchanging any form of determination in favor of a complete lack of restrictions. Rather, improvisation can be regarded here as a constant play between these two poles; better yet, the one is always already present within the other, not only because each presupposes the other, but because there is always a certain amount of freedom in any fixedness or order and vice versa. "Invocation" makes listeners experience the mutually constitutive relationship between control and spontaneity, between order and disorder, between 
constraints and possibilities, between freedom and fixity. Order without any unpredictable, free elements is complete homogeneity. Freedom without any order is mere chaos (Montuori 2003: 250). Complex systems, improvisation being one of them, contain both order and disorder, freedom and fixity, simultaneously. The first notes of "Invocation" already illustrate this "double bind": although (probably) not played at random, they also seem not to be predetermined. The repetition of the musical gestures tend toward a certain amount of fixity; and yet, within these recurrent patterns, many elements continually fluctuate, thus presenting differences within repetitions, or freedom within fixity as well as fixity within freedom. The continuation of the music is profoundly influenced by this beginning. However, concurrently, it can branch off into many directions and lead to an emergent order in ways that are intrinsically unpredictable. All actants contributing to the musical development can affect which subsequent path the music pursues, however, always within certain constraints.

In The Other Side of Nowhere Daniel Fischlin and Ajay Heble call it a mere myth that improvisation in music involves adherence to neither convention nor protocol, that it tolerates no system of constraint, and that it is best understood as a kind of free zone where someone is responsible only to herself and to the dictates of her taste. Instead it presents "multiple possibilities for resolving the paradox embedded in the trope of organized freedom" (Fischlin and Heble 2004: 23 and 32). Investigating concrete improvisations can lead to what Alfonso Montuori calls a "post-dichotomous" thinking, e.g. a thinking in which freedom and fixity or order are not regarded as binary oppositions anymore but instead as two sides of one concept, presupposing and interacting with one another.

[5] In The Embodied Mind, Francisco Varela, Evan Thompson, and Eleanor Rosch have offered almost the same line of thought with regard to freedom and the autonomous subject. They also stress the idea that freedom cannot be achieved in (relative) isolation but takes place in interaction with others.

In modern society, freedom is generally thought of as the ability to do whatever one wants. The view of codependent origination is radically different. (One contemporary Buddhist teacher even titled a book The Myth of Freedom.)

Doing whatever one wants out of a sense of ego (volitional action), according to this system is the least free of actions; it is chained to the past by cycles of conditioning, and it results in further enslavement to habitual patterns in the future. To be progressively more free is to be sensitive to the conditions and genuine possibilities of some present situation and to be able to act in an open manner that is not conditioned by grasping and egoistic volitions. This openness and sensitivity encompasses not only one's own immediate sphere of perceptions; it also enables one to appreciate others and to develop compassionate insight into their predicaments. (Varela, Thompson, and Rosch 1991: 123)
The second contribution the practice of improvisation can make to discourses about freedom is in questioning the emphasis, "common in modern society," on individual forms of freedom. Varela \& co. oppose this idea by stating that, both with and without preexisting rules and regulations, we always interact with our environment, navigating through time, place, and situations. This characterizes not only our human everyday life but also musical improvisation. According to Fischlin and Heble, the assumption that improvisation is, first and foremost, about unblocking the obstacles that impede access to forms of individual self-expression should be reconsidered. Improvisation, instead, "has been about community building (rather than individual self-expression), about fostering new ways of thinking, and participating in, human relationships" (Fischlin and Heble 2004: 22-3). What the practice of musical improvisation can specifically add to thoughts about freedom is that freedom is established, developed, and negotiated in a direct relation with the environment, consisting of both human and non-human actants.

"Invocation" is not about three individuals trying to liberate themselves from the constrictions the others impose on them: a mode of personal freedom is made possible precisely through their tight cooperation. The same goes, mutatis mutandis, for the (almost) inevitable interactions with the other actants operative in or during the performing of "Invocation": instruments, acoustics, and technology are just three actants that not only regulate certain musical choices and discipline musical behavior but also give access to new ideas through their mere in- or output, inspire by offering resistance, and activate an exploratory attitude. The more the environment is allowed to influence the individual musician, the greater her freedom of choice.

[6] Writing about the difference between a Eurological and Afrological approach to improvisation, George Lewis states that, freedom in Afrological improvisation "is perceived as being possible only through discipline, defined as technical knowledge of music theory and of one's instrument as well as through attention to the background, history, and culture of one's music" (Lewis in Fischlin and Heble 2004: 153; cf. Vlatko Stefanovski - The Past as Actant, section 5).

Freedom in improvisation is not about functioning within high degrees of uncertainty or unpredictability per se. According to Gary Peters, in agreement with Lewis, discipline is necessary as it offers the improvising musician the certitude of what to do and how to do it and, simultaneously, the certainty that the final result could have been otherwise (Peters 2012: 7). Freedom of choice does not mean that the improviser liberates herself from the forces that allegedly devastate this "ability" - the past, the collective, the environment, etc.; this would be nothing more than "brute negativity" (Peters 2009: 73). Freedom is inconceivable without the discipline of preparatory work and can only be achieved with and through rigorousness, with and through a continuous interaction with the forces that together (in)form the environment in which the musician acts. 


\section{Management - Richard Barrett}

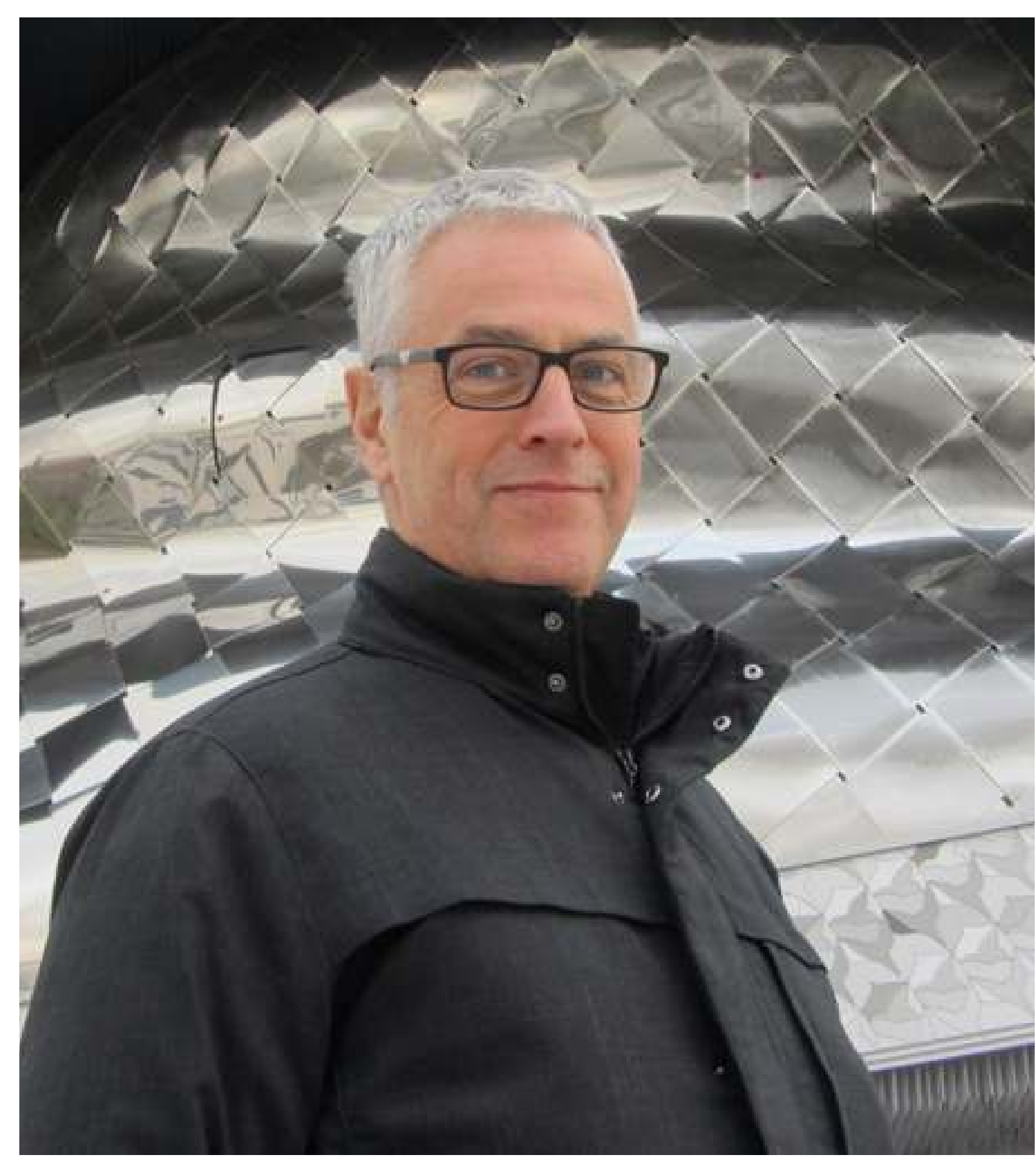

Richard Barrett
[1] As explained in the introduction to Part 4, it is my principle aim here to offer a few meditations as to how insights directly stemming from the field of musical improvisation can in one way or another contribute something to extra-musical discourses, disciplines, cultural fields, and / or events. Not too much effort needs to be made when trying to map out the influence of thoughts on improvisation within the domain of management theories and organization studies. Journals such as Communication Research (15/5, 1988), Organization Science (9/5, 1998), Organization Studies $(25 / 5,2004)$, and Negotiation Journal $(21 / 4,2005)$ have dedicated special issues to the role of improvisation in management practices and organization theories; along with theater, most examples and inspiration were taken from music. Also, several monographs have been published on this topic (e.g. Weick 1995; Kamoche, Cunha and Cunha 2002; Keefe 2003; Madson 2005; Shaw and Stacey 2006; Vyas 2014), often containing references to standard works of jazz literature, such as Paul Berliner's Thinking in Jazz and Barry Kernfeld's What to Listen for in Jazz.

[2] A closer look at this literature could lead to two general observations. First, authors such as Ciborra (1999), Kamoche, Cunha and Cunha (2002), and Dehlin (2008) refuse to regard improvisation as a rare, extraordinary, magical, or elitist phenomenon; rather, they consider it to be a fundamental trait of existence, an integral aspect of everyday life (Dehlin 2008: 38). Almost all human activities require some kind of spontaneity, imagination, and/or creativity, three concepts that these authors relate more or less directly to improvisation.

Their central idea is very much in line with my own position that improvisation takes place in all music making instead of being an exclusive preserve of specific musical gestures (cf. The Omnipresence of Improvisation, section 1). Although I am not the only one within the musical discourse claiming this - according to, for example, George Lewis, improvisation is a basic human condition (Lewis 2013: 2) - I nevertheless regard this idea, stemming from management and organizational studies, as a gift to music and its discourses. As the Norwegian scholar Erlend Dehlin (2008: 327) writes in "The Flesh and Blood of Improvisation. A Study of Everyday Organizing," there is no reason why improvisation should be made into some exceptional attribute of certain contexts or professions.

Improvisation is a mode of action, or even attitude, that involves not only degrees of spontaneity but also an implicit valuation of such freedom with respect to the activity. Such a broad conception accords with the word's use in everyday language, in which it means so much more than a certain kind of musical performance. (Sheehy 2013: 1)

The second observation, however, I appraise less positively. Many authors seem to create an opposition between improvisation on the one side and planning, routine, 
and structure on the other. Furthermore, this opposition is constituted hierarchically: improvisation is (re)presented as a form of inferior or ad hoc action that occurs when planning breaks down. It is a downgraded (re)action of coping with unplanned events by people lacking the ability to predict, analyze, and plan properly (Dehlin 2008: 3; Ciborra 1999). While in music and in the other performing arts improvisation is more and more accepted and respected, in management and organizational theories it is often still regarded as a kind of emergency measure, an admission of weakness.

It is especially with regard to this latter prejudice that the field of musical improvisation can offer some alternative thinking and acting. Through a

short analysis of cell, a piece by the British musician Richard Barrett, several counterarguments can be formulated in response to the alleged opposition between improvising and planning.

[3] In "Notation As Liberation" Barrett describes a development in his own works that can be characterized as a deconstruction of the opposition of improvisation and composition, a development he terms "seeded improvisation." On the one hand, improvisation becomes a method of composition, on the other hand, notation is used to "suggest possible directions or possible points of focus" and regarded as "a liberating factor in improvisation," thereby "freeing the imagination" (Barrett 2013: n.p.). For Barrett, composing and improvising are not two distinct qualities; they are just different strategies of dealing with musical materials. His music moves between fully notated parts and unspecified improvisatory passages, without a listener being always able to distinguish between the two. Structural inconsistency becomes a compositional variable in the notated parts, while, simultaneously, these notated parts affect the improvisations, though without prescribing them.

cell, for alto sax, accordion, and contrabass, written for the Norwegian trio POING in 2011 is an example of the use of this seeded improvisation technique alternated with fully-coordinated trio sections.

play

Richard Barrett - cell (excerpt)

Although cell consists of composed and improvised parts, it is clear that this duality cannot be equated with e.g. fixity versus fluidity or structure versus disorder. Both musical strategies contain controlled and spontaneous elements, constraints and possibilities; both combine traditions or conventions and risk taking. cell fluctuates between stability and turbulence in the composed as well as in the improvised parts. More in general: To connote improvisation solely with fluidity and contingency implies rendering it in essentialist terms that work to elide the complexities and contradictions that comprise it. Improvisations contain unpredictable but also more stable behaviors; repetitive elements, sophisticated variations, or melodic sequences do not function deterministically, but they can serve to keep an improvisation from sounding random or arbitrary. That is why Alfonso Montuori can describe the phenomenology of improvisation as "a series of dialectical paradoxes," as "postdichotomous," or "complex" (Montuori 2003: 250-1). Improvisations occur in contexts, in histories, which somehow restrict their leeway; however, simultaneously, improvisations affect these contexts and histories, thereby occupying a space of freedom and choice. In short, improvisations take place between planning and decision-making on the spot; they move from fixity to fluidity and back again; they oscillate between order and chaos, diachronically or synchronically (cf. "Mitchell Waldrop and the Field of Musical Improvisation," section 3).

[4] Dehlin already seems to have heard this call from comprovised music. Taking "technical rationality" as a metaphor or equivalent of control, planning, or predetermined structures in organizations, Dehlin argues that this form of rationality, usually presented as a given set of rules, might become an instrument rather than a restraint jacket, not to be obeyed and followed indiscriminately, but to be used creatively and spontaneously: "Abstract models such as rules and structures, which are essential for the execution of technical rational action, can be used in improvisation as tools" (Dehlin 2008: 94-5).

To make this change in attitude - from prescription to potentiality, from the fixed to the fluid - more concrete, I will consider the concept of routine as it is dealt with by various authors of organization theories. In general, routine is described as a standard procedure, an unvarying or habitual method, and a fixed, detailed course of actions to be followed regularly, strictly, and unimaginatively. Understood as such routine is a concept contemned by many musicians, especially those coming from free improvised music. According to them, routinization hampers the development of creativity as well as the search for the unexpected and the new (e.g. Bailey 1993:

53 and 115; Prévost 1995: 65 and 74). In short, "improvising cannot be learnt by rote" (Prévost 1995: 138)

However, according to management theorists Brian Pentland and Henry Rueter, routines do not determine the future nor do they describe the past; at most, they constrain a set of possibilities (Pentland and Rueter 1994: 508). This is so because routines as such do not exist; in practice such generalizations as provided in the above definitions cannot even be found. Routines are continuously constructed and reconstructed, shaping and being shaped by individual actions, social interactions, and specific contexts. In that sense, routines can never be exactly repeated and are (thus) always improvised upon. Consequently, any organizing practice is always already permeated by a degree of unpredictability, and improvisation concerns the challenge of how to make this technical rationality - these rules, routines, structures, plans, and systems - work within a specific situation (Dehlin 2008: 230). As stability and order will always remain provisional, improvising is constantly needed. 
To improvise on a routine means to continually evaluate it in the light of the perceived best way of action taking context into consideration. This means that even if action seems routine-like, the actual thought processes preceding or taking place in action can be improvisatory. (Dehlin 2008: 112)

Thus, routines must be made to work: analyzing which routine best fits a particular situation and how it can be adapted to specific circumstances. Instead of merely providing a sense of security, of making a situation in which something unexpected occurs manageable, routines function as useful tools for particular contexts to which they must be adapted.

In much the same way as routines, structures and plans emerge through human practice, rather than being (pre)determined, (pre)fixed, and (pre-)established by insensitive planning and system implementations; instead of stability and rigidity, and instead of functioning as control instruments, they provide guidance, can act as sources of inspiration, and offer creative points of departure: "Strategic plans are a lot like maps. They animate and orient people" (Weick 1995: 55) and "what may look as planned, structured decision making appears to be intrinsically improvised" (Ciborra 1999: 79).

Conversely, improvisation does not a priori exclude planning, creating structures, or relying on certain routines. It can be conceived of as a more or less spontaneous acting according to a situation's demands; and particular situations might demand plans, structures, or routines. Effective organization can be discovered within improvisation: formal and/ or unwritten rules (rules for harmonization, voicing, and substitutions, or conventions of phrasing and timing) function as (necessary) constraints. Therefore, technical rationality and improvisation are woven together and involve each other. The former is (almost) always subjected to scrutiny and adjusted to fit a particular context; the means of organizing changes in an ongoing process of self-renewal that never happens in isolation and abstraction. This living process of making it work in specific situations is a matter not only of practical wisdom but also of improvising.

[5] Just as Barrett's cell criticizes a rigid opposing of improvising and composing, it is hard to maintain an unavoidable, natural, and categorical separation between improvisation and technical rationality in the practice of organizing and managing In any given instance, the former might in fact entail the latter, although, of course, organizational processes vary between being more or less improvisatory and, consequently, more or less technical-rational. The two constructs, antagonisms in theory, seem much less easy to separate in practice. Management and organization studies might benefit from this "non-dualistic counter-move against improvisation as either present or not" (Dehlin 2008: 233) which is already apparent in music. Allowing improvisation to play a role in (daily) routines, planning, and organizing is a worthwhile development, but it is equally important to be aware that improvisation is in fact always already present in each process of decision-making, in each action.

\section{Play - John Zorn}

[1] "A major aesthetic tenet [...] is that musical improvisation has strong similarities to gaming, play, and sports. This should not be seen metaphorically: rather, to improvise is to play a game" (Nilsson 2011: 77). These are the opening sentences of a chapter in A Field of Possibilities, the $\mathrm{PhD}$ dissertation by saxophonist and artistic researcher Per Anders Nilsson concerning the possible roles of digital instruments in an improvisatory setting.

Equating improvising with playing a game is not new, if only because "making music" is often replaced by the word "playing" while "musicians" are "players." Several features connect playing a game to music making in general and improvising in particular. To investigate the similarities, I rely here mainly on Johan Huizinga's thoughts on play in his book Homo Ludens from 1938:

- With both, participation is voluntary. Playing implies the gratuitous effort to overcome (unnecessary) obstacles. Playing on command is no longer play. According to Huizinga "a play can be deferred or suspended at any time. It is never imposed by physical necessity or moral duty. It is never a task. It is done at leisure, during 'free time'" (Huizinga 1970: 26).

- They both incorporate and come into being through rules. Huizinga: "All play has its rules. They determine what 'holds' in the temporary world circumscribed by play. The rules of a game are absolutely binding and allow no doubt" (Huizinga 1970: 30). Brian Massumi expresses himself in a similar way: rules frame the game, "describing its form as a set of constant relations between standardized terms" (Massumi 2002: 71)

- Closely connected to the presence of rules is the idea that play generates order. "Play demands order absolute and supreme. The least deviation from it 'spoils the game,' robs it of its character, and makes it worthless" (Huizinga 1970: 29). In that sense seriousness is necessary to make the play wholly play (Gadamer 2004: 103)

- $\quad$ Rules and order make possible that play and improvisation become meaningful in themselves. "It is a stepping out of 'real' life into a temporary sphere of activity with a disposition all of its own [...] It interpolates itself as a temporary activity satisfying in itself and ending there" (Huizinga 1970: 26-7; Small 1998: 63).

- $\quad$ Taking place outside everyday life also implies that both begin and play themselves to an end. In other words, both have certain time limitations and can be repeated over and over again. The element of repetition, which simultaneously implies alternation, codetermines the inner structure of play and improvisation (Huizinga 1970: 28)

- $\quad$ Both are not only limited in time, but also in space. "All play moves and has its being within a playground marked off beforehand either materially or ideally, deliberately or as a matter of course" (Huizinga 1970: 28).

- $\quad$ "Baby reaching for a toy, pussy patting a bobbin, a little girl playing ball - all want to achieve something difficult, to succeed, to end a tension" (Huizinga 1970: 29). This element of tension arises from the innate compulsion to expand one's own skills; any game requires the development of competences, be they physical, mental, or social. 
[2] On the basis of this far-from-exhaustive list of similarities between play and improvisation, the question I wish to raise here is not so much about whether improvisation can be considered as a kind of game, a subdivision of the category "play," as to what improvisation can contribute to the current ideas, theories, and reflections on play. A valid contribution might be, for example, that one or more characteristics of play mentioned above are questioned, challenged, or refuted, thereby enriching its conceptualization.

To take up this challenge, I will turn to one of the most paradigmatic game pieces in the field of improvisation, John Zorn's Cobra. Rather than regarding Cobra as a piece of music, I think it can be considered a good example of music theater; in my opinion, it is absolutely necessary, for a complete experience of the piece, to be able to see all interactions taking place between the musicians as well as hearing them. Cobra is a piece for an, in principle, unlimited amount of players and one prompter. The prompter holds up cue cards of various colors, each containing a coded instruction for the players. A yellow card with the letter " $R$ " on it, referring to the word "Runner," means that the prompter will point to any number of players; those who are pointed at come in on the downbeat, while the others stop playing. A white card with the " $\mathrm{T}$ " of "Trades" means that the music is passed along a chain of players, one by one. Red cards with a 1, 2 or 3 on it indicate that the musicians should memorize what they are playing and repeat it once the same card is held up again.

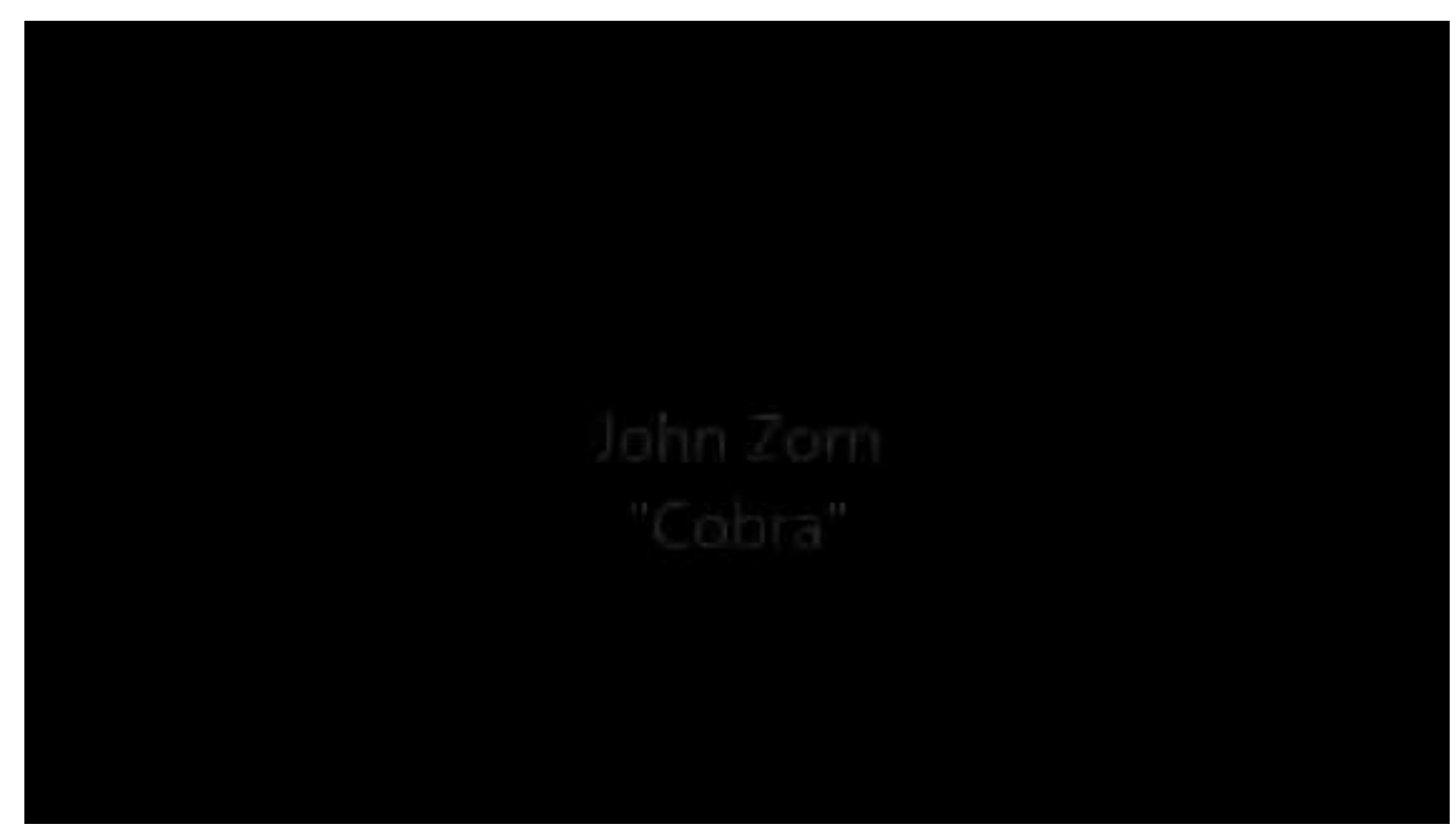

John Zorn - Cobra

To increase the amount of possible interactions, not only the prompter instigates specific musical gestures: the musicians themselves can start, end, change, or interrupt certain sonic developments. The white "T" card, for example, also designates that at any time, anyone may start or stop a chain. As the musicians do not have their own cue cards, they use alternative visual signals to attract the attention of the prompter and the other players. Touching one's nose and raising two fingers is the equivalent of the white " $\mathrm{T}$ " card. Touching one's nose and raising only one finger means that the player wants to do a duo with another musician. The initiator needs to make eye contact with the other player and the latter has to agree before they can start. When one duo is playing, anyone else may initiate a duo as well. A performance of Cobra thus leads to a constant alternation between solos, duos, trios, and collective improvisations either imposed by the prompter or initiated by the musicians themselves. As Dana Reason observes, "the group dynamic may push the improviser to relinquish control over the shape of the piece, adding pieces to a puzzle in which no one 'owns' a finalized version" (Reason in Fischlin and Heble 2004: 73). Cobra's structure depends on the interactive strategies of the participants and can never be predetermined or repeated in exactly the same way; neither musicians nor prompter are in full control of the structural development a performance of Cobra will generate.

[3] So far, Cobra shows a direct correlation with the features of play as outlined by Huizinga, Massumi, and Gadamer. There is a clear formal structure in which the prompter is sometimes an initiator and more often a coordinating intermediary, although she can always overrule or ignore the musicians' initiatives; the rules of the game piece, e.g. those presented on the cue cards, are clear and incontestable; it is limited in space and time, although a clear time frame is not determined in advance; playing this piece requires a high level of instrumental as well as social skills; and although some musicians might perform Cobra to gain cultural, social, and/or economic capital, participation is not compulsory.

Nevertheless, Cobra can offer a specific contribution to reflections and definitions of play, and this input is related to the ideas about rules and order that are part of its description. As Huizinga and others emphasize, without rules, games lack order and are doomed to fail; they become uninteresting, because chaotic, when players do not recognize, accept, and respect the instructions. Of course, the same applies to a Cobra performance; as a true presentation of Cobra, it fails when musicians do not understand or follow the specific musical gestures proposed by either the prompter or fellow performers through the cue cards. (As a musical result, it can be still interesting though.) However, what makes Cobra a particularly interesting piece in relation to the discourses on play is exactly the built-in possibility of deviating from these rules, to create disorder, and to ignore the predetermined directives. Each player has a headband; putting it on turns them into "guerrillas," meaning that they can ignore (almost) all rules, make other players stop, play whatever they like, and even choose two allies to form a squad; these two then get the same guerrilla rights. One of the possible operations of the squad leader, called "divisi," is to take over the game completely, sidelining the prompter and giving "orders" to any of the other players. Only a so-called "spy" can cut the guerilla squad; this spy can be any player, but she must remain unidentified by the squad in order to destroy its power. 
In soccer, a team cannot simply decide to ignore the offside rule for some time; chess players may not suddenly change the strict move patterns of a knight or a bishop; and playing ludo doesn't allow you to direct your pawns now and then in the opposite direction or to crisscross over the board. Huizinga's stipulation that respecting the rules to guarantee an intrinsic order needs to be upheld for these games to function as games.

However, negating the rules and undermining the order of the instructions necessary to arrive at a potentially adequate performance of Cobra is here an integral part of the game itself. Cobra contains within itself the paradoxical possibility that its most interesting performances are the ones in which the rules themselves are violated. What makes playing a game impossible for Huizinga, Massumi, and Gadamer are precisely the conditions of possibility for Cobra. This game piece actually requires that the rules be infringed upon, that disorder is created, thereby contributing simultaneously to its complexity. More so than soccer, chess, and ludo, Cobra operates in a constant imbalance between order and chaos.

If a game is defined by its rules and order, then what should we call Cobra? Put differently, does this game piece - a conducted improvisation dependent upon the abilities of the performers to listen, to act, to react, and to interact - compel us to rethink what makes a game a game? To subsume improvisation in general, and improvised musics such as Cobra in particular, into the category "game" as defined by scholars who did not take music into account, seems to ignore the questioning of this category that arises through concrete musical events. In Cobra the rules are stretched to such an extent that Huizinga, Massumi, and Gadamer's definitions are seriously challenged. As a game itself, Cobra deconstructs current ideas about a game.

[4] Several months after the writing of this text, a short postscript is needed. Being situated in Prague for a conference, I attended a concert by Pauline Oliveros (accordion), George Lewis (computer and trombone) and Joëlle Leandre (double bass) in a venue that was extremely hot. About halfway through the performance, Leandre introduced her voice as an extra instrument. A wordless concert at first, she gradually uttered the sentence "It is (so) hot," repeating it several times. Contrary to what Huizinga and Small suggested was one of the key characteristics of play, namely that it takes place outside everyday reality, this "free" improvisation concert suddenly made the audience aware that the "outside," in this case the heat, had always already been a part of the "inside," codetermining the course of the piece; sonically integrating it into the performance, Leandre made clear that the ("external" and "non-musical") reality of the temperature was an non-negligible actant in the way the improvisation unfolded. For me, she thereby, implicitly, added another caveat in regarding improvisation uncritically as a subcategory of play; or, more positively, she added an extra dimension to the theories on play by playing, by rethinking the boundaries between inside and outside while improvising.

\section{Politics - John Doe}

[1] In 1977 French thinker Jacques Attali cautiously adumbrated the rise of a new economic, social, and political order (see his book Noise, especially Chapter 5). Of course, predicting social changes is eternal, but perhaps for the first time in history, this forecast was based on contemporary developments in music. Although Attali explicitly mentions free jazz as a truly new mode of production and therefore as a $20^{\text {th }}$-century indictment of the commodification of music and cultural alienation - a way of thinking which resembles that of Adorno's albeit proposing a different musical genre as its promesse de bonheur - he expects more from listener-consumers turning into musicians, from music produced by "each individual for himself, for pleasure outside of meaning, usage, and exchange" (Attali 1985: 137). The increasing amount of amateurs who play for free and for fun establishes a new musical practice that, according to Attali, has far-reaching social, economic, political, and ethical implications. Socially, this new order in which music making becomes more relevant than the mere consumption of music calls into question the distinction between producer and consumer and creates new ways of communication; economically, making music without clearly defined goals, such as selling records, becoming famous, entertaining an audience, and earning money, enables a rethinking of the concept of labor: instead of an emphasis on the output of that labor, the focus shifts towards labor enjoyed in its own right, its time fully experienced; politically, collective music making at least partially ends the silencing of people, silenced because of the omnipresence of uniformed, commodified music. Instead, people are freed to express themselves again in the most diverse musical ways; ethically, making music under non-predetermined, non-generalizable, singular conditions demands and presupposes a high degree of tolerance, as one has to accept the input of others which might be radically different and opposed to one's own.

[2] It is exactly this emphasis not on a new music, but on new ways of making music that interests me here and which carries within itself the germs of (micro)political interventions. According to Attali this new music making is based on

doing solely for the sake of doing, without trying artificially to recreate the old codes in order to reinsert communication into them. Inventing new codes, inventing the message at the same time as the language. Playing for one's own pleasure, which alone can create the conditions for new communication. (Attali 1985: 134)

Attali calls this new order "Composition"; according to me, and this idea is also based on the quote above, it would not be too odd to rename it as "(collective) Improvisation." To create, in common, the codes within which communication will take place; allowing noise to become a potential relationship, establishing and forming a new order; producing local knowledge that can perpetually be called into question; creating open and unstable forms of communication through temporary order and structures - all these elements through which Attali elaborates this 
concept of Composition seem to accrue directly from commonly accepted ideas on improvisation.

[3] The music that somehow underpins this theoretical framework is not ambitious, not of high quality, not played very well, and does not consist of really innovative and challenging musical ingredients. It is played by amateurs, by students of a music school in Rotterdam, by people who gather once a week, after their daytime jobs, to make music together. For these musicians, without exception only accustomed to playing the most well-known standards from The Real Book, I created a simple

"composition" called "Intermezzo," consisting of eight different motifs which can be played in any desired order, either after or layered on top of each other.

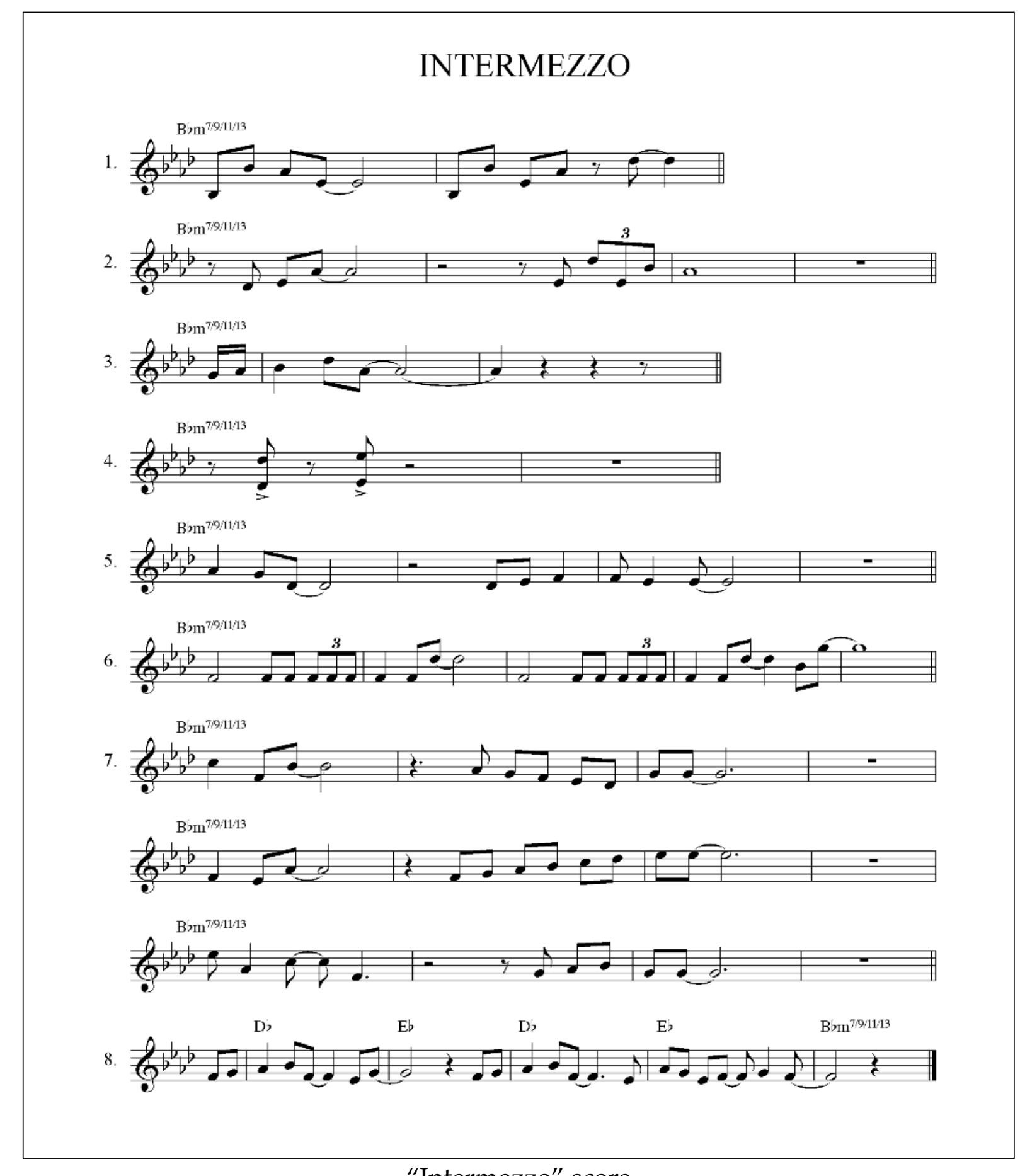

"Intermezzo" score
It is not compulsory to play all the motifs in one performance of "Intermezzo." The choice and order of the fragments, as well as any possible repetition, are left to the

discretion of the musicians themselves. All this produces the following effects:

- There is no clear and a priori distinction between principal and sub- or accompanying themes; this can change even within one performance.

- The binary opposite and hierarchical relationship between solo and accompanying instruments becomes less clear. More so than in mainstream jazz music, their function can alter in the course of a performance.

- Beginning and rounding off are arbitrary to a great extent. There is no apparent opening theme that is repeated near the end in order to close the circle, as in most jazz standards. In theory, "Intermezzo" can be expanded infinitely.

- The use of only one chord or harmony subverts the compelling linearity of the classical II-V-I progression, the basis of so much jazz music. In that sense, "Intermezzo" knows no development.

"Intermezzo" is not a linear composition, but rather an associative network, a rhizome, opening up a principally infinite web of possible routes. One could call it unstable music, as it is in a constant state of evolution, a perpetual becoming, never solidified, never definitely fixed. This means that it is primarily the process of exploration, the continual discovery of various musical gestures and interactions, and not the finished product, that becomes most prominent. "Intermezzo" is meant to set out on a search that has no end, and thus, no goal. The musicians might not know where they are going until they get there. The outline of the project only emerges with any clarity as they progress with it (Cobussen 2002: "Intermezzo," sections 4 and 5).

Below you can find two short samples that should illustrate two of the possibilities "Intermezzo" offers.

\section{play}

"Intermezzo" as played by music school students in Rotterdam

\section{play}

“Intermezzo" as played by Ernst Reijseger (cello) and Eric Vloeimans (trumpet)

[4] Although not directly emerging from Attali's rather controversial ideas, it is not difficult to relate those to "Intermezzo." The piece is meant to offer pleasure in making music together (according to Roland Barthes there are two musics: the music one listens to and the music one plays; "Intermezzo" might perhaps be best situated in the second category), in inventing new structures every time, in discovering new 
possibilities in communicating with the musical material as well as with fellow musicians, in trying to stretch and transgress certain conventions and fixed patterns, in changing the course of "Intermezzo" while playing it, etc.

However, simultaneously, the "composition" has enough built-in safety nets so that the musicians - amateurs, used to play jazz standards on a rather modest level - do not immediately get lost. The simple melodic lines based on one single chord and an easy, steady rhythm and meter ensure that the players feel safe enough to be able to start taking some risks as well. With Erlind Dehlin I could call this "positive improvisation": whereas negative improvisation is a reaction to external pressure, a desire to resolve complexity and avoid chaos, positive improvisation is voluntary, "twisting and turning rules, systems, ideas, viewing them as temporary constructs that can be used as tools" (Dehlin 2008: 223). Positive improvisation is directly related to the pleasure of doing without caring too much about pre-established goals.

[5] How can all of the above be connected to politics? It is obvious that "Intermezzo" differs significantly from Charles Mingus's "Fables of Faubus," Sonny Rollins's "Freedom Suite" or John Coltrane's "Alabama," all three directly commenting on and condemning American racism (Alperson 2010: 278-9). "Intermezzo" is not meant to create a clear connection between improvisation in music and the development of new social and political forms. It also differs from protest songs in pop music in which all kinds of political abuses (including religious, racial, and gender issues) are denounced. Furthermore it is not primarily intended to disrupt already existing musical languages and systems; no radical transformations are aspired to. Nevertheless, I defend the idea that "Intermezzo" gives concrete shape to Attali's prospects formulated in 1977, albeit in a different, more modest manifestation. Whereas Attali regards large-scale music making by non-professionals as a force that will in the end overthrow the current socio-political and economic system, it is my opinion that improvisation - in "Intermezzo," in music, but also in other cultural fields - works and intrudes on a micropolitical level.

[6] Micropolitics, as formulated by, for example, Michel Foucault, refers to smallscale interventions that are used for governing the behavior of large populations of people. These regulations - instilling certain attitudes, dispositions, and skills - take place at individual or moderate levels in locations such as prisons, hospitals, schools, and family gatherings. However, micropolitics also concerns the little cracks in the dominant and disciplining systems; it is what escapes these systems, although micropolitics needs these very systems in order to disrupt and change them. In this latter sense micropolitics refers to "a point of resistance and a starting point for an opposing strategy," the attempts to break from the grip of disciplinary powers by creating new modes of desire and pleasure (Foucault 1978: 101 and 157).

There is a social dimension of improvisation that goes beyond the more or less purely musical features (Alperson 2010: 277).
One political aspect of "Intermezzo," one political aspect of improvising, is not so much expressed in its explicit themes, but, rather, in the search for gradually and cautiously changing the way people listen, (re)act, and communicate. Instead of offering general cultural, moral, and intellectual guidance to people, this proffers a political aesthetics of small differences, of details, an invitation to question identities, a call for risk-taking - always within certain constraints. In the words of the Italian composer Luigi Nono:

Today more than ever the artist has the responsibility to avoid conclusive, finalized results. They must understand that (as Musil says) 'it isn't important what is, but rather what could have been.' This does away with all Manicheism, all sectarianism and intellectual rigidity. (Nono 2001: 273-5) 


\section{Ending - Frank Zappa}

[1] In The Philosophy of Improvisation Gary Peters asks himself what a successful improvisation would be. His answer: "The care for the work, one that overrides the more trivial concerns of intersubjectivity, is a care for the work's beginning, not its end," (Peters 2009: 51) and it is the task of the musicians to maintain this sense of a beginning during an improvisation (Peters 2009: 98). Improvising for Peters is an endless beginning.

If improvisation can be connected to the Deleuzian concept of rhizome, a creative and ever-branching network of possibilities, it should be accepted that it has no ending. "A rhizome has no beginning or end" (Deleuze and Guattari 1987: 25). Like a rhizome, improvisation happens between things; "where are you going?" is a useless question, as "it" always begins in the middle. In a way, these thoughts connect to those of Derrida, who claims that both beginning and ending are (almost) impossible to demarcate: everything is always already happening.

Johan Huizinga, writing about games or play - terms that are often connected to improvisation (cf. Play - John Zorn, section 1) - simply writes that "play begins, and then at a certain moment it is 'over'" (Huizinga 1970: 28).

None of these scholars seem to be interested in how an improvisation actually ends. Admittedly, Huizinga rightfully claims that play - and in this, an improvisation indeed resembles play - ends, that it "plays itself to an end," but how this occurs in musical improvisation remains relatively undertheorized.

[2] One scholar who does address endings in (improvised) music is John Corbett According to Corbett, in most tonal, "classical" music, the problem of ending is solved rather bluntly: the listener "forgets" the work's inconclusive openness, not only by a return to its tonal center, but mainly through a sonic bombardment of resolving chords, each one more solid and authoritative than the last. Conventional cadences shut the music machine down; with the cadence, earlier tensions are resolved (Corbett in Fischlin and Heble 2004: 387-389).

However, Corbett continues, improvisers, generally lacking "a script" that composer and performers of composed music have at their disposal, are left with the question of how to end their musical event. What are the criteria by which they decide that the piece is over? (Corbett in Fischlin and Heble 2004: 390-1) How to end Peters' endless beginning? How to end in Deleuze's middle? How to end a Huizinga-like game which is not about winning or using up all the materials?

[3] Of course, improvisers have developed their own conventions: mainstream jazz and many songs coming from popular music return to the chorus after the improvised parts. Sometimes there is a composed outro, at other times the last fou bars are repeated, usually three times. Less conventional structures, e.g. when the theme does not re-occur at the end or when a real theme is lacking, can end with a fade-out, with extended tones, or with some short notes by all players, rhythmically and melodically identical or not. A piece can also end with a cadenza in which one 
musician "composes" a final solo that leads to an ending. Often, this is not decided in advance but left open, decided during the unfolding of the music at the concert or in the studio; the ending appears as a question mark.

[4] Less concerned with the ending of a complete musical piece, philosopher William Day focuses exclusively on the ending of solos, particularly in jazz music. His claim is that these endings are of no particular concern to the improviser, not even a significant part of the story she wants to tell (Day 2010: 293). What is more, Day characterizes the practice of jazz improvisation as "averse to treating the end of the solo as an ending" (Day 2010: 295). The aim of this music making is to play on, not so much to never end as to never propose an ending, to avoid an ending that is foisted upon musicians (Day 2010: 296). This idea is sonically depicted quite well in David Murray's Baltic Suite, discussed in Part 1. Baltic Suite often seems like a kind of auditory relay race in which the final musical gesture of one soloist is - sometimes literally, sometimes modified - the beginning of the next solo, thereby creating the impression that the former solo, or at least its driving idea, has not ended (cf. Baltic Suite, section 1).

[5] So, what to do with a topic that does not want to end, that inherently refuses closures, that is by definition vectorial? How do I end a series of texts on improvisation while doing justice to one of its principles, namely starting in the middle, over and over again, without ever coming to a conclusion? Should it end? Instead of an inconclusive ending, I propose here a conclusive non-ending, giving one last example within the field of musical improvisation the "final" "word."

play

Frank Zappa - “Weasels Ripped My Flesh”

Goodnight boys and girls 


\section{Bibliography}




\section{Bibliography}

Adorno, Th. W. “On Jazz” in Adorno, TH. W. and R. Leppert (ed.) Essays on Music. Berkeley: University of California Press, 2002, pp. 470-495.

Ake, D. Jazz Cultures. Berkeley: University of California Press, 2002.

Alias, D. [Liner notes]. Bitches Brew [CD]. New York: Columbia Records, 1969.

Alperson, Ph. "A Topography of Improvisation." The Journal of Aesthetics and Art Criticism 68/3 (2010), pp. 273-280.

Appadurai, A. Modernity at Large: Cultural Dimensions of Globalization. Minneapolis: University of Minnesota Press, 1996

Arendt, H. “Labor, Work, Action" in Baehr, P. (ed.) The Portable Hannah Arendt. London: Penguin Putnam, 2000, pp. 167-181.

Ashline, B. [Liner notes] Amplify 2003 [CD + DVD]. New York: Erstwhile Records.

Attali, J. Noise. The Political Economy of Music (trans. Brian Massumi). Minneapolis: University of Minnesota Press, 1985.

Bailey, D. Improvisation. Its Nature and Practice in Music. New York: Da Capo Press, 1993.

Bakhtin, M.M. Speech Genres and Other Late Essays (trans. Vern W. McGee). Austin: University of Texas Press, 1986.

Barrett, R. “Notation As Liberation.” Unpublished paper, 2013.

Bateson, G. Steps to an Ecology of Mind. Chicago: University of Chicago Press, 2000.

Becker, H.S. Art Worlds. Berkeley: University of California Press, 1982

Béhague, G. "Improvisation in Latin American Musics". Music Educator's Journal 66/5 (1980): 118-125.

Belgrad, D. The Culture of Spontaneity. Improvisation and the Arts in Postwar America. Chicago: University of Chicago Press, 1998

Benson, B.E. The Improvisation of Musical Dialogue. A Phenomenology of Music.

Cambridge: Cambridge University Press, 2003.

Berger, J. Why Look at Animals? London: Penguin Books, 2009. 
Berliner, P. Thinking in Jazz. The Infinite Art of Improvisation. Chicago: The University of Chicago Press, 1994.

Berry, D.M. “The Poverty of Networks”. Theory, Culture \& Society 25 / 7-8 (2008): 364372

Bogue, R. Deleuze on Music, Painting, and the Arts. New York: Routledge, 2003.

Borgo, D. Sync of Swarm. Improvising Music in a Complex Age. New York: Routledge, 2005.

Borgo, D. "The Ghost in the Music: Improvisers, Technology, and the Extended Mind".

Boulez, P. Orientations. Cambridge (MA): Harvard University Press, 1986.

Bourriaud, N. Relational Aesthetics (trans. Simon Pleasance and Fronza Woods). Dijon: Les presses du reel, 2002.

Bowman, W.D. "Cognition and the Body: Perspectives from Music Education" in Bresler, L. (ed.) Knowing Bodies, Moving Minds: Toward Embodied Teaching and Learning. Dordrecht: Kluwer Academic Press, 2004: 29-50.

Brendel, A. Music Sounded Out. Essays, Lectures, Interviews, Afterthoughts. London: Robson Books, 1990.

Brooks, H. [Liner notes]. Bitches Brew [CD]. New York: Columbia Records, 1969.

Cage, J. For the Birds. John Cage in Conversation with Daniel Charles. London: M. Boyars, 1981.

Canguilhem, P. "Singing upon the Book According to Vicente Lusitano" (trans. Alexander Stalarow). Early Music History 30 (2011): 55-103.

Carles, Ph. [Liner notes] The Life of a Trio: Saturday [CD]. Universal Music, 1989.

Carr, I. Keith Jarrett. The Man and His Music. London: Grafton Books, 1991.

Castelein, J. "Primaire reacties als uitgangspunt voor jazzanalyse. Een onderzoek naar muziek van Steve Coleman" (Master thesis). Amsterdam: University of Amsterdam, 1995.

Chiel, H. J. and R. D. Beer "The brain has a body: adaptive behavior emerges from interactions of nervous system, body and environment." Trends Neurosci 20 (1997): $553-557$.
Ciborra, C.U. "Notes on improvisation and time in organizations." Accounting, Management and Information Technologies 9/2 (1999): 77-94.

Cillari, S. "Space is Body Centred" in Altena, A. and Sonic Acts (eds.) The Poetics of Space. Amsterdam: Sonic Acts Press, 2010: 169-178.

Clark, A. and D. Chalmers “The Extended Mind.” Analysis 58/1 (1998): 7-19.

Clarke, E. Ways of Listening: An Ecological Approach to the Perception of Musical Meaning. Oxford: Oxford University Press, 2005.

Cobussen, M. “Deconstruction in Music" (Doctoral thesis). Rotterdam: Erasmus University Rotterdam, 2002.

Cobussen, M. and N. Nielsen Music and Ethics. Farnham: Ashgate, 2012.

Cook, N. Music, Imagination, and Culture. Oxford: Oxford University Press, 1990.

Costa, R. “Free Musical Improvisation and the Philosophy of Gilles Deleuze." 2012.

Cox, Chr. and D. Warner Audio Culture. Readings in Modern Music. New York: Continuum, 2009.

Craenen, P. “tubes" (unpublished text). 2008.

Czerny, C. Systematische Anleitung zum Fantasieren auf dem Pianoforte. Breitkopf und Härtel, 1829.

Czerny, C. Briefe über den Unterricht auf dem Pianoforte. A. Diabelli und Comp, 18371841.

Davis, T., A. Renaud, J. Geistweidt, and J. Dixon “Interfacing the Network: An Embedded Approach to Network Instrument Creation." Poster presentation at ICMC 2012.

Day, W. "The Ends of Improvisation". The Journal of Aesthetics and Art Criticism 68/3 (2010), pp. 291-296.

Dean, R.T. Creative Improvisation: Jazz, Contemporary Music and Beyond. Maidenhead: Open University Press, 1989.

Deforce, A. “Laborinth II: denken als experiment. 472 'meditaties' over de noodzaak van het creatief denken en experimenteren in het uitvoeren van complexe muziek van 1962 tot heden" (Doctoral dissertation). Leiden: Leiden University, 2012. 
Dehlin, E. “The Flesh and Blood of Improvisation. A Study of Everyday Organizing” (Doctoral dissertation). Trondheim: Norwegian University of Science and Technology, 2008.

DeLanda, M. A New Philosophy of Society. Assemblage Theory and Social Complexity. London: Continuum, 2006

Deleuze, G. and C. Parnet Dialogues II (trans. Hugh Tomlinson and Barbara Habberjam). New York: Columbia University Press, 2002.

Deleuze, G. and F. Guattari A Thousand Plateaus. Capitalism and Schizophrenia (trans. Brian Massumi). Minneapolis: University of Minnesota Press, 1987.

Deleuze, G. and F. Guattari What Is Philosophy? (trans. Hugh Tomlinson and Graham Burchell). New York: Columbia University Press, 1994.

Denzin, N. and Y. Lincoln (eds.) Handbook of Qualitative Research. London: Sage Publications, 2000

Derrida, J. “On Improvisation,” 1982.

Eck, C. van "Between Air and Electricity. Microphones and Loudspeakers as Musical Instruments" (Doctoral dissertation). Leiden: Leiden University, 2013.

Elsdon, P. “Listening in the Gaze: The Body in Keith Jarrett's Solo Piano Improvisations" in Gritten, A. and E. King (eds.) Music and Gesture. Aldershot: Ashgate, 2006, pp. 192-207.

Eskow, G. “Herbie Hancock”. Mix 26/1, January 1, 2002, p. 171

Evens, A. Sound Ideas. Music, Machines, and Experience. Minneapolis: University of Minnesota Press, 2005.

Ferneyhough, B. Collected Writings (eds. James Boros and Richard Toop) Amsterdam: Harwood Academic Publishers, 1998

Ferrara, L. Philosophy and the Analysis of Music. Bridges to Musical Sound, Form, and Reference. Bryn Mawr (PA): Excelsior Music Publishing, 1991.

Fidom, H. “Organ Improvisation - An Introduction.” New Sound 32 (2008): 62-77.

Fischlin, D. and A. Heble (eds.) The Other Side of Nowhere. Jazz, Improvisation, and Communities in Dialogue. Middletown: Wesleyan University Press, 2004.
Foster, S.L. "Taken by Surprise: Improvisation in Dance and Mind" in Albright, A.C. and D. Gere (eds.) Taken by Surprise: A Dance Improvisation Reader. Middletown (CT): Wesleyan University Press, 2003, pp. 3-12.

Foucault, M. The History of Sexuality, Volume 1: An Introduction (transl. Robert Hurley). New York: Pantheon Books, 1978.

Gadamer, H.-G. Truth and Method (trans. Joel Weinsheimer and Donald G. Marshall). London: Continuum, 2004.

Gibson, J.J. The Ecological Approach to Visual Perception. Hillsdale (NJ): Lawrence Erlbaum Associates Inc., 1986.

Goebbels, H. Musica Viva. Forum der Gegenwartsmusik. Heiner Goebbels [DVD]. Mainz: Wergo, 2008.

Goehr, L. The Imaginary Museum of Musical Works. An Essay in the Philosophy of Music. Oxford: Clarendon Press, 1992.

Gould, C.S. and K. Keaton "The Essential Role of Improvisation in Musical Performance." The Journal of Aesthetics and Art Criticism 58/ 2 (2000): 143-148.

Haeckel, E. Generelle Morphologie der Organismen : allgemeine Grundzüge der organischen Formen-Wissenschaft, mechanisch begründet durch die von Charles Darwin reformirte Descendenz-Theorie. Berlin: G. Reimer Pubs, 1866

Hall, G. “Teo: The Man Behind the Scene.” Down Beat (1974), pp. 13-15.

Hopkins, P. Amplified Gesture. An Introduction to Free Improvisation: Practitioners and Their Philosophy. London: Samadhisound, 2009.

Human, O. and P. Cilliers "Towards an Economy of Complexity: Derrida, Morin and Bataille." Theory, Culture \& Society $30 / 5$ (2013): 24-44.

Huizinga, J. Homo Ludens. London: Paladin, 1970.

Ihde, D. Listening and Voice. Phenomenologies of Sound. Albany: SUNY Press, 2007.

Ijer, V. “Embodied Mind, Situated Cognition, and Expressive Microtiming in AfricanAmerican Music." Music Perception 19/3 (2002): 387-414.

Iyer, V. "On Improvisation, Temporality, and Embodied Experience" in Miller, P.D. (ed.) Sound Unbound. Sampling Digital Music and Culture. Cambridge (MA): MIT Press, 2008, pp. 273-292. 
Ingarden, R. Ontology of the Work of Art (trans. Raymond Meyer and John T. Goldthwait). Athens: Ohio University Press (1989).

Jarrett, K. Interview with Ethan Iverson. Do The Math (2009).

Jewell, D. Duke - A Portrait of Duke Ellington. New York: W.W. Norton \& Company, 1977.

Joas, H. The Creativity of Action. Cornwall: Hartnolls, 1996.

Johnstone, K. Impro: Improvisation and the Theatre. London: Faber and Faber Ltd., 1979.

Kamoche, K. N., M. P. Cunha, and J. V. Cunha Organizational Improvisation. London: Routledge. 2002.

Kearney, R. On Stories. London: Routledge, 2002.

Keefe, J.A. Improv Yourself. Business Spontaneity at the Speed of Thought. Hoboken (NJ): John Wiley and Sons Inc, 2003.

Kirchner, B. (ed.) A Miles Davis Reader. Washington (DC): Smithsonian, 1997.

Kivy, P. Authenticities. Philosophical Reflections on Musical Performance. Ithaca: Cornell University Press, 1995.

Kleiner, M.S. and A. Szepanski (eds.) Soundcultures. Über elektronische und digitale Musik. Frankfurt a/M: Suhrkamp, 2003.

Klemp, N. et al. “Plans, Takes, and Mis-takes.” Critical Social Studies 10 (2008): 4-21.

Kruger, D. "Organ Improvisation in German Fundamenta of the $15^{\text {th }}$ Century." New Sound 32 (2008): 44-61.

Kundera, M. The Curtain. An Essay in Seven Parts. London: Faber and Faber, 2006.

LaBelle, B. “Museum of Instruments.” 2005.

LaBelle, B. Background Noise. Perspectives on Sound Art. New York: Continuum, 2006.

Landgraf. E. Improvisation as Art. Conceptual Challenges, Historical Perspectives. New York: Bloomsbury, 2014.

Latour, B. Reassembling the Social. An Introduction to Actor-Network-Theory. Oxford: Oxford University Press, 2007.
Leach, D. “Improving Your DJing With Free Improvisation.” http:// www. DJTechTools.com, 2011.

Lévy, P. Collective Intelligence. Mankind's Emerging World in Cyberspace (trans. Robert Bononno). Cambridge (MA): Perseus Books, 1997.

Lewis, G. “Too Many Notes. Computers, Complexity and Culture in Voyager." Leonardo Music Journal 10 (2000): 33-39.

Lewis, G. "Improvisation as a Way of Life: Reflections on Human Interaction". University Lecture (2011)

Lewis, G. "Critical Responses to "Theorizing Improvisation (Musically)'." MTO - a Journal of the Society for Music Theory 19/2 (2013): 1-6.

Lewis, J. “Running the Voodoo Down”. The Wire 130 (1994): 20-26.

Limb, Ch. J. “Your Brain on Improvisation”. Ted Talk (2010).

Madson, P.R. Improv Wisdom: Don't Prepare, Just Show Up. New York: Bell Tower, 2005.

Massumi, B. Parables for the Virtual. Movement, Affect, Sensation. Durham: Duke University Press, 2002.

McCartney, A. "Meaningful Listening through Soundwalks." Proceedings of the Electroacoustic Music Studies Network Conference Meaning and Meaningfulness in Electroacoustic Music. Stockholm (June 2012).

McCartney, A. “Soundwalking and Improvisation." Paper published on the Improvisation, Community and Social Practice website (May 2010).

Meelberg, V. “Moving to Become Better: The Embodied Performance of Musical Groove." Journal of Artistic Research 1 (2011).

Merleau-Ponty, M. Phenomenology of Perception (trans. Colin Smith). London Routledge, 2005.

Miller, P.D. (ed.) Sound Unbound. Sampling Digital Music and Culture. Cambridge, MA: MIT Press, 2008.

Miller, P. and V. Iyer "Improvising Digital Culture: A Conversation." Critical Studies in Improvisation 5/ 1 (2009).

Mills, R. and K. Beilharz "Listening Through the Firewall: Semiotics of sound in networked improvisation." Organised Sound 17/1 (2012): 16-27. 
Monson, I. Saying Something. Jazz Improvisation and Interaction. Chicago: University of Chicago Press, 1996.

Montuori, A. "The Complexity of Improvisation and the Improvisation of

Complexity: Social Science, Art and Creativity." Human Relations 56/ 2 (2003): 237-255.

Moore, R. "The Decline of Improvisation in Western Art Music: An Interpretation of Change." International Review of the Aesthetics and Sociology of Music 23/1 (1992): 61-84.

Moseley, R. "Entextualization and the Improvised Past." MTO - a Journal of the Society for Music Theory 19/2 (2013).

Nancy, J-L. Being Singular Plural (Meridian: Crossing Aesthetics) (transl. Robert Richardson and Anne O'Byrne. Stanford, CA: Stanford University Press, 2000.

Nettl, B. "Contemplating the Concept of Improvisation and its History in Scholarship." MTO - a Journal of the Society for Music Theory 19/2 (2013).

Nettl, B. and G. Solis (eds.) Musical Improvisation. Art, Education, and Society. Urbana: University of Illinois Press, 2009.

Nettl, B. and M. Russell (eds.) In The Course of Performance. Studies in the World of Musical Improvisation. Chicago: University of Chicago Press, 1998.

Nettl, B. “Thoughts on Improvisation: A Comparative Approach." The Musical Quarterly 60/1 (1974): 1-19.

Nilsson, P.A. A Field of Possibilities. Designing and Playing Digital Musical Instruments. Gothenburg: ArtMonitor, 2011.

Nono, L. Scritti e colloqui (Volume II). Milan: Ricordi, 2001.

Nussbaum, M. Love's Knowledge. Essays on Philosophy and Literature. New York: Oxford University Press, 1990.

Nyman, M. Experimental Music. Cage and Beyond. Cambridge: Cambridge University Press, 1999.

Olewnick, B. “Sachiko M - Salon de Sachiko.” bagatellen December 2 (2007).

Ouelette, D. “Bitches Brew: The Making of the Most Revolutionary Jazz Album in History." Down Beat (December 1999): 32-37.

Parker, E. [Liner notes]. Conic Sections [CD]. Ah Um, 1993.
Pelinski, R. “Embodiment and Musical Experience." Revista Transcultural de Música 9 (2005)

Pentland, B. T. and H. H. Rueter "Organizational routines as grammars of action." Administrative Science Quarterly, 39/3 (1994): 484-510.

Peters, G. "Certainty, Contingency, and Improvisation." Critical Studies in Improvisation 8/ 2 (2012): 1-8

Peters, G. The Philosophy of Improvisation. Chicago: University of Chicago Press, 2009.

Petsche, J. “Channelling the Creative: Keith Jarrett's Spiritual Beliefs Through a Gurdjieffian Lens." Literature \& Aesthetics 19/2 (2009): 138-158.

Plant, S. Zeros + Ones. Digital Women + The New Technoculture. London: Fourth Estate, 1998.

Pranger, J. "The Incommensurability of Musical Materialisation and Mediation." Unpublished paper, 2010: 1-16.

Prévost, E. No Sound Is Innocent. Matching Tye: Copula, 1995.

Rammert, W. "Where the action is: Distributed agency between humans, machines, and programs." The Technical University Technology Studies Working Papers (2008) pp. 1-27.

Renaud, A. "Renditions. A multisite real time network music performance for shared networked environments." https:/ / vimeo.com/65709362, 2013.

Renaud, A., A. Carôt, and P. Rebelo "Networked Music Performance: State of the Art." Paper presented at AES $30^{\text {th }}$ International Conference. Finland, 2007, pp. 1-7.

Reybrouck, M. “Body, mind and music: musical semantics between experiential cognition and cognitive economy." TRANS - Transcultural Music Review 9 (article 16) (2005).

Rintzler, P. The Contradictions of Jazz (Studies in Jazz, No. 57). Lanham, MD: The Scarecrow Press, 2008.

Sawyer, K.R. "Improvisation and Teaching." Critical Studies in Improvisation 3/2 (2008).

Schaeffer, P. Traité des objets musicaux. Paris: Éditions du Seuil, 1966. 
Schroeder, F. and M. Ó hAodha (eds.) Soundweaving. Writings on Improvisation. Newcastle upon Tyne: Cambridge Scholars Publishing, 2014.

Schubert, P. "Counterpoint Pedagogy in the Renaissance" in Christensen, Th. (ed.) The Cambridge History of Western Music Theory. Cambridge: Cambridge University Press, 2002, pp. 503-533.

Schutz, A. "Making Music Together: A Study in Social Relationship" in Dolgin, J.L., D.S. Kemnitzer, and D.M. Schneider (eds.) Symbolic Anthropology: A Reader in the Study of Symbols and Meanings. New York: Columbia University Press, 1977, pp. 106119.

Shaw, P. and R. Stacey (eds.) Experiencing Risk, Spontaneity and Improvisation in Organizational Change. Working Live. London: Routledge, 2016.

Sheehy, A. "Improvisation, Analysis, and Listening Otherwise." MTO - a Journal of the Society for Music Theory 19/2 (2013).

Sheehy, A. and P. Steinbeck "Introduction: Theorizing Improvisation (Musically)." MTO - a Journal of the Society for Music Theory 19/2 (2013).

Shipp, E.R. "Fans Recollect the 'Eternal Music' of Miles Davis." New York Times obituary, October 7, 1991.

Small, Chr. Musicking. The Meanings of Performing and Listening. Middletown (CT): Wesleyan University Press, 1998.

Stefanovski, V. “Until I Satisfy My Artistic Appetite” (interview by Nenad Giorgievski). All About Jazz (2005).

Steinbeck, P. “Improvisational Fictions." MTO - a Journal of the Society for Music Theory 19/2 (2013).

Strickland, E. “Keith Jarrett and the Abyss.” Fanfare (1983): 89-93.

Tingen, P. Miles Beyond. The Electric Explorations of Miles Davis 1967-1991. New York: Billboard Books, 2001

Toop, D. Haunted Weather. Music, Silence, and Memory. London: Serpent's Tail, 2004.

Von Uexküll, J. “Die neue Umweltlehre. Ein Bindeglied zwischen Natur- und Kulturwissenschaften." Die Erziehung 13/5 (1937): 185-197.

Varela, F.J., E. Thompson and E. Rosch The Embodied Mind. Cognitive Science and Human Experience. Cambridge (MA): MIT Press, 1991.
Vyas, H. Improvisation for Work. 5 Ways Improvisation Can Help Your Work Life. Edgware: Stuttering Hub Limited, 2014.

Waldrop, M. Complexity. The Emerging Science at the Edge of Order and Chaos. New York: Touchstone, 1992

Walser, R. "Out of Notes: Signification, Interpretation, and the Problem of Miles Davis." The Musical Quarterly 77/2 (1993): 343-365.

Warren, J. Music and Ethical Responsibility. Cambridge: Cambridge University Press, 2014

Weick, K.E. Sensemaking in Organizations. Thousand Oaks: Sage Publications, 1995.

Werner, H. and B. Kaplan Symbol Formation: An Organismic Developmental Approach to Language and the Expression of Thought. New York: John Wiley, 1963.

White, H. Tropics of Discourse. Essays in Cultural Criticism. Baltimore (MD): The Johns Hopkins University Press, 1978.

Zappa, F. and P. Occhiogrosso The Real Frank Zappa Book. New York: Poseidon Press, 1989. 


\section{List of Audio and Video files}

Barrett, R. Cell (performed by POING). Excerpt, 2011.

Bley, P., J. Giuffre, and S. Swallow The Life of a Trio: Saturday [CD]. Santa Monica, CA: Universal Music Group, 2001.

Chang, J., K. Nutters, and M. J. Olsen "Adjustments Episode 2 - Chico Mello". Excerpt taken from https://soundcloud.com/johnnychchang/sets/the-new-silence (posted by Johnny Chang on 12 November 2013).

Coleman, S. and Five Elements. The Tao of Mad Phat - Fringe Zones [CD]. München: Bmg International, 1993.

Craenen, P. tubes (performed by Cathy van Eck and Paul Craenen) Excerpt taken from https:// paulcraenen.com/tubes-2007/ (posted by Paul Craenen).

Davis, M. Winter in Europe [CD] New York: Sony Legacy Recordings, 2011.

Davis, M. Bitches Brew [CD]. New York: Columbia Records, 1999.

Deep Purple. Made in Japan [CD]. Burbank, CA: Warner Off Roster, 1990.

Fell Clutch, The. The Fell Clutch [CD]. Brooklyn, NY: Animul, 2006

Ferneyhough, B. Time and Motion Study II (performed by Arne Deforce)

Excerpt taken from https://vimeo.com/90784680 (posted by Arne Deforce on 2 April 2014).

Frith, F. "Solo at the Good Sheppard Center Chapel in Seattle, 25 April 2009".

Excerpt taken from https:/ / www.youtube.com/watch?v=QFhy1ISTp5w (posted by MBoer's handmade videos on 26 April 2009).

Goebbels, H. "Schwarz auf Weiß" and "... même soir" [DVD]. München: B.O.A. Videofilmkunst, 2008.

Group Ongaku. Music of Group Ongaku [CD].

Heide, E. van der "Radioscape".

Excerpt taken from https:/ / vimeo.com/6980743 (posted by Edwin van der Heide on 9 October 2009).

Jarrett, K. Last Solo [DVD]. Tokyo: VideoArts Music Inc., 1987.

"Jovano Jovanke" (trad.) (performed by Leb i Sol) 
Excerpt taken from https://www.youtube.com/watch?v=aZb4todw IE (posted by MetalOrDie on 18 October 2012).

“Jovano Jovanke" (trad.) (performed by VS Trio).

Excerpt taken from https: / / www.youtube.com/watch?v=WU4svOMyhKM (posted by Gordon Matthew Sumner on 5 March 2010).

“Jovano Jovanke" (trad.) (performed by Vlatko Stefanovski and Stefan Milenkovic). Excerpt taken from https:// www.youtube.com/ watch? v=imOgW3nyNV8 (posted by Filip983 on 28 December 2011).

"Jovano Jovanke" (trad.) (performed by Vlatko Stefanovski, Vasko Atanasovski, and the SPSCO).

Excerpt taken from https: / / www.youtube.com/ watch?v=bWyQoH2qyUY (posted by Vasko Atanasovski on 30 November 2013).

“Jovano Jovanke" (trad.) (performed by Vlatko Stefanovski and Miroslav Tadić). Excerpt taken from https://www.youtube.com/watch?v=kyFwwIHw6nw (posted by sslavi on 30 January 2010).

Lewis, G. Voyager [CD]. Tokyo: Avant Records, 1997.

Medeski, J., B. Martin, and C. Wood Tonic [CD]. New York: Blue Note, 2011.

Miller, P.D. Sound Unbound [CD]. Cambridge MA: MIT Press, 2008.

Moore, M., W. Holshouser, and H. Bennink. "Skylark".

Excerpt taken from https: / / www.youtube.com/watch?v=602jCInwlPc (posted by Marius Jurgens on 12 April 2008).

Mozart, W.A. Piano Concerto in D Minor, K466 (performed by Maria João Pires and the Amsterdam Concertgebouworkest conducted by Riccardo Chailly).

Excerpt taken from https: / / www.youtube.com/watch?v=CIXnYMl SuA (posted by Kees de Jong on 11 June 2009).

Mozart, W.A. Piano Concerto in D, K537 (performed by Alfred Brendel and the Academy of St. Martin in the Fields conducted by Sir Neville Marriner) [CD] London: Decca, 2004.

Murray, D. Baltic Suite [CD]. Krakow: Gowi Records, 1993.

Renaud, A. “Renditions” (performed by Franziska Schroeder, Clemens Frühstück, and Carola Schaal)

Excerpt taken from http://vimeo.com/ 65709362 (posted by Alain Renaud on 8 May 2013).
Rothenberg, D. "Jams with Cicadas".

Excerpt taken from https://www.youtube.com/watch?v=tv0qOTurt6c (posted on 19 June 2013).

Sachiko M. Salon de Sachiko [CD]. Tokyo: Hitorri, 2007.

Sugimoto, T. and the Taku Sugimoto Quartet "Live at Amplify 2002" [DVD]. New York: Erstwhile, 2003.

Yo La Tengo “Don't Cry No Tears".

Excerpt taken from https://www.youtube.com/watch?v=aNmP32Vzw c (posted by jacquestourneur on 11 June 2009).

Zappa, F. Weasels Ripped My Flesh [CD]. Los Angeles: Zappa Records, 2012.

\section{Zorn, J. Cobra}

Excerpt taken from https://www.youtube.com/watch?v=1m1pjR1AQbc (posted by bbbsilver on 27 March 2007). 


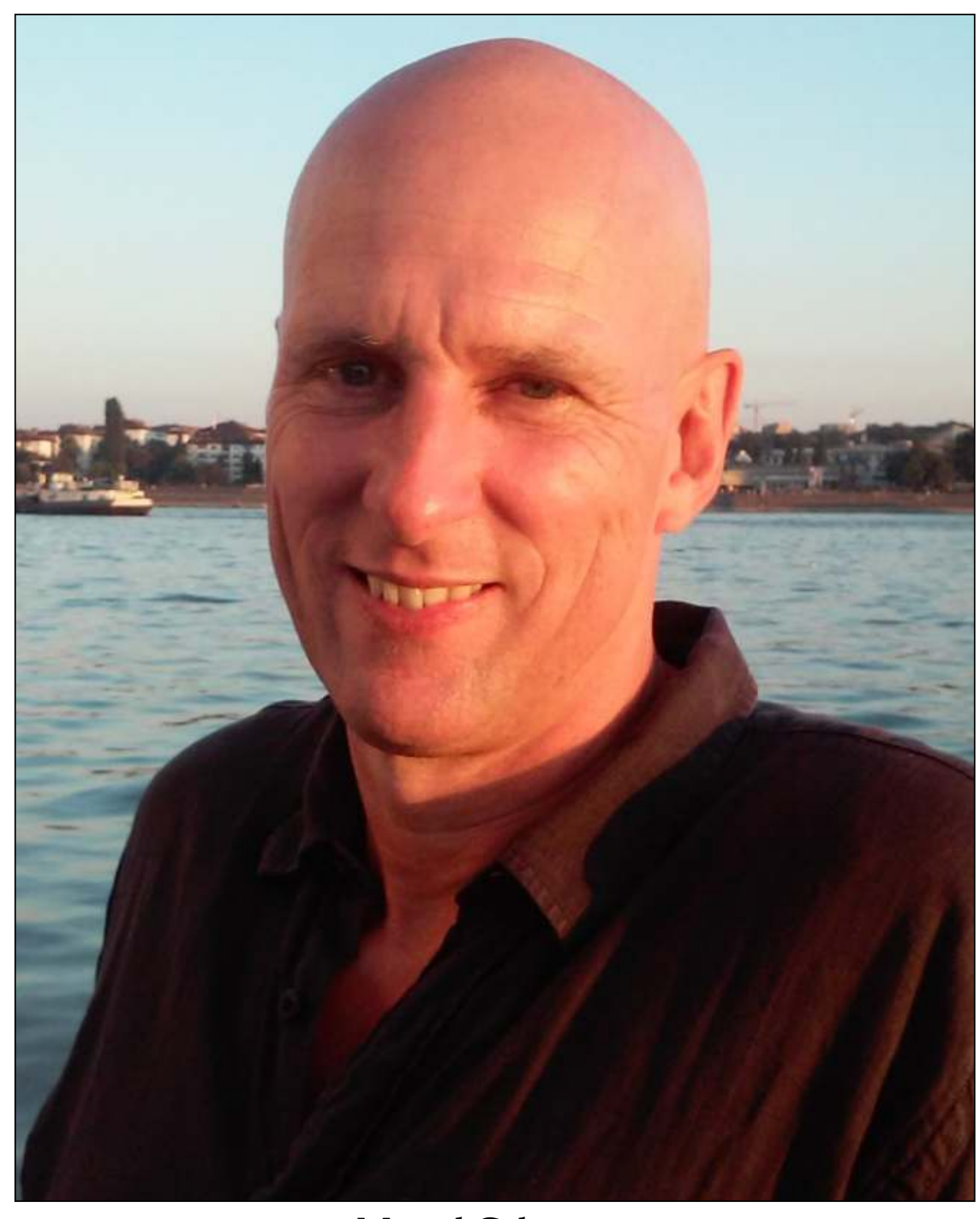

Marcel Cobussen

\section{About the Author}

Marcel Cobussen studied jazz piano at the Conservatory of Rotterdam and Art and Cultural Studies at Erasmus University, Rotterdam (the Netherlands). He currently teaches Music Philosophy and Auditory Culture at Leiden University (the Netherlands) and the Orpheus Institute in Ghent (Belgium).

Cobussen is author of the book Thresholds. Rethinking Spirituality Through Musi (Ashgate 2008), editor of Resonanties. Verkenningen tussen kunsten en wetenschappen (LUP 2011), co-author of Music and Ethics (Ashgate 2012) and Dionysos danst weer. Essays over hedendaagse muziekbeleving (Kok Agora 1996), and co-editor of The Sounding Art Companion (Routledge, 2016). He is editor-in-chief of the open access online Journal of Sonic Studies (www.sonicstudies.org). His Ph.D. dissertation Deconstruction in Music (Erasmus University Rotterdam 2002) is presented as an online website located at www.deconstruction-in-music.com. 


\section{Acknowledgements}

When the idea came to me that my next research project should be about improvisation (in music) I was at the same time surprised why it had taken me that long to start reflecting on a topic which has been an almost intrinsic part of my daily (musical) life since the late 1970s. Although the piano lessons I had from the age of 12 on didn't allow for much improvisation, I was always inventing new tunes, all the more so after my high school friends introduced me into the secret world of triads and harmonic progressions, and we started playing in bands performing our own music.

So, if the acknowledgements is the place to list everyone who has had a significant influence on how I think about music in general and improvisation in particular, I must start with those friends I know already for some forty years now: Ad, Wim Wilbert, Bart, Tarcies, Milly.

If I stick to a chronological order, this group should be followed by the closest friend I made while studying jazz piano at the Rotterdam Conservatory: Ruud, Raymond Max. Next in line: my colleagues from the music school Rotterdam and the Royal Conservatoire of The Hague, with whom I developed several courses on improvisation: Hans, Henk, Jos, Eric, Ine, Nico, Adri, Rolf, and so many others.

When I actually commenced upon my research project on improvisation, complexity, and singularity, many people and organizations offered me possibilities to present my ideas, often in combination with workshops and / or publications. In no particular order and far from exhaustive, I would like to mention: Hans Fidom, Rogerio Costa, Franziska Schroeder, Jeffrey Librett, Nanette Nielsen, Ajay Heble, Werner Aguiar, Eric Lewis, Sara Ramshaw, Stefan Őstersjö, Henrik Frisk, Mirjana Veselinovic-Hofman, Paul Hegarty, Steven Vande Moortele, STEIM, Per Anders Nilsson, Giampaolo di Rosa, Jonathan Impett, ASCA, IAPL, Leon Stefanija, docARTES.

More closely and directly connected to the realization of this publication were the PhD candidates in my improvisation seminars (Willem, Bert, Ilya, Miguelangel, Christopher), Richard Barrett and Paul Craenen (for making available their compositions), Rob Walser (for his literature suggestions), Michael Bull and David Borgo (they know why), Sharon Stewart (my crucial support concerning English grammar), Karsten Wentink (why not?), and Anniek Meinders and Romy Uijen (LUP).

Finally, not concretely involved but nevertheless indispensable, my daughters Eva and Sarah who are always wondering why I spend so much time in my study - it is to them that I dedicate this work. 

It is startlingly original in so much as it brings a philosophical/social understanding to the field of musical improvisation. I've not really encountered a work that does this so imaginatively and thoroughly. Indeed - reading the work - I think the whole manuscript is one wonderful set of improvisations - and as such works very well.

Professor of Sound Studies at the University of Sussex

Marcel Cobussen offers a concise and compelling account of musical improvisation that spans - and at times transgresses - conventional notions of musical genre and academic discipline. A wonderful approach that leverages the multimodal aspects of improvisation and of learning in general. Bravo!

Professor of Music at UC San Diego

The central aim of this book is to present a new approach to "the field of musical improvisation" (FMI), a theory which understands improvisation as a nonlinear dynamic and complex system. The study provocatively argues that during an improvisation more actants are "at work" than musicians alone: space, acoustics, instruments, audience, technicians, musical and socio-cultural backgrounds, technology, and the like all play a significant role. However, not all of these actants determine every improvisation to the same extent; some are more prominent and active than others in certain situations (periods, styles, cultures, as well as more singular circumstances). Therefore, the FMI theory will prove to be more than a theory dealing with improvisation "in general". Rather, FMI emphasizes singularity: each improvisation thus yields a different network of actants and interactions, a unique configuration or assembly.

is Professor of Music Philosophy and Auditory Culture at Leiden University. He is the author and editor of several books including Music and Ethics (Ashgate, 2012) and The Routledge Companion to Sounding Art (Routledge 2016). $\mathrm{He}$ is also editor-in-chief of the open access online Journal of Sonic Studies (www. sonicstudies.org). 